GUILHERME AUGUSTO MARQUES ARAUJO

AVALIAÇÃO DOS GANHOS EM EFICIÊNCIA ENERGÉTICA EM ILUMINAÇÃO ADOTANDO A REGULAMENTAÇÃO DE ETIQUETAGEM EM EDIFICAÇÕES

SÃO PAULO

2009 
GUILHERME AUGUSTO MARQUES ARAUJO

\section{AVALIAÇÃO DOS GANHOS EM EFICIÊNCIA ENERGÉTICA EM ILUMINAÇÃO ADOTANDO A REGULAMENTAÇÃO DE ETIQUETAGEM EM EDIFICAÇÕES}

Dissertação apresentada à Escola Politécnica da Universidade de São Paulo para obtenção do título de Mestre em Engenharia. 


\section{AVALIAÇÃO DOS GANHOS EM EFICIÊNCIA ENERGÉTICA EM ILUMINAÇÃO ADOTANDO A REGULAMENTAÇÃO DE ETIQUETAGEM EM EDIFICAÇÕES}

Dissertação apresentada à Escola Politécnica da Universidade de São Paulo para obtenção do título de Mestre em Engenharia.

Área de concentração:

Sistemas de Potência

Orientador:

Prof. Dr. Marco Antônio Saidel 


\section{DEDICATÓRIA}

Aos alicerces da minha vida, meus pais, José Roberto e Neusa, e irmão, Gustavo por me proporcionarem os méritos para que nunca deixe de buscar as vitórias mais importantes. 


\section{AGRADECIMENTOS}

Ao professor Marco Antonio Saidel pela orientação, paciência, apoio e principalmente confiança depositados ao longo de todo desenvolvimento dessa dissertação.

A minha namorada Mariana, pelo incentivo e companheirismo, apoiando-me de forma decisiva durante todo o transcorrer deste trabalho, com amor, carinho, dedicação e tolerância.

Ao meu irmão Gustavo, pelas relevantes contribuições relacionadas principalmente a elaboração dos cálculos estatísticos e, mais ainda, pelo exemplo de envolvimento e conhecimento do ofício do profissional acadêmico.

A amiga e colega de mestrado, Erika Barbosa, pelo estímulo e motivação nos momentos mais difíceis.

Aos amigos Alexandra Meireles, Marcos Geraldini, Benedito Paulo de Campos, Ana Paula de Assis Carvalho e Evando Moreira pelas inspirações e ensinamentos em engenharia, por acreditarem sempre na minha capacidade e pela importante ajuda que proporcionaram na realização deste trabalho.

Aos meus melhores amigos, Marcos Zanetti, Ana Silvia Leber e Ana Melanie Leber que sempre estiveram presentes em todos os momentos dessa empreitada. 
Os resultados provêm do aproveitamento das oportunidades e não da solução dos problemas. A solução de problemas só restaura a normalidade. As oportunidades significam explorar novos caminhos.

(Peter Druker) 


\section{RESUMO}

Este trabalho tem por finalidade avaliar os ganhos em eficiência energética através da classificação de níveis, atribuídos a sistemas de iluminação das instalações, com a aplicação da proposta de regulamentação para etiquetagem voluntária do nível de eficiência energética de edificações comerciais, de serviços e públicos, em fase de homologação. Foi realizada uma contextualização da importância da referida proposta de regulamentação, com uma abordagem dos principais sistemas de avaliação de desempenho ambiental de edifícios em âmbito internacional e no Brasil, considerando as principais iniciativas e estado atual das mesmas. Com o uso da referida metodologia, foram realizados três estudos distintos: o primeiro, considerando um levantamento de dados em uma edificação existente que se caracteriza por sediar uma organização administrativa que faz parte do poder público, composta de 275 dependências. O segundo e o terceiro estudo tratam da aplicação em um projeto luminotécnico, no mesmo empreendimento, de duas luminárias distintas (compostas de sistemas ópticos com e sem aletas, respectivamente). A partir dessas atividades que norteiam a aplicação direta da metodologia para confecção de projetos, foram estabelecidas comparações entre os resultados obtidos e realizadas considerações sobre os índices de iluminância, de densidade de potência instalada total em iluminação e da densidade de potência em iluminação. De posse de todos os resultados obtidos em uma edificação com relevante representatividade no segmento dos prédios públicos, bem como das considerações pertinentes, podemos inferir que com o uso somente de iluminação geral, sem iluminação local é possível atingir no máximo a classificação $B$ e que temos a possibilidade de uso dos dois tipos de luminárias adotadas sem alterar a classificação dos níveis de eficiência energética encontrados.

Palavras-chave: Eficiência energética. Etiquetagem. Sistemas de Iluminação. Uso de luminárias. 


\begin{abstract}
This study aims to assess the gains in energy efficiency through the classification levels, assigned to the installation of lighting systems, with the implementation of the proposed regulations for voluntary labeling of the level of energy efficiency in commercial buildings, of services and public in stage of approval. One contextualization of the importance of the proposed regulation was held with major systems for evaluating environmental of buildings in the international and Brazil, considering the major initiatives and current status of them. With the use of that methodology, three separate studies were conducted: first, considering a survey of data in an existing building which is hosting an administrative organization of the public power, composed of 275 dependences. The second and third studies dealing with the application in a lighting project in the same enterprise, in two different luminaires (composed of optical systems with and without fins, respectively). From these activities that guide the direct application of the methodology for preparation of projects there have been established comparisons between the results and made comments on the levels of illuminance, the density of total installed power in lighting and in lighting power density. In possession of all results obtained in a building with significant representation in the segment of public buildings, as well as the relevant considerations, we can infer that with the use only of general lighting, local lighting is not possible to achieve the maximum rating $B$ and we have the possibility to use both types of luminaires adopted without changing the classification of levels of energy efficiency found.
\end{abstract}

Keywords: Energy efficiency. Labeling. Lighting systems. Use of luminaires. 


\section{LISTA DE ILUSTRAÇÕES}

Figura 1 - Evolução do comportamento do consumo de energia elétrica e PIB considerando a razão entre valores das respectivas grandezas em cada ano de 1987 a 2004 e os valores das mesmas em 1987. Fonte: (PROCEL EDIFICA, 2009).

Figura 2 - Intensidade Energética do PIB (exclusive consumo não energético) tep/ US\$ 1000 [2005]. Fonte: Plano 2030 (2007).

Figura 3 - Distribuição dos usos finais de eletricidade no setor público em 2004. Fonte:

Plano 2030 (2007)

Figura 4 - Comparação de sistemáticas através da distribuição de categorias de impacto ambiental nos esquemas BREEAM, LEED, CASBEE e GBC. Fonte: adaptado de Silva (2003)

Figura 5 - Modelo de etiqueta que representa o nível de eficiência para edificação ou elementos da mesma conforme regulamentação abordada. Fonte: Eletrobras (2008) ......53 Figura 6 - Etiqueta de eficiência. Fonte: INMETRO (2008).

Figura 7 - Fluxograma de aplicação da proposta de regulamentação para sistemas de iluminação.

Figura 8 - Nível de eficiência obtido por tipo de dependência, no primeiro estudo realizado.

Figura 9 - Nível de eficiência obtido por tipo de dependência, no segundo estudo realizado.

Figura 10 - Nível de eficiência obtido por tipo de dependência, no terceiro estudo realizado. 


\section{LISTA DE TABELAS}

Tabela 1 - Comparação dos sistemas de avaliação ambiental abordados .43

Tabela 2 - Fatores determinantes de iluminância adequada

Tabela 3 - Limite máximo aceitável de densidade de potência de iluminação (DPIRL) para cada nível de eficiência energética.

Tabela 4 - disposição das dependências por tipo de ambiente no interior da edificação ..69

Tabela 5 - Comparação dos índices de nível de eficiência entre os grupos.

Tabela 6 - Média e erro padrão da média (SEM) dos valores de densidade de potência total instalada $\left(\mathrm{W} / \mathrm{m}^{2}\right.$ ), iluminância (lux) e densidade de potência de iluminação (DPI $\mathrm{RF}_{\text {) }}$ para o pavimento térreo.

Tabela 7 - Média e erro padrão da média (SEM) dos valores de densidade de potência total instalada $\left(\mathrm{W} / \mathrm{m}^{2}\right)$, iluminância (lux) e densidade de potência de iluminação ( $\mathrm{DPI} \mathrm{RF}_{\mathrm{RF}}$ ) para o primeiro pavimento

Tabela 8 - Média e erro padrão da média (SEM) dos valores de densidade de potência total instalada $\left(\mathrm{W} / \mathrm{m}^{2}\right)$, iluminância (lux) e densidade de potência de iluminação (DPI $\mathrm{RF}_{\mathrm{RF}}$ para o segundo pavimento

Tabela 9 - Média e erro padrão da média (SEM) dos valores de densidade de potência total instalada $\left(\mathrm{W} / \mathrm{m}^{2}\right)$, iluminância (lux) e densidade de potência de iluminação (DPI $I_{\mathrm{RF}}$ ) para o terceiro pavimento

Tabela 10 - Média e erro padrão da média (SEM) dos valores de densidade de potência total instalada $\left(\mathrm{W} / \mathrm{m}^{2}\right.$ ), iluminância (lux) e densidade de potência de iluminação (DPI $\mathrm{RF}_{\text {) }}$ para o quarto pavimento.

Tabela 11 - Média e erro padrão da média (SEM) dos valores de densidade de potência total instalada $\left(\mathrm{W} / \mathrm{m}^{2}\right)$, iluminância (lux) e densidade de potência de iluminação (DPI $I_{\mathrm{RF}}$ ) para o quinto pavimento

Tabela 12 - Média e erro padrão da média (SEM) dos valores de densidade de potência total instalada $\left(\mathrm{W} / \mathrm{m}^{2}\right)$, iluminância (lux) e densidade de potência de iluminação (DPI $I_{\mathrm{RF}}$ ) para o sexto pavimento

Tabela 13 - Média e erro padrão da média (SEM) dos valores de densidade de potência total instalada $\left(\mathrm{W} / \mathrm{m}^{2}\right)$, nos diferentes ambientes da edificação ......

Tabela 14 - Média e erro padrão da média (SEM) dos valores de iluminância (lux), nos diferentes ambientes da edificação

Tabela 15 - Média e erro padrão da média (SEM) dos valores de densidade de potência de iluminação (DPI $\mathrm{RF}_{\text {) }}$, nos diferentes ambientes da edificação. 


\section{LISTA DE ABREVIATURAS E SIGLAS}

ABNT - Associação Brasileira de Normas Técnicas

ANEEL - Agência Nacional de Energia Elétrica

ANP - Agência Nacional do Petróleo

AQUA - Processo de Alta Qualidade Ambiental

ASHRAE - American Society of Heating, Refrigerating and Air-Conditioning Engineers

ASTM - American Society for Testing and Materials

BEN - Balanço Energético Nacional

BEPAC - Building Environmental Performance Assessment Criteria

BRE - Building Research Establishment

BREEAM - Building Establishment Environmental Assessment Method

CASBEE - Comprehensive Assessment System for Building Environmental Efficiency

CGIEE - Comitê Gestor de índices e Níveis de Eficiência Energética

CLASP - Collaborative Labeling and Appliance Standards Program

CNUMAD - Conferência das Nações Unidas para o Meio Ambiente e o Desenvolvimento

CONPET - Programa Nacional de Racionalização do Uso dos Derivados do Petróleo e do Gás Natural

DOE - United States Department Of Energy

EPA - Environmental Protection Agency

EPI - Environmental Performance Index

EUA - Estados Unidos da América

GBC - Green Building Challenge

GLD - Gerenciamento pelo Lado da Demanda

GLP - Gás Liquefeito de Petróleo

GN - Gás Natural

HK-BEAM - Hong Kong Building Environmental Assessment Method

HQE - Haute Qualité Environnementale 
IBGE - Instituto Brasileiro de Geografia e Estatística

ILUM - iluminância

INC - Incandescente

INMETRO - Instituto Nacional de Metrologia, Normalização e Qualidade Industrial IPCA - Índice Nacional de Preços ao Consumidor Amplo

LUM - Luminária

LEED - Leadership in Energy and Environmental Design

MME - Ministério das Minas e Energia

NABERS - National Australian Building Environment Rating Scheme

NBR - Norma Brasileira

PBE - Programa Brasileiro de Etiquetagem

PIB - Produto Interno Bruto

PNE 2030 - Plano Nacional de Energia 2030

PROCEL - Programa Nacional de Conservação de Energia Elétrica

USGBC - United States Green Building Council

USP - Universidade de São Paulo 


\section{SUMÁRIO}

1 INTRODUÇÃO 14

1.1 AÇÕES DE EFICIÊNCIA ENERGÉTICA APLICADAS EM ÂMBITO NACIONAL. 24 1.2 MOTIVAÇÃO E OBJETIVOS 29

1.3 ESTRUTURA DA DISSERTAÇÃO 30

2 ESTÁGIO ATUAL DE AVALIAÇÃO DE DESEMPENHO AMBIENTAL DE EDIFÍCIOS - PRINCIPAIS INICIATIVAS. 32

2.1 INICIATIVAS INTERNACIONAIS DE SISTEMAS DE AVALIAÇÃO DE DESEMPENHO AMBIENTAL EM EDIFÍCIOS 32

2.2 INICIATIVAS NO BRASIL DE SISTEMAS DE AVALIAÇÃO DE DESEMPENHO AMBIENTAL EM EDIFÍCIOS 47 3 PROCEDIMENTOS PARA AVALIAÇÃO DO USO DA REGULAMENTAÇÃO PARA ETIQUETAGEM VOLUNTÁRIA DE NÍVEL DE EFICIÊNCIA ENERGÉTICA DE EDIFÍCIOS COMERCIAIS, DE SERVIÇOS E PÚBLICOS .......................................61

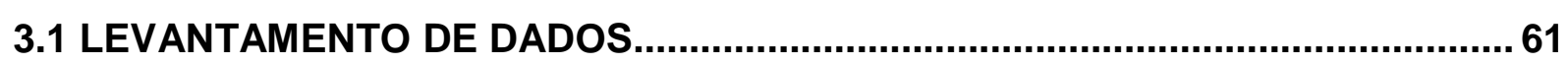

3.2 APLICAÇÃO DA PROPOSTA DE REGULAMENTAÇÃO DE ETIQUETAGEM

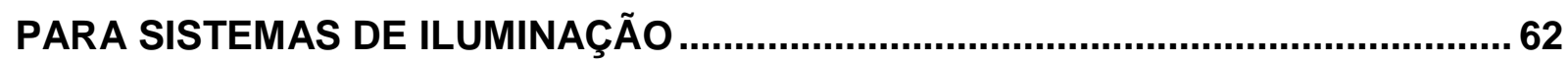

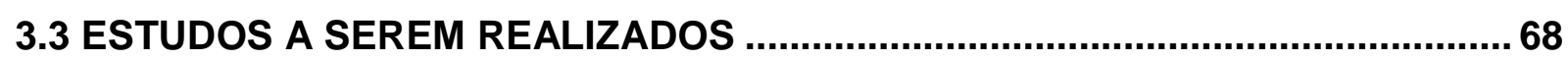

3.4 ANÁLISES DOS RESULTADOS OBTIDOS ……..........................................73

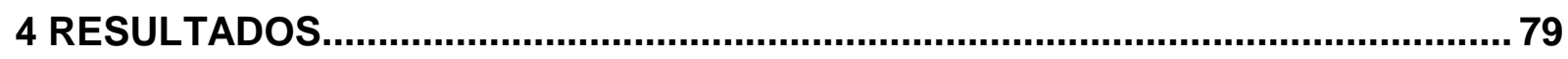

5 DISCUSSÃO

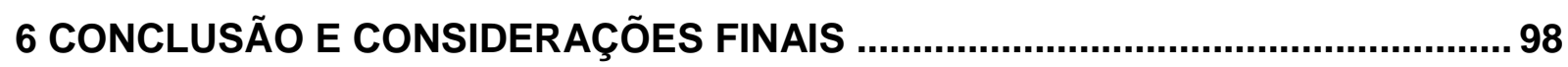

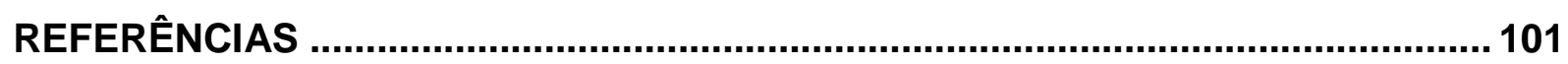

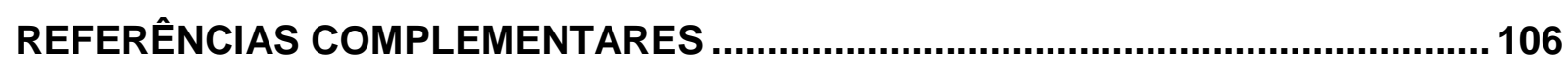

ANEXO A

ANEXO B

ANEXO C

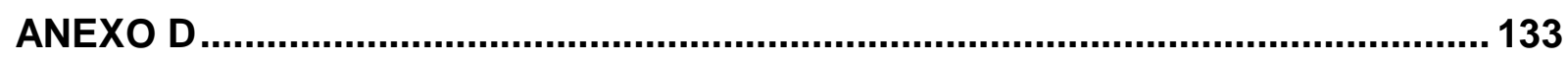




\section{INTRODUÇÃO}

A energia hídrica com potencial de geração maior que $30 \mathrm{MW}$ corresponde a $74,1 \%$ da estrutura de oferta interna no Brasil e no mundo a $16 \%$ do total gerado, conforme expresso no BEN (2007), representando um lugar de destaque na matriz energética brasileira como insumo essencial.

Segundo o MME (2008), em âmbito nacional, tal parcela percentual representativa deve-se a questão da hidrografia favorável somado a um histórico de investimentos da iniciativa privada no segmento, que se iniciaram na primeira metade da década de 1920 e posterior a 1940 com a estatização do setor, tendo como destaques a criação da Chesf (Companhia Hidroelétrica do São Francisco), da usina de Paulo Afonso e a construção de Furnas em 1962.

Como importante marco da atuação governamental no setor, em 1954 foi proposta a criação da empresa Centrais Elétricas Brasileiras (Eletrobras) pelo então presidente Getúlio Vargas. O projeto enfrentou grande oposição e só foi aprovado após sete anos de tramitação no Congresso Nacional. A instalação da empresa ocorreu oficialmente no dia 11 de junho de 1962.

A Eletrobras veio a tornar-se a controladora do sistema elétrico e fez muitos investimentos nas décadas de 1960 a 1980 para aumentar o parque gerador e o sistema de transmissão no Brasil. As reformas institucionais e as privatizações na década de 1990 acarretaram a perda de algumas funções da estatal e mudanças no perfil da empresa. Nesse período, a companhia passou a atuar também, por determinação legal e transitoriamente, na distribuição de energia elétrica (ELETROBRAS, 2008). 
Com uma capacidade instalada de 39402 MW para produção de energia elétrica, incluindo metade da potência da usina de Itaipu pertencente ao Brasil, a Eletrobras possui $59765 \mathrm{~km}$ de linhas de transmissão, representando mais de $56 \%$ do total nacional, 29 usinas hidroelétricas, 15 termoelétricas e duas nucleares, conforme dados atualizados em 2008. (ELETROBRAS, 2008).

No decorrer dos anos, especificamente em meados da década de setenta até a década de 90, o setor elétrico enfrentou diversos períodos de restrições financeiras e várias crises de energia, como foi o caso da alta do petróleo na década de 70 . Durante esse período, houve esforços governamentais e incentivos para a substituição do petróleo por eletricidade aliada a uma cultura estabelecida até a década de 70 e preocupada em consolidar o mercado brasileiro de energia elétrica através de uma estrutura industrial baseada em segmentos intensivos em energia elétrica (JANNUZZI, 2001).

Diante dos desequilíbrios fiscais no setor e conseqüentes dificuldades cada vez maiores de atender as necessidades de investimentos no segmento, com destaque para a ausência de cumprimento de execução de obras previstas no plano decenal da Eletrobras, em abril de 2001 os níveis das represas apresentaram uma capacidade de armazenamento correspondente a $30 \%$ do total o que indicava uma grande chance que os reservatórios secassem quase completamente antes da nova estação de chuvas (GOLDEMBERG; PRADO, 2003).

Para evitar uma perspectiva de crise ainda maior, foi implementado em $1^{\circ}$ de junho de 2001 a $1^{\circ}$ de março de 2002 o racionamento de energia, com meta de economizar $20 \%$ de energia elétrica. Tal medida resultou em reduções acima do patamar 
estipulado, em parte devido a introdução de tecnologias mais eficientes e substituição de eletricidade por energia solar e gás (GN e GLP) além de grandes alterações nos padrões de comportamento, especialmente do consumidor residencial.

Outra parcela das economias verificadas foi decorrente do decréscimo da atividade produtiva tanto na indústria como no comércio e serviços durante o período supracitado.

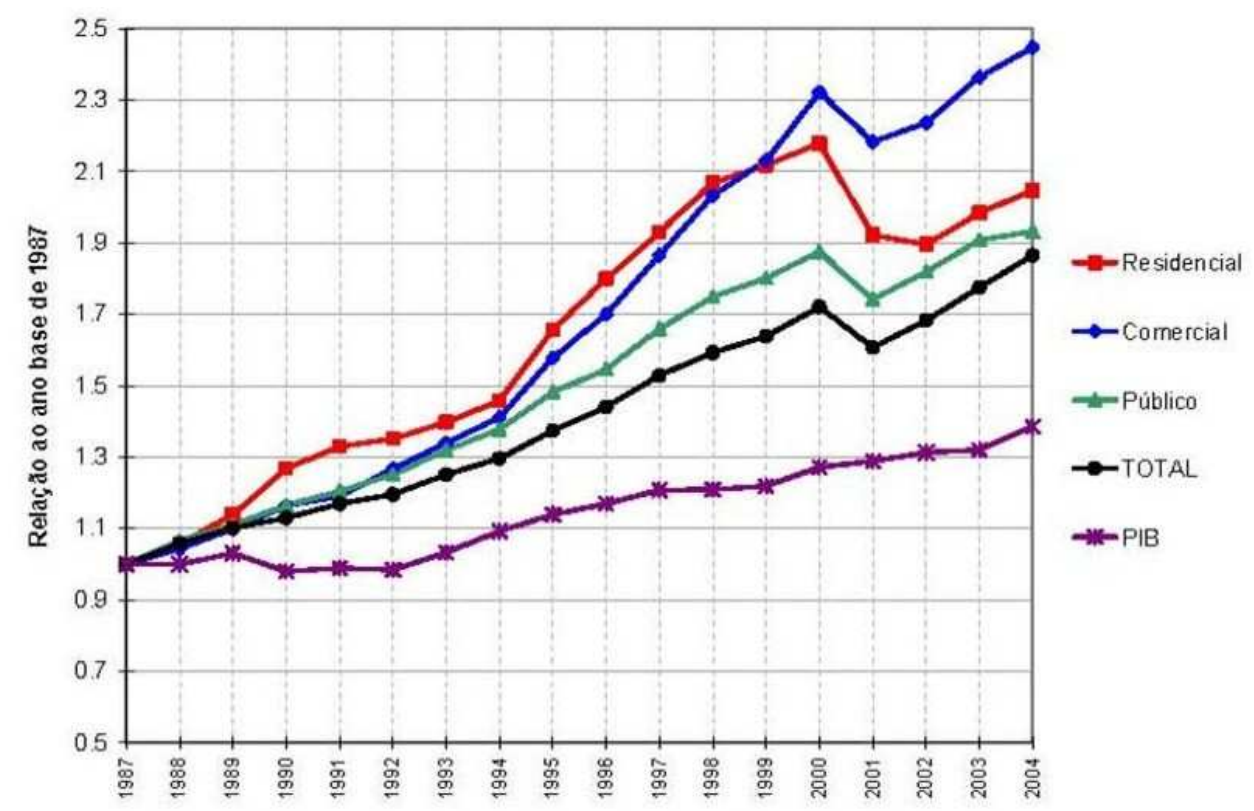

Figura 1 - Evolução do comportamento do consumo de energia elétrica e PIB considerando a razão entre valores das respectivas grandezas em cada ano de 1987 a 2004 e os valores das mesmas em 1987. Fonte: (PROCEL EDIFICA, 2009).

Inserido neste contexto, temos como característica relevante o crescimento do consumo de energia elétrica (nos setores residencial, comercial e público) contínuo a taxas superiores às do crescimento do PIB, apenas apresentando pequenas flutuações durante períodos de estagnação e recessão econômica, como observado na figura 1 no tocante ao período de 2001 (JANNUZZI, 2001). 
Como uma das principais alternativas para o Governo no atendimento a essa evolução no consumo de energia, os projetos de eficiência energética minimizam impactos sócio-ambientais na medida em que implicam em ações para proporcionar economia desse insumo durante a execução de atividades, seja por uso de equipamentos mais eficientes ou mesmo de uma nova tecnologia, ou apenas pelo uso racional da energia (PNE 2030, 2007).

Em 2008 é divulgado um estudo pioneiro no Brasil chamado de Plano Nacional de Energia 2030, o PNE 2030 (2007). Tal estudo, contratado à Empresa de Pesquisa Energética - EPE pelo Ministério das Minas e Energia, foi realizado por um ente governamental visando um planejamento de longo prazo de caráter energético, vale dizer, cobrindo não somente a questão da energia elétrica, como também dos demais energéticos, notadamente petróleo, gás natural e biomassa, admitindo e explicitando a integração dos recursos energéticos.

Segundo o PNE 2030 (2007), o ciclo de planejamento no setor energético pode ser dividido em quatro etapas: 1) a de diagnóstico, identificando os potenciais energéticos; 2) a de elaboração de diretrizes, políticas e definição dos programas de expansão do Sistema Energético, inclusive projeções de consumo final de energia; 3) a de implementação; e por fim, 4) a etapa de monitoramento. Estas etapas se apóiam em duas naturezas de estudos e pesquisas. A primeira abarca as análises de diagnóstico estratégico para o setor energético, enquanto a segunda incorpora os planos de desenvolvimento energético.

Ressalta-se a representatividade dos potenciais de redução estimados, conforme expresso no PNE 2030 (2007), na qual se considera um cenário de energia para o 
Brasil em 2020 com uma forte penetração de eficiência energética, com um potencial de economia total de $25 \%$, dentro dos parâmetros estipulados e que contempla a adoção da estratégia de expansão da oferta de energia considerar, como diretriz, iniciativas na direção do uso mais eficiente da energia (PNE 2030, 2007).

Tais ações em eficiência energética, não só servem para diminuir as taxas de expansão das cadeias produtivas dos principais energéticos, mas principalmente, atuam como importantes instrumentos de controle da poluição atmosférica e outras externalidades negativas associadas, melhorar a competitividade da indústria nacional e conseguir avanços em metas sociais (PNE 2030, 2007).

Neste contexto, torna-se imprescindível a adoção do planejamento energético setorial, orientando tendências e estratégias de expansão a longo prazo, objetivando definir metas e a perpetuação da energia conservada, seja por meio do chamado gerenciamento pelo lado da demanda (GLD) ou de outros mecanismos de mercado criados para estimular as empresas a investir em projetos de uso eficiente de energia (PNE 2030, 2007).

As ações que aprimoram a eficiência no uso da energia elétrica possuem também vantagens de promover uma menor agressão ao meio ambiente bem como implementar uma necessária redução das taxas de expansão das cadeias produtivas e conseqüente aprimoramento das mesmas, no tocante principalmente a intensidade energética ${ }^{1}$, em um esforço de mitigar os problemas relativos aos atuais padrões de energia envoltos em seus danos e riscos.

\footnotetext{
${ }^{1}$ Definida como a razão entre a energia consumida e o Produto Interno Bruto (GOLDEMBERG, 1996)
} 
Uma medida dinâmica dessa eficiência é dada pela evolução da intensidade energética. Entre 1970 e 1980, houve uma redução drástica desse parâmetro, indicando que o produto nacional aumentou com menor uso relativo de energia. Nesse período, o elemento chave dessa dinâmica foi a substituição de energéticos menos eficientes (lenha) por outros mais eficientes (derivados do petróleo e eletricidade). Nos períodos subseqüentes, houve aumento da intensidade energética, o que encontra respaldo no estágio de desenvolvimento econômico do país, em especial de sua indústria (GOLDEMBERG, 2003).

De acordo com o PNE 2030 (2007), nos primeiros anos do horizonte de projeção, componentes inerciais da oferta e da demanda de energia explicam porque esse indicador ainda cresce (por exemplo, decisões de investimentos em indústrias e a dinâmica de reposição tecnológica insuficiente para afetar significativamente a eficiência global no uso de energia).

Esta tendência só é revertida ao longo do horizonte do estudo, na medida em que ações de eficiência energética produzam resultados mais efetivos. A trajetória percorrida evidencia o que se chama de efeito colina. Nessas condições, a intensidade energética em 2030, será aproximadamente igual a de 1990, porém a economia será quatro vezes maior. Conforme indicado na figura 2, a despeito do crescimento do PIB, a intensidade energética cai de aproximadamente 0,28, em 2005, para aproximadamente 0,26 , ao final do período (2030). 


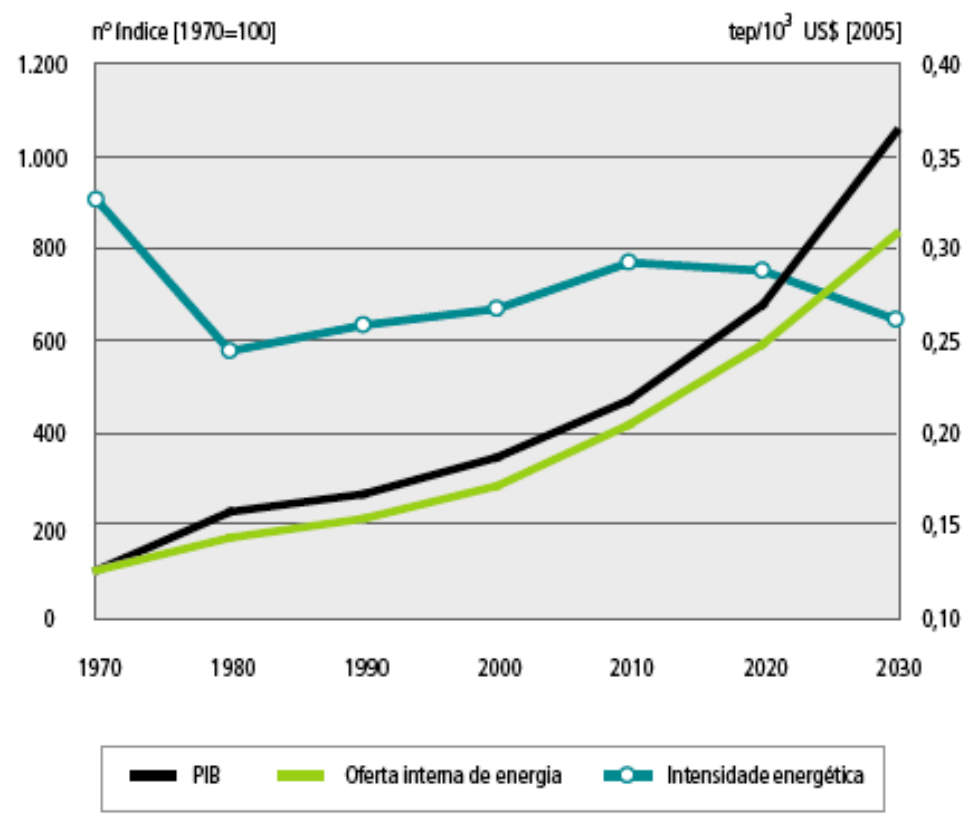

Figura 2 - Intensidade Energética do PIB (exclusive consumo não energético) tep/ US\$ 1000 [2005]. Fonte: Plano 2030 (2007).

Abordando especificamente as despesas públicas, um dos insumos que vem representando significativo aumento é a energia elétrica. Dados do BEN 2005 mostram que entre os anos de 1988 e 2004, o consumo desse insumo no setor público cresceu $81 \%$ enquanto que, neste mesmo período, a população brasileira teve um crescimento de 23\% (KURAHASSI, 2006).

Além disso, verifica-se que a tarifa média brasileira para a classe de consumo do Poder Público aumentou 225\% nos últimos 11 anos, saindo de $\mathrm{R} \$ 84,07 / \mathrm{MWh}$ em 1995 para alcançar o valor de $\mathrm{R} \$ 273,13 / \mathrm{MWh}$, em 2005, conforme análise de dados obtidos junto a ANEEL (KURAHASSI, 2006). Ressalta-se que o IPCA no mesmo período correspondeu a um aumento de $208 \%$, menor do que a variação da referida tarifa (IBGE, 2009).

O setor público engloba as entidades do poder público e os serviços de utilidade pública (TOLMASQUIM, 2000). O poder público é composto pelas Forças Armadas, 
escolas e hospitais da rede oficial e órgãos da administração pública, nos diversos níveis governamentais. Entre os serviços de utilidade pública destacam-se, quanto ao consumo de eletricidade, os prestados pelos prédios públicos e pelas empresas de água e saneamento e a iluminação pública (PNE 2030, 2007).

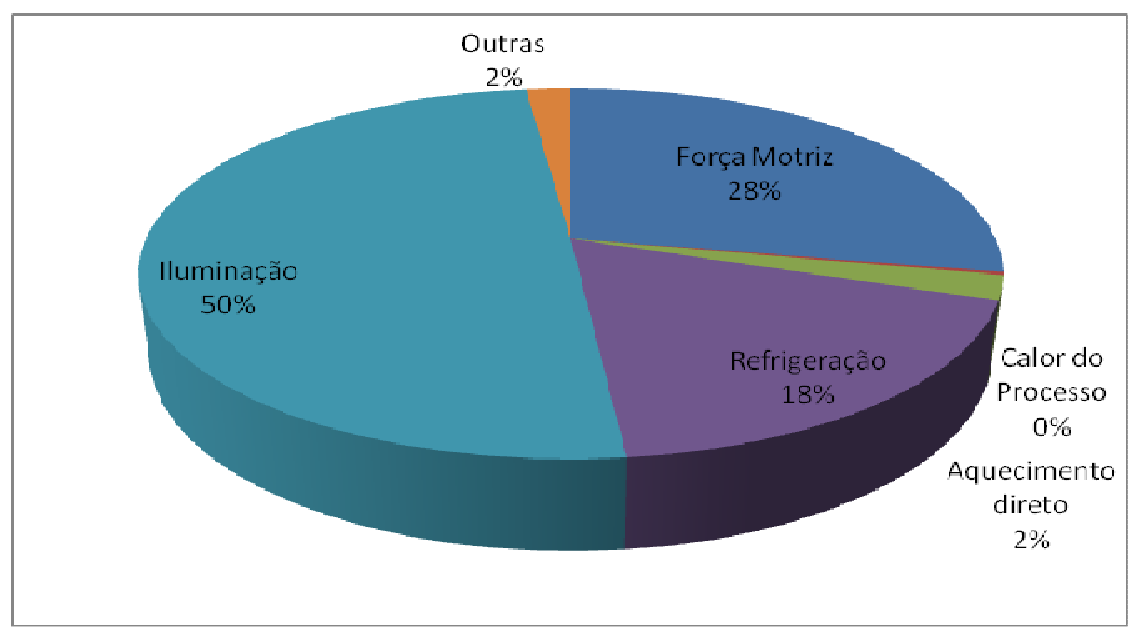

Figura 3 - Distribuição dos usos finais de eletricidade no setor público em 2004. Fonte: Plano 2030 (2007).

Segundo o PNE 2030 (2007), o setor público possui uma representatividade correspondente a parcela de $8 \%$ do consumo final de energia elétrica, apresentando uma segmentação de consumo conforme indicado na figura 3.

De acordo com o Procel (2009), o consumo de energia elétrica em prédios públicos representa cerca de $80 \%$ do total consumido pelo poder público, incluídos os níveis federal, estadual e municipal.

Dada a perspectiva de potencial de conservação apresentada, além da otimização dos usos finais em instalações existentes, torna-se de fundamental importância a inserção de parâmetros de eficiência energética na confecção de projetos de instalações elétricas do Poder Público, bem como a realização, nesta fase dos 
empreendimentos, de um detalhamento dos produtos a serem utilizados durante a execução das obras, o que hoje não é uma prática difundida.

No momento de implementação das iniciativas que aprimoram a eficiência no uso da energia elétrica, deve ser considerado como um importante foco de atuação as instalações prediais (em particular de caráter comercial), caracterizadas pela existência de gastos mais do que necessários no tocante ao consumo e um significativo potencial para economia de energia e aumento da qualidade dos sistemas postos em funcionamento, principalmente pelo uso intenso de equipamentos com tecnologias ultrapassadas como lâmpadas fluorescentes tubulares comuns de $20 \mathrm{~W}$ e 40W, reatores eletromagnéticos (muitas vezes com baixo fator de potência), motores ineficientes e lâmpadas incandescentes.

Além do uso de equipamentos ineficientes, verifica-se frequentemente em aplicações comerciais, projetos luminotécnicos superdimensionados, sem controles de acionamentos adequados e sem manutenção preventiva eficaz, que acarretam em maiores depreciações dos equipamentos e conseqüente diminuição dos níveis de iluminância (IWASHITA, 2004).

A iluminação é um dos grandes responsáveis pelo consumo de energia elétrica em edificações, principalmente naquelas não condicionadas artificialmente. Além do que, é, dentre os responsáveis pelo consumo do edifício, aquele item que permite maior facilidade de redução de consumo frente ao forte desenvolvimento tecnológico dos componentes de sistemas de iluminação verificados nos últimos anos. E permite, também, além da redução do consumo, a correção de eventuais falhas no sistema e nos níveis de iluminação no tocante ao atendimento de normativas da ABNT. 
Em termos percentuais, nos Estados Unidos, a iluminação é responsável por 20 a $25 \%$ do total de eletricidade utilizada, sendo que a iluminação utilizada em indústrias, lojas, escritórios e depósitos representam de 80 a $90 \%$ do total de eletricidade em iluminação (IAEEL, 1992).

Segundo EPRI (1993), o consumo com iluminação em edifícios comerciais nos Estados Unidos representa mais da metade da eletricidade consumida nestes edifícios. Um edifício comercial típico, neste país, consome aproximadamente 36 $\mathrm{kWh} / \mathrm{m}^{2}$.ano em iluminação e um adicional de $6 \mathrm{kWh} / \mathrm{m}^{2}$.ano $(16,7 \%)$ para retirar o calor gerado pela iluminação artificial.

CADDET (1995) também apresenta a iluminação do setor comercial nos Estados Unidos como responsável por $57 \%$ da carga total de eletricidade para iluminação daquele país.

Na Inglaterra, segundo CADDET (1995), os edifícios comerciais são responsáveis por $63 \%$ da energia elétrica consumida em iluminação.

No Brasil, com o intuito de analisar o consumo de energia elétrica de edifícios de escritórios, Lamberts; Dutra; Pereira (1997), propõe que os sistemas de iluminação sejam responsáveis por $24 \%$ do total do consumo do mesmo.

Embora a questão do uso racional e eficiente de energia tenha se tornado uma preocupação atual, muitos projetos ainda ignoram aspectos simples e de baixo custo relacionados com a tecnologia de iluminação adotada. 
Este raciocínio, de caráter imediato, acaba apenas considerando seu custo inicial na aquisição dos equipamentos nesta etapa de concepção de projeto e deixa de evitar gastos excedentes relacionados com o consumo de energia elétrica, a substituição e a manutenção dos mesmos e, talvez, o mais importante, o custo da perda de eficiência das pessoas que fazem uso de todo sistema.

A estas despesas excedentes, que deveriam ter sido previstas num primeiro momento, deve-se somar, ainda, a possível necessidade de compatibilização de interferências arquitetônicas ou de restabelecimento de padrões de acabamento quando da necessidade de se substituir posteriormente um sistema de iluminação já instalado por outro, mais eficiente.

\subsection{AÇÕES DE EFICIÊNCIA ENERGÉTICA APLICADAS EM ÂMBITO NACIONAL}

Desde a década de 80, o Governo Federal vem atuando significativamente para colocar em prática ações de eficiência energética com o foco no Gerenciamento do Lado da Demanda (GLD), tornando necessária a intervenção junto às instalações consumidoras através de medidas que otimizem a utilização das mesmas, sem o comprometimento da qualidade de vida e eliminando prioritariamente o desperdício (PROCEL EDIFICA, 2009).

A aprovação da lei no 10.295 (BRASIL, 2001), conhecida com a "Lei de Eficiência Energética" vem a instituir a etiquetagem obrigatória no Brasil devido a necessidade de se estabelecer um mecanismo de reconhecida eficácia para melhorar o uso da eficiência energética (GELLER, 2003) proporcionando a adoção de medidas necessárias para que sejam obedecidos os níveis máximos de consumo de energia e 
mínimos de eficiência energética, constantes da regulamentação específica estabelecida para cada tipo de máquina e aparelho impactando diretamente na fabricação e importação de máquinas e aparelhos consumidores de energia.

Com o intuito de se viabilizar tal mecanismo, destaca-se como marco a criação do Selo Procel - INMETRO através de decreto presidencial de 8 de dezembro de 1993, estabelecendo o Programa Brasileiro de Etiquetagem - PBE.

O Selo Procel tem por objetivo orientar o consumidor no ato da compra, indicando os produtos que apresentam os melhores níveis de eficiência energética dentro de cada categoria, proporcionando assim economia na sua conta de energia elétrica. Também estimula a fabricação e a comercialização de produtos mais eficientes, contribuindo para o desenvolvimento tecnológico e a preservação do meio ambiente.

Em uma abordagem ambiental com ênfase em edificações, as preocupações com os impactos ambientais gerados durante as fases de planejamento e construção ou durante a operação, são cada vez maiores. Tanto que já existem vários selos internacionais para verificar os recursos consumidos, as emissões de carbono e os resíduos gerados pelas edificações, bem como o conforto e a saúde das pessoas que convivem nelas, a partir de uma avaliação do grau de sustentabilidade dos edifícios baseada em critérios específicos de cada selo.

No Brasil, diante da ausência de selos que indiquem uma classificação para o desempenho ambiental e de eficiência em edificações, existem em uso no mercado duas certificações de caráter sustentável para edificações, a certificação da Construção Sustentável - Processo AQUA (Alta Qualidade Ambiental) e o LEED 
(Leadership in Energy and Environmental Design). Tais certificações se aplicam para reformas e novas construções, de escritórios, escolas e hotéis (AQUA) e prédios comerciais e institucionais, hotéis e alguns tipos de residências (LEED).

Inspirado no selo francês HQE, o AQUA foi desenvolvido por professores da Escola Politécnica da USP através da Fundação Vanzolini, estabelecendo o primeiro referencial técnico brasileiro para construções sustentáveis, com o intuito de promover uma maior qualidade de vida ao usuário, economias de água, de energia, da disposição de resíduos e manutenção e contribuindo para o desenvolvimento sócioeconômico e ambiental da região.

Com a certificação realizada em sua totalidade em âmbito nacional, por meio de auditorias presenciais com auditores capacitados na avaliação do desempenho das construções sustentáveis e experientes na realidade brasileira, o selo AQUA leva em conta as especificidades do Brasil para elaborar seus 14 critérios que avaliam a gestão ambiental das obras e as especificidades técnicas e arquitetônicas, abordando desde aspectos de entorno da edificação e escolha integrada de produtos, sistemas e processos construtivos até gestão de recursos (energia, água e resíduos) e qualidade sanitária de ambientes.

Alguns empreendimentos brasileiros, com objetivo de concorrer internacionalmente, vêm adquirindo nos últimos anos, o certificado norte-americano do USGBC, o LEED pautado em pressupostos e critérios relacionados principalmente a legislação, clima, fontes de energia e condições sociais, econômicas e ambientais que nem sempre condizem com a realidade brasileira. 
O LEED propõe uma avaliação do desempenho ambiental de forma global, ao longo de todo o ciclo de vida do edifício, numa tentativa de considerar os preceitos essenciais do que compõem um empreendimento no qual foram aplicadas medidas construtivas e de procedimentos que buscam o aumento de sua eficiência no uso de recursos, com foco na redução dos impactos sócio-ambientais.

O critério mínimo de nivelamento exigido para avaliação de um edifício pelo LEED é o cumprimento de uma série de pré-requisitos. Satisfeitos todos estes pré-requisitos, passa-se à etapa de classificação do desempenho, em que a atribuição de créditos indica o grau de conformidade do atendimento aos itens avaliados.

Em continuidade ao atendimento lei no 10.295 (BRASIL, 2001), que prevê no artigo 4 que caberá ao Poder Executivo desenvolver mecanismos que promovam a eficiência energética nas edificações construídas no país, está atualmente em processo de homologação junto ao INMETRO a regulamentação para etiquetagem do nível de eficiência energética de edifícios comerciais, de serviços e públicos, confeccionada por um grupo técnico do CGIEE, criado pelo decreto-lei no 4059 (BRASIL, 2001).

A regulamentação trata do estabelecimento aos edifícios, concluídos ou em reforma, de níveis de eficiência energética $A, B, C, D$ e $E$ através de uma metodologia de avaliação que divide o prédio em três elementos distintos: envoltória (análise de elementos construtivos), sistemas de iluminação e sistema de condicionamento ambiental. Cada um desses elementos é certificado separadamente e posteriormente há a especificação de um nível geral de eficiência para a edificação. 
A aplicação da regulamentação para etiquetagem do nível de eficiência energética de edifícios comerciais, de serviços e públicos é de caráter voluntário para edificações novas e existentes. Tal aplicação se propõe passar a ter caráter obrigatório para edificações no prazo máximo de cinco anos a partir da data de sua entrada em vigor.

Em uma tentativa de se atribuir um caráter de qualidade e credibilidade aos empreendimentos, a regulamentação proposta representa uma importante iniciativa na consideração de um método que considera equações paramétricas definidas por regiões geográficas e tipologia do território brasileiro, estimando uma economia de energia em projetos eficientes de construção que pode chegar a 50\% e em reformas, a 30\%. No que tange a substituição a sistemas existentes, a troca de envoltório, iluminação e ar condicionado, a economia pode variar entre 10\% e 30\%. (PROCEL EDIFICA, 2009).

Torna-se inevitável a associação de melhorias na classificação de níveis de eficiência energética e a adoção de medidas que promovam usos de equipamentos, dispositivos e tecnologias (e, quando possível, orientadas a elaboração do projeto) criando oportunidades para educação de usuários e projetistas e avanços de qualidade de especificação. Uma vez que estas medidas tornarem-se prática comum, o sistema pode gradualmente mover-se em direção a critérios orientados ao desempenho através do controle do consumo total de energia.

Seja qual for o ramo de atividade, no processo de gestão de energia elétrica, vários aspectos devem ser levados em consideração para apoiar decisões e ações (MORALES, 2007). Considerando aspectos de definição de níveis de eficiência, os sistemas de avaliação existentes contemplam, em sua grande maioria, apenas 
impactos ambientais dos edifícios. A questão central em países em desenvolvimento é aprimorar uma avaliação ambiental para obter uma avaliação sustentável dos edifícios, considerando também aspectos econômicos e sociais relacionados a produção, operação e modificação do ambiente construído.

\subsection{MOTIVAÇÃO E OBJETIVOS}

A motivação para este trabalho foi a carência de estudos relacionados a aplicação de metodologias e regulamentações que possibilitem mensurar o potencial de conservação e economia de energia elétrica, particularmente em iluminação com aplicação direta na confecção de projetos de instalações elétricas de prédios administrativos no Setor Público, de maneira a contribuir significativamente para reduzir os impactos deste insumo essencial nas contas públicas e permitir a destinação de tais economias para outras iniciativas necessárias.

Destaca-se, ainda, a ausência de estudos que se propõem a buscar uma avaliação dos ganhos da implantação metodologias, bem como a viabilidade prática do uso das mesmas na confecção de projetos, visando à substituição de equipamentos e edificações.

Inserido neste contexto, surge uma metodologia, de caráter inédito em âmbito nacional, desenvolvida especificamente com apoio governamental denominada regulamentação para etiquetagem do nível de eficiência energética de edifícios comerciais, de serviços e públicos abordando aspectos de iluminação, condicionamento de ar e de envoltória.

Em função do cenário apresentado, este trabalho tem como objetivos: 
- Avaliar os principais sistemas de avaliação de desempenho ambiental de edifícios no Brasil e em âmbito internacional, considerando as principais iniciativas e estado atual.

- Realizar estudos que promovam a aplicação da metodologia proposta na regulamentação para etiquetagem do nível de eficiência energética de edifícios comerciais, de serviços e públicos, em uma abordagem voltada para elaboração de projetos luminotécnicos.

- Comparar os índices e a classificação do nível de eficiência energética em iluminação obtidos nos três estudos realizados, com a aplicação da proposta na regulamentação para etiquetagem do nível de eficiência energética de edifícios comerciais, de serviços e públicos.

\subsection{ESTRUTURA DA DISSERTAÇÃO}

Este Trabalho está estruturado em seis capítulos.

O primeiro capítulo apresenta uma breve consideração do contexto em que o trabalho se insere. São apresentadas a motivação e os objetivos do trabalho, assim como a estrutura do texto.

O segundo capítulo discorre sobre os sistemas de avaliação de desempenho ambiental de edifícios, descrevendo as principais iniciativas em âmbito internacional e nacional, bem como o estado atual das mesmas. 
O terceiro capítulo apresenta procedimentos para avaliação do uso da regulamentação para etiquetagem do nível de eficiência energética de edifícios comerciais, de serviços e públicos, no que tange a sistemas de iluminação, considerando na edificação existente a partir do levantamento de dados realizado e em projetos luminotécnicos desenvolvidos com uso de duas luminárias distintas.

O quarto capítulo mostra os resultados obtidos com a aplicação dos procedimentos para avaliar o uso da referida regulamentação.

O quinto capítulo apresenta a discussão acerca dos resultados obtidos. É realizada uma avaliação estatística no intuito de se estabelecer relações entre os dados coletados no prédio existente (dentre as luminárias estudadas em confronto com dados da edificação existente). Estabelece-se, ainda, um confronto com dados de literatura seguindo outras metodologias/normativas existentes.

Por fim, o sexto capítulo trata das conclusões e das considerações finais do trabalho. 


\section{ESTÁGIO ATUAL DE AVALIAÇÃO DE DESEMPENHO AMBIENTAL DE EDIFÍCIOS - PRINCIPAIS INICIATIVAS}

Este capítulo se propõe a traçar um panorama das principais iniciativas de avaliação ambiental de edifícios tanto em âmbito internacional quanto ao atual estado-da-arte do assunto no Brasil, a partir da abordagem de algumas sistemáticas em vigor na atualidade.

\subsection{INICIATIVAS INTERNACIONAIS DE SISTEMAS DE AVALIAÇÃO DE DESEMPENHO AMBIENTAL EM EDIFÍCIOS}

As diretrizes em busca do desenvolvimento sustentável na construção têm um enorme impacto nos países onde são aplicadas propondo mudanças dos paradigmas para a concepção de empreendimentos, balizando muitas vezes as exigências funcionais e estéticas do edifício, com um foco na consideração de novas exigências (relativas a energia, água, ar, conforto, clima, transportes, entre outras) dando maior importância a fatores ambientais numa evolução da prioridade adotada pelo cliente e pelos projetistas, que enfatizava anteriormente os aspectos financeiros.

Tais iniciativas poderiam ser consideradas como códigos que se aplicam em todas as especialidades no mundo da construção atuando como alavancas para as mudanças organizacionais e institucionais que afetam diretamente os profissionais do setor.

É característica dos métodos analisados, a concentração exclusiva na dimensão ambiental da sustentabilidade, por várias razões. A mais óbvia delas diz respeito à necessidade de implantação da agenda para a sustentabilidade em países desenvolvidos, nos quais o desenvolvimento econômico foi encorajado e acelerado 
proporcionando a sociedade um patamar de qualidade de vida, de igualdade social e de distribuição de riqueza - ou ao menos de eliminação de extremos de desigualdade - sem precedentes ou paralelos quando comparado aos níveis dessas referências encontrados nos países em desenvolvimento.

A contrapartida deste desenvolvimento foi a causa ou a acentuação de fenômenos que afetam diretamente a destruição de elementos naturais em seu próprio território ou - como mais tarde seria constatado - em escala global. Por esta razão, a agenda dos países desenvolvidos em relação à sustentabilidade tem sido tão centrada na dimensão ambiental.

Diante desta conjuntura, foram estabelecidas metas ambientais locais a partir de eventos internacionais com destaque para a Conferência das Nações Unidas para o Meio Ambiente e o Desenvolvimento (CNUMAD), realizada em 1992 no Rio de Janeiro, e posteriormente, a partir das necessidades de atendimento aos índices mínimos de redução impostos a partir do ano de 2004 da ordem de 20\%, através do Protocolo de Quioto, discutido e negociado no Japão em 1997 (SILVA; SILVA; AGOPYAN, 2001).

Como parte das estratégias para o cumprimento das metas ambientais estabelecidas, foi necessário o desenvolvimento de metodologias para avaliação ambiental de edifícios que surgiram na década de 90 na Europa, nos EUA e no Canadá (SILVA; SILVA; AGOPYAN, 2001).

Segundo Silva (2000), o resultado prático desses esforços é o altíssimo nível de regulamentações e de democratização da tomada de decisões orientadas à produção, 
manutenção e renovação do ambiente construído urbano, com o objetivo de encorajar a demanda do mercado por níveis superiores de desempenho ambiental, provendo avaliações ora detalhadas, para o diagnóstico de eventuais necessidades de intervenção no estoque construído, ora simplificadas, para orientar projetistas ou sustentar a atribuição de selos ambientais para edifícios.

Normalmente as avaliações de desempenho ambiental de edifícios abordam aspectos críticos no desempenho dos mesmos, fundamentados nas sensações humanas (fisiológicas, psicológicas, sociológicas e econômicas) e relacionados as necessidades básicas de saúde, segurança e bem-estar.

Cada país europeu - além de Estados Unidos, Canadá, Austrália, Japão e Hong Kong - possui um sistema de avaliação de edifícios. Embora não exista uma classificação formal neste sentido, os esquemas de avaliação ambiental disponíveis podem ser claramente separados em duas categorias. De um lado, temos aqueles orientados para o mercado, isto é, desenvolvidos para serem facilmente absorvidos por projetistas ou para receber e divulgar o reconhecimento do mercado pelos esforços dispensados para melhorar a qualidade ambiental de projetos, execução e gerenciamento operacional.

Segundo Silva; Silva e Agopyan (2001), Os esquemas desenvolvidos na categoria orientada ao mercado têm estrutura mais simples e estão vinculados a algum tipo de certificação de desempenho. Este é o caso do BREEAM (Reino Unido), do HQE (França), do HK-BEAM (Hong Kong), do LEED (Estados Unidos), do CASBEE (Japão), BREEAM Canadá (Canadá) e do NABERS (Austrália). 
Do outro lado, estão os esquemas de avaliação orientados para pesquisa, como o BEPAC (Canadá) e seu sucessor, o GBC (Internacional). Neste segundo caso, a ênfase é o desenvolvimento de uma metodologia abrangente e com fundamentação científica, que possa orientar o desenvolvimento de novos sistemas.

O primeiro e mais conhecido sistema de avaliação de desempenho ambiental é o BREEAM, desenvolvido no Reino Unido por pesquisadores do BRE e do setor privado em 1990 (BALDWIN et al., 1990). Este sistema atribui uma certificação de desempenho, direcionada a contribuir para a valorização da imagem da empresa diretamente ligada aos empreendimentos ou edifícios, pelo público em geral ou determinado segmento específico e, indiretamente, de projetistas e empreendedores.

Através de uma lista detalhada de itens a serem checados, verifica-se 0 atendimento de componentes mínimos de desempenho, projeto e operação dos edifícios e atribuem-se créditos ambientais. Estes créditos são posteriormente ponderados e chega-se a um número único. Quando atendida uma quantidade mínima de créditos, este índice habilita a certificação em uma das classes de desempenho do BREEAM (bom, muito bom e excelente) e permite comparação relativa entre os edifícios certificados pelo sistema.

Segundo Silva; Silva e Agopyan (2001), o BREEAM é fortemente baseado em análise documental e na verificação de presença de características de base, incluindo aspectos de gestão ambiental na concessão de créditos, a partir da avaliação do empreendimento concluído, gestão do projeto e operação de empreendimentos. Sua aplicação pode ser realizada numa variedade de tipos de edifícios (escritórios, indústrias, escolas, fábricas, prisões, cortes, residências e multi-residências). 
Estima-se que, no final da década de 90 , entre $30 \%$ e $40 \%$ dos novos edifícios de escritórios do Reino Unido foram submetidos a esta avaliação anualmente (HOWARD, 2001). Versões internacionais do BREEAM foram adaptadas às condições da Europa para alguns tipos de ambientes de escritórios, fábricas, indústrias e lojas de varejo e de países do Golfo Pérsico para maioria de finalidades de empreendimentos.

Uma das aplicações interessantes desses ajustes trata do atendimento da necessidade de algumas empresas multinacionais que podem querer que todo o seu estoque possua uma classificação utilizando o mesmo indicador ambiental (nos diferentes locais do mundo onde os edifícios estejam localizados). Isto também pode ser realizado utilizando a rota internacional da referida avaliação. Por exemplo, um regime separado BREEAM foi desenvolvido para todos os ambientes preparados especialmente para apresentação e demonstração de produtos e equipamentos a clientes dos veículos da marca Toyota localizados na Europa (BREEAM, 2009).

Outro sistema de avaliação de edifícios que se destaca é o LEED, com seu desenvolvimento iniciado nos Estados Unidos em 1996, com o intuito de facilitar a transferência de conceitos de construção ambientalmente responsável para os profissionais e para a indústria de construção americana e proporcionar reconhecimento junto ao mercado pelos esforços despendidos para essa finalidade.

A singularidade do LEED resulta principalmente do fato de ser um documento consensual, aprovado pelas 13 categorias da indústria de construção representadas no conselho gestor do esquema. O apoio de associações e fabricantes de materiais e produtos favoreceu a ampla disseminação deste esquema nos EUA. Através da 
aplicação deste sistema há possibilidade de se atingir os níveis de certificado prata, ouro ou platina, sendo este último o nível máximo a ser alcançado.

O LEED é um meio termo entre critérios puramente prescritivos e especificação de desempenho, e toma por referência princípios ambientais e de uso de energia consolidados em normas e recomendações de organismos com credibilidade reconhecida, como a ASHRAE, a ASTM, a EPA e o DOE. Estas práticas de efetividade já conhecidas são então balanceadas com princípios emergentes, de forma a estimular a adoção de tecnologias e conceitos inovadores.

Assim como o BREEAM, este sistema é também constituído por uma lista detalhada de itens a serem checados, que atribui créditos para o atendimento de critérios préestabelecidos, basicamente ações de projeto, construção ou gerenciamento que contribuam para reduzir os impactos ambientais de edifícios.

Abordando a base de avaliação ambiental utilizada na França, o HQE consiste em dois sistemas relacionados entre si, que aferem o desempenho ambiental de edifícios. Sua estrutura subdivide-se em gestão do empreendimento - SMO (Système de Management de l'Opération) - e qualidade ambiental - QEB (Qualité Environnementale du Bâtiment) -, que avaliam as fases de projeto, execução e uso, cada qual com uma certificação em separado.

O método Francês é diferenciado do BREEAM e LEED, apresentados anteriormente. A avaliação não possui escala de pontuação mas sim uma estrutura baseada em um perfil ambiental determinado pelo empreendedor, dentre os quatro blocos de 
avaliação, que possuem juntos 14 itens. Os blocos são: impactos do empreendimento no meio ambiente, gestão de recursos, conforto ambiental e saúde do usuário.

Na composição do perfil ambiental são escolhidos itens que deverão atender aos níveis de desempenho definidos. Há três níveis de desempenho, o máximo (Très Performant), que representa os melhores níveis de desempenho que podem ser obtidos, o médio (Performant) e o mínimo (Base), que já corresponde às boas práticas correntes. Para se obter a certificação, dos 14 itens quatro devem atender pelo menos ao nível médio, e pelo menos três, ao nível máximo. As outras categorias devem se enquadrar no nível base. Não há classificação do desempenho do edifício em níveis, obtendo-se ou não a certificação.

Merece destaque, também, o método de avaliação adotado no Japão, o CASBEE, que possui quatro instrumentos de avaliação: voltados ao projeto (em desenvolvimento), construções novas, edifícios existentes e reformas. Os critérios de avaliação abordam a qualidade ambiental e desempenho do edifício ( $Q$ - Building environmental quality and performance) e diminuição de cargas ambientais (LR Reduction of building environmental loadings).

O "Q" considera questões relativas à qualidade do ambiente interno (conforto e saúde do usuário), qualidade do serviço (funcionalidade, durabilidade) e meio ambiente local (preservação vegetal e animal, e características paisagísticas, culturais locais, etc.). Já o "LR" aborda eficiência energética (desempenho da envoltória, uso de energia renovável, eficiência dos sistemas e sua operação), gestão de recursos (economia e reúso de água, reúso e reciclagem de materiais etc.) e impactos na vizinhança (poluição do ar, sonora, vibrações etc.) 
A pontuação dos dois subsistemas é ponderada e resulta em uma nota final (BEE Building Environmental Efficency) que corresponde à classificação do edifício em um dos cinco níveis possíveis.

Abordando os esquemas orientados a pesquisa, a iniciativa que merece maior destaque é o chamado GBC, um consórcio internacional reunido com o objetivo de desenvolver um novo método para avaliar o desempenho ambiental de edifícios: um protocolo de avaliação com uma base comum, porém capaz de respeitar diversidades técnicas e regionais (SILVA; SILVA; AGOPYAN, 2001).

O GBC caracteriza-se por ciclos sucessivos de pesquisa e difusão de resultados. A etapa de desenvolvimento inicial (24 meses), integralmente financiada pelo governo do Canadá, envolveu 15 países e culminou em uma conferência internacional em Vancouver, Canadá - a GBC'98.

A divulgação dos resultados da segunda fase de desenvolvimento (18 meses), compreendendo trabalhos de 19 países, foi um dos ramos centrais da conferência Internacional Sustainable Buildings 2000, realizada em Maastricht, Holanda. Desta etapa em diante, o governo canadense deixou de ser responsável pela gestão do processo. A coordenação do GBC, assim como a co-responsabilidade pela seqüência de conferências Sustainable Buildings (SB) foi absorvida pela IISBE (International Iniciative for Sustainable Built Environment) em 2000 (SILVA; SILVA; AGOPYAN, 2001).

Com isso, as equipes participantes do GBC tornaram-se responsáveis pela captação dos recursos necessários para condução de suas avaliações. O terceiro ciclo (24 
meses) envolveu pesquisas conduzidas em 24 países, entre eles o Brasil, cujos resultados foram divulgados em nova conferência internacional (SB'02/GBC'02), realizada no ano de 2002 em Oslo, Noruega.

O GBC procura diferenciar-se como uma nova geração de sistemas de avaliação, desenvolvida especificamente para refletir as diferentes prioridades, tecnologias, tradições construtivas e até mesmo valores culturais de diferentes países ou regiões em um mesmo país, considerando inclusive aspectos econômicos em sua análise.

$\mathrm{Na}$ primeira fase da pesquisa, foi produzido e utilizado um software chamado GBTOOL. Na segunda etapa de desenvolvimento houve a migração para uma plataforma constituída por uma série de planilhas de dados-padrão. O conceito-chave de ponderação de impactos personalizada, no entanto, foi mantido (SILVA; SILVA; AGOPYAN, 2001).

A diferença mais notável entre o GBC e a primeira geração de esquemas de avaliação ambiental de edifícios (categorias orientadas ao mercado) é que estes últimos fornecem alguma forma de classificação de desempenho, normalmente vinculadas a um esquema de certificação ambiental. No GBC, a pontuação final acaba sendo uma conseqüência - importante, sem dúvida, mas uma conseqüência da investigação principal, que é o desenvolvimento de uma metodologia de avaliação que possa ser incrementada ou simplificada para atender às necessidades de cada local.

Para fornecer resultados aderentes às particularidades locais, o GBC estabelece desempenhos de referência e as equipes de avaliação são encorajadas a indicar a 
melhor ponderação entre as categorias de impacto em cada caso. Para cada item avaliado, utiliza-se uma escala $(-2$ a +5$)$ para graduar o desempenho obtido pelo edifício, com relação ao desempenho de referência adotado com base na prática típica local.

O GBC vem trabalhando no refinamento da entrada de dados e incorporando estimadores simplificados, ainda que não tão precisos para elementos como energia incorporada e impactos associados a transporte. Outros comitês do GBC concentramse na busca de fundamentação consistente para a definição de desempenhos de referência; de ponderações entre categorias e entre itens das diversas categorias; e de uma gama mais ampla de indicadores de sustentabilidade, para refinar as comparações internacionais (SILVA; SILVA; AGOPYAN, 2001).

O referido sistema de avaliação trata basicamente de consumo de recursos, cargas ambientais, qualidade do ambiente interno, qualidade do serviço, aspectos econômicos e gestão antes da ocupação do edifício. Uma característica relevante trata que não há para esta modalidade um órgão certificador especifico, ressaltando o caráter ferramental que contribui para discussão e aprimoramento de projetos podendo ser adotado por qualquer entidade de avaliação que defina fatores de ponderação para os elementos considerados.

A análise dos métodos expostos demonstra que eles são naturalmente diferentes, porém construídos sobre uma base comum. E eles são diferentes basicamente pelas seguintes razões: 
- Os níveis de pressão sobre determinados aspectos ambientais (metas e agendas ambientais) variam de um país a outro, mesmo que dentro do bloco dos países desenvolvidos. O mesmo acontece nos grupos de países em desenvolvimento ou de economias em transição;

- As práticas construtivas e de projeto são diferentes, e influenciadas também porém não somente - por aspectos climáticos.

- A receptividade dos mercados à introdução dos métodos era diferente (SILVA; SILVA; AGOPYAN, 2001).

$\mathrm{Na}$ tabela 1, estabelece-se um comparativo entre os sistemas de avaliação e classificação ambiental comentados.

As estruturas do LEED e do BREEAM são organizadas em função das informações de entradas ou campos em que investidores, projetistas e construtores precisam necessariamente tomar decisões tais como implantação, uso de água e energia, materiais e ambiente interno.

Em contrapartida, o GBC é organizado em função de impactos ambientais associados a elementos ou características do edifício e o quesito uso de energia não renovável, por exemplo, aparece duplamente enquanto aspecto de consumo de energia e de poluição ambiental.

Por ter sido projetado também para funcionar como uma ferramenta de auxílio à tomada de decisões, os aspectos avaliados no LEED têm peso idêntico e a sua 
estrutura permite que apenas os quesitos para que se pretende obter a certificação sejam avaliados (TODD, LINDSAY, 2000).

Tabela 1 - Comparação dos sistemas de avaliação ambiental abordados

\begin{tabular}{|c|c|c|c|c|}
\hline aspectos & $\begin{array}{l}\text { escopo da } \\
\text { avaliação }\end{array}$ & método de aplicação & categorias avaliadas & resultados \\
\hline BREEAM & Ambiental & $\begin{array}{l}\text { Atendimento de itens } \\
\text { obrigatórios e } \\
\text { classificatórios. } \\
\text { Classificação do edifício. }\end{array}$ & $\begin{array}{l}\text { Saúde, poluição, conforto, uso da } \\
\text { energia, uso de água, uso de } \\
\text { materiais, uso do solo, ecologia local, } \\
\text { transporte. }\end{array}$ & $\begin{array}{c}\text { Classificação em vários níveis, } \\
\text { pontuação total obtida. }\end{array}$ \\
\hline LEED & Ambiental & $\begin{array}{l}\text { Atendimento de itens } \\
\text { obrigatórios e } \\
\text { classificatórios. } \\
\text { Classificação do edifício. }\end{array}$ & $\begin{array}{l}\text { Sítios sustentáveis, energia e } \\
\text { atmosfera, uso eficiente da água, } \\
\text { materiais e recursos, qualidade do } \\
\text { ambiente interno, inovação e } \\
\text { processo de projeto. }\end{array}$ & $\begin{array}{l}\text { Quatro níveis, pontuação total } \\
\text { obtida. }\end{array}$ \\
\hline HQE & Ambiental & $\begin{array}{l}\text { Atendimento de perfil } \\
\text { ambiental. Certificação ou } \\
\text { não do edifício. }\end{array}$ & $\begin{array}{l}\text { Impactos no meio ambiente, gestão } \\
\text { de recursos, conforto e saúde do } \\
\text { usuário. }\end{array}$ & $\begin{array}{l}\text { Não há classificação. A } \\
\text { certificação é obtida a partir do } \\
\text { atendimento ao perfil de } \\
\text { desempenho ambiental } \\
\text { escolhido. }\end{array}$ \\
\hline CASBEE & Ambiental & $\begin{array}{l}\text { Verificação do } \\
\text { atendimento dos itens. } \\
\text { Classificação do edifício. }\end{array}$ & $\begin{array}{l}\text { Ambiente interno, qualidade dos } \\
\text { serviços, ambiente externo (dentro do } \\
\text { terreno), energia, recursos e } \\
\text { materiais, ambiente externo (fora do } \\
\text { terreno). }\end{array}$ & $\begin{array}{l}\text { Cinco níveis de classificação, } \\
\text { com atribuição de indicador } \\
\text { global de eficiência. }\end{array}$ \\
\hline GBC & $\begin{array}{l}\text { Ambiental e } \\
\text { econômica }\end{array}$ & $\begin{array}{l}\text { Verificação do } \\
\text { atendimento dos itens. }\end{array}$ & $\begin{array}{l}\text { Uso de recursos, cargas ambientais, } \\
\text { qualidade do ambiente interno e dos } \\
\text { serviços, aspectos econômicos, } \\
\text { gestão de transporte. }\end{array}$ & $\begin{array}{c}\text { Pontuação global do } \\
\text { desempenho por categoria. }\end{array}$ \\
\hline
\end{tabular}

Fonte: adaptado de Silva, 2003. 
Segundo Silva; Silva e Agopyan (2001), se por um lado, o LEED é provavelmente, dentre os sistemas apresentados, o esquema disponível mais amigável enquanto ferramenta de projeto, o que facilita a sua incorporação à pratica profissional, por outro, deve-se ter sempre em mente que, em determinadas condições, o resultado da avaliação pode ser incompleto e não necessariamente reflete o desempenho global do edifício.

Ainda, segundo Silva; Silva e Agopyan (2001), o desenvolvimento ideal das metodologias de avaliação de edifícios é migrar dos critérios prescritivos para critérios de desempenho. Neste caso, a função de referência de desempenho - considerado de forma implícita na definição das metas - passa para o primeiro plano e sinaliza o grande desafio que se apresenta neste caso: o acúmulo de dados para construção destas performances.

Diante da complexidade de aplicar os conceitos de avaliação de desempenho, a maior parte das metodologias é orientada a características de base, isto é, trabalham com uma lista detalhada de itens a serem checados que concedem créditos em função da aplicação de determinadas estratégias de projeto ou especificação de determinados equipamentos.

Esta é uma saída com nível de complexidade menor, que presume que uma coleção de estratégias e equipamentos provavelmente levará a alguma melhoria de desempenho, ainda que ela não possa ser estimada. $O$ problema é que, apesar de poder ser facilmente incorporada como ferramenta de projeto, o fato de um edifício atender completamente à lista de verificação não necessariamente garante o melhor desempenho global. 
Em outras palavras: as listas detalhadas de itens a serem checados embutem o risco de favorecer a qualificação de edifícios que contenham equipamentos em detrimento do seu desempenho ambiental global. Por esta razão, estes mecanismos vêm sendo contestados durante o desenvolvimento da nova geração de sistemas de avaliação.

O único esquema de avaliação vigente e pautado pela abordagem de desempenho econômico é o utilizado pelo GBC.

Após a avaliação das categorias relevantes, alguns esquemas aplicam pesos diferenciados para indicar maior ou menor importância relativa das categorias, seja para chegar a uma série de indicadores (um por categoria), como no caso do GBC, ou a um número único, indicador de desempenho global, como faz o BREEAM. Mas nem todos os esquemas atribuem ponderações. Isto se deve basicamente à falta de uma metodologia consensual que permita decidir objetivamente que impactos são mais críticos que os demais.

A figura 4 procura dar uma noção geral da distribuição de itens nas categorias avaliadas nos esquemas LEED, BREEAM, CASBEE e GBC em cada sistemática. Os quesitos sem preenchimento indicam a não aplicação dos mesmos nas avaliações consideradas. Observa-se que, devido à diferença na estruturação das categorias, um mesmo item pode aparecer em categorias diferentes de um esquema para outro, 0 que dificulta a comparação direta de categorias de impacto, sem análise item a item conforme representado.

No LEED, por exemplo, todos os créditos atribuídos a cada categoria da sistemática têm peso idêntico na composição da pontuação final, ainda que seja notável a 
concentração de créditos em determinados grupos (Figura 4). A certificação de desempenho é conferida com base no total de créditos obtidos, não sendo necessário, portanto, atender a um número mínimo de créditos em cada uma das categorias.

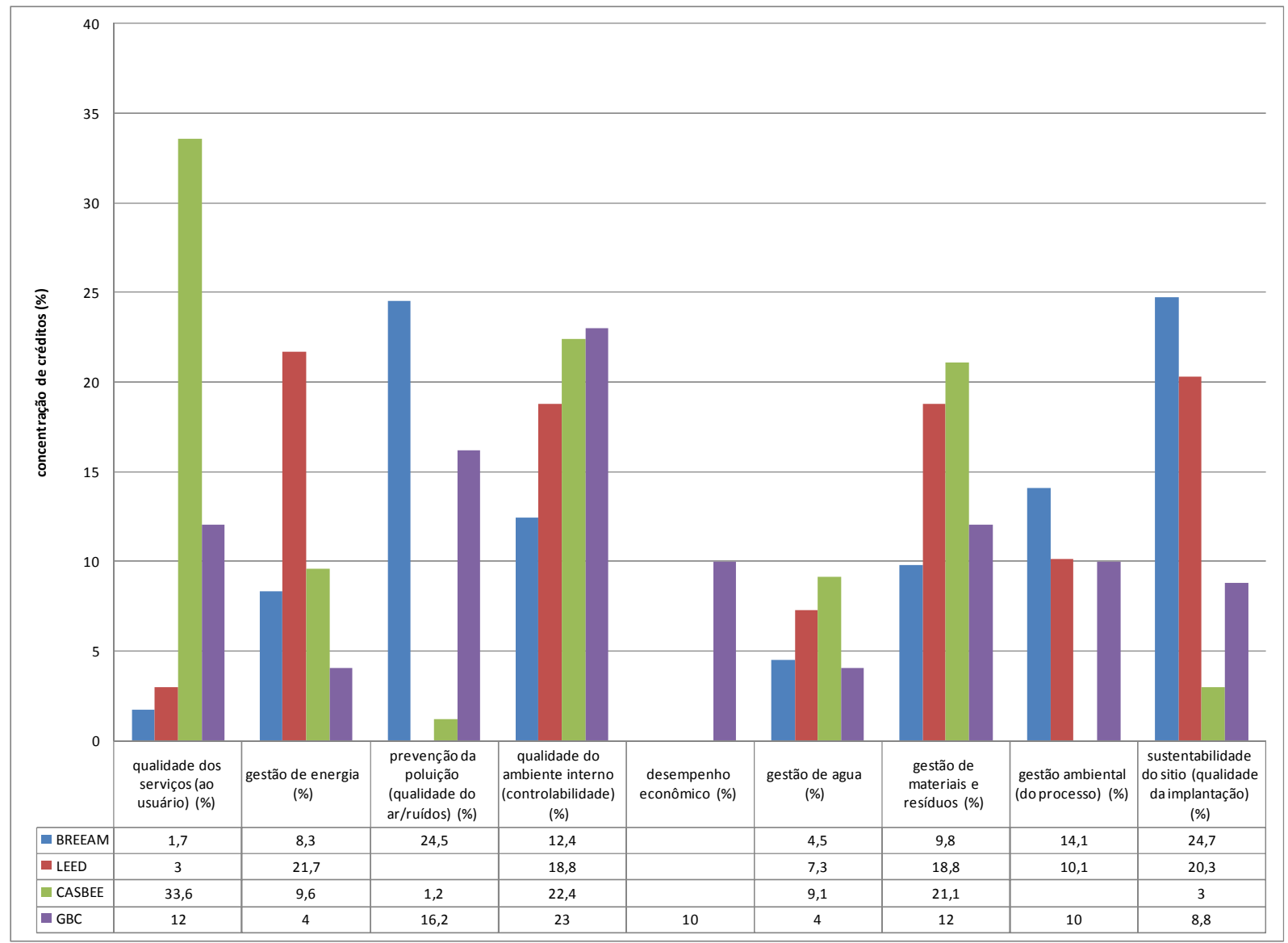

Figura 4 - Comparação de sistemáticas através da distribuição de categorias de impacto ambiental nos esquemas BREEAM, LEED, CASBEE e GBC. Fonte: adaptado de Silva (2003).

Já no BREEAM, a quantidade de itens em uma determinada categoria não indica a sua importância, mas a abrangência ou o grau de profundidade considerado na avaliação. Os itens das nove categorias são avaliados e, posteriormente, os créditos obtidos em cada categoria são ponderados para a obtenção do Índice de Desempenho Ambiental, chamado no referido sistema de EPI, um índice único que fornece a classificação de desempenho. 
O GBC também prevê a aplicação de pesos diferenciados por categoria e sugere uma ponderação-padrão a partir de dados canadenses. Esta ponderação pode ser redefinida pelas equipes de avaliação dos demais países participantes, mas o projeto GBC ainda tenta chegar a um método com fundamentação científica para a derivação das ponderações.

\subsection{INICIATIVAS NO BRASIL DE SISTEMAS DE AVALIAÇÃO DE DESEMPENHO AMBIENTAL EM EDIFÍCIOS}

Restringindo o foco para o Gerenciamento pelo Lado da Demanda, não existe paralelo no Brasil de uma metodologia amadurecida de avaliação ambiental, apesar de estudos intensos no exterior, com o intuito de se manter o conforto ambiental e a qualidade do ar, consumindo menos energia elétrica e mitigando impactos ambientais e sócio-econômico.

Em termos práticos, de modo a implementar uma metodologia de avaliação ambiental, existe a necessidade do desenvolvimento de uma ferramenta de projeto que informe objetivamente os projetistas nas primeiras etapas do processo de concepção dos empreendimentos (momentos que concentram as decisões de maior potencial gerador de impactos ambientais) das melhores práticas a se adotarem.

Desse modo, o delineamento da metodologia de avaliação adaptada às práticas de projeto e construção brasileiros permitirá identificar e extrair as informações de maior relevância para alimentar o desenvolvimento de uma ferramenta de projeto adequada ao caso nacional. 
Dada a ausência de uma metodologia homologada pelo Governo Federal, atualmente vigoram o uso de duas iniciativas de certificação em avaliação ambiental no Brasil: 0 LEED e o AQUA.

Por se tratar de uma certificação norte-americana, estão sendo envidados esforços por parte do USGBC, através da sua sucursal no Brasil, para interpretar e adaptar o LEED para o mercado nacional desde o mês de janeiro de 2008. Tal intento, hoje já conta com a participação ativa de 78 profissionais da mais alta capacidade técnica, entre eles, professores acadêmicos, projetistas, arquitetos, engenheiros, biólogos, médicos, consultores e profissionais LEED AP (certificados na metodologia), associações de classe, empresas dos diversos ramos da construção civil, além de vários outros colaboradores com as mais diversas experiências profissionais e com diferentes graduações, que se doaram nesta tarefa de analisarem a versão atual do LEED - Versão 2.2 para proposição ao USGBC de um projeto de regionalização do LEED para o Brasil com prazo para conclusão dos trabalhos até o final do ano de 2009 (GBCBRASIL, 2009).

A avaliação do LEED contempla a submissão do empreendimento a cinco subcomitês temáticos, que abordam os cinco critérios de avaliação da ferramentas: Materiais e Recursos (MR), Energia e Atmosfera (EA), Espaço Sustentável - Site (SS), Qualidade Ambiental Interna (EQ) e o Uso Racional da Água (WE). Estes subcomitês analisarão os critérios adotados pelo LEED e apresentarão uma proposta dos créditos que venham a julgar necessária, devidamente adaptada.

Atualmente no Brasil, mesmo com a ausência desses ajustes relacionados a particularidades regionais, temos o registro de 56 empreendimentos certificados em 
2008 e um número de 20, somente até março de 2009. Deste universo, temos a maioria do tipo comercial $(73,59 \%$ do total certificado) e com a predominância de $82,67 \%$ do total de empreendimentos localizado no Estado de São Paulo. (GBCBRASIL, 2009).

Como desvantagens da aplicação do LEED em âmbito nacional, sem as devidas adaptações regionais, podemos citar:

- Ausência de adaptação a dados nacionais relevantes, comprometendo a consistência técnica dos resultados conseqüentes da aplicação do método;

- Ausência de adaptação ao mercado, práticas de construção e tradições locais, inviabilizando a aplicação do mesmo;

- Ausência de um comprometimento com as principais partes interessadas: investidores, empreendedores e projetistas, principalmente através da participação dos mesmos na aprovação e confecção da metodologia;

- Ausência de ponderação dos itens avaliados para refletir prioridades e interesses nacionais, apropriados ao contexto na qual a sistemática é aplicada; e

- Excesso de detalhes para os padrões brasileiros, assim como para qualquer país com histórico de ausência de normas ou deficiência das normas existentes. 
Torna-se evidente a impossibilidade de aplicação de um método estrangeiro no Brasil, para obter resultados satisfatórios e condizentes com a realidade do empreendimento, com base no sucesso que tal método tenha obtido em seu país de origem. Certos aspectos perdem validade ou, por outro lado, itens nem sempre considerados pelos métodos internacionais são importantes no nosso contexto e devem ser incluídos na avaliação.

No que tange ao selo AQUA, o mesmo é obtido no Brasil e a auditoria é feita na própria obra, com acompanhamento de todas as fases da construção - programação, concepção e realização.

Enquanto o USGBC se baseia na soma de pontos para fornecer o selo, o AQUA faz a avaliação a partir de 14 critérios e a obra recebe uma classificação entre bom, superior e excelente:

- Bom: corresponde ao desempenho mínimo aceitável para um empreendimento de Alta Qualidade Ambiental;

- Superior: corresponde a boas práticas de sustentabilidade; e

- Excelente: corresponde aos desempenhos máximos constatados em empreendimentos de Alta Qualidade Ambiental.

O método utilizado por essa certificação também é interessante porque, apesar de, atualmente, haver um referencial técnico apenas para escolas e escritórios, outros setores podem manifestar interesse pelo selo. Nesse caso, o empreendimento que quer se enquadrar nos padrões AQUA serve como piloto: as escolhas são feitas a 
partir do referencial básico e passam pelas adaptações necessárias. Depois, a eficiência do edifício é testada na prática. Se atender às exigências, ganha a certificação - e ainda passa a servir de referência para as demais construções daquele setor.

O primeiro caso brasileiro em vias de certificação é o hotel The Reef Club, em Pernambuco. Com o interesse em representar uma ambientação característica do respectivo país de origem de cada hóspede europeu - e competir com opções portuguesas e espanholas -, o hotel precisava atingir os níveis de exigência desse público.

Atualmente, o empreendimento avalia em quais categorias é economicamente viável ser considerado excelente. Entre as iniciativas, está prevista a redução da poluição do rio que passa pelo local e estudos para que a população carente da região possa se beneficiar com projeto.

O processo AQUA atesta a Alta Qualidade Ambiental do Empreendimento, provada por meio de auditorias independentes, considerando parâmetros adaptados a realidade brasileira, trazendo como benefícios melhorias na qualidade de vida do usuário; economias de água, energia, disposição de resíduos e manutenção; e contribuição para o desenvolvimento sócio-econômico e ambiental da região.

Para obter a certificação o empreendedor da construção deve estabelecer o controle total do projeto em todas as suas fases - Programa, Concepção (Projeto), Realização (Obra) e Operação (Uso), por meio do sistema de Gestão do empreendimento (SGE), para que sejam atendidos os critérios de desempenho da Qualidade Ambiental do 
Edifício (QAE). A certificação é concedida ao final de cada fase, mediante verificação de atendimento ao referencial técnico.

Por parte do Governo Federal, baseada na lei de $n^{\circ} 10.295$, de 17 de outubro de 2001, foi desenvolvida, como parte do programa Procel Edifica (PROCEL EDIFICA, 2009), a "Regulamentação de etiquetagem voluntária de nível de eficiência energética de edifícios comerciais e públicos". Aprovada em setembro de 2006 pelo CGIEE e pelo MME e atualmente em processo de homologação junto ao INMETRO, esta sistemática se propõe a avaliar as edificações a partir do desempenho dos sistemas de iluminação, da eficiência dos sistemas de condicionamento de ar, e desempenho da envoltória.

Numa iniciativa a ser homologada com grau de detalhamento inédito, a Regulamentação de etiquetagem voluntária de nível de eficiência energética de edifícios comerciais e públicos é baseada em equações paramétricas por região geográfica e tipologia do território brasileiro, e desenvolvido através de protótipos representativos, simulada em mais de 10000 casos, com medição de energia elétrica em 10 prédios e com validação de modelos com diversos parceiros (ELETROBRAS, 2008).

A regulamentação preceitua que os edifícios submetidos à análise devem atender a todas as normas da ABNT, vigentes e aplicáveis de maneira a se manter uma diretriz de consonância com as legislações técnicas vigentes e, a partir daí, propor medidas de melhorias nos sistemas avaliados para melhorar seus níveis de eficiência energética. 
Temos na figura 5 o modelo de etiqueta a ser adotado para indicar classificação do nível de eficiência energética atribuída com o uso da sistemática abordada.

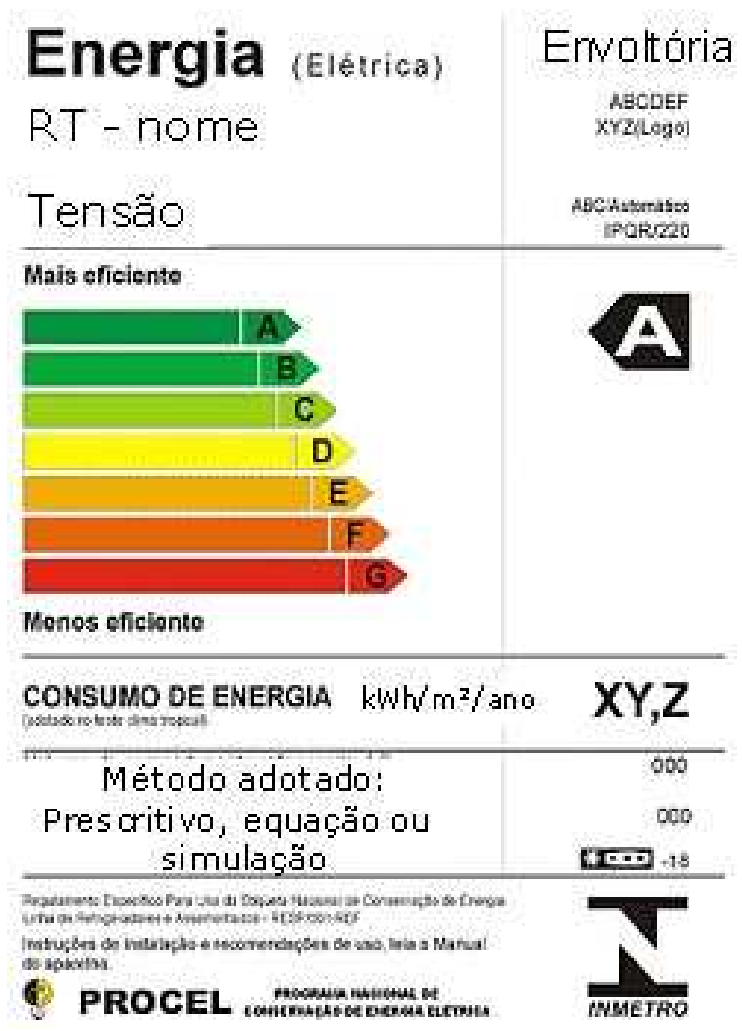

Figura 5 - Modelo de etiqueta que representa o nível de eficiência para edificação ou elementos da mesma conforme regulamentação abordada. Fonte: Eletrobras (2008).

A concessão da etiqueta será realizada nas diferentes fases do edifício (projeto, edificação concluída após o habite-se, edificação existente após a reforma com vistas à melhoria da eficiência energética). Ainda, ressalta-se que a etiqueta será dividida em quatro partes: envoltória, sistema de iluminação, sistema de condicionamento de ar e a edificação como um todo.

Os projetos poderão ser avaliados antes da execução das obras, permitindo a identificação de itens críticos que coloquem em risco o conforto térmico no ambiente construído. Já a fiscalização será feita de acordo com os projetos certificados. 
Após esta fase, será procedida uma auditoria no edifício em uso (após habite-se e com sistemas instalados) realizada por um auditor credenciado. Nesta etapa, atestada a consonância com o que prevê a referida regulamentação, será fornecida uma placa com o certificado, que poderá ser exposta no edifício.

Com atribuição de pesos, distribuídos para 30\% a considerar na envoltória, 30\% na iluminação e $40 \%$ no condicionamento de ar, pode-se obter a classificação geral do edifício resultando em uma classificação final do empreendimento. Ainda, existe a possibilidade de se obter a classificação da envoltória para a edificação como um todo ou parcialmente (para um pavimento ou salas) dos sistemas de iluminação e/ou condicionamento de ar.

Tal sistema de avaliação se aplicará a edifícios com área total útil mínima de $500 \mathrm{~m}^{2}$ ou com tensão de fornecimento superior a ou igual a 2,3kV (subgrupos $A 1, A 2, A 3$, A3a, A4 e AS) condicionados, parcialmente condicionados ou não condicionados.

Com o intuito de promover a redução de consumo e uso de energias alternativas, estimulando a adoção de ações nesse sentido, a regulamentação para etiquetagem voluntária do nível de eficiência energética de edifícios comerciais, de serviços e públicos, a partir de 2012, passará a vigorar como lei. Espera-se que o primeiro prédio deva ser certificado neste ano, na forma de um estudo piloto.

Perante um contexto no segmento da construção civil no qual são poucas as incorporadoras que se preocupam com o nível de eficiência energética de seus empreendimentos, a certificação será um forte instrumento de mudança no mercado, agregando valor às edificações e dando oportunidade para que esses 
empreendimentos se diferenciem dos convencionais através de uma classificação atribuída por uma regulamentação de um órgão governamental.

Para manter a liberdade do projetista, a sistemática considera também a opção de análise de conformidade por meio de simulação computacional. Neste caso, o projeto não precisa seguir os itens prescritivos da regulamentação, desde que seja comprovado, por meio de simulação térmica e energética, que a solução proposta apresenta eficiência maior ou igual à norma.

Com a implantação da sistemática, haverá impactos à maneira brasileira de projetar, pela mudança de paradigmas na medida em que cada projeto será um projeto diferente, o que exige uma cada vez maior integração entre os projetistas e torna cada vez mais escassas a existência de respostas genéricas para solucionar aspectos de concepção de elementos construtivos. Diante desse fato, práticas já consagradas como o uso de fachadas envidraçadas, isolamento térmico em paredes e vidros duplos deverão ser questionadas através da aplicação da metodologia.

Cabe salientar que as tecnologias que proporcionam redução de consumo já estão disponíveis no mercado e podem acarretar economia de até $12 \%$ no consumo de energia do país de 2000 a 2020, segundo Eletrobras (2008).

Com a concessão da etiqueta, o Ministério de Minas e Energia acredita que será possível nortear parâmetros para construções mais eficientes, estimulando o mercado a adotar as melhores práticas no que se refere à economia de energia, contribuindo para postergar investimentos em novos projetos de geração de energia 
economizando divisas para o País e minimizando os impactos negativos ao meio ambiente, segundo MME (2009).

Segundo Procel (2009), em relação às edificações residenciais, a regulamentação para etiquetagem do nível de eficiência energética ainda está sendo elaborada. Com tipologias variadas e pouco uso de condicionamento de ar, a regulamentação irá avaliar o nível de conforto térmico proporcionado por um determinado projeto. Para isso, a simulação de desempenho térmico será fundamental.

A proposição da sistemática de etiquetagem para edifícios comerciais, de serviços e públicos, foi um dos recentes resultados de um processo de regulamentação da eficiência energética no Brasil, obtido a partir de duas relevantes iniciativas: o Programa Brasileiro de Etiquetagem - PBE e a implementação da lei no 10.295 (BRASIL, 2001).

O PBE é um programa de conservação de energia que, por meio de etiquetas informativas, visa orientar o consumidor quanto à eficiência energética de alguns produtos comercializados no país. Seu objetivo é estimular a racionalização do consumo de energia pela utilização de produtos mais eficientes. A etiquetagem permite que o consumidor avalie os diversos produtos quanto a seu rendimento energético e selecione os que Ihe trarão maior economia durante sua utilização (CONPET, 2008).

A adesão ao Programa Brasileiro de Etiquetagem é voluntária e somente são feitos testes com os produtos dos fabricantes que querem fazer parte do programa. Assim, no Brasil, os fabricantes não são obrigados sob formas legais a participarem do 
programa de eficiência energética. Na figura 6, temos a apresentação de uma etiqueta de eficiência que informa ao consumidor o quão eficiente é o produto que está sendo adquirido.

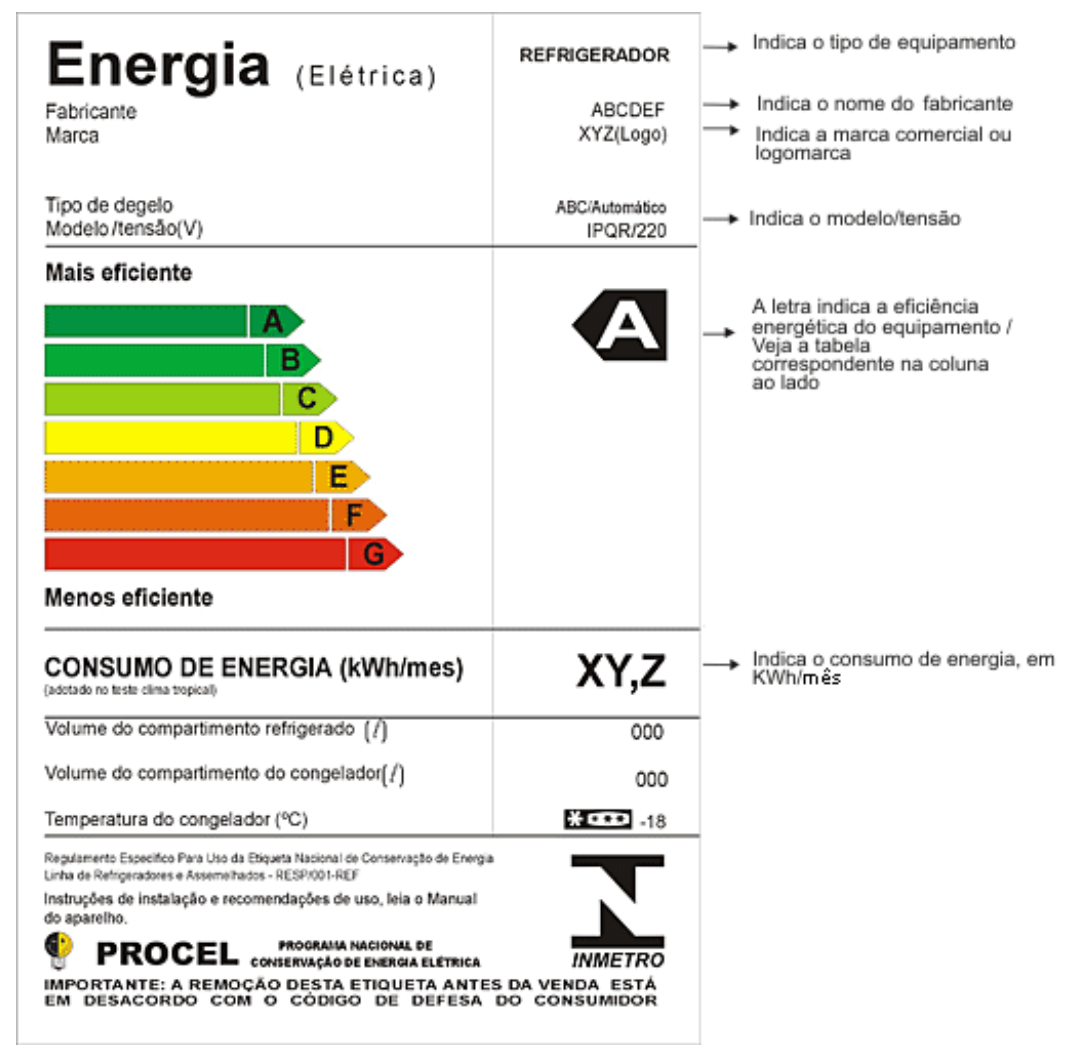

Figura 6 - Etiqueta de eficiência. Fonte: INMETRO (2008).

Em um cenário globalizado, uma transferência de informações cada vez mais rápida (ocasionado pela mídia e a disseminação da alta tecnologia como computadores, Internet, etc.) e fortes questões comerciais (exportações de aparelhos e/ou equipamentos para países onde existem e/ou são exigidos padrões, etc.) que podem se transformar em grandes barreiras comerciais entre países, os produtores estão sendo forçados a se enquadrarem a estes programas por causa de uma maior exigência do mercado, mesmo considerando o caráter voluntário dos mesmos. 
A educação e a legislação ambiental, juntamente com as recentes preocupações sobre a necessidade de economia de energia (por exemplo, um planejamento energético integrado com vistas ao desenvolvimento sustentável), também se mostraram ótimos aliados na campanha de adesão dos fabricantes de eletrodomésticos ao PBE. Esse tipo de pressão estimula a competitividade do mercado a cada nova avaliação e desta forma, o programa incentiva a melhoria contínua do desempenho dos eletrodomésticos e/ou equipamentos, buscando otimizar o processo de qualidade dos mesmos.

Atualmente, participam do PBE os setores produtores de geladeiras, freezers, chuveiros, aparelhos de ar condicionado, motores elétricos trifásicos, máquinas de lavar roupa, sistemas de aquecimento solar de água, lâmpadas fluorescentes compactas, lâmpadas incandescentes, reatores, fornos e fogões (INMETRO, 2008).

Num contexto mundial, existem vários países que aderiram aos programas de eficiência energética e muitos deles os fazem em caráter compulsório. Um dos mais conhecidos, segundo (WIEL; MCMAHON, 2005), é o selo comparativo de eficiência energética europeu.

Este selo comparativo classifica o consumo, em $\mathrm{kWh} / \mathrm{ano}$, dos equipamentos por categorias ( $A, B, C, D, E, F$ e $G$ ). Desta forma, os equipamentos que atingirem a categoria "A" serão os mais eficientes energeticamente e os encontrados na categoria “G” serão os menos eficientes (JUNIOR, 2005).

A lei de n¹0.295 (BRASIL, 2001), de 17 de outubro de 2001, é outro importante destaque no que tange ao uso racional de energia integrada desde os recursos 
primários, até sua conversão pelo consumidor final, dispondo sobre a política nacional de conservação e uso racional de energia, e instituindo os níveis máximos de consumo de energia, ou mínimos de eficiência energética de máquinas e aparelhos consumidores de energia fabricados ou comercializados no país, sendo válida tanto para equipamentos nacionais quanto importados.

Os principais órgãos envolvidos no desenvolvimento e cumprimento das metas para o cumprimento da lei de $\mathrm{n}^{\circ} 10.295$ são: a Agência Nacional de Energia Elétrica (ANEEL), a Agência Nacional do Petróleo (ANP), o Instituto Nacional de Metrologia, Normalização e Qualidade Industrial (INMETRO), as Secretarias Executivas do Programa Nacional de Conservação de Energia Elétrica (Procel) e do Programa Nacional de Racionalização do Uso de Derivados de Petróleo e do Gás Natural (Conpet).

Para regulamentar esta lei, foi promulgado em 19 de dezembro de 2001 o Decreto no 4.059 (BRASIL, 2001), que, para tal tarefa, criou o Comitê Gestor de Indicadores e Níveis de Eficiência Energética - CGIEE, constituído dos ministérios MME (minas e energia), MCT (ciência e tecnologia) e MDIC (desenvolvimento, indústria e comércio exterior), as agências ANEEL e ANP, um representante de universidade e um cidadão brasileiro, ambos especialistas em energia.

O CGIEE elaborou um extenso plano de estudos no final de 2002, de abrangência geral que visa montar uma estrutura que possa atender a todos os produtos com objetivo final de atingir uma regulamentação. Nesse contexto, cabe, portanto, avaliar a experiência internacional em programas de padronização e etiquetagem, estudar as diversas metodologias de estabelecimento dos índices mínimos, consolidar parcerias 
institucionais com, por exemplo, fabricantes e entidades de classe (já existentes no Programa Brasileiro de Etiquetagem -PBE).

Ainda, ressaltam-se como medidas necessárias objetivando tal regulamentação avaliar as implicações comerciais nos mercados interno e externo, articulando-se a implementação da lei com outras políticas de desenvolvimento industrial e com políticas de comércio exterior (para que não seja vista como barreira à importação), implementar procedimentos operacionais para a aplicação sustentada da lei e identificação de recursos disponíveis que possam ser usados no processo. 


\section{PROCEDIMENTOS PARA AVALIAÇÃO DO USO DA REGULAMENTAÇÃO PARA ETIQUETAGEM VOLUNTÁRIA DE NÍVEL DE EFICIÊNCIA ENERGÉTICA DE EDIFÍCIOS COMERCIAIS, DE SERVIÇOS E PÚBLICOS}

Este capítulo trata da aplicação da metodologia proposta na regulamentação de etiquetagem voluntária de nível de eficiência energética de edifícios comerciais e públicos no que tange a sistemas de iluminação, com emprego direto na confecção de um projeto luminotécnico de reforma de uma edificação do poder público bem como de uma proposta de avaliação da mesma.

É apresentado um método para a coleta de dados. A partir dessas informações, é possível calcular alguns indicadores de uso energia correspondente a iluminação, bastante útil para se proceder a um diagnóstico energético além de proporcionar a classificação do nível de eficiência obtido pela aplicação da referida proposta de regulamentação.

\subsection{LEVANTAMENTO DE DADOS}

Esta é uma das fases mais importantes do diagnóstico energético. Nesta etapa são obtidos todos os dados primários imprescindíveis à determinação da classificação do nível de eficiência energética com o emprego da referida metodologia. Dessa maneira, os resultados fornecidos pelos diagnósticos obtidos dependem diretamente da precisão das informações coletadas no levantamento de dados, que deve ser realizada de forma bastante criteriosa e precisa. 
O levantamento de dados é obtido pelo processo de inspeção, correspondendo ao procedimento de aquisição de informações sobre as características físicas e os hábitos de uso da instalação em análise.

Nesta fase, após a inspeção de todos os ambientes da edificação objeto de análise, deve ser registrado, no mínimo, as seguintes informações para cada ambiente:

- localização (andar e sala), finalidade (tipo de ambiente), área útil $\left(\mathrm{m}^{2}\right)$ e pé direito $(\mathrm{m})$;

- Sistema de iluminação artificial existente contemplando a tecnologia de iluminação (tipos de luminária, quantidade e potência total instalada de iluminação) e iluminância (lux) conforme metodologia aplicada em Ghisi (1997) e de acordo com as recomendações expressas na NBR 5382 - verificação de iluminância de interiores (NBR 5382, 1985). As medições são realizadas durante a noite evitando a influência da iluminação natural nos resultados, com o auxílio de luxímetros portáteis.

\subsection{APLICAÇÃo DA PROPOSTA DE REGULAMENTAÇÃo DE ETIQUETAGEM PARA SISTEMAS DE ILUMINAÇÃO}

Como primeiro passo para se aplicar a metodologia proposta, conforme a regulamentação, devem ser atendidos três pré-requisitos para se estabelecer condições de obter a classificação de nível de eficiência A em sistemas de iluminação (LABEEE, 2008). São eles:

- Cada ambiente fechado por paredes ou divisórias até o teto deve possuir pelo menos um dispositivo de controle manual para o acionamento independente da 
iluminação interna do ambiente. Cada controle manual deve ser facilmente acessível e localizado de tal forma que o ocupante possa ver todo o sistema de iluminação que está sendo controlado. No tocante a ambientes com áreas superiores a $250 \mathrm{~m}^{2}$, cada dispositivo de controle instalado deve controlar uma área de até $250 \mathrm{~m}^{2}$ no caso de ambientes com áreas até $1000 \mathrm{~m}^{2}$; para ambientes com áreas maiores do que $1000 \mathrm{~m}^{2}$, cada dispositivo de controle instalado deve controlar uma área de até 1000 m²;

- Ambientes com janela voltada para o ambiente externo ou voltada para átrio não coberto ou de cobertura translúcida e com mais de uma fileira de luminárias paralelas à(s) janela(s) devem possuir um controle instalado, manual ou automático, para o acionamento independente da fileira de luminárias mais próxima à janela de forma a propiciar o aproveitamento da luz natural disponível;

- O sistema de iluminação interna de ambientes com áreas superiores a $250 \mathrm{~m}^{2}$ deverá possuir um dispositivo de controle automático para desligamento da iluminação, a exceção de ambientes que devem propositadamente funcionar durante $24 \mathrm{~h}$, ambientes onde existe tratamento ou repouso de pacientes e ambientes onde 0 desligamento automático da iluminação pode comprovadamente oferecer riscos à integridade física dos usuários.

Satisfeitas essas condições, com o intuito de se definir a classificação do nível de eficiência energética (variando de $\mathrm{A}$ - mais eficiente a $\mathrm{E}$ - menos eficiente) de cada espaço interno do edifício, haverá uma ponderação com as áreas de cada ambiente para estimar o equivalente numérico final do sistema de iluminação e, portanto, o 
nível de eficiência do sistema de iluminação de cada dependência. A referida sistemática não se aplica a ambientes externos.

A definição do nível de eficiência energética para cada ambiente é realizado a partir da obtenção da densidade de potência total de iluminação.

A densidade de potência total de iluminação (DPI) é definida como a razão entre a densidade de potência total instalada $\left(\mathrm{W} / \mathrm{m}^{2}\right)$ para cada 100 lux de lluminância, expressando o consumo de potência por unidade de área com a consideração da distribuição do fluxo luminoso do sistema.

Como etapa seguinte, deve-se confeccionar o projeto luminotécnico, adotando como base as prescrições da NBR 5413 - iluminância de interiores (ABNT, 1992), dimensionando e identificando o número de conjuntos de lâmpadas/luminárias/reator e calculando a iluminância no final da vida útil do sistema de iluminação (24 meses, utilizando coeficiente de manutenção de 0,80).

Cabe salientar que se deve adotar nos pesos atribuídos a fatores determinantes de iluminância adequada (tabela 2), perfazendo um somatório igual a -2 ou -3 para alcançar os limites mínimos de iluminância da NBR 5413 - iluminância de interiores (ABNT, 1992), adotando-se medidas locais para complementar as iluminâncias em casos especiais onde a idade do observador for superior a 55 anos ou a velocidade e precisão de tarefa for crítica ou importante. 
Tabela 2 - Fatores determinantes de iluminância adequada

\begin{tabular}{|c|c|c|c|}
\hline \multirow{2}{*}{$\begin{array}{l}\text { Características } \\
\text { do observador } \\
\text { e da tarefa }\end{array}$} & \multicolumn{3}{|c|}{ Peso } \\
\hline & -1 & 0 & 1 \\
\hline Idade & $\begin{array}{l}\text { Inferior a } 40 \\
\text { anos }\end{array}$ & $\begin{array}{l}40 \text { a } 55 \\
\text { anos }\end{array}$ & $\begin{array}{l}\text { Superior } \\
\text { a } 55 \\
\text { anos }\end{array}$ \\
\hline $\begin{array}{l}\text { Velocidade de } \\
\text { precisão }\end{array}$ & $\begin{array}{l}\text { Sem } \\
\text { importância }\end{array}$ & importante & Crítica \\
\hline $\begin{array}{l}\text { Refletância do } \\
\text { fundo da tarefa }\end{array}$ & $\begin{array}{l}\text { Superior a } 3 \\
70 \%\end{array}$ & 30 a $70 \%$ & $\begin{array}{l}\text { Inferior a } \\
30 \%\end{array}$ \\
\hline
\end{tabular}

Fonte: NBR 5413 - iluminância de interiores (ABNT, 1992)

Ainda, se deve excluir do cálculo da potência instalada de iluminação os sistemas que forem complementares à iluminação geral e com controle independente nas seguintes situações: sistemas de lluminação de uso sem interrupção, como destaque em galerias, museus e monumentos; parte integrante de equipamentos, como geladeiras; procedimentos médicos ou dentários; voltada a proporcionar o crescimento de plantas; propaganda e sinalização; vitrines ou demonstrativos com propósitos educacionais ou vendas; fins teatrais e apresentações ao vivo, bem como filmes e vídeos; ambientes projetados para uso de deficientes; e áreas de jogos ou atletismo em estrutura permanente para transmissão para televisão.

Posteriormente, de posse dos dimensionamentos obtidos na fase de projeto, calculase o índice $\mathrm{DPI}_{\mathrm{RF}}$ (Densidade de Potência de lluminação Relativa Final), expresso em [(W/m2)/100lux]. A iluminância a se considerar nesse cálculo se refere a adotada no final da vida útil do sistema de iluminação.

Para cada ambiente, determina-se a densidade de potência total instalada em iluminação $\left(\mathrm{W} / \mathrm{m}^{2}\right)$ pela iluminância do ambiente (lux) para cada 100 lux de Iluminância. 
Para se obter a classificação do correspondente nível de eficiência do ambiente, devemos calcular o valor do limite máximo aceitável de densidade de potência de iluminação (DPI $\left.I_{\mathrm{RL}}\right)$. A partir do cálculo do índice do ambiente de cada dependência da edificação (K) usando a eq. (1), obtem-se na tabela 3 o $\mathrm{DPI}_{\mathrm{RL}}$.

$$
K=\frac{C L}{h(C+L)}
$$

Onde:

K é o índice de ambiente (adimensional)

C é o comprimento total do ambiente $(\mathrm{m})$

$\mathrm{L}$ é a largura total do ambiente $(\mathrm{m})$

$h$ é a altura média $(\mathrm{m})$ entre a superficie de trabalho e o plano das luminárias no teto.

Encerrando o processo, classifica-se o ambiente em função dos limites estabelecidos na tabela 3, sendo que $\mathrm{DPI}_{\mathrm{RF}}$ deve ser menor que $\mathrm{DPI} \mathrm{R}_{\mathrm{RL}}$, expresso em $[(\mathrm{W} / \mathrm{m} 2) / 100 l u x]$. No caso de $\mathrm{DPI}_{\mathrm{RF}}$ maior que $\mathrm{DPI} \mathrm{RL}_{\mathrm{R}}$ do nível $\mathrm{D}$, os sistemas serão considerados de nível $E$ (menos eficiente).

Na figura 7, temos a representação estruturada sucinta de todo esse processo. 


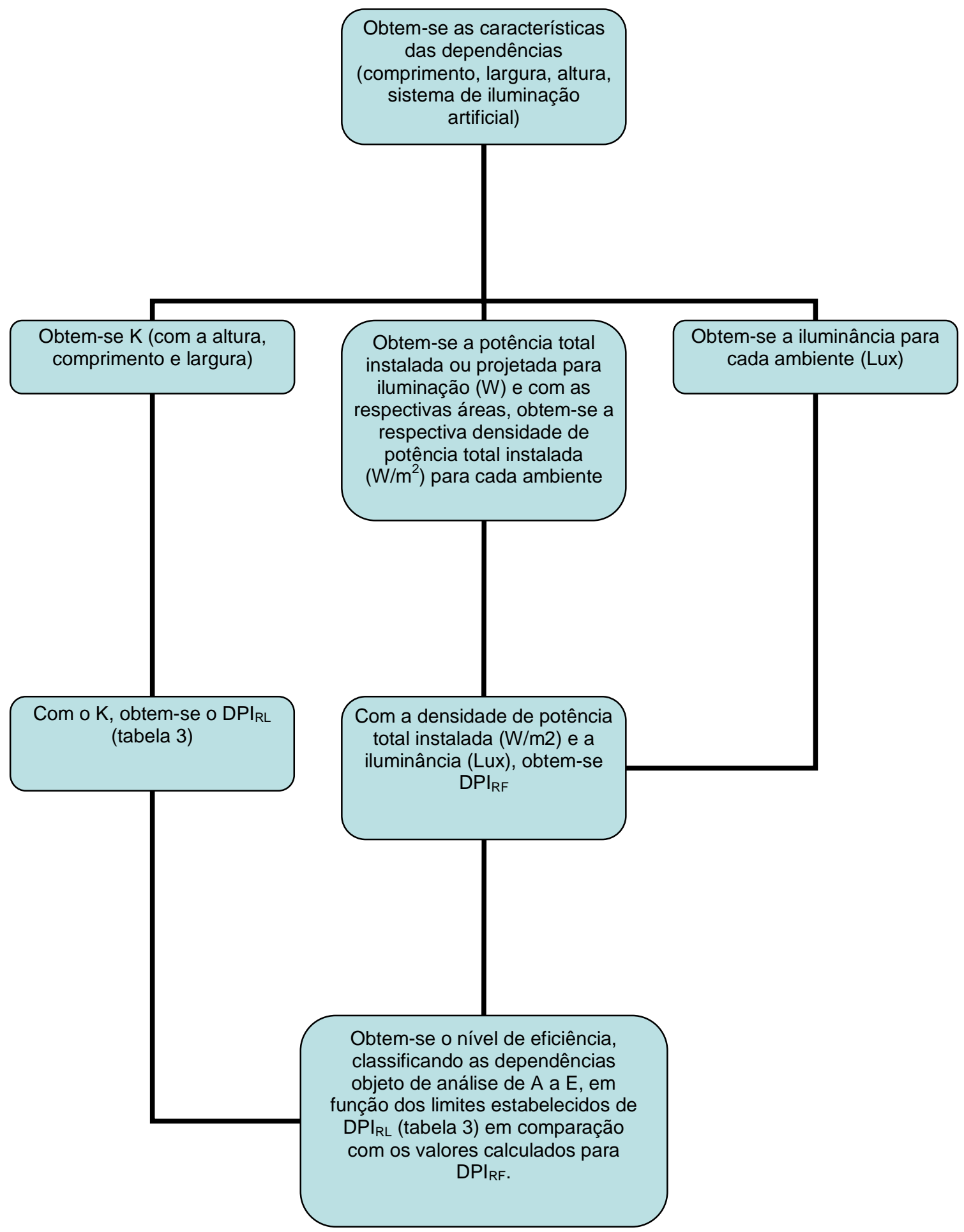

Figura 7 - Fluxograma de aplicação da proposta de regulamentação para sistemas de iluminação. 


\begin{tabular}{|c|c|c|c|c|}
\hline $\begin{array}{c}\text { Índice de } \\
\text { ambiente } \\
\text { K }\end{array}$ & $\begin{array}{l}\mathrm{DPI} \mathrm{RL}_{\mathrm{RL}} \\
\text { (A) }\end{array}$ & $\begin{array}{l}\mathrm{DPI}_{\mathrm{RL}} \\
\text { (B) }\end{array}$ & $\begin{array}{l}\mathrm{DPI} I_{\mathrm{RL}} \\
\text { (C) }\end{array}$ & $\begin{array}{l}\mathrm{DPI}_{\mathrm{RL}} \\
\text { (D) }\end{array}$ \\
\hline 0,60 & 2,84 & 4,77 & 5,37 & 6,92 \\
\hline 0,80 & 2,50 & 3,86 & 4,32 & 5,57 \\
\hline 1,00 & 2,27 & 3,38 & 3,77 & 4,86 \\
\hline 1,25 & 2,12 & 3,00 & 3,34 & 4,31 \\
\hline 1,50 & 1,95 & 2,75 & 3,00 & 3,90 \\
\hline 2,00 & 1,88 & 2,53 & 2,77 & 3,57 \\
\hline 2,50 & 1,83 & 2,38 & 2,57 & 3,31 \\
\hline 3,00 & 1,76 & 2,27 & 2,46 & 3,17 \\
\hline 4,00 & 1,73 & 2,16 & 2,33 & 3,00 \\
\hline 5,00 & 1,71 & 2,09 & 2,24 & 2,89 \\
\hline
\end{tabular}

Fonte: LABEEE (2008).

Para valores de $\mathrm{K}$ que não se encontram especificados na tabela 3 , deve-se determinar o valor de $\mathrm{DPI}_{\mathrm{RL}}$ através de interpolação.

\subsection{ESTUDOS A SEREM REALIZADOS}

O levantamento de dados foi realizado em uma edificação que se caracteriza por sediar uma organização administrativa militar que faz parte do Poder Público. Localizada na região sul da cidade de São Paulo, com uma área útil construída de $7801,71 \mathrm{~m}^{2}$, essa edificação apresenta uma funcionalidade de escritório.

Ressalta-se a importância da edificação objeto de estudo que se caracteriza como um empreendimento típico do segmento administrativo militar representando uma tendência de distribuição de ambientes associado a particularidades de uso e 
execução das atividades profissionais que se estendem por cerca de 30 edificações só no estado de São Paulo e 200 em nível nacional.

Composto de seis andares e possuindo cerca de 400 ocupantes, a edificação possui 275 dependências, divididas em quatro tipos de ambientes: de escritório, de depósito, de banheiro e de circulação de acordo com o exposto na tabela 4.

Tabela 4 - disposição das dependências por tipo de ambiente no interior da edificação

escritório depósito banheiro circulação

\begin{tabular}{|c|c|c|c|c|}
\hline & & & & \\
\hline térreo & 16 & 5 & 6 & 5 \\
\hline primeiro & 34 & 3 & 6 & 2 \\
\hline segundo & 32 & 3 & 6 & 2 \\
\hline terceiro & 32 & 4 & 5 & 5 \\
\hline quarto & 37 & 4 & 9 & 5 \\
\hline quinto & 22 & 2 & 6 & 7 \\
\hline sexto & 3 & - & 8 & 6 \\
\hline quantidade total & 176 & 21 & 46 & 32 \\
\hline área util $\left(\mathrm{m}^{2}\right)$ & 5398,19 & 550,51 & 625,18 & 1227,83 \\
\hline Porcentagem da área total (\%) & 69,19 & 7,06 & 8,01 & 15,74 \\
\hline
\end{tabular}


De acordo com as recomendações da referida regulamentação no que tange aplicação dos valores médios de iluminamento, deve-se adotar os limites mínimos da NBR 5413 - lluminância de interiores (ABNT, 1992), obtendo as referências para o ambiente de escritório de 500 lux, de depósito de 100 lux, de banheiro de 100 lux e de circulação de 75 lux.

O primeiro estudo foi elaborado a partir do levantamento de dados realizado, no qual é aplicada a metodologia proposta na regulamentação para etiquetagem voluntária do nível de eficiência energética de edifícios comerciais, de serviços e públicos no que tange a sistemas de iluminação, obtendo a classificação do nível de eficiência energética para cada ambiente.

Para cada dependência da edificação será obtido o índice $\mathrm{K}$ e a potência total de iluminação $(\mathrm{W})$ possibilitando o cálculo da densidade de potência total instalada $\left(\mathrm{W} / \mathrm{m}^{2}\right)$.

Com o nível de iluminamento (lux) de cada ambiente, procede-se a obtenção da densidade de potência de iluminação $\left(\mathrm{DPI}_{\mathrm{RF}}\right)$, aplicando a metodologia proposta na regulamentação para etiquetagem voluntária do nível de eficiência energética de edifícios comerciais, de serviços e públicos. Com o $\mathrm{DPI}_{\mathrm{RL}}$, obtido com a interpolação (regressão linear) da tabela 3 através do uso do software datafit ${ }^{2}$, estabelece-se a classificação do nível de eficiência energética em iluminação para cada ambiente.

Foram realizados mais dois estudos distintos, considerando a aplicação de dois tipos diferentes de luminárias com intuito de comparar os ganhos em eficiência energética

\footnotetext{
${ }^{2}$ Datafit versão 9.0, Oakdaling engineering, PA, Estados Unidos
} 
com a situação atual da edificação objeto de estudo com a aplicação da proposta da regulamentação para etiquetagem voluntária do nível de eficiência energética de edifícios comerciais, de serviços e públicos.

No segundo estudo será utilizado como referência uma luminária de embutir em forro, para duas lâmpadas fluorescentes tubulares de $32 \mathrm{~W}$ e de $16 \mathrm{~W}$, com corpo em chapa de aço tratada com acabamento em pintura eletrostática epóxi-pó na cor branca. Esta luminária possui refletor em alumínio anodizado de alto brilho e está equipada com porta-lâmpada antivibratório em policarbonato, com trava de segurança e proteção contra aquecimento dos contatos e com um reator eletrônico com fator de potência mínimo de 0,98 incorporado para cada luminária. 0 rendimento dessa luminária é de 84\%. No decorrer deste trabalho, esta luminária é identificada como luminária 1.

No terceiro estudo foi utilizada como referência uma luminária de embutir em forro, para duas lâmpadas fluorescentes tubulares de $32 \mathrm{~W}$ e de $16 \mathrm{~W}$, com corpo e aletas planas em chapa de aço tratada com acabamento em pintura eletrostática epóxi-pó na cor branca. Esta luminária possui refletor em alumínio anodizado de alto brilho e está equipada com porta-lâmpada antivibratório em policarbonato, com trava de segurança e proteção contra aquecimento dos contatos e com um reator eletrônico com fator de potência mínimo de 0,98 incorporado para cada luminária. O rendimento dessa luminária é de $73 \%$. No decorrer deste trabalho, esta luminária é identificada como luminária 2.

No segundo estudo, foi utilizado o software softlux ${ }^{3}$ para determinação do nível de iluminamento médio de cada ambiente. O referido software adota o método dos

\footnotetext{
${ }^{3}$ Softlux versão 2.2, Itaim Ltda, São Paulo, Brasil
} 
lúmens como referência. Nesta aplicação, foram considerados os dados obtidos com o dimensionamento dos equipamentos de iluminação (luminária 1) e os níveis de iluminância de acordo com a norma ABNT 5413 - iluminância de interiores (ABNT, 1992).

A partir da entrada de dados de dimensões do ambiente (comprimento, largura, pé direito, altura do plano de trabalho e altura de suspensão das luminárias), índices de cores e refletâncias, tipo de ambiente e condições do local (limpo, médio ou sujo) e tipo de luminária o software softlux dimensiona a quantidade dos referidos equipamentos bem como o nível de iluminância médio do local.

Para cada dependência da edificação, a partir dos índices K obtidos (que não variam) e a potência total de iluminação (W) estabelece-se o cálculo da densidade de potência total instalada $\left(\mathrm{W} / \mathrm{m}^{2}\right)$.

Com o nível de iluminância (lux) de cada ambiente, procede-se a obtenção da densidade de potência de iluminação $\left(\mathrm{DPI}_{\mathrm{RF}}\right)$, aplicando a metodologia proposta na regulamentação para etiquetagem voluntária do nível de eficiência energética de edifícios comerciais, de serviços e públicos. Com o $\mathrm{DPI}_{\mathrm{RL}}$, obtido com a interpolação (regressão linear) da tabela 3 através do uso do software datafit, estabelece-se a classificação do nível de eficiência energética em iluminação para cada ambiente.

No terceiro estudo, adotou-se a metodologia análoga a realizada no segundo estudo, com a utilização da luminária 2 e mantendo-se a mesma quantidade de luminárias projetada para o segundo estudo. Com a utilização do software softlux, obtem-se o 
nível de iluminamento médio de cada ambiente, a partir da quantidade de luminárias proposta.

Em resumo, adotou-se a metodologia exposta no fluxograma da figura 7 , com a utilização do sistema de iluminação artificial existente na edificação para o primeiro estudo. No segundo e terceiro estudo, foram utilizadas as luminárias 1 e 2, respectivamente, considerando a mesma sistemática apresentada.

\subsection{ANÁLISES DOS RESULTADOS OBTIDOS}

De posse dos resultados obtidos, foram realizados testes pautados em métodos de estatística descritiva com o objetivo básico de proporcionar uma visão média local e global da variação dos mesmos, caso elas ocorram.

Com aplicação destes métodos estatísticos e a consequente síntese de séries de valores da mesma natureza, foi possível obter resultados expressos com média \pm erro padrão da média (SEM).

Tais análises proporcionam a obtenção de inferências com base em uma amostra submetida a um respectivo tratamento (no caso, aplicação da metodologia apresentada nos diferentes estudos realizados), por meio de testes estatísticos comparativos (por exemplo, o teste ANOVA, o teste-t, o teste qui-quadrado, o teste exato de Fisher, o teste de Student-Newman-Keuls e outros), oferecendo assim condições para realizar, além das comparações dos valores numéricos absolutos, uma comparação estatística (ferramenta matemática que leva em conta a parte da variação observada que se deve ao acaso) provando uma diferença ou semelhança 
de maneira consistente quando comparado em um determinado nível de significância $(\mathrm{P})^{4}$.

Toda inferência é passível de erro, na medida em que o fato de ser muito provável que os resultados sejam estatisticamente significantes não significa necessariamente que isto ocorre em todas as situações. Tal erro não representa que o pesquisador tenha errado, mas que este possa ter observado uma amostra que não corresponda a população. A probabilidade da ocorrência desse erro é conhecida como o nível de significância do teste $(P)$.

Quanto mais alto o nível de significância do teste $(P)$, menos se pode acreditar que a relação observada entre as variáveis na amostra é um indicador confiável da relação entre as respectivas variáveis na população.

A escolha do valor do nível de significância é arbitrária, mas é tradicional usar valores iguais a $0,05(5 \%)$, haja vista tal valor representar um ponto crítico geralmente obtido em experiências gerais de pesquisa (VIEIRA, 2006).

Com o intuito de se estabelecer comparações entre os resultados obtidos com a aplicação da metodologia entre os diferentes grupos (nesta aplicação, definidos como os diferentes tipos de ambientes existentes na edificação), foi utilizado o teste estatístico conhecido como análise de variância (ANOVA).

O teste de análise de variância $\mathrm{ANOVA}^{5}$ compara qualquer tipo de médias de tratamentos, por meio do teste $\mathrm{F}^{6}$, com a variação devido ao acaso, ou seja,

\footnotetext{
${ }^{4}$ No presente trabalho, o nível de significância é representado pela letra $P$.

${ }^{5} \mathrm{O}$ detalhamento do método de cálculo do referido teste pode ser obtido em (VIEIRA, 2006).
} 
analisando se as diferenças observadas entre as médias das amostras são estatisticamente significantes. No presente trabalho, este teste é aplicado para os valores obtidos de densidade de potência total instalada $\left(\mathrm{W} / \mathrm{m}^{2}\right)$, iluminância (lux) e densidade de potência de iluminação (DPI $\mathrm{RF}_{\text {) }}$ nos diferentes estudos realizados, considerando o total de dependências distribuídas por cada pavimento e particularmente, os quatro tipos de ambientes (de escritório, de depósito, de banheiro e de circulação).

O teste de análise de variância ANOVA, comprova a veracidade das hipóteses $\mathrm{H}_{0}$ (no caso, se a grandeza apresenta valores estatisticamente semelhantes nas comparações entre os mesmos parâmetros obtidos no primeiro e segundo estudo, primeiro e terceiro estudo e segundo e terceiro estudo). Caso não seja comprovada tal condição, a hipótese $\mathrm{H}_{1}$ (que supõe a ocorrência de diferenças estatísticas entre os tratamentos realizados) é a que se torna verdadeira. Salienta-se que tal teste é realizado com a consideração de um nível de significância de 5\%, representando a probabilidade de rejeitar determinada hipótese, quando a mesma é verdadeira.

Desse modo, no tocante as comparações é bom salientar que mesmo havendo uma superioridade numérica de um grupo e valores numéricos distintos, não se prova necessariamente uma diferença estatística entre os respectivos valores objeto de análise.

Com cada um dos dados obtidos, estabelece-se um modelo que representa a resposta aos tratamentos que é expresso pela média de todas as respostas possíveis $\left(\mu_{\mathrm{i}}\right)$ acrescida de uma quantidade $\left(\varepsilon_{\mathrm{ij}}\right)$, que os estatísticos chamam de erro (SEM). entre indivíduos dentro das amostras (VIEIRA, 2006). 


$$
Y_{i j}=\mu_{i}+\varepsilon_{i j}
$$

Onde:

$Y_{\mathrm{ij}}$ é o modelo do tratamento i para a quantidade de dados j

$\mu_{\mathrm{i}}$ é a média

$\varepsilon_{\mathrm{ij}}$ é o erro padrão da média (SEM)

Salienta-se que a análise de variância a ser realizada contempla uma abordagem voltada para medidas repetidas (RM) haja vista que existe a designação de medidas feitas na mesma unidade experimental (cada um dos diferentes ambientes da edificação existente) em mais de uma ocasião. Tal análise possui como vantagem o fato de desvincular o impacto do efeito individual da amostra, na medida em que há a aplicação dos tratamentos no mesmo local.

Posteriormente a aplicação da análise da variância ANOVA, será procedido o exame das médias e das diferenças entre elas, de modo a estabelecer quais as diferenças apresentadas através de um teste que realiza a comparação de médias pareadas (duas a duas), chamado de teste de Student-Newman-Keuls (SNK) ${ }^{7}$ para os valores de densidade de potência total instalada $\left(\mathrm{W} / \mathrm{m}^{2}\right)$, nível de iluminância (lux) e densidade de potência de iluminação (DPI $\mathrm{RF}_{\mathrm{RF}}$.

Desde modo, em cada uma das tabelas elaboradas, são atribuídas letras maiúsculas (A, B ou C) ao lado de cada modelo representativo de dado, expressando as diferenças entre os dados. Tais letras maiúsculas têm como intuito representar diferenças estatísticas nas mesmas colunas de cada tabela quando o nível de

\footnotetext{
${ }^{7} \mathrm{O}$ detalhamento do método de cálculo do referido teste pode ser obtido em (HINES et al., 2006).
} 
significância é menor que $5 \%(P<0,05)$ de forma a classificar os respectivos dados analisados para que se possam realizar as comparações.

Tais aplicações destas ferramentas estatísticas proporcionam a obtenção das seguintes tabelas:

- Sete tabelas elaboradas para cada pavimento, que comparam primeiramente o desempenho dos modelos de valores (expressos pela média e erro padrão da média) de densidade de potência total instalada $\left(\mathrm{W} / \mathrm{m}^{2}\right)$, nível de iluminância (lux) e densidade de potência de iluminação $\left(\mathrm{DPI} I_{\mathrm{RF}}\right)$, em cada estudo realizado;

- Três tabelas elaboradas para cada grandeza obtida (potência total instalada, nível de iluminância e densidade de potência de iluminação) que comparam o desempenho dos modelos de valores (expressos pela média e erro padrão da média) para cada tipo de ambientes (de escritório, de depósito, de banheiro e de circulação), nos três estudos realizados.

Em seguida, utilizou-se do teste de qui-quadrado ${ }^{8}$ para comparar as porcentagens das quantidades dos índices de nível de eficiência obtidos nos estudos entre os grupos, também a 5\% de significância.

Tal teste não depende dos parâmetros populacionais, como a média e a variância, comparando proporções a fim de avaliar se as mesmas observadas destes eventos mostram ou não diferenças significativas.

\footnotetext{
${ }^{8} \mathrm{O}$ detalhamento do método de cálculo do referido teste pode ser obtido em (HINES et al., 2006).
} 
A aplicação desse teste estatístico proporciona a obtenção de uma tabela, que explicita a distribuição percentual de cada nível de eficiência energética $(A, B, C, D$ e E) ao longo de cada estudo, ressaltando as diferenças e semelhanças estatísticas.

Do mesmo modo que os testes anteriores, na tabela elaborada, são atribuídas letras maiúsculas ( $A, B$ ou $C$ ) ao lado de cada modelo representativo de dado, expressando as diferenças entre os dados. Tais letras maiúsculas têm como intuito representar diferenças estatísticas nas mesmas colunas de cada tabela quando o nível de significância é menor que $5 \%(P<0,05)$ de forma a classificar os respectivos dados analisados para que se possam realizar as comparações.

Todos os testes estatísticos foram realizados com a utilização do software Sigmastat ${ }^{9}$, inclusive as verificações prévias necessárias para que os resultados obtidos após a análise de variância fossem considerados válidos ${ }^{10}$.

\footnotetext{
${ }^{9}$ Sigmastat versão 4, Jandel Corporation, San Rafael, CA, E.U.A.

${ }^{10} \mathrm{O}$ detalhamento do método de cálculo destas verificações pode ser obtido em (VIEIRA, 2006).
} 


\section{RESULTADOS}

Após a conclusão da etapa de levantamento de dados no edifício objeto de estudo e posterior aplicação da metodologia proposta para sistemas de iluminação na regulamentação para etiquetagem voluntária do nível de eficiência energética de edifícios comerciais, de serviços e públicos, foram alcançados os resultados expressos no anexo A, compostos dos valores das áreas de cada dependência $\left(\mathrm{m}^{2}\right)$, altura, K, potência total instalada de iluminação $(W)$, densidade de potência total instalada de iluminação $\left(\mathrm{W} / \mathrm{m}^{2}\right)$, iluminância (lux), $\mathrm{DPI} \mathrm{R}_{\mathrm{RF}}$, correspondente $\mathrm{DPI} \mathrm{I}_{\mathrm{RL}} \mathrm{e}$ consequente nível de eficiência, para cada ambiente.

Consta também do anexo $\mathrm{A}$, a tabela de interpolação dos valores de $\mathrm{K}$ a partir da tabela 3 possibilitando a definição de faixas de $\mathrm{DPI} \mathrm{RL}_{\mathrm{L}}$ correspondentes aos níveis de eficiência de A a D. Esta tabela também se aplica aos estudos realizados com o uso da luminária 1 e da luminária 2, haja vista o fator $\mathrm{K}$ estar relacionado as áreas e as alturas de cada ambientes, parâmetros estes que se mantém constantes em todos os casos.

Temos a existência na edificação analisada de conjuntos de luminárias com lâmpadas fluorescentes de $4 \times 40 \mathrm{~W}, 3 \times 40 \mathrm{~W}, 2 \times 40 \mathrm{~W}, 2 \times 32 \mathrm{~W}, 3 \times 20 \mathrm{~W}, 2 \times 20 \mathrm{~W}$ e $1 \times 20 \mathrm{~W}$ e com lâmpadas incandescentes de $1 \times 60 \mathrm{~W}$. As potências totais de iluminação que fazem parte desses conjuntos, para cada ambiente, estão apresentadas no anexo $A$, com a consideração do consumo de todos os seus respectivos reatores. Salienta-se que na ocasião do levantamento dos dados expostos todas as luminárias encontravam-se com todas as lâmpadas em funcionamento e apresentavam, em sua maioria, elevado grau de sujeira tanto na parte externa dos conjuntos quanto nos refletores. 
Nos anexos B e C, temos a exposição dos resultados obtidos com a aplicação da metodologia proposta para sistemas de iluminação na regulamentação para etiquetagem voluntária do nível de eficiência energética de edifícios comerciais, de serviços e públicos, respectivamente, com a utilização da luminária 1 e da luminária 2. De maneira análoga aos dados expressos no anexo $A$, são obtidos os níveis de eficiência de A a E, para cada dependência da edificação.

É de bom alvitre salientar que em todos os estudos realizados temos o atendimento de todos os pré-requisitos estabelecidos na proposta de regulamentação supracitada para dar condições de se obter a classificação de nível de eficiência A em sistemas de iluminação, pertinentes a dispositivos de controle manual e automático.

No primeiro estudo, foi verificado através do levantamento de dados realizado, que a potência instalada de iluminação corresponde a $77828,40 \mathrm{~W}$ em toda a edificação.

No segundo e no terceiro estudo, a potência instalada de iluminação corresponde a 84977,00 W em toda a edificação, representando um aumento de 9,2\%.

A partir dos níveis de eficiência relacionados nos anexos $A, B$ e $C$, tem-se a apresentação dos referidos dados para cada tipo de dependência (escritórios, depósitos, banheiros e circulação) em cada estudo realizado, na figura 8 (primeiro estudo), na figura 9 (segundo estudo) e na figura 10 (terceiro estudo). Não foram definidos níveis de eficiência para ambientes externos, haja vista a referida regulamentação só se aplicar a ambientes internos. 


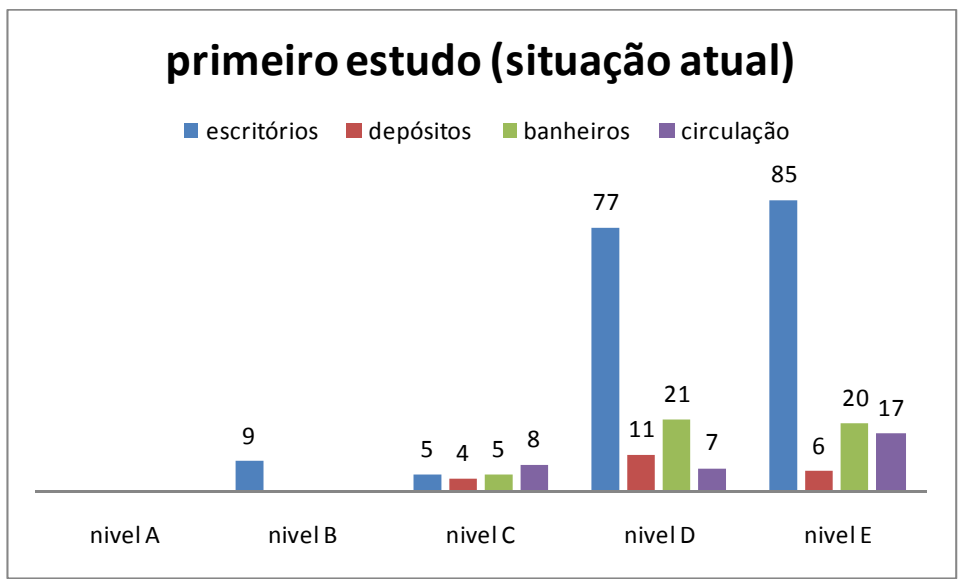

Figura 8 - Nível de eficiência obtido por tipo de dependência, no primeiro estudo realizado.

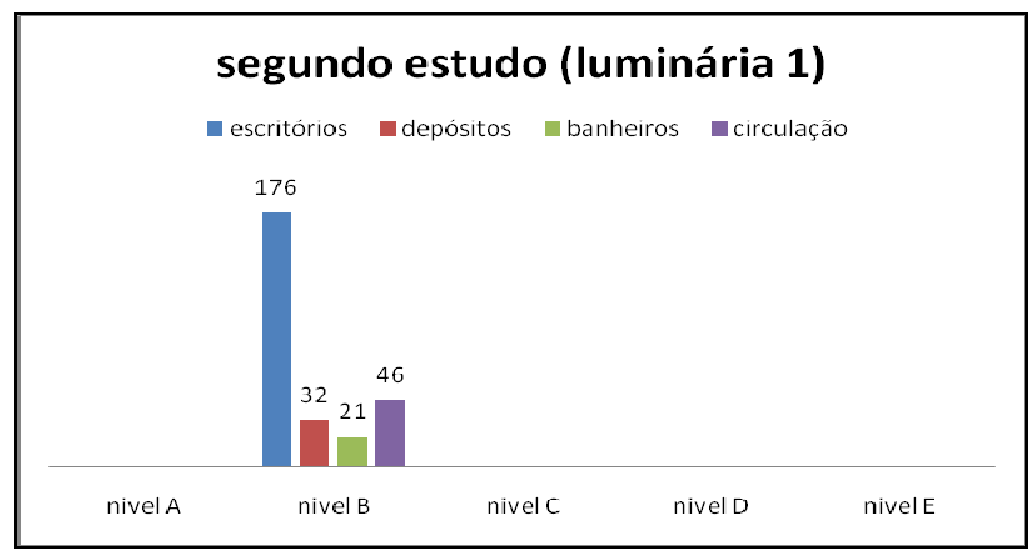

Figura 9 - Nível de eficiência obtido por tipo de dependência, no segundo estudo realizado.

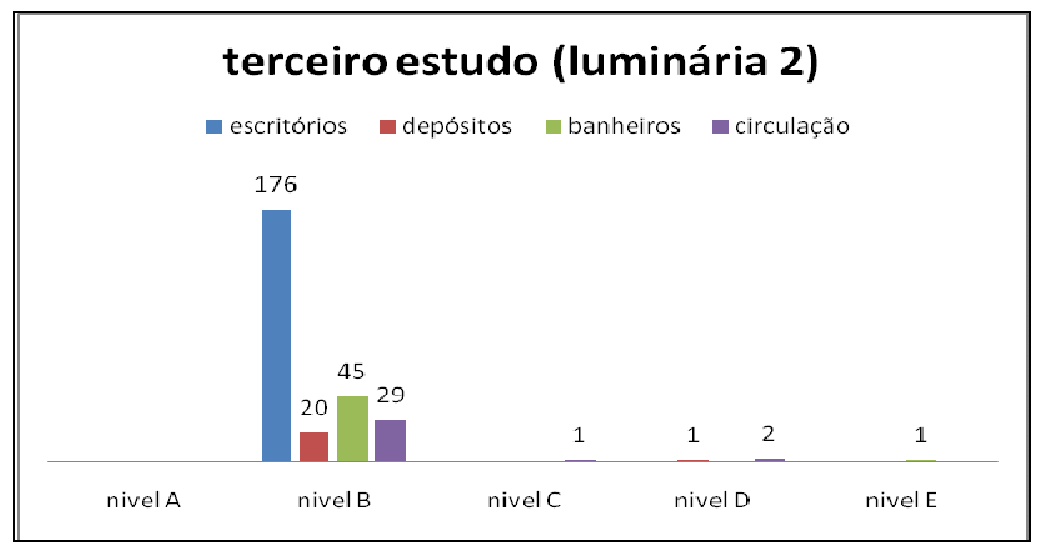

Figura 10 - Nível de eficiência obtido por tipo de dependência, no terceiro estudo realizado. 
A partir da comparação dos níveis de eficiência energética expressos nos anexos $A, B$ e C e obtidos com a aplicação da metodologia da regulamentação supracitada, na tabela 5 observam-se as melhorias na classificação das dependências, nos seus diferentes grupos.

De acordo com a tabela 5, observa-se que na situação atual as quantidades de classificações para o nível de eficiência $B$ apresentam-se menores $(P<0,05)$ que da luminária 1 (segundo estudo) e que da luminária 2 (terceiro estudo). Por sua vez, estas luminárias (1 e 2) apresentaram tais quantidades de classificações em cada um dos níveis semelhantes estatisticamente $(P>0,05)$. A mesma disposição de dados ocorre para os demais níveis ( $C, D$ e $E$ ), porém com valores estatisticamente iguais para as luminárias 1 e $2(P>0,05)$ e inferiores em relação a situação atual $(P<0,05)$.

Tabela 5 - Comparação dos índices de nível de eficiência entre os grupos

\begin{tabular}{cccccc}
\hline & A & B & C & D & E \\
\hline Atual & $0 \%$ & $3,27 \%$ & $8 \%$ & $42,18 \%$ & $46,54 \%$ \\
& $(0 / 275)$ & $(9 / 275) \mathrm{B}$ & $(22 / 275) \mathrm{A}$ & $(116 / 275) \mathrm{A}$ & $(128 / 275) \mathrm{A}$ \\
Luminária 1 & $0 \%$ & $100 \%$ & $0 \%$ & $0 \%$ & $0 \%$ \\
& $(0 / 275)$ & $(275 / 275) \mathrm{A}$ & $(0 / 275) \mathrm{B}$ & $(0 / 275) \mathrm{B}$ & $(0 / 275) \mathrm{B}$ \\
Luminária 2 & $0 \%$ & $98,18 \%$ & $0,36 \%$ & $1,09 \%$ & $0,36 \%$ \\
& $(0 / 275)$ & $(270 / 275) \mathrm{A}$ & $(1 / 275) \mathrm{B}$ & $(3 / 275) \mathrm{B}$ & $(1 / 275) \mathrm{B}$ \\
\hline
\end{tabular}

Letras maiúsculas distintas indicam diferença estatística no teste qui-quadrado $(P<0,05)$

Em cada pavimento da edificação, apresenta-se a média e o erro padrão da média (SEM) para os valores das densidades de potência total instalada de iluminação $\left(\mathrm{W} / \mathrm{m}^{2}\right)$, iluminância (lux) e densidade de potência de iluminação $\left(\mathrm{DPI} \mathrm{RF}_{\mathrm{RF}}\right)$ de acordo com os dados apresentados nas tabelas 6 a 12. 
Tabela 6 - Média e erro padrão da média (SEM) dos valores de densidade de potência total instalada $\left(\mathrm{W} / \mathrm{m}^{2}\right)$, iluminância (lux) e densidade de potência de iluminação (DPI $\mathrm{RF}$ ) para o pavimento térreo.

\begin{tabular}{ccccc}
\hline & $\mathbf{n}$ & densidade & iluminância & $\mathrm{DPI}_{\mathrm{RF}}$ \\
\hline Atual & 32 & $15,79 \pm 1,38^{\mathrm{A}}$ & $195,43 \pm 20,10^{\mathrm{B}}$ & $9,88 \pm 1,01^{\mathrm{A}}$ \\
Luminária 1 & 32 & $11,69 \pm 0,93^{\mathrm{B}}$ & $360,90 \pm 34,48^{\mathrm{A}}$ & $3,68 \pm 0,28^{\mathrm{B}}$ \\
Luminária 2 & 32 & $11,69 \pm 0,93^{\mathrm{B}}$ & $314,28 \pm 30,30^{\mathrm{A}}$ & $4,26 \pm 0,33^{\mathrm{B}}$ \\
\hline
\end{tabular}

Letras maiúsculas distintas indicam diferenças estatísticas nas mesmas colunas $(P<0,05)$.

Tabela 7 - Média e erro padrão da média (SEM) dos valores de densidade de potência total instalada

$\left(\mathrm{W} / \mathrm{m}^{2}\right)$, iluminância (lux) e densidade de potência de iluminação ( $\mathrm{DPl} \mathrm{IF}_{\mathrm{RF}}$ ) para o primeiro pavimento

\begin{tabular}{ccccc}
\hline & $\mathbf{n}$ & densidade & iluminância & DPI $_{\mathrm{RF}}$ \\
\hline Atual & 45 & $10,734 \pm 0,55^{\mathrm{B}}$ & $201,80 \pm 22,49^{\mathrm{C}}$ & $7,01 \pm 0,58^{\mathrm{A}}$ \\
Luminária 1 & 45 & $12,953 \pm 0,66^{\mathrm{A}}$ & $418,44 \pm 23,39^{\mathrm{A}}$ & $3^{\mathrm{B}}, 27 \pm 0,11^{\mathrm{B}}$ \\
Luminária 2 $^{\mathrm{B}}$ & 45 & $12,953 \pm 0,66^{\mathrm{B}}$ & $365,15 \pm 20,54^{\mathrm{B}}$ & $3,76 \pm 0,14^{\mathrm{B}}$ \\
\hline
\end{tabular}

Letras maiúsculas distintas indicam diferenças estatísticas nas mesmas colunas $(P<0,05)$.

Tabela 8 - Média e erro padrão da média (SEM) dos valores de densidade de potência total instalada $\left(\mathrm{W} / \mathrm{m}^{2}\right)$, iluminância (lux) e densidade de potência de iluminação (DPI $\mathrm{RF}$ ) para o segundo pavimento

\begin{tabular}{ccccc}
\hline & $\mathbf{n}$ & densidade & iluminância & $\mathrm{DPI}_{\mathrm{RF}}$ \\
\hline Atual & 43 & $11,92 \pm 1,04^{\mathrm{A}}$ & $160,32 \pm 10,01^{\mathrm{C}}$ & $9,03 \pm 1,13^{\mathrm{A}}$ \\
Luminária 1 & 43 & $13,35 \pm 0,60^{\mathrm{A}}$ & $433,18 \pm 25,76^{\mathrm{A}}$ & $3,44 \pm 0,21^{\mathrm{B}}$ \\
Luminária 2 & 43 & $13,35 \pm 0,60^{\mathrm{A}}$ & $378,62 \pm 22,70^{\mathrm{B}}$ & $3,97 \pm 0,26^{\mathrm{B}}$ \\
\hline
\end{tabular}

Letras maiúsculas distintas indicam diferenças estatísticas nas mesmas colunas $(P<0,05)$.

Tabela 9 - Média e erro padrão da média (SEM) dos valores de densidade de potência total instalada

$\left(\mathrm{W} / \mathrm{m}^{2}\right)$, iluminância (lux) e densidade de potência de iluminação (DPI $\mathrm{RF}$ ) para o terceiro pavimento

\begin{tabular}{ccccc}
\hline & $\mathbf{n}$ & densidade & iluminância & DPI $_{\mathrm{RF}}$ \\
\hline Atual & 46 & $12,15 \pm 1,03^{\mathrm{A}}$ & $180,39 \pm 14,87^{\mathrm{C}}$ & $7,18 \pm 0,55^{\mathrm{A}}$ \\
Luminária 1 & 46 & $13,28 \pm 0,75^{\mathrm{A}}$ & $429,84 \pm 27,20^{\mathrm{A}}$ & $3,30 \pm 0,12^{\mathrm{B}}$ \\
Luminária 2 & 46 & $13,28 \pm 0,75^{\mathrm{A}}$ & $376,19 \pm 23,96^{\mathrm{B}}$ & $3,79 \pm 0,15^{\mathrm{B}}$ \\
\hline
\end{tabular}

Letras maiúsculas distintas indicam diferenças estatísticas nas mesmas colunas $(P<0,05)$. 
Tabela 10 - Média e erro padrão da média (SEM) dos valores de densidade de potência total instalada $\left(\mathrm{W} / \mathrm{m}^{2}\right)$, iluminância (lux) e densidade de potência de iluminação (DPI $\mathrm{RF}$ ) para o quarto pavimento

\begin{tabular}{ccccc}
\hline & $\mathbf{n}$ & densidade & iluminância & DPI $_{\mathrm{RF}}$ \\
\hline Atual & 55 & $9,72 \pm 0,73^{\mathrm{B}}$ & $148,96 \pm 11,08^{\mathrm{C}}$ & $6,99 \pm 0,47^{\mathrm{A}}$ \\
Luminária 1 & 55 & $12,83 \pm 0,64^{\mathrm{A}}$ & $425,21 \pm 26,35^{\mathrm{A}}$ & $3,33 \pm 0,13^{\mathrm{B}}$ \\
Luminária 2 & 55 & $12,83 \pm 0,64^{\mathrm{A}}$ & $372,10 \pm 23,19^{\mathrm{B}}$ & $3,83 \pm 0,16^{\mathrm{B}}$ \\
\hline
\end{tabular}

Letras maiúsculas distintas indicam diferenças estatísticas nas mesmas colunas $(P<0,05)$.

Tabela 11 - Média e erro padrão da média (SEM) dos valores de densidade de potência total instalada $\left(\mathrm{W} / \mathrm{m}^{2}\right)$, iluminância (lux) e densidade de potência de iluminação (DPI $I_{\mathrm{RF}}$ ) para o quinto pavimento

\begin{tabular}{|c|c|c|c|c|}
\hline & $\bar{n}$ & densidade & iluminância & $\mathrm{DPI}_{\mathrm{RF}}$ \\
\hline Atual & 37 & $11,89 \pm 1,12^{A}$ & $165,973 \pm 13,67^{c}$ & $8,37 \pm 0,76^{A}$ \\
\hline Luminária 1 & 37 & $12,28 \pm 0,82^{A}$ & $404,784 \pm 32,17^{A}$ & $3,39 \pm 0,20^{5}$ \\
\hline Luminária 2 & 37 & $12,28 \pm 0,82^{A}$ & $355,000 \pm 28,33^{\text {в }}$ & $3,89 \pm 0,24^{{ }^{b}}$ \\
\hline
\end{tabular}

Letras maiúsculas distintas indicam diferenças estatísticas nas mesmas colunas $(P<0,05)$.

Tabela 12 - Média e erro padrão da média (SEM) dos valores de densidade de potência total instalada $\left(\mathrm{W} / \mathrm{m}^{2}\right)$, iluminância (lux) e densidade de potência de iluminação (DPI $\mathrm{RF}$ ) para o sexto pavimento

\begin{tabular}{ccccc}
\hline & $\mathbf{n}$ & densidade & iluminância & DPI $_{\mathrm{RL}}$ \\
\hline Atual & 17 & $13,55 \pm 1,36^{\mathrm{A}}$ & $194,00 \pm 23,77^{\mathrm{A}}$ & $8,32 \pm 1,16^{\mathrm{A}}$ \\
Luminária 1 & 17 & $7,62 \pm 0,97^{\mathrm{B}}$ & $230,29 \pm 37,23^{\mathrm{A}}$ & $3,66 \pm 0,26^{\mathrm{B}}$ \\
Luminária 2 & 17 & $7,62 \pm 0,97^{\mathrm{B}}$ & $203,88 \pm 32,49^{\mathrm{A}}$ & $4,17 \pm 0,32^{\mathrm{B}}$ \\
\hline
\end{tabular}

Letras maiúsculas distintas indicam diferenças estatísticas nas mesmas colunas $(P<0,05)$.

Na tabela 6, observa-se que na situação Atual a densidade de potência total instalada de iluminação apresenta-se maior $(P=0,002)$ que a luminária 1 (segundo estudo) e que a luminária 2 (terceiro estudo). Por sua vez, estas luminárias (1 e 2) apresentaram tais densidades semelhantes estatisticamente $(P>0,05)$. A mesma situação observa-se quanto a iluminância o qual é estatisticamente igual entre as luminária 1 e $2(P>0,05)$, porém, superiores em valor em relação à situação atual 
$(P<0,001)$. Seguindo também a tendência observada no tocante aos resultados de $\mathrm{DPI}_{\mathrm{RF}}$, os quais apresentam menores valores as luminárias 1 e $2(\mathrm{P}<0,001)$.

Os dados de $\mathrm{DPI} \mathrm{RF}_{\mathrm{RF}}$ expressos nas tabelas 7 a 12, seguem a tendência dos resultados do mesmo índice da tabela 6 apresentando menores valores para as luminárias 1 e 2 $(P<0,001)$.

As tabelas 7, 8, 9, 10 e 11 apresentam iluminamentos diferentes, sendo maiores no segundo estudo (luminária 1), acompanhados pelos valores apresentados no terceiro estudo (luminária 2) e em seguida pelos dados da situação atual $(P<0,001)$. Diferem dessa disposição os iluminamentos apresentados na tabela 12, que se apresentam semelhantes estatisticamente $(P=0,442)$ e as representações do referido parâmetro expressos na tabela 6 .

Observa-se que as densidades de potência total instalada de iluminação da tabela 12 seguem a mesma tendência apresentada na tabela $6(\mathrm{P}<0,001)$. Tais densidades que compõem as tabelas 7 e 10 acompanham a mesma disposição de dados, porém, com valores estatisticamente iguais entre as luminárias 1 e $2(P>0,05)$ e superiores em relação a situação atual $(P<0,001)$. Na tabela 8,9 e 11 , temos este parâmetro com valores semelhantes estatisticamente $(P>0,05)$.

Em uma abordagem voltada a edificação como um todo, após a realização de testes estatísticos, obteve-se a Média e o erro padrão da média (SEM) para os valores das densidades de potência total instalada $\left(\mathrm{W} / \mathrm{m}^{2}\right)$ nos diferentes ambientes da edificação, conforme expresso na tabela 13. 
Os escritórios apresentaram na situação atual densidades de potência total instalada em iluminação menores que nos demais estudos realizados (luminária 1 e 2), que por sua vez apresentaram valores semelhantes estatisticamente $(P>0,05)$. Os resultados dos demais tipos de ambientes seguem a mesma tendência observada, apresentando maiores valores na situação atual de acordo com a tabela 13.

Tabela 13 - Média e erro padrão da média (SEM) dos valores de densidade de potência total instalada $\left(\mathrm{W} / \mathrm{m}^{2}\right)$, nos diferentes ambientes da edificação

\begin{tabular}{|c|c|c|c|c|}
\hline & escritório & circulação & depósito & banheiro \\
\hline $\begin{array}{c}\mathbf{n} \\
\text { Atual } \\
\text { Luminária 1 } \\
\text { Luminária } 2\end{array}$ & $\begin{array}{c}176 \\
11,03 \pm 0,39^{B} \\
15,32 \pm 0,21^{A} \\
15,32 \pm 0,21^{A}\end{array}$ & $\begin{array}{c}32 \\
11,23 \pm 1,31^{A} \\
5,22 \pm 0,33^{\mathrm{B}} \\
5,22 \pm 0,33^{\mathrm{B}}\end{array}$ & $\begin{array}{c}21 \\
12,66 \pm 1,25^{A} \\
9,09 \pm 0,86^{B} \\
9,09 \pm 0,86^{B}\end{array}$ & $\begin{array}{c}46 \\
15,16 \pm 1,30^{\circ} \\
8,21 \pm 0,44^{\text {b }} \\
8,21 \pm 0,44^{\circ}\end{array}$ \\
\hline
\end{tabular}

Letras maiúsculas distintas indicam diferenças estatísticas nas mesmas colunas $(P<0,05)$

De maneira análoga, nas tabelas 14 e 15 obtiveram-se a Média e o erro padrão da média (SEM), respectivamente, para os valores dos iluminamentos (lux) e das densidades de potência de iluminação ( $\mathrm{DPI} \mathrm{RF}_{\mathrm{RF}}$ ) nos diferentes ambientes da edificação.

Destaca-se nos ambientes de escritório os maiores valores de iluminamento no segundo estudo com a utilização da luminária 1, seguidos pelo uso da luminária 2 (terceiro estudo) e, por fim, pela situação atual. O ambiente de circulação apresentou valores semelhantes estatisticamente $(P=0,104)$ nos três estudos realizados e os ambientes de depósito e banheiro apresentaram iluminamentos maiores no primeiro estudo (luminária 1) que nos demais estudos realizados (luminária 2 e situação atual), que por sua vez apresentaram valores semelhantes estatisticamente $(P>0,05)$ conforme expresso na tabela 14. 
Tabela 14 - Média e erro padrão da média (SEM) dos valores de iluminância (lux), nos diferentes ambientes da edificação

\begin{tabular}{ccccc}
\hline & escritório & circulação & depósito & banheiro \\
\hline $\mathbf{n}$ & 176 & 32 & 21 & 46 \\
Atual & $197,72 \pm 8,22^{\mathrm{C}}$ & $104,25 \pm 11,13^{\mathrm{A}}$ & $145,09 \pm 16,16^{\mathrm{B}}$ & $151,67 \pm 12,10^{\mathrm{B}}$ \\
Luminária 1 & $533,85 \pm 5,32^{\mathrm{A}}$ & $123,96 \pm 3,90^{\mathrm{A}}$ & $226,19 \pm 17,42^{\mathrm{A}}$ & $182,23 \pm 5,69^{\mathrm{A}}$ \\
Luminária 2 & $467,44 \pm 4,70^{\mathrm{B}}$ & $107,56 \pm 3,68^{\mathrm{A}}$ & $195,33 \pm 14,93^{\mathrm{B}}$ & $159,28 \pm 5,25^{\mathrm{B}}$ \\
\hline
\end{tabular}

Letras maiúsculas distintas indicam diferenças estatísticas nas mesmas colunas $(P<0,05)$

Considerando os valores apresentados na tabela 15, enfatizam-se os maiores valores de $\mathrm{DPI}_{\mathrm{RF}}$ em todos os tipos ambientes na situação atual $(\mathrm{P}<0,001)$. Nos ambientes de escritório, temos valores de $\mathrm{DPI}_{\mathrm{RF}}$ maiores da luminária 2 que da luminária 1 e nos demais tipos de ambientes temos valores semelhantes estatisticamente $(P>0,05)$ da luminária 1 e da luminária 2.

Tabela 15 - Média e erro padrão da média (SEM) dos valores de densidade de potência de iluminação $\left(\mathrm{DPl} \mathrm{RF}_{\mathrm{RF}}\right)$, nos diferentes ambientes da edificação

\begin{tabular}{ccccc}
\hline & escritório & circulação & depósito & banheiro \\
\hline $\mathbf{n}$ & 176 & 32 & 21 & 46 \\
Atual & $6,12 \pm 0,16^{\mathrm{A}}$ & $11,47 \pm 1,07^{\mathrm{A}}$ & $9,70 \pm 1,09^{\mathrm{A}}$ & $11,70 \pm 1,10^{\mathrm{A}}$ \\
Luminária 1 & $2,88 \pm 0,034^{\mathrm{C}}$ & $4,24 \pm 0,24^{\mathrm{B}}$ & $4,07 \pm 0,30^{\mathrm{B}}$ & $4,51 \pm 0,19^{\mathrm{B}}$ \\
Luminária 2 & $3,29 \pm 0,040^{\mathrm{B}}$ & $4,94 \pm 0,30^{\mathrm{B}}$ & $4,73 \pm 0,37^{\mathrm{B}}$ & $5,21 \pm 0,24^{\mathrm{B}}$ \\
\hline
\end{tabular}

Letras maiúsculas distintas indicam diferenças estatísticas nas mesmas colunas $(P<0,05)$ 


\section{DISCUSSÃO}

A proposta de regulamentação para etiquetagem voluntária do nível de eficiência energética de edifícios comerciais, de serviços e públicos vem suprir uma necessidade existente hoje no contexto nacional, representando um importante mecanismo de atuação no mercado consumidor através da avaliação do desempenho ambiental dos empreendimentos e, consequentemente, promovendo o uso eficiente de energia.

Nota-se a variedade de sistemas de iluminação existentes hoje na edificação objeto de estudo bem como a ineficiência dos equipamentos que as compõem (reatores eletromagnéticos e luminárias com calhas em elevado estado de deterioração e sujas) comprometendo seu rendimento. Tal levantamento representa bem a situação hoje encontrada em grande parte das dependências do setor público, que devido a ausência de investimentos em manutenção e em substituição de equipamentos comprometidos ou obsoletos, os sistemas de iluminação acabam trabalhando muitas vezes em situação precária o que pode acarretar falhas no funcionamento dos mesmos.

Um fato que confirma os aspectos elencados anteriormente, conforme o anexo $A$, trata dos baixos índices de iluminância apresentados no primeiro estudo em comparação com os valores recomendados pela NBR 5413 - iluminância de interiores (ABNT, 1992) para cada um dos tipos de ambientes internos que compõem a edificação (escritório, circulação, depósito e banheiro), considerando que todas as luminárias que compõem o levantamento realizado estavam em perfeito funcionamento, sem qualquer lâmpada queimada. 
Segundo Santamouris (1996), a falta de manutenção em luminárias pode reduzir o fluxo luminoso em até 30\%. Porém, lesna (1995) afirma que a falta de manutenção em luminárias pode reduzir a iluminância em 25 a 50\%, dependendo da aplicação e do equipamento utilizado.

Tal situação de depreciação e de baixos valores de iluminância contribui em grande parte para a definição dos níveis expostos na figura 8, na qual observa-se uma predominância de dependências classificadas nos níveis de eficiência $D$ e $E$. Ressalta-se que os índices melhores de eficiências no primeiro estudo foram atribuídos a recentes reformas realizadas naquelas dependências, corroborando a idéia de que as construções do setor público sem reformas recentes com pouco ou nenhum esforço de manutenção periódica e aprimoramento de sistemas ópticos com a utilização de conjuntos com melhores rendimentos, apresentam baixos índices de eficiência.

No segundo estudo, conforme verificado na figura 9, utilizando um sistema de iluminação mais eficiente (luminária 1 , com rendimento de $84 \%$ e com reatores eletrônicos com fator de potência maior ou igual a 0,98 ) observa-se que todas as dependências são classificadas no nível de eficiência B. A melhoria do nível de eficiência já era esperada devido ao uso de equipamentos com rendimento maior aos existentes hoje na edificação.

De acordo com Ghisi (1997) as luminárias com refletor de alumínio sem aletas (luminária 1) representam a melhor solução em termos de minimização de carga instalada em iluminação, para qualquer refletância de parede. Tal análise é realizada considerando além da luminária citada, outros conjuntos com refletor de alumínio e 
aletas brancas, refletor e aletas de alumínio, refletor e aletas brancos, refletor branco sem aletas e refletor branco com difusor. O referido autor sugere o uso de tal conjunto óptico em ambientes que não necessitem de controle de ofuscamento.

Outra informação relevante apresentada em Ghisi (1997) corresponde ao uso de luminárias de refletor e aletas de alumínio (luminária 2), que corresponde a um aumento médio da potência total instalada em iluminação de $24,2 \%$, atendendo as mesmas condições de iluminamento previstas nas normas pertinentes quando utilizam-se esses conjuntos ópticos em substituição as luminárias com refletor de alumínio sem aletas (luminária 1). Ainda, o uso de tal luminária com aletas é recomendado em instalações que exijam controle de ofuscamento.

Tais fatores foram importantes na escolha das luminárias que fariam parte dos estudos realizados somado ao fato que é uma prática comum no segmento da construção, durante a execução de empreendimentos, a substituição em projetos luminotécnicos confeccionados com o uso da luminária 1, dos referidos conjuntos ópticos pelo uso da luminária 2 , sem os devidos ajustes de dimensionamento no que tange a quantidade de luminárias para alcançar os níveis médios de iluminância recomendados pela NBR 5413 - iluminância de interiores (ABNT, 1992), seja por necessidades de opção de material por parte do cliente ou para minimizar os efeitos de ofuscamento.

No que tange ao ofuscamento, podemos relacionar a necessidade de controle do mesmo intimamente ligado a ambientes, como os escritórios, que possuem usuários que na execução de suas atividades utilizam com freqüência computadores. Tal fato se deve a tela do computador possuir brilho específico (luminância) e alto grau de 
refletância, podendo até influenciar na percepção da iluminação espacial, ou até mesmo distorcê-la (NISSOLA, 2005).

Com o intuito de se avaliar o real impacto dessa mudança (durante a execução dos empreendimentos) na determinação do nível de eficiência de cada dependência, de acordo com a proposta da regulamentação para etiquetagem voluntária do nível de eficiência energética de edifícios comerciais, foram considerados nos segundos e terceiros estudos realizados a mesma quantidade de luminárias. No segundo estudo essa quantidade foi obtida pela aplicação do software softlux, considerando as recomendações da NBR 5413 - iluminância de interiores (ABNT, 1992), enquanto que no terceiro estudo, a partir da quantidade de conjuntos ópticos definida anteriormente, foi obtido a iluminância para cada ambiente da edificação objeto de análise.

No terceiro estudo, com o uso da luminária 2, que apresenta um rendimento de $73 \%$ e com reatores eletrônicos com fator de potência maior ou igual a 0,98, observa-se na figura 10 que a maioria das dependências são classificadas no nível de eficiência $B$, à exceção de 1 depósito (nível D), um banheiro (nível E) e 3 dependências de circulação (uma classificada no nível $\mathrm{C}$ e as outras duas classificadas no nível D).

Não obstante as informações apresentadas acerca das particularidades dos dois conjuntos ópticos utilizados no segundo e no terceiro estudo, a grande maioria das dependências se classifica no nível de eficiência $B$, conforme observado na tabela 5 , permitindo inferir que tais características ligadas ao desempenho da luminária 2 não influenciam expressivamente na definição do referido nível de eficiência. 
No que tange as dependências que apresentaram níveis de eficiência diferentes da classificação B (no terceiro estudo), os quais correspondem a ambientes de depósito (um com nível D), de banheiro (um com nível E) e de circulação (uma classificada no nível $\mathrm{C}$ e as outras duas classificadas no nível D), podemos observar uma variação numérica de iluminância em relação ao primeiro estudo que corresponde a uma associação a níveis menores dado o comportamento de dados obtidos para $\mathrm{DPI}_{\mathrm{RF}} \mathrm{e}$ conseqüente associação destes com $\mathrm{DPI}_{\mathrm{RL}}$ e $\mathrm{K}$ para os respectivos ambientes.

É relevante ressaltar que não foi obtido em nenhum estudo realizado o nível de eficiência A para qualquer dependência (tabela 5), evidenciando que o limite a ser atingido utilizando-se somente a iluminação geral é o nível de eficiência $B$. Para se atingir a classificação $\mathrm{A}$, recomenda-se a utilização de iluminação local para execução da tarefa aliada à redução do nível de iluminância geral, atingindo assim um $\mathrm{DPI}_{\mathrm{RF}}$ compatível (PROCEL EDIFICA, 2009).

Uma característica interessante da proposta de regulamentação para etiquetagem voluntária do nível de eficiência energética de edifícios comerciais, de serviços e públicos trata da possibilidade da avaliação de parcelas das edificações e de cada um dos aspectos (envoltória, condicionamento de ar e iluminação) em separado. Em específico para iluminação, pode-se estabelecer uma classificação de nível de eficiência para um pavimento ou salas.

Esse aspecto de categorização colabora para encontrar os ambientes mais deficientes no quesito avaliado possibilitando a atuação local para implementar melhorias, se necessário. Tal ação torna-se mais difícil quando aplicamos o LEED e o 
AQUA devido ao caráter global de atribuição de eficiência nessas metodologias de avaliação de desempenho ambiental.

Como era de se esperar, em cada um dos pavimentos (conforme tabelas 6 a 12), podemos observar que a luminária 1 obteve valores numéricos de iluminância superiores as aplicações realizadas nos demais estudos (situação atual e luminária 2) e que as diferenças numéricas entre os valores do referido parâmetro para as luminárias 1 e 2 diferem em média de 12,43\%. Ainda, entre a situação atual e a luminária 1 temos um aumento médio percentual numérico no iluminamento de 121,22\% para satisfazer as recomendações da NBR 5413 - iluminância de interiores (ABNT, 1992).

É possível observar na tabela 13 que as densidades de potência total instalada de iluminação (expressas em $\left[\mathrm{W} / \mathrm{m}^{2}\right]$ ), nas dependências de escritório representam um aumento numérico de 138,82\% (entre o primeiro e o segundo e terceiro estudo), indicando um subdimensionamento dos respectivos sistemas de iluminação existente nos referidos ambientes na situação atual (primeiro estudo) e um necessário acréscimo de carga instalada do uso final abordado nestes locais, referenciados pelos níveis mínimos de iluminância recomendados pela NBR 5413 - iluminância de interiores (ABNT, 1992).

Em contrapartida, as densidades de potência total instalada de iluminação (expressas em $\left.\left[\mathrm{W} / \mathrm{m}^{2}\right]\right)$, nas dependências de circulação, banheiro e depósitos apresentaram uma redução numérica respectivamente de 53,49\%, 45,81\% e 28,21\% (tabela 13), indicando um superdimensionamento dos respectivos sistemas de iluminação existente nos referidos ambientes na situação atual (primeiro estudo) e uma 
necessária redução de carga instalada do uso final abordado nestes locais, referenciados pelos níveis mínimos de iluminância recomendados pela NBR 5413 iluminância de interiores (ABNT, 1992).

O balanço de tais aumentos e reduções de densidades de potência total instalada de iluminação (expressas em $\left[\mathrm{W} / \mathrm{m}^{2}\right]$ ) nas comparações do referido parâmetro nas mesmas dependências (mesmos ambientes e respectivas dimensões), expressa um crescimento da potência instalada total de iluminação para toda edificação de $9,2 \%$, entre o segundo e terceiro estudo $(84977,00 \mathrm{~W})$ e o primeiro estudo (77828,40 W), para se adequar aos respectivos níveis mínimos de iluminância recomendados pela NBR 5413 - iluminância de interiores (ABNT, 1992).

Fica notório a representatividade dos ambientes de escritório (correspondendo a 69,19\% da área útil construída da edificação associado a um aumento numérico das densidades de potência total instalada de iluminação equivalente a $138,82 \%$ ) e os conseqüentes impactos relacionados a adequações necessárias nos respectivos sistemas de iluminação dos mesmos em comparação com a parcela correspondente aos demais tipos de dependências (equivalente a 30,81\% de área útil construída associada a uma redução média numérica das densidades de potência total instalada de iluminação equivalente a 42,50\%).

Diante dessas informações, fica evidente que a atividade a ser desenvolvida nos ambientes de escritório na edificação existente está comprometida na situação atual pela menor qualidade da iluminação nestas dependências, afetando a capacidade visual e percepção de espaços. 
Considerando uma análise pormenorizada por pavimento, os valores apresentados para densidade total de potência instalada de iluminação não apresentam uma tendência de apresentação dos dados uniforme para edificação, deparando-se com valores discrepantes nas tabelas 6 a 12. Diante dessa característica, não foi possível estabelecer uma consistência entre os padrões dos andares devido a desigualdade de distribuição dos ambientes em cada pavimento, podendo apenas afirmar que as referidas densidades são iguais nos segundo e terceiro estudos porque as luminárias 1 e 2 possuem as mesmas potências totais instaladas para cada conjunto.

O critério de avaliação estabelecido para sistemas de iluminação da proposta de regulamentação para etiquetagem voluntária do nível de eficiência energética de edifícios comerciais, de serviços e públicos, quando aplicado nos segundo e terceiro estudos, apresenta valores semelhantes estaticamente $(p>0,05)$ para os $D_{R P}$ da luminária 1 e da luminária 2, em cada andar (tabelas 6 a 12).

Este fato corrobora que apesar das diferenças existentes entre as luminárias 1 e 2 as mesmas apresentam a mesma faixa de níveis de eficiência. O valor do referido parâmetro apresenta em todos os andares na situação atual valores maiores estatisticamente que nos demais estudos realizados $(p<0,001)$ devido os valores coletados no levantamento de dados apresentarem menores iluminâncias (proporcionado pelas luminárias existentes) para serem distribuídos ao longo das mesmas áreas de cada respectiva dependência, com uma variação menor das densidades de potência total instalada de iluminação $\left(\mathrm{W} / \mathrm{m}^{2}\right)$ em relação a variação dos iluminamentos. 
Desse modo, pode-se afirmar, no que tange a variação dos valores apresentados para densidade total de potência instalada de iluminação (tabelas 6 a 12), que os mesmos estão diretamente relacionados a distribuição dos diferentes tipos de dependências em cada andar, associados a representatividade de cada ambiente na área útil do pavimento e seu respectivo impacto no acréscimo ou redução de carga instalada (potência) no sistema de iluminação para atender aos níveis mínimos de iluminância recomendados pela NBR 5413 - iluminância de interiores (ABNT, 1992) e as melhorias significativas de rendimento dos conjuntos ópticos adotados nos segundo e terceiro estudos.

De acordo com as recomendações da NBR 5413 - iluminância de interiores (ABNT, 1992) observa-se na tabela 14 que as iluminâncias apresentam uma ordem gradativa do ambiente de circulação, de depósito, de banheiro e de escritório, o qual possui os maiores valores. Como esperado, mantêm-se a distribuição de iluminamentos observada nas tabelas 6 a 12, nas quais podemos observar que a luminária 1 obteve valores numéricos de iluminamento superiores as aplicações realizadas nos demais estudos (situação atual e luminária 2), nesta etapa, considerando cada tipo de ambiente.

É interessante destacar que mesmo após a realização dos estudos verificarmos que houve a apresentação de valores semelhantes estaticamente $(p>0,05)$ para os $\mathrm{DPI}_{\mathrm{RF}}$ da luminária 1 e da luminária 2, em cada andar (tabelas 6 a 12), se considerarmos uma abordagem particularizando cada tipo de ambiente, a tendência se mantêm para todos os tipos de dependências à exceção dos escritórios, que possuem valores estatisticamente maiores para segundo caso ( luminária 1) do que para o terceiro caso (luminária 2) $(p<0,001)$, conforme tabela 15. 
Apesar desta ocorrência, não há mudança de nível de eficiência para o tipo de ambiente de escritório apresentando tanto no segundo quanto no terceiro estudo nível de eficiência B para todas as dependências. Isso é explicado pelo fato que mesmo comprovada tal variação de $\mathrm{DPI}_{\mathrm{RF}}$ esta não é significativa para afetar a classificação obtida para sistemas de iluminação com o uso da proposta de regulamentação para etiquetagem voluntária do nível de eficiência energética de edifícios comerciais, de serviços e públicos.

Cabem algumas sugestões interessantes para trabalhos a se realizarem nessa área de pesquisa, complementando os estudos realizados.

Primeiramente, sugere-se realizar a avaliação da proposta da regulamentação para etiquetagem voluntária do nível de eficiência energética de edifícios comerciais, de serviços e públicos considerando a envoltória, os sistemas de condicionamento de ar e os sistemas de iluminação para obter a classificação final da edificação. Tal análise proporcionaria uma inserção de parâmetros de envoltória e de condicionamento de ar na avaliação de sistemas de iluminação, complementando os resultados obtidos.

Outro trabalho importante trataria da realização de pesquisa de verificação do potencial de economia energética que pode ser conseguido pelas atuais formas de controle de luz natural, e o que poderia ser viabilizado por outras estratégias obtidas através do uso de programas de simulação energética de edificações;

Por fim, recomenda-se uma análise mais pormenorizada das condicionantes para se atingir o nível de eficiência $A$ através principalmente de uma avaliação de sistemas de iluminação local para execução de tarefa em complemento a iluminação geral. 


\section{CONCLUSÃO E CONSIDERAÇÕES FINAIS}

Este trabalho promoveu uma aplicação da metodologia proposta na regulamentação para etiquetagem do nível de eficiência energética de edifícios comerciais, de serviços e públicos, em uma abordagem voltada para sistemas de iluminação, em três estudos distintos. Tal metodologia, com grau de detalhamento inédito no país, foi elaborada a partir de equações paramétricas por região geográfica e tipologia do território brasileiro.

A partir de comparações estabelecidas entre as classificações dos níveis de eficiência energética obtidas por cada um dos sistemas de iluminação abordados nos estudos realizados foi possível avaliar os ganhos em eficiência obtidos com o uso da nova metodologia e as possibilidades de usos das luminárias analisadas.

A aplicação da metodologia proposta na regulamentação para etiquetagem do nível de eficiência energética de edifícios comerciais, de serviços e públicos, considerando apenas o dimensionamento de iluminação geral, proporciona o estabelecimento de no máximo o nível de eficiência $B$ para o segmento de prédios públicos de uso administrativo. Para se atingir níveis de classificação $A$, deve-se usar iluminação local.

É possível afirmar, ainda, que as práticas correntes no segmento da construção que se referem a substituição da luminária 2 pela luminária 1 quando da execução de empreendimentos, anteriormente projetados para serem realizados com a luminária 1, durante a aplicação da metodologia proposta não apresentaram diferenças na obtenção dos níveis de eficiência energética, mesmo considerando uma variação de cerca de $12 \%$ nos valores numéricos de iluminância. 
Se for necessário realizar a referida substituição, sugere-se que a mesma seja realizada somente nos ambientes de escritórios, adotando-se nestes locais a luminária 2 e mantendo-se nos demais locais a luminária 1, de modo a atender as recomendações no que concernem ao controle de ofuscamento.

Nas mesmas edificações, é possível afirmar que com um aumento da ordem de 9\% na potência instalada total de iluminação temos um aumento médio percentual de cerca de $120 \%$ na iluminância dos ambientes, considerando como base de comparação a luminária 1 e a situação atual, conforme observado no capítulo 5. Tais dados apresentam a relevância da aplicação do método para obter-se ganhos em eficiência e melhor qualidade de iluminação dos ambientes, proporcionando adequadas condições de execução das tarefas por parte dos usuários.

Diante desse relevante aumento de iluminância obtida para as dependências objeto do segundo estudo, podemos inferir que a ausência de manutenção periódica bem como a carência de reformas recentes proporciona a apresentação de baixos índices de eficiência energética no tipo de edificação analisada no segmento de prédios públicos de uso administrativo.

A proposta da regulamentação para etiquetagem voluntária do nível de eficiência energética de edifícios comerciais, de serviços e públicos, no que tange a sistemas de iluminação, apresenta uma importante iniciativa na implementação de um sistema de avaliação ambiental no Brasil, perfeitamente aplicável a situações reais realmente agregando ganhos significativos em eficiência energética, num contexto atual caracterizado pela busca de racionalização de recursos naturais como aliado 
fundamental na busca de um trabalho saudável, com nível de sofisticação aplicáveis aos padrões brasileiros de técnicas de projeto e tecnologias.

Apesar dessa relevante iniciativa, o Brasil - e isto vale para todos os países em desenvolvimento - tem um longo caminho a percorrer na busca da satisfação das necessidades de redução de desigualdade social e econômica somada à necessidade fundamental de equilíbrio entre o custo e o benefício ambiental envolvidos nas ações para o desenvolvimento da nação. Torna-se claro, portanto, que a nossa agenda para o cumprimento de metas ambientais deve necessariamente contemplar as várias dimensões da sustentabilidade e que qualquer iniciativa neste sentido, entre elas a avaliação de edifícios, deve alinhar-se a esta premissa.

Salienta-se a necessidade de realização de mais estudos teóricos e práticos para que se evidencie o real papel da contribuição das diferentes partes da instalação nas perdas energéticas em instalações antigas, considerando os outros aspectos abordados na proposta de regulamentação (envoltória e ar condicionado). 


\section{REFERÊNCIAS}

ABNT. Associação Brasileira de Normas. NBR 5382: Verificação de iluminância de interiores. Rio de Janeiro, 1985. 4 p.

ABNT. Associação Brasileira de Normas. NBR 5413: Iluminância de interiores. Rio de Janeiro, 1992. $13 \mathrm{p}$.

ANEEL. Agência Nacional de Energia Elétrica. Disponível em: <http://www.aneel.gov.br>. Acesso em: 30 de novembro 2008.

BALDWIN, R. et al. BREEAM 1/90: an environmental assessment for new office designs. Garston: BRE Report, 1990.

BRASIL. Decreto $n^{0} 4.059,19$ de dezembro de 2001. Dispõe sobre a regulamentação da lei no 10.295 que dispõe sobre a Política Nacional de Conservação e Uso Racional de Energia e dá outras providências correlatas. Disponível em: $<$ http://www.planalto.gov.br/ccivil 03/decreto/2001/D4059.htm>. Acesso em: 15 abril 2009.

BRASIL. Lei $n^{0} 10.295,17$ de outubro de 2001. Dispõe sobre a Política Nacional de Conservação e Uso Racional de Energia e dá outras providências correlatas. Disponível em: <http://www.planalto.gov.br/ccivil 03/Leis/ lei-principal.htm>. Acesso em: 15 abril 2009.

BREEAM. BRE Environmental Assessment Method. England. Disponível em: <http://www.breeam.org >. Acesso em: 17 de abril 2009.

CADDET. Centre for the Analysis and Dissemination of Demonstrated Energy Technologies. Saving energy with efficient lighting in commercial buildings. Sittard: CADDET energy efficiency, 1995. 22 p.

CLASP. Collaborative Labeling and Appliance Standards Program. Disponível em: <http://www.clasponline.org/index.php >. Acesso em: 30 setembro 2008.

CONPET. Programa Nacional de Racionalização do Uso dos Derivados do Petróleo e do Gás Natural. Disponível em: <http://www.conpet.gov.br>. Acesso em: 23 setembro 2008. 
DOGGART, J.; BALDWIN, R. BREEAM Internacional: regional similarities and differences of an internacional strategy for environmental assessment of buildings. In: SECOND INTERNACIONAL CONFERENCE BUILDINGS AND THE ENVIRONMENT, 1997, Paris. Proceedings. p. 83-90.

ELETROBRAS. Centrais Elétricas Brasileiras. Disponível em: <http://www.eletrobras.gov.br>. Acesso em: 15 julho 2008.

EPE. Empresa de Pesquisa Energética. Balanço Energético Nacional - BEN 2007 ano base 2006. Brasília, 2007. Disponível em: <http://www.ben.epe.gov.br $>$. Acesso em: 10 outubro 2008.

EPRI. Electric Power Research Institute. Advanced lighting guidelines: 1993. Washington: Eley associates, San Francisco, 1993. 210 p.

GBCBRASIL. Green Building Council Brasil. Disponível em: <http://www.gbcbrasil.org.br/pt/>. Acesso em: 30 maio 2009.

GELLER, H.S. et al. Policies for advancing energy efficiency and renewable energy use in Brazil. 2003. Disponível em: <http://www.sciencedirect.com>. Acesso em: 10 setembro 2008. $13 \mathrm{p}$.

GHISI, E. Desenvolvimento de uma metodologia para retrofit em sistemas de iluminação: estudo de caso na Universidade Federal de Santa Catarina. 1997. 246p. Dissertação (Mestrado) - Programa de Pós-Graduação em Engenharia Civil Universidade Federal de Santa Catarina, Florianópolis, 1997.

GOLDEMBERG, J. Física e políticas públicas. Revista Estudos Avançados do Instituto de Estudos Avançados da USP, v. 27, p. 109-113, 1996.

GOLDEMBERG, J.; PRADO L. T. S. Reforma e crise do setor elétrico no período FHC. Tempo Social. Revista de Sociologia da USP, v. 15, p. 219, 2003.

GOLDEMBERG, J.; VILLANUEVA, L.D. Energia, Meio Ambiente \& Desenvolvimento. 2 ed. São Paulo: Edusp,2003. 226 p.

HINES, W. W. et al. Probabilidade e estatística na engenharia. 4 ed. Rio de Janeiro: LTC, 2006. 588 p. 
HOWARD, N. Environmental assessment methods in the UK. 2001. (Comunicação durante a reunião do GBC em Santiago do Chile, abril 2001). Metodologias de avaliação de desempenho ambiental de edifícios: estado atual e discussão metodológica, São Paulo, Projeto Finep 2386/04, p. 12, 2007.

KURAHASSI, L. F. Gestão da Energia Elétrica - bases para uma política pública municipal. 2006. 267 p. Tese (Doutorado) - Escola Politécnica, Universidade de São Paulo, São Paulo, 2006.

IAEEL. International Association for Energy-Efficient Lighting. Big Business sees the light. Newsletter 1/92, Capitulo 1, v. 1, 1992. Disponível em: $<$ http://www.iaeel.org/iaeel/newsl/1992/ett1992/PrN a 1 92.html >. Acesso em: 10 abril 2009.

IBGE. Instituto Brasileiro de Geografia e Estatística. Disponível em: <http://www.ibge.gov.br>. Acesso em: 16 janeiro 2009.

IESNA. Illuminating Engineering Society of North America. Lighting handbook: reference \& application. 8 ed. New York: Illuminating Engineering Society of North America, 1995.

INMETRO. Instituto Nacional de Metrologia, Normalização e Qualidade Industrial. Disponível em: <http://www.inmetro.gov.br>. Acesso em: 07 setembro 2008.

ITAIM ILUMINAÇÃO. Catálogo de produtos Itaim 2008. São Paulo, 2008. 209 p.

IWASHITA, J. Eficiência energética em sistemas de iluminação de interiores: análise de luminárias comerciais. 2004. 205 p. Dissertação (Mestrado) - Escola Politécnica, Universidade de São Paulo, São Paulo, 2004.

JANNUZZI, G. de M. Aumentando a eficiência nos usos finais de energia no Brasil. Campinas: UNICAMP, 2001. Publicações. Disponível em: <http://www.fem.unicamp.br/ jannuzzi/documents/unicamp-20anos.pdf>. Acesso em: 18 novembro 2008.

JUNIOR, H. X. da S. Aplicação das metodologias de análise estatística e de análise do custo do ciclo de vida (ACCV) para o estabelecimento de padrões de eficiência energética: refrigeradores brasileiros. 2005. Dissertação (Mestrado) Programa de Pós-Graduação em Engenharia Mecânica - Universidade Estadual de Campinas, Campinas, 2005. 
LABEEE. Laboratório de Eficiência Energética em Edificações da Universidade Federal de Santa Catarina. Regulamentação para etiquetagem voluntária do nível de eficiência energética de Edifícios Comerciais, de Serviços e Públicos. pp. 58. Disponível em: <http://www.labeee.ufsc.br>. Acesso em: 18 novembro 2008.

LAMBERTS, R.; DUTRA, L. ;PEREIRA, Fernando $O$ R. Eficiência energética na arquitetura. 2. ed. São Paulo: PW editores, 2004. v. 1. 188 p.

MME. Ministério das Minas e Energia. Disponível em: <http://www.mme.gov.br>. Acesso em: 20 de novembro 2008.

MME. Ministério de Minas e Energia. Plano Nacional de Energia 2030 - PNE 2030. Brasília, 2007. 242 p.

MORALES, C. Indicadores de consumo de energia elétrica como ferramentas de apoio à gestão: classificação por prioridades de atuação na Universidade de São Paulo. 2007. 101 p. Dissertação (Mestrado) - Escola Politécnica, Universidade de São Paulo, São Paulo, 2007.

NISSOLA, E. A Influência da luz natural na probabilidade de ocorrência de ofuscamento em ambientes com terminais de vídeo - um estudo de caso. 2005. 246p. Dissertação (Mestrado) - Programa de Pós-Graduação em Arquitetura Universidade Federal de Santa Catarina, Florianópolis, 2005.

PROCEL EDIFICA. Programa Nacional de Conservação de Energia Elétrica eficiência energética em edificações. Disponível em: <http://www.labeee.ufsc.br/eletrobras/>. Acesso em: 13 janeiro 2009.

PROCEL. Programa Nacional de Conservação de Energia Elétrica. Disponível em: <http://www.procel.gov.br>. Acesso em: 10 maio 2009.

REIS, L.B. dos R; SILVEIRA, S. (Org.) Energia elétrica para o desenvolvimento sustentável. 2 ed. São Paulo: Edusp,2001. 284 p.

SANTAMOURIS, M. et al. Energy conservation and retrofitting potential in Hellenic Hotels. Energy and Buildings, vol 24, n. 1, p. 65-75, 1996. Amsterdam: Elsevier, 1996.

SILVA, M. G.; SILVA, V. G.; AGOPYAN, V. Avaliação do desempenho ambiental de edifícios: estágio atual e perspectivas para desenvolvimento no Brasil. Revista Engenharia, Ciência \& Tecnologia, v. 4, n. 3, p. 3-8, 2001. Vitória, 2001. 
SILVA, V. G. Avaliação da sustentabilidade de edifícios de escritórios brasileiros: diretrizes e base metodológica. 2007. 210 p. Tese (Doutorado) Escola Politécnica, Universidade de São Paulo, São Paulo, 2007.

SILVA, V. G. Avaliação do desempenho ambiental de edifícios. Revista Qualidade na Construção. n. 25, p.14-22, 2000.

VIEIRA, S. Análise de variância (ANOVA). 1 ed. São Paulo: Atlas,2006. 204 p.

TODD, J. A.; LINDSAY, G. Comparative assessment of GBC2000 and LEED: lessons learned for internacional and national systems. In: INTERNATIONAL CONFERENCE ON SUSTAINABLE BUILDING, 2000, Maastricht. Proceedings. p. 210-212.

TOLMASQUIM, M. T.; SZKLO, A. S. (Org.). A matriz energética brasileira na virada do milênio. Rio de Janeiro: Ed. COPPE/UFRJ Energe, 2000. 541 p.

WIEL, S.; MCMAHON, J. E. Energy-efficiency labels and standards: a guidebook CLASP for appliances, equipment, and lighting. 2 ed. Washington: CLASP, 2005. $300 \mathrm{p}$. 


\section{REFERÊNCIAS COMPLEMENTARES}

ALVAREZ, A. L. M. Uso racional e eficiente de energia elétrica: metodologia para a determinação dos potenciais de conservação dos usos finais em instalações de ensino e similares. 1998. 159p. Dissertação (Mestrado) - Escola Politécnica, Universidade de São Paulo, São Paulo, 1998.

COTRIM, A. A. M. B. Instalações elétricas. 3 ed. São Paulo. Makron Books, 1992. $887 p$.

ESTADOS UNIDOS. U.S. Department of Energy and U.S. Enverinmental Protection Agency. Model energy efficiency program impact evalution guide. Washington, 2007. 152p.

FILHO, J. M. Instalações elétricas industriais. 7 ed. Rio de Janeiro: LTC,2001. 913p.

FISHER, D. Interior Lighting. IEEE proceedings. v. 133, n. 2, p. 115-139. 1986.

GARCIA, A. G. P. Impacto da lei de eficiência energética para motores elétricos no potencial de conservação de energia na indústria. 2003. 125p. Dissertação (Mestrado) - Programa de Pós-Graduação de Engenharia da Universidade Federal do Rio de Janeiro, Rio de Janeiro, 2003.

GOULART, S.V.G; LAMBERTS, R. AET № 03/04 - Levantamento da experiência internacional - experiência nos Estados Unidos. Convênio ECV-007/2004 Eletrobras/UFSC. Florianópolis, 2005. 65p.

INATOMI, T. A. H. Análise da eficiência energética do sistema de condicionamento de ar com distribuição pelo piso em ambiente de escritório, na cidade de São Paulo, utilizando o modelo computacional Energyplus. 2008. 87p. Dissertação (Mestrado) - Escola Politécnica, Universidade de São Paulo, São Paulo, 2008.

JANNUZZI, G de M.; SWISHER, J. N. Planejamento Integrado de Recursos Energéticos: meio ambiente, conservação de energia e fontes renováveis. Campinas: Editora Autores Associados, 1997. 276 p.

LAMBERTS, R.; CARLO, J. C. Proposta de inclusão de parâmetros de eficiência energética no código de obras de Salvador. Relatório Final de Atividades. Convênio Coelba - FEESC/UFSC. Florianópolis, 2003. 16p. 
PEREIRA, F. O. R.; SOUZA M. B de. Conforto ambiental - Iluminação. Florianópolis:

UFSC. 2000. 51 p. (Apostila do curso de Pós-Graduação em Arquitetura e Urbanismo).

SIGNOR, R. Análise de regressão do consumo de energia elétrica frente a variáveis arquitetônicas para edifícios comerciais climatizados para 14 capitais brasileiras. 1999. Dissertação (Mestrado) - Programa de Pós-Graduação em Engenharia Civil - Universidade Federal de Santa Catarina, Florianópolis, 1999. 
ANEXO A

\begin{tabular}{|c|c|c|c|c|c|c|c|c|c|c|c|}
\hline \multicolumn{6}{|c|}{ K - PAVIMENTO TÉRREO } & \multicolumn{6}{|c|}{ K - PRIMEIRO PAVIMENTO } \\
\hline $\begin{array}{c}\text { número } \\
\text { da } \\
\text { amostra }\end{array}$ & K & $\begin{array}{c}\mathrm{DPI}_{\mathrm{RL}} \\
(\mathrm{NIVEL} A)\end{array}$ & $\begin{array}{c}\mathrm{DPI}_{\mathrm{RL}} \\
\text { (NIVEL B) }\end{array}$ & $\begin{array}{c}\mathrm{DPI}_{\mathrm{RL}} \\
\text { (NIVEL C) }\end{array}$ & $\begin{array}{c}\text { DPI }_{\mathrm{RL}} \\
\text { (NIVEL D) }\end{array}$ & $\begin{array}{c}\text { número } \\
\text { da } \\
\text { amostra }\end{array}$ & K & $\begin{array}{c}\text { DPI }_{\text {RL }} \\
\text { (NIVEL A) }\end{array}$ & $\begin{array}{c}\mathrm{DPI}_{\mathrm{RL}} \\
\text { (NIVEL B) }\end{array}$ & $\begin{array}{c}\text { DPI }_{\mathrm{RL}} \\
\text { (NIVEL C) }\end{array}$ & $\mid \begin{array}{c}\text { DPI }_{\mathrm{RL}} \\
\text { (NIVEL D) }\end{array}$ \\
\hline 1 & 2,83 & 1,78 & 2,31 & 2,50 & 3,22 & 1 & 1,85 & 1,90 & 2,57 & 2,80 & 3,63 \\
\hline 2 & 1,46 & 2,01 & 2,80 & 3,08 & 3,99 & 2 & 1,30 & 2,08 & 2,94 & 3,25 & 4,21 \\
\hline 3 & 0,68 & 2,68 & 4,32 & 4,81 & 6,23 & 3 & 1,03 & 2,25 & 3,33 & 3,71 & 4,79 \\
\hline 4 & 0,63 & 2,78 & 4,57 & 5,12 & 6,62 & 4 & 1,41 & 2,03 & 2,84 & 3,12 & 4,04 \\
\hline 5 & 0,68 & 2,68 & 4,32 & 4,81 & 6,23 & 5 & 0,64 & 2,76 & 4,50 & 5,03 & 6,51 \\
\hline 6 & 1,81 & 1,91 & 2,59 & 2,82 & 3,65 & 6 & 0,74 & 2,57 & 4,06 & 4,53 & 5,86 \\
\hline 7 & 0,56 & 2,95 & 5,16 & 5,92 & 7,53 & 7 & 0,62 & 2,81 & 4,66 & 5,22 & 6,74 \\
\hline 8 & 0,63 & 2,78 & 4,57 & 5,12 & 6,62 & 8 & 1,27 & 2,10 & 2,98 & 3,29 & 4,26 \\
\hline 9 & 0,48 & 3,21 & 7,05 & 9,07 & 10,58 & 9 & 0,64 & 2,76 & 4,50 & 5,03 & 6,51 \\
\hline 10 & 0,56 & 2,95 & 5,16 & 5,92 & 7,53 & 10 & 0,56 & 2,95 & 5,16 & 5,92 & 7,53 \\
\hline 11 & 2,41 & 1,81 & 2,39 & 2,60 & 3,35 & 11 & 1,39 & 2,04 & 2,85 & 3,14 & 4,07 \\
\hline 12 & 0,71 & 2,62 & 4,18 & 4,66 & 6,03 & 12 & 0,46 & 3,31 & 8,38 & 11,43 & 12,73 \\
\hline 13 & 1,56 & 1,98 & 2,73 & 2,99 & 3,87 & 13 & 0,31 & 4,27 & 11,48 & 16,39 & 22,15 \\
\hline 14 & 0,54 & 3,01 & 5,46 & 6,39 & 8,02 & 14 & 0,56 & 2,95 & 5,16 & 5,92 & 7,53 \\
\hline 15 & 0,61 & 2,82 & 4,69 & 5,26 & 6,79 & 15 & 0,51 & 3,10 & 6,00 & 7,27 & 8,88 \\
\hline 16 & 0,59 & 2,88 & 4,90 & 5,54 & 7,12 & 16 & 0,41 & 3,52 & 8,34 & 12,05 & 15,10 \\
\hline 17 & 0,75 & 2,55 & 4,01 & 4,48 & 5,79 & 17 & 0,62 & 2,81 & 4,66 & 5,22 & 6,74 \\
\hline 18 & 0,58 & 2,90 & 4,94 & 5,61 & 7,19 & 18 & 0,46 & 3,31 & 8,38 & 11,43 & 12,73 \\
\hline 19 & 0,66 & 2,72 & 4,41 & 4,92 & 6,37 & 19 & 0,48 & 3,21 & 7,05 & 9,07 & 10,58 \\
\hline 20 & 0,48 & 3,21 & 7,05 & 9,07 & 10,58 & 20 & 0,49 & 3,17 & 6,63 & 8,33 & 9,89 \\
\hline 21 & 0,64 & 2,76 & 4,50 & 5,03 & 6,51 & 21 & 0,55 & 2,98 & 5,30 & 6,13 & 7,75 \\
\hline 22 & 0,66 & 2,72 & 4,41 & 4,92 & 6,37 & 22 & 0,79 & 2,50 & 3,90 & 4,36 & 5,62 \\
\hline 23 & 0,77 & 2,53 & 3,96 & 4,42 & 5,71 & 23 & 0,63 & 2,78 & 4,57 & 5,12 & 6,62 \\
\hline 24 & 0,32 & 4,17 & 10,68 & 15,64 & 21,26 & 24 & 0,68 & 2,68 & 4,32 & 4,81 & 6,23 \\
\hline 25 & 0,33 & 4,11 & 9,27 & 14,43 & 19,05 & 25 & 0,57 & 2,94 & 5,11 & 5,85 & 7,45 \\
\hline 26 & 0,47 & 3,24 & 7,40 & 9,68 & 11,14 & 26 & 0,62 & 2,81 & 4,66 & 5,22 & 6,74 \\
\hline 27 & 1,34 & 2,06 & 2,91 & 3,21 & 4,15 & 27 & 0,69 & 2,66 & 4,27 & 4,76 & 6,16 \\
\hline 28 & 1,72 & 1,93 & 2,63 & 2,88 & 3,73 & 28 & 1,51 & 1,99 & 2,76 & 3,03 & 3,92 \\
\hline 29 & 0,24 & 5,04 & 15,76 & 21,14 & 28,81 & 29 & 0,69 & 2,66 & 4,27 & 4,76 & 6,16 \\
\hline 30 & 0,25 & 4,98 & 14,96 & 19,94 & 27,71 & 30 & 0,70 & 2,64 & 4,21 & 4,70 & 6,08 \\
\hline 31 & 0,27 & 4,66 & 13,43 & 18,14 & 24,41 & 31 & 0,99 & 2,28 & 3,40 & 3,80 & 4,90 \\
\hline \multirow[t]{14}{*}{32} & 0,21 & 5,55 & 17,11 & 23,29 & 31,03 & 32 & 0,62 & 2,81 & 4,66 & 5,22 & 6,74 \\
\hline & & & & & & 33 & 0,39 & 3,67 & 8,97 & 12,80 & 15,89 \\
\hline & & & & & & 34 & 0,88 & 2,38 & 3,64 & 4,07 & 5,24 \\
\hline & & & & & & 35 & 0,82 & 2,46 & 3,80 & 4,25 & 5,48 \\
\hline & & & & & & 36 & 0,52 & 3,08 & 5,88 & 7,07 & 8,69 \\
\hline & & & & & & 37 & 0,60 & 2,84 & 4,76 & 5,35 & 6,90 \\
\hline & & & & & & 38 & 0,58 & 2,90 & 4,94 & 5,61 & 7,19 \\
\hline & & & & & & 39 & 1,63 & 1,96 & 2,68 & 2,93 & 3,80 \\
\hline & & & & & & 40 & 0,70 & 2,64 & 4,21 & 4,70 & 6,08 \\
\hline & & & & & & 41 & 0,50 & 3,14 & 6,38 & 7,90 & 9,49 \\
\hline & & & & & & 42 & 0,53 & 3,05 & 5,66 & 6,71 & 8,33 \\
\hline & & & & & & 43 & 0,51 & 3,10 & 6,00 & 7,27 & 8,88 \\
\hline & & & & & & 44 & 0,47 & 3,24 & 7,40 & 9,68 & 11,14 \\
\hline & & & & & & 45 & 2,33 & 1,82 & 2,41 & 2,62 & 3,38 \\
\hline
\end{tabular}




\begin{tabular}{|c|c|c|c|c|c|}
\hline \multicolumn{6}{|c|}{ K - SEGUNDO PAVIMENTO } \\
\hline $\begin{array}{c}\text { número } \\
\text { da } \\
\text { amostra }\end{array}$ & K & $\begin{array}{c}\mathrm{DPI}_{\mathrm{RL}} \\
(\mathrm{NIVEL} \mathrm{A})\end{array}$ & $\begin{array}{c}\mathrm{DPI}_{\mathrm{RL}} \\
\text { (NIVEL B) }\end{array}$ & $\begin{array}{c}\mathrm{DPI}_{\mathrm{RL}} \\
\text { (NIVEL C) }\end{array}$ & $\begin{array}{c}D_{\mathrm{RI}} \\
\text { (NIVEL D) }\end{array}$ \\
\hline 1 & 1,13 & 2,17 & 3,15 & 3,51 & 4,53 \\
\hline 2 & 0,51 & 3,10 & 6,00 & 7,27 & 8,88 \\
\hline 3 & 0,88 & 2,38 & 3,64 & 4,07 & 5,24 \\
\hline 4 & 0,72 & 2,61 & 4,15 & 4,63 & 5,99 \\
\hline 5 & 0,24 & 5,04 & 15,76 & 21,14 & 28,81 \\
\hline 6 & 0,47 & 3,24 & 7,40 & 9,68 & 11,14 \\
\hline 7 & 0,31 & 4,27 & 11,48 & 16,39 & 22,15 \\
\hline 8 & 0,31 & 4,27 & 11,48 & 16,39 & 22,15 \\
\hline 9 & 0,46 & 3,31 & 8,38 & 11,43 & 12,73 \\
\hline 10 & 0,60 & 2,84 & 4,76 & 5,35 & 6,90 \\
\hline 11 & 0,48 & 3,21 & 7,05 & 9,07 & 10,58 \\
\hline 12 & 0,91 & 2,36 & 3,57 & 4,00 & 5,15 \\
\hline 13 & 0,60 & 2,84 & 4,76 & 5,35 & 6,90 \\
\hline 14 & 0,68 & 2,68 & 4,32 & 4,81 & 6,23 \\
\hline 15 & 0,98 & 2,29 & 3,41 & 3,81 & 4,91 \\
\hline 16 & 2,02 & 1,87 & 2,51 & 2,73 & 3,52 \\
\hline 17 & 0,96 & 2,31 & 3,46 & 3,87 & 4,98 \\
\hline 18 & 0,80 & 2,49 & 3,88 & 4,34 & 5,59 \\
\hline 19 & 0,38 & 3,73 & 9,20 & 13,15 & 16,18 \\
\hline 20 & 1,09 & 2,20 & 3,22 & 3,58 & 4,62 \\
\hline 21 & 1,32 & 2,07 & 2,93 & 3,23 & 4,18 \\
\hline 22 & 0,52 & 3,08 & 5,88 & 7,07 & 8,69 \\
\hline 23 & 0,57 & 2,94 & 5,11 & 5,85 & 7,45 \\
\hline 24 & 0,76 & 2,55 & 4,00 & 4,47 & 5,78 \\
\hline 25 & 0,71 & 2,62 & 4,18 & 4,66 & 6,03 \\
\hline 26 & 0,28 & 4,51 & 13,21 & 17,90 & 24,02 \\
\hline 27 & 0,50 & 3,14 & 6,38 & 7,90 & 9,49 \\
\hline 28 & 0,95 & 2,31 & 3,47 & 3,89 & 5,01 \\
\hline 29 & 0,78 & 2,51 & 3,93 & 4,39 & 5,67 \\
\hline 30 & 0,22 & 5,44 & 16,43 & 22,21 & 29,92 \\
\hline 31 & 0,65 & 2,74 & 4,45 & 4,97 & 6,44 \\
\hline 32 & 1,17 & 2,15 & 3,10 & 3,44 & 4,45 \\
\hline 33 & 0,81 & 2,47 & 3,82 & 4,28 & 5,52 \\
\hline 34 & 0,72 & 2,61 & 4,15 & 4,63 & 5,99 \\
\hline 35 & 0,62 & 2,81 & 4,66 & 5,22 & 6,74 \\
\hline 36 & 1,39 & 2,04 & 2,85 & 3,14 & 4,07 \\
\hline 37 & 0,87 & 2,39 & 3,66 & 4,10 & 5,28 \\
\hline 38 & 1,24 & 2,11 & 3,01 & 3,33 & 4,31 \\
\hline 39 & 0,88 & 2,38 & 3,64 & 4,07 & 5,24 \\
\hline 40 & 0,81 & 2,47 & 3,82 & 4,28 & 5,52 \\
\hline 41 & 1,31 & 2,07 & 2,93 & 3,23 & 4,18 \\
\hline 42 & 0,86 & 2,41 & 3,69 & 4,13 & 5,32 \\
\hline 43 & 2,43 & 1,81 & 2,39 & 2,59 & 3,34 \\
\hline
\end{tabular}

\begin{tabular}{|c|c|c|c|c|c|}
\hline \multicolumn{6}{|c|}{ K - TERCEIRO PAVIMENTO } \\
\hline $\begin{array}{c}\text { número } \\
\text { da } \\
\text { amostra }\end{array}$ & K & $\begin{array}{c}\text { DPI }_{\text {RL }} \\
\text { (NIVEL A) }\end{array}$ & $\begin{array}{c}\mathrm{DPI}_{\mathrm{RL}} \\
\text { (NIVEL B) }\end{array}$ & $\begin{array}{c}\mathrm{DPI}_{\mathrm{RL}} \\
(\text { NIVEL C) }\end{array}$ & $\begin{array}{c}\mathrm{DPI}_{\mathrm{RL}} \\
\text { (NIVEL D) }\end{array}$ \\
\hline 1 & 2,37 & 1,82 & 2,40 & 2,61 & 3,37 \\
\hline 2 & 1,23 & 2,12 & 3,02 & 3,35 & 4,33 \\
\hline 3 & 0,64 & 2,76 & 4,50 & 5,03 & 6,51 \\
\hline 4 & 0,50 & 3,14 & 6,38 & 7,90 & 9,49 \\
\hline 5 & 0,66 & 2,72 & 4,41 & 4,92 & 6,37 \\
\hline 6 & 0,31 & 4,27 & 11,48 & 16,39 & 22,15 \\
\hline 7 & 0,53 & 3,05 & 5,66 & 6,71 & 8,33 \\
\hline 8 & 0,70 & 2,64 & 4,21 & 4,70 & 6,08 \\
\hline 9 & 0,91 & 2,36 & 3,57 & 4,00 & 5,15 \\
\hline 10 & 0,92 & 2,35 & 3,55 & 3,98 & 5,12 \\
\hline 11 & 0,57 & 2,94 & 5,11 & 5,85 & 7,45 \\
\hline 12 & 0,62 & 2,81 & 4,66 & 5,22 & 6,74 \\
\hline 13 & 0,72 & 2,61 & 4,15 & 4,63 & 5,99 \\
\hline 14 & 0,69 & 2,66 & 4,27 & 4,76 & 6,16 \\
\hline 15 & 0,66 & 2,72 & 4,41 & 4,92 & 6,37 \\
\hline 16 & 1,52 & 1,99 & 2,75 & 3,02 & 3,91 \\
\hline 17 & 0,85 & 2,43 & 3,73 & 4,18 & 5,38 \\
\hline 18 & 0,81 & 2,47 & 3,82 & 4,28 & 5,52 \\
\hline 19 & 0,51 & 3,10 & 6,00 & 7,27 & 8,88 \\
\hline 20 & 0,98 & 2,29 & 3,41 & 3,81 & 4,91 \\
\hline 21 & 0,86 & 2,41 & 3,69 & 4,13 & 5,32 \\
\hline 22 & 0,65 & 2,74 & 4,45 & 4,97 & 6,44 \\
\hline 23 & 0,68 & 2,68 & 4,32 & 4,81 & 6,23 \\
\hline 24 & 0,79 & 2,50 & 3,90 & 4,36 & 5,62 \\
\hline 25 & 0,62 & 2,81 & 4,66 & 5,22 & 6,74 \\
\hline 26 & 1,06 & 2,22 & 3,27 & 3,64 & 4,70 \\
\hline 27 & 0,66 & 2,72 & 4,41 & 4,92 & 6,37 \\
\hline 28 & 0,74 & 2,57 & 4,06 & 4,53 & 5,86 \\
\hline 29 & 0,78 & 2,51 & 3,93 & 4,39 & 5,67 \\
\hline 30 & 0,67 & 2,70 & 4,35 & 4,86 & 6,29 \\
\hline 31 & 0,48 & 3,21 & 7,05 & 9,07 & 10,58 \\
\hline 32 & 0,99 & 2,28 & 3,40 & 3,80 & 4,90 \\
\hline 33 & 0,53 & 3,05 & 5,66 & 6,71 & 8,33 \\
\hline 34 & 0,72 & 2,61 & 4,15 & 4,63 & 5,99 \\
\hline 35 & 0,72 & 2,61 & 4,15 & 4,63 & 5,99 \\
\hline 36 & 0,83 & 2,44 & 3,77 & 4,22 & 5,43 \\
\hline 37 & 0,75 & 2,55 & 4,01 & 4,48 & 5,79 \\
\hline 38 & 0,38 & 3,73 & 9,20 & 13,15 & 16,18 \\
\hline 39 & 0,45 & 3,32 & 8,51 & 11,65 & 12,93 \\
\hline 40 & 0,41 & 3,52 & 8,34 & 12,05 & 15,10 \\
\hline 41 & 0,81 & 2,47 & 3,82 & 4,28 & 5,52 \\
\hline 42 & 0,60 & 2,84 & 4,76 & 5,35 & 6,90 \\
\hline 43 & 1,19 & 2,14 & 3,07 & 3,40 & 4,40 \\
\hline 44 & 0,52 & 3,08 & 5,88 & 7,07 & 8,69 \\
\hline 45 & 0,31 & 4,27 & 11,48 & 16,39 & 22,15 \\
\hline 46 & 2,04 & 1,87 & 2,50 & 2,72 & 3,51 \\
\hline
\end{tabular}




\begin{tabular}{|c|c|c|c|c|c|}
\hline \multicolumn{6}{|c|}{ K - QUARTO PAVIMENTO } \\
\hline $\begin{array}{l}\text { número } \\
\text { da } \\
\text { amostra }\end{array}$ & K & $\begin{array}{c}\mathrm{DPI}_{\mathrm{RL}} \\
\text { (NIVELA) }\end{array}$ & $\begin{array}{c}\mathrm{DPI}_{\mathrm{RL}} \\
\text { (NIVEL B) }\end{array}$ & $\begin{array}{c}\mathrm{DPI}_{\mathrm{RL}} \\
\text { (NIVEL C) }\end{array}$ & $\begin{array}{c}\mathrm{DPI}_{\mathrm{RL}} \\
\text { (NIVEL D) }\end{array}$ \\
\hline 1 & 1,05 & 2,23 & 3,29 & 3,67 & 4,73 \\
\hline 2 & 0,85 & 2,43 & 3,73 & 4,18 & 5,38 \\
\hline 3 & 0,82 & 2,46 & 3,80 & 4,25 & 5,48 \\
\hline 4 & 0,52 & 3,08 & 5,88 & 7,07 & 8,69 \\
\hline 5 & 0,61 & 2,82 & 4,69 & 5,26 & 6,79 \\
\hline 6 & 0,53 & 3,05 & 5,66 & 6,71 & 8,33 \\
\hline 7 & 0,51 & 3,10 & 6,00 & 7,27 & 8,88 \\
\hline 8 & 0,59 & 2,88 & 4,88 & 5,51 & 7,09 \\
\hline 9 & 0,90 & 2,36 & 3,59 & 4,02 & 5,18 \\
\hline 10 & 1,05 & 2,23 & 3,29 & 3,67 & 4,73 \\
\hline 11 & 1,02 & 2,25 & 3,33 & 3,72 & 4,79 \\
\hline 12 & 1,13 & 2,17 & 3,15 & 3,51 & 4,53 \\
\hline 13 & 0,50 & 3,14 & 6,38 & 7,90 & 9,49 \\
\hline 14 & 0,81 & 2,47 & 3,82 & 4,28 & 5,52 \\
\hline 15 & 0,89 & 2,37 & 3,61 & 4,04 & 5,20 \\
\hline 16 & 0,77 & 2,53 & 3,96 & 4,42 & 5,71 \\
\hline 17 & 0,85 & 2,43 & 3,73 & 4,18 & 5,38 \\
\hline 18 & 0,56 & 2,95 & 5,16 & 5,92 & 7,53 \\
\hline 19 & 0,59 & 2,88 & 4,88 & 5,51 & 7,09 \\
\hline 20 & 0,70 & 2,64 & 4,21 & 4,70 & 6,08 \\
\hline 21 & 0,93 & 2,33 & 3,52 & 3,94 & 5,07 \\
\hline 22 & 0,39 & 3,67 & 8,97 & 12,80 & 15,89 \\
\hline 23 & 0,55 & 2,98 & 5,30 & 6,13 & 7,75 \\
\hline 24 & 0,69 & 2,66 & 4,27 & 4,76 & 6,16 \\
\hline 25 & 0,71 & 2,62 & 4,18 & 4,66 & 6,03 \\
\hline 26 & 1,03 & 2,25 & 3,33 & 3,71 & 4,79 \\
\hline 27 & 0,78 & 2,51 & 3,93 & 4,39 & 5,67 \\
\hline 28 & 0,87 & 2,39 & 3,66 & 4,10 & 5,28 \\
\hline 29 & 0,28 & 4,51 & 13,21 & 17,90 & 24,02 \\
\hline 30 & 0,76 & 2,55 & 4,00 & 4,47 & 5,78 \\
\hline 31 & 0,63 & 2,78 & 4,57 & 5,12 & 6,62 \\
\hline 32 & 0,37 & 3,80 & 9,01 & 13,10 & 17,01 \\
\hline 33 & 0,64 & 2,76 & 4,50 & 5,03 & 6,51 \\
\hline 34 & 0,83 & 2,44 & 3,77 & 4,22 & 5,43 \\
\hline 35 & 0,99 & 2,28 & 3,40 & 3,80 & 4,90 \\
\hline 36 & 0,79 & 2,50 & 3,90 & 4,36 & 5,62 \\
\hline 37 & 0,61 & 2,82 & 4,69 & 5,26 & 6,79 \\
\hline 38 & 0,96 & 2,31 & 3,46 & 3,87 & 4,98 \\
\hline 39 & 0,82 & 2,46 & 3,80 & 4,25 & 5,48 \\
\hline 40 & 0,96 & 2,31 & 3,46 & 3,87 & 4,98 \\
\hline 41 & 1,03 & 2,25 & 3,33 & 3,71 & 4,79 \\
\hline 42 & 0,86 & 2,41 & 3,69 & 4,13 & 5,32 \\
\hline 43 & 0,55 & 2,98 & 5,30 & 6,13 & 7,75 \\
\hline 44 & 0,75 & 2,55 & 4,01 & 4,48 & 5,79 \\
\hline 45 & 1,08 & 2,21 & 3,23 & 3,60 & 4,65 \\
\hline 46 & 1,03 & 2,25 & 3,33 & 3,71 & 4,79 \\
\hline 47 & 0,64 & 2,76 & 4,50 & 5,03 & 6,51 \\
\hline 48 & 0,66 & 2,72 & 4,41 & 4,92 & 6,37 \\
\hline 49 & 0,62 & 2,81 & 4,66 & 5,22 & 6,74 \\
\hline 50 & 0,51 & 3,10 & 6,00 & 7,27 & 8,88 \\
\hline 51 & 0,70 & 2,64 & 4,21 & 4,70 & 6,08 \\
\hline 52 & 0,49 & 3,17 & 6,63 & 8,33 & 9,89 \\
\hline 53 & 0,31 & 4,27 & 11,48 & 16,39 & 22,15 \\
\hline 54 & 0,31 & 4,27 & 11,48 & 16,39 & 22,15 \\
\hline 55 & 2,29 & 1,83 & 2,42 & 2,63 & 3,40 \\
\hline
\end{tabular}

K - QUINTO PAVIMENTO

\begin{tabular}{|c|c|c|c|c|c|}
\hline $\begin{array}{c}\text { número } \\
\text { da } \\
\text { amostra }\end{array}$ & K & $\begin{array}{c}\mathrm{DPI}_{\mathrm{RL}} \\
(\mathrm{NIVEL} A)\end{array}$ & $\begin{array}{c}\mathrm{DPI}_{\mathrm{RL}} \\
(\mathrm{NIVEL} \mathrm{B})\end{array}$ & $\begin{array}{c}\mathrm{DPI}_{\mathrm{RL}} \\
(\mathrm{NIVEL} \mathrm{C})\end{array}$ & $\begin{array}{c}\mathrm{DPI}_{\mathrm{RL}} \\
(\mathrm{NIVEL} \mathrm{D})\end{array}$ \\
\hline 1 & 1,18 & 2,15 & 3,09 & 3,43 & 4,43 \\
\hline 2 & 1,09 & 2,20 & 3,22 & 3,58 & 4,62 \\
\hline 3 & 0,72 & 2,61 & 4,15 & 4,63 & 5,99 \\
\hline 4 & 0,63 & 2,78 & 4,57 & 5,12 & 6,62 \\
\hline 5 & 0,64 & 2,76 & 4,50 & 5,03 & 6,51 \\
\hline 6 & 0,41 & 3,52 & 8,34 & 12,05 & 15,10 \\
\hline 7 & 1,03 & 2,25 & 3,33 & 3,71 & 4,79 \\
\hline 8 & 0,90 & 2,36 & 3,59 & 4,02 & 5,18 \\
\hline 9 & 1,92 & 1,89 & 2,54 & 2,77 & 3,58 \\
\hline 10 & 1,40 & 2,04 & 2,85 & 3,14 & 4,06 \\
\hline 11 & 0,64 & 2,76 & 4,50 & 5,03 & 6,51 \\
\hline 12 & 1,16 & 2,15 & 3,11 & 3,45 & 4,46 \\
\hline 13 & 1,97 & 1,88 & 2,52 & 2,75 & 3,55 \\
\hline 14 & 0,44 & 3,37 & 9,30 & 13,09 & 14,21 \\
\hline 15 & 0,70 & 2,64 & 4,21 & 4,70 & 6,08 \\
\hline 16 & 0,87 & 2,39 & 3,66 & 4,10 & 5,28 \\
\hline 17 & 1,08 & 2,21 & 3,23 & 3,60 & 4,65 \\
\hline 18 & 0,74 & 2,57 & 4,06 & 4,53 & 5,86 \\
\hline 19 & 0,86 & 2,41 & 3,69 & 4,13 & 5,32 \\
\hline 20 & 0,64 & 2,76 & 4,50 & 5,03 & 6,51 \\
\hline 21 & 0,54 & 3,01 & 5,46 & 6,39 & 8,02 \\
\hline 22 & 1,13 & 2,17 & 3,15 & 3,51 & 4,53 \\
\hline 23 & 0,61 & 2,82 & 4,69 & 5,26 & 6,79 \\
\hline 24 & 0,61 & 2,82 & 4,69 & 5,26 & 6,79 \\
\hline 25 & 0,69 & 2,66 & 4,27 & 4,76 & 6,16 \\
\hline 26 & 0,71 & 2,62 & 4,18 & 4,66 & 6,03 \\
\hline 27 & 0,96 & 2,31 & 3,46 & 3,87 & 4,98 \\
\hline 28 & 0,39 & 3,67 & 8,97 & 12,80 & 15,89 \\
\hline 29 & 0,76 & 2,55 & 4,00 & 4,47 & 5,78 \\
\hline 30 & 0,75 & 2,55 & 4,01 & 4,48 & 5,79 \\
\hline 31 & 0,28 & 4,51 & 13,21 & 17,90 & 24,02 \\
\hline 32 & 1,57 & 1,97 & 2,72 & 2,98 & 3,86 \\
\hline 33 & 1,25 & 2,11 & 3,00 & 3,32 & 4,30 \\
\hline 34 & 0,65 & 2,74 & 4,45 & 4,97 & 6,44 \\
\hline 35 & 0,31 & 4,27 & 11,48 & 16,39 & 22,15 \\
\hline 36 & 0,35 & 3,91 & 9,06 & 13,41 & 18,14 \\
\hline 37 & 1,79 & 1,92 & 2,60 & 2,84 & 3,67 \\
\hline
\end{tabular}




\begin{tabular}{|c|c|c|c|c|c|}
\hline \multicolumn{7}{|c|}{ K - SEXTO PAVIMENTO } \\
\hline $\begin{array}{c}\text { número } \\
\text { da } \\
\text { amostra }\end{array}$ & $\mathrm{K}$ & $\begin{array}{c}\text { DPI }_{\text {RL }} \\
\text { (NIVEL A) }\end{array}$ & $\begin{array}{c}\text { DPI }_{\text {RL }} \\
\text { (NIVEL B) }\end{array}$ & $\begin{array}{c}\text { DPI }_{\text {RL }} \\
\text { (NIVEL C) }\end{array}$ & $\begin{array}{c}\text { DPI }_{\text {RL }} \\
\text { (NIVEL D) }\end{array}$ \\
\hline 1 & 1,48 & 2,00 & 2,78 & 3,05 & 3,95 \\
\hline 2 & 0,75 & 2,55 & 4,01 & 4,48 & 5,79 \\
\hline 3 & 0,92 & 2,35 & 3,55 & 3,98 & 5,12 \\
\hline 4 & 1,28 & 2,09 & 2,96 & 3,28 & 4,24 \\
\hline 5 & 1,19 & 2,14 & 3,07 & 3,40 & 4,40 \\
\hline 6 & 3,15 & 1,76 & 2,26 & 2,45 & 3,14 \\
\hline 7 & 0,39 & 3,67 & 8,97 & 12,80 & 15,89 \\
\hline 8 & 0,70 & 2,64 & 4,21 & 4,70 & 6,08 \\
\hline 9 & 0,65 & 2,74 & 4,45 & 4,97 & 6,44 \\
\hline 10 & 2,61 & 1,79 & 2,35 & 2,55 & 3,28 \\
\hline 11 & 0,66 & 2,72 & 4,41 & 4,92 & 6,37 \\
\hline 12 & 0,66 & 2,72 & 4,41 & 4,92 & 6,37 \\
\hline 13 & 0,34 & 3,96 & 9,18 & 14,16 & 18,68 \\
\hline 14 & 0,30 & 4,36 & 12,34 & 17,14 & 23,08 \\
\hline 15 & 0,55 & 2,98 & 5,30 & 6,13 & 7,75 \\
\hline 16 & 0,60 & 2,84 & 4,76 & 5,35 & 6,90 \\
\hline 17 & 0,56 & 2,95 & 5,16 & 5,92 & 7,53 \\
\hline 18 & 0,71 & 2,62 & 4,18 & 4,66 & 6,03 \\
\hline 19 & 3,02 & 1,76 & 2,28 & 2,47 & 3,17 \\
\hline
\end{tabular}


PRIMEIRO ESTUDO - LEVANTAMENTO DE DADOS - TÉRREO

\begin{tabular}{|c|c|c|c|c|c|c|c|c|c|c|c|c|c|c|c|c|c|c|c|}
\hline $\begin{array}{c}\text { número } \\
\text { da } \\
\text { amostra }\end{array}$ & $\begin{array}{c}\text { tipo de } \\
\text { ambiente }\end{array}$ & $\begin{array}{c}\text { comprimento } \\
(\mathrm{m})\end{array}$ & $\begin{array}{c}\text { largura } \\
(\mathrm{m})\end{array}$ & $\begin{array}{l}\text { área } \\
\left(\mathrm{m}^{2}\right)\end{array}$ & $\begin{array}{l}\text { altura média } \\
(\mathrm{m})\end{array}$ & $\mathrm{K}$ & $\begin{array}{l}\text { qtd lum } \\
4 \times 40 W\end{array}$ & $\begin{array}{l}\text { qtd lum } \\
3 \times 40 \mathrm{~W}\end{array}$ & $\begin{array}{c}\text { gtd lum } \\
2 \times 40 \mathrm{~W}\end{array}$ & \begin{tabular}{|} 
qtd lum \\
$2 \times 32 W$
\end{tabular} & $\begin{array}{l}\text { qtd lum } \\
3 \times 20 W\end{array}$ & $\begin{array}{l}\text { qtd lum } \\
2 \times 20 \mathrm{~W}\end{array}$ & $\begin{array}{l}\text { qtd lum } \\
1 \times 20 W\end{array}$ & $\begin{array}{l}\text { qtd lum } \\
\text { inc } \\
1 \times 60 \mathrm{~W}\end{array}$ & $\begin{array}{l}\text { potência } \\
\text { total (W) }\end{array}$ & $\begin{array}{c}\text { densidade } \\
\left(\mathrm{W} / \mathrm{m}^{2}\right)\end{array}$ & \begin{tabular}{|l|} 
ilum \\
(Lux)
\end{tabular} & $\mathrm{DPI}_{\mathrm{RF}}$ & $\begin{array}{c}\text { nível de } \\
\text { eficiência }\end{array}$ \\
\hline 1 & escritório & 24,05 & 11,80 & 283,79 & 2,80 & 2,83 & 0,00 & 16,00 & 0,00 & 0,00 & 0,00 & 0,00 & 0,00 & 0,00 & \begin{tabular}{|l|}
2304,00 \\
\end{tabular} & 8,12 & 242,00 & 3,35 & $\mathrm{E}$ \\
\hline 2 & escritório & 9,10 & 7,38 & 67,16 & 2,80 & 1,46 & 0,00 & 9,00 & 0,00 & 0,00 & 0,00 & 0,00 & 0,00 & 0,00 & \begin{tabular}{|l|}
1296,00 \\
\end{tabular} & 19,30 & 397,00 & 4,86 & $\mathrm{E}$ \\
\hline 3 & escritório & 6,06 & 2,75 & 16,67 & 2,80 & 0,68 & 0,00 & 4,00 & 0,00 & 0,00 & 0,00 & 0,00 & 0,00 & 0,00 & 576,00 & 34,56 & 477,00 & 7,25 & $\mathrm{E}$ \\
\hline 4 & escritório & 6,06 & 2,51 & 15,21 & 2,80 & 0,63 & 0,00 & 2,00 & 0,00 & 0,00 & 0,00 & 0,00 & 0,00 & 0,00 & 288,00 & 18,93 & 255,00 & 7,43 & $\mathrm{E}$ \\
\hline 5 & escritório & 6,47 & 2,70 & 17,47 & 2,80 & 0,68 & 0,00 & 2,00 & 0,00 & 0,00 & 0,00 & 0,00 & 0,00 & 0,00 & 288,00 & 16,49 & 238,00 & 6,93 & $\mathrm{E}$ \\
\hline 6 & escritório & 16,75 & 7,29 & 122,11 & 2,80 & 1,81 & 0,00 & 10,00 & 0,00 & 0,00 & 2,00 & 0,00 & 0,00 & 0,00 & 1584,00 & 12,97 & 285,00 & 4,55 & $E$ \\
\hline 7 & escritório & 7,78 & 1,97 & 15,33 & 2,80 & 0,56 & 2,00 & 0,00 & 0,00 & 0,00 & 0,00 & 0,00 & 0,00 & 0,00 & 307,20 & 20,04 & 305,00 & 6,57 & D \\
\hline 8 & circulação & 25,00 & 1,89 & 47,25 & 2,80 & 0,63 & 0,00 & 1,00 & 0,00 & 0,00 & 0,00 & 0,00 & 0,00 & 0,00 & 144,00 & 3,05 & \begin{tabular}{|l|}
42,00 \\
\end{tabular} & 7,26 & $\mathrm{E}$ \\
\hline 9 & depósito & 3,75 & 2,10 & 7,88 & 2,80 & 0,48 & 0,00 & 1,00 & 0,00 & 0,00 & 0,00 & 0,00 & 0,00 & 0,00 & 144,00 & 18,29 & 188,00 & 9,73 & D \\
\hline 10 & escritório & 3,30 & 3,00 & 9,90 & 2,80 & 0,56 & 0,00 & 2,00 & 0,00 & 0,00 & 0,00 & 0,00 & 0,00 & 0,00 & 288,00 & 29,09 & 344,00 & 8,46 & $\mathrm{E}$ \\
\hline 11 & escritório & 21,13 & 9,94 & 210,03 & 2,80 & 2,41 & 13,00 & 0,00 & 0,00 & 0,00 & 0,00 & 0,00 & 0,00 & 0,00 & \begin{tabular}{|l|}
1996,80 \\
\end{tabular} & 9,51 & 326,00 & 2,92 & $\mathrm{D}$ \\
\hline 12 & depósito & 5,38 & 3,14 & 16,89 & 2,80 & 0,71 & 0,00 & 2,00 & 0,00 & 0,00 & 0,00 & 0,00 & 0,00 & 0,00 & 288,00 & 17,05 & 256,00 & 6,66 & $\mathrm{E}$ \\
\hline 13 & depósito & 9,05 & 8,40 & 76,02 & 2,80 & 1,56 & 0,00 & 9,00 & 0,00 & 0,00 & 0,00 & 0,00 & 0,00 & 0,00 & 1296,00 & 17,05 & 384,00 & 4,44 & $\mathrm{E}$ \\
\hline 14 & circulação & 5,75 & 2,05 & 11,79 & 2,80 & 0,54 & 0,00 & 2,00 & 0,00 & 0,00 & 0,00 & 0,00 & 0,00 & 0,00 & 288,00 & 24,43 & 192,00 & 12,73 & $\mathrm{E}$ \\
\hline 15 & escritório & 4,17 & 2,90 & 12,09 & 2,80 & 0,61 & 0,00 & 0,00 & 0,00 & 0,00 & 0,00 & 0,00 & 0,00 & 1,00 & 60,00 & 4,96 & 41,00 & 12,10 & $\mathrm{E}$ \\
\hline 16 & escritório & 4,17 & 2,7 & 11,26 & 2,80 & 0,59 & 0,00 & 0,00 & 0,00 & 0,00 & 0,00 & 0,00 & 0,00 & 1,00 & 60,00 & 5,33 & 46,00 & 11,58 & $\mathrm{E}$ \\
\hline 17 & escritório & 6,37 & 3,15 & 20,07 & 2,80 & 0,75 & 0,00 & 0,00 & 0,00 & 0,00 & 0,00 & 0,00 & 0,00 & 1,00 & 60,00 & 2,99 & 30,00 & 9,97 & $\mathrm{E}$ \\
\hline 18 & circulação & 4,65 & 2,5 & 11,63 & 2,80 & 0,58 & 0,00 & 1,00 & 0,00 & 0,00 & 0,00 & 0,00 & 0,00 & 0,00 & 144,00 & 12,39 & 161,00 & 7,69 & $\mathrm{E}$ \\
\hline 19 & escritório & 5,75 & 2,7 & 15,53 & 2,80 & 0,66 & 0,00 & 0,00 & 0,00 & 0,00 & 2,00 & 0,00 & 0,00 & 0,00 & 144,00 & 9,28 & 138,00 & 6,72 & $\mathrm{E}$ \\
\hline 20 & circulação & 5,9 & 1,75 & 10,33 & 2,80 & 0,48 & 0,00 & 0,00 & 0,00 & 0,00 & 1,00 & 0,00 & 0,00 & 0,00 & 72,00 & 6,97 & 24,00 & 29,06 & $\mathrm{E}$ \\
\hline 21 & banheiro & 5,75 & 2,6 & 14,95 & 2,80 & 0,64 & 0,00 & 0,00 & 0,00 & 0,00 & 2,00 & 0,00 & 0,00 & 0,00 & 144,00 & 9,63 & 148,00 & 6,51 & D \\
\hline 22 & escritório & 5,75 & 2,7 & 15,53 & 2,80 & 0,66 & 0,00 & 2,00 & 0,00 & 0,00 & 0,00 & 0,00 & 0,00 & 0,00 & 288,00 & 18,55 & 259,00 & 7,16 & $\mathrm{E}$ \\
\hline 23 & escritório & 7,35 & 3,05 & 22,42 & 2,80 & 0,77 & 0,00 & 2,00 & 0,00 & 0,00 & 0,00 & 0,00 & 0,00 & 0,00 & 288,00 & 12,85 & 208,00 & 6,18 & $\mathrm{E}$ \\
\hline 24 & banheiro & 2,6 & 1,35 & 3,51 & 2,80 & 0,32 & 0,00 & 0,00 & 0,00 & 0,00 & 1,00 & 0,00 & 0,00 & 0,00 & 72,00 & 20,51 & 128,00 & 16,03 & $\mathrm{D}$ \\
\hline 25 & banheiro & 2,6 & 1,4 & 3,64 & 2,80 & 0,33 & 0,00 & 0,00 & 0,00 & 0,00 & 1,00 & 0,00 & 0,00 & 0,00 & 72,00 & 19,78 & 127,00 & 15,57 & $\mathrm{D}$ \\
\hline 26 & escritório & 2,7 & 2,6 & 7,02 & 2,80 & 0,47 & 0,00 & 1,00 & 0,00 & 0,00 & 0,00 & 0,00 & 0,00 & 0,00 & 144,00 & 20,51 & 215,00 & 9,54 & C \\
\hline 27 & depósito & 9,05 & 6,37 & 57,65 & 2,80 & 1,34 & 0,00 & 0,00 & 0,00 & 0,00 & 3,00 & 0,00 & 0,00 & 0,00 & 216,00 & 3,75 & 101,00 & 3,71 & D \\
\hline 28 & circulação & 10,54 & 8,83 & 93,07 & 2,80 & 1,72 & 0,00 & 0,00 & 0,00 & 0,00 & 0,00 & 0,00 & 0,00 & 29,00 & 1740,00 & 18,70 & 192,00 & 9,74 & $\mathrm{E}$ \\
\hline 29 & banheiro & 2,8 & 0,9 & 2,52 & 2,80 & 0,24 & 0,00 & 0,00 & 0,00 & 0,00 & 0,00 & 0,00 & 0,00 & 1,00 & 60,00 & 23,81 & 127,00 & 18,75 & C \\
\hline 30 & depósito & 3 & 0,9 & 2,70 & 2,80 & 0,25 & 0,00 & 0,00 & 0,00 & 0,00 & 0,00 & 0,00 & 0,00 & 1,00 & 60,00 & 22,22 & 124,00 & 17,92 & C \\
\hline 31 & banheiro & 2,46 & 1,77 & 4,35 & 3,80 & 0,27 & 0,00 & 0,00 & 1,00 & 0,00 & 0,00 & 0,00 & 0,00 & 0,00 & 96,00 & 22,05 & 127,00 & 17,36 & C \\
\hline 32 & banheiro & 2,44 & 1,77 & 4,32 & 4,80 & 0,21 & 0,00 & 0,00 & 1,00 & 0,00 & 0,00 & 0,00 & 0,00 & 0,00 & 96,00 & 22,23 & 127,00 & 17,50 & C \\
\hline
\end{tabular}


PRIMEIRO ESTUDO - LEVANTAMENTO DE DADOS - PRIMEIRO PAVIMENTO

\begin{tabular}{|c|c|c|c|c|c|c|c|c|c|c|c|c|c|c|c|c|c|c|c|}
\hline $\begin{array}{c}\text { número } \\
\text { da } \\
\text { amostra }\end{array}$ & \begin{tabular}{|c|} 
tipo de \\
ambiente
\end{tabular} & $\begin{array}{c}\text { comprimento } \\
(\mathrm{m})\end{array}$ & $\begin{array}{l}\text { largura } \\
\text { (m) }\end{array}$ & $\begin{array}{l}\text { área } \\
\left(\mathrm{m}^{2}\right)\end{array}$ & $\begin{array}{l}\text { altura média } \\
(\mathrm{m})\end{array}$ & K & $\begin{array}{l}\text { qtd lum } \\
4 \times 40 \mathrm{~W}\end{array}$ & $\begin{array}{l}\text { qtd lum } \\
3 \times 40 \mathrm{~W}\end{array}$ & $\begin{array}{l}\text { qtd lum } \\
2 \times 40 \mathrm{~W}\end{array}$ & \begin{tabular}{|l|} 
atd lum \\
$2 \times 32 \mathrm{~W}$
\end{tabular} & $\begin{array}{l}\text { qtd lum } \\
3 \times 20 \mathrm{~W}\end{array}$ & $\begin{array}{l}\text { qtd lum } \\
2 \times 20 \mathrm{~W}\end{array}$ & $\begin{array}{c}\text { qtd lum } \\
1 \times 20 \mathrm{~W}\end{array}$ & $\begin{array}{c}\text { atd lum } \\
\text { inc } \\
1 \times 60 \mathrm{~W}\end{array}$ & $\begin{array}{l}\text { potência } \\
\text { total }(W)\end{array}$ & $\begin{array}{c}\text { densidade } \\
\left(\mathrm{W} / \mathrm{m}^{2}\right)\end{array}$ & $\begin{array}{l}\text { ilum } \\
\text { (Lux) }\end{array}$ & $\mathrm{DPI}_{\mathrm{RF}}$ & \begin{tabular}{|c} 
nível de \\
eficiência
\end{tabular} \\
\hline 1 & \begin{tabular}{|l|l} 
escritório \\
\end{tabular} & 11,88 & 9,20 & 109,30 & 2,80 & 1,85 & 0,00 & 0,00 & 0,00 & 16,00 & 0,00 & 0,00 & 0,00 & 0,00 & 1072,00 & 9,81 & 461 & 2,13 & $B$ \\
\hline 2 & escritório & 8,85 & 6,19 & 54,78 & 2,80 & 1,30 & 0,00 & 0,00 & 0,00 & 15,00 & 0,00 & 0,00 & 0,00 & 0,00 & 1005,00 & 18,35 & 781 & 2,35 & $B$ \\
\hline 3 & \begin{tabular}{|l|l} 
escritório \\
\end{tabular} & 8,80 & 4,27 & 37,58 & 2,80 & 1,03 & 0,00 & 0,00 & 0,00 & 9,00 & 0,00 & 0,00 & 0,00 & 0,00 & 603,00 & 16,05 & 631 & \begin{tabular}{|l|}
2,54 \\
\end{tabular} & $B$ \\
\hline 4 & \begin{tabular}{|l|l|} 
escritório \\
\end{tabular} & 11,78 & 5,95 & 70,09 & 2,80 & 1,41 & 0,00 & 0,00 & 0,00 & 10,00 & 0,00 & 0,00 & 0,00 & 0,00 & 670,00 & 9,56 & 418 & \begin{tabular}{|l|}
2,29 \\
\end{tabular} & $B$ \\
\hline 5 & \begin{tabular}{|l|l} 
escritório \\
\end{tabular} & 4,70 & 2,90 & 13,63 & 2,80 & 0,64 & 0,00 & 0,00 & 0,00 & 2,00 & 0,00 & 0,00 & 0,00 & 0,00 & 134,00 & 9,83 & 311 & \begin{tabular}{|l|}
3,16 \\
\end{tabular} & $B$ \\
\hline 6 & escritório & 4,70 & 3,70 & 17,39 & 2,80 & 0,74 & 0,00 & 0,00 & 0,00 & 2,00 & 0,00 & 0,00 & 0,00 & 0,00 & 134,00 & 7,71 & 263 & \begin{tabular}{|l|}
2,93 \\
\end{tabular} & $B$ \\
\hline 7 & banheiro & 4,70 & 2,73 & 12,83 & 2,80 & 0,62 & 0,00 & 0,00 & 0,00 & 1,00 & 0,00 & 0,00 & 0,00 & 1,00 & 127,00 & 9,90 & 162 & \begin{tabular}{|l|}
6,11 \\
\end{tabular} & D \\
\hline 8 & escritório & 7,73 & 6,56 & 50,71 & 2,80 & 1,27 & 0,00 & 0,00 & 0,00 & 7,00 & 0,00 & 0,00 & 0,00 & 0,00 & 469,00 & 9,25 & 337 & \begin{tabular}{|l|}
2,74 \\
\end{tabular} & $B$ \\
\hline 9 & \begin{tabular}{|l|l} 
escritório \\
\end{tabular} & 4,19 & 3,10 & 12,99 & 2,80 & 0,64 & 0,00 & 0,00 & 0,00 & 1,00 & 0,00 & 0,00 & 0,00 & 0,00 & 67,00 & 5,16 & 163 & \begin{tabular}{|l|}
3,16 \\
\end{tabular} & $B$ \\
\hline 10 & escritório & 3,34 & 2,93 & 9,79 & 2,80 & 0,56 & 0,00 & 0,00 & 0,00 & 2,00 & 0,00 & 0,00 & 0,00 & 0,00 & 134,00 & 13,69 & 406 & \begin{tabular}{|l|}
3,37 \\
\end{tabular} & $B$ \\
\hline 11 & escritório & 8,22 & 7,43 & 61,07 & 2,80 & 1,39 & 0,00 & 3,00 & 0,00 & 0,00 & 4,00 & 0,00 & 0,00 & 0,00 & 720,00 & 11,79 & 179 & \begin{tabular}{|l|}
6,59 \\
\end{tabular} & $E$ \\
\hline 12 & escritório & 4,02 & 1,87 & 7,52 & 2,80 & 0,46 & 0,00 & 0,00 & 0,00 & 0,00 & 1,00 & 0,00 & 0,00 & 0,00 & 72,00 & 9,58 & 104 & \begin{tabular}{|l|}
9,21 \\
\end{tabular} & C \\
\hline 13 & banheiro & 2,75 & 1,25 & 3,44 & 2,80 & 0,31 & 0,00 & 0,00 & 0,00 & 0,00 & 0,00 & 0,00 & 2,00 & 0,00 & 48,00 & 13,96 & 57 & 24,50 & $E$ \\
\hline 14 & escritório & 3,95 & 2,62 & 10,35 & 2,80 & 0,56 & 0,00 & 0,00 & 1,00 & 0,00 & 0,00 & 0,00 & 0,00 & 0,00 & 96,00 & 9,28 & 98 & \begin{tabular}{|l|l|}
9,47 \\
\end{tabular} & $E$ \\
\hline 15 & escritório & 2,95 & 2,80 & 8,26 & 2,80 & 0,51 & 0,00 & 0,00 & 1,00 & 0,00 & 0,00 & 0,00 & 0,00 & 0,00 & 96,00 & 11,62 & 110 & \begin{tabular}{|l|l|}
10,57 \\
\end{tabular} & $E$ \\
\hline 16 & escritório & 2,65 & 2,05 & 5,43 & 2,80 & 0,41 & 0,00 & 0,00 & 1,00 & 0,00 & 0,00 & 0,00 & 0,00 & 0,00 & 96,00 & 17,67 & 124 & \begin{tabular}{|l|}
14,25 \\
\end{tabular} & $\mathrm{D}$ \\
\hline 17 & escritório & 4,9 & 2,7 & 13,23 & 2,80 & 0,62 & 0,00 & 0,00 & 2,00 & 0,00 & 0,00 & 0,00 & 0,00 & 0,00 & 192,00 & 14,51 & 162 & 8,96 & $E$ \\
\hline 18 & depósito & 4,2 & 1,85 & 7,77 & 2,80 & 0,46 & 0,00 & 0,00 & 1,00 & 0,00 & 0,00 & 0,00 & 0,00 & 0,00 & 96,00 & 12,36 & 100 & 12,36 & D \\
\hline 19 & depósito & 4,2 & 2 & 8,40 & 2,80 & 0,48 & 0,00 & 0,00 & 1,00 & 0,00 & 0,00 & 0,00 & 0,00 & 0,00 & 96,00 & 11,43 & 99 & \begin{tabular}{|l|}
11,54 \\
\end{tabular} & $E$ \\
\hline 20 & banheiro & 4 & 2,1 & 8,40 & 2,80 & 0,49 & 0,00 & 0,00 & 1,00 & 0,00 & 0,00 & 0,0 & 0,0 & 0,00 & 96,00 & 11, & 102 & \begin{tabular}{|l|l|}
11,20 \\
\end{tabular} & $E$ \\
\hline 21 & banheiro & 3,9 & 2,55 & 9,95 & 2,80 & 0,55 & 0,00 & 0,00 & 0,00 & 0,00 & 1,00 & 0,00 & 0,00 & 2,00 & 192,00 & 19,31 & 273 & \begin{tabular}{|l|}
7,07 \\
\end{tabular} & D \\
\hline 22 & escritório & 5,08 & 3,9 & 19,81 & 2,80 & 0,79 & 0,00 & 0,00 & 0,00 & 0,00 & 1,00 & 0,00 & 0,00 & 0,00 & 72,00 & 3,63 & 75 & 4,85 & $\mathrm{D}$ \\
\hline 23 & \begin{tabular}{|l|l} 
escritório \\
\end{tabular} & 3,9 & 3,24 & 12,64 & 2,80 & 0,63 & 0,00 & 0,00 & 0,00 & 0,00 & 3,00 & 0,00 & 0,00 & 0,00 & 216,00 & 17,09 & 252 & \begin{tabular}{|l|}
6,78 \\
\end{tabular} & $E$ \\
\hline 24 & \begin{tabular}{|l|l} 
escritório \\
\end{tabular} & 3,9 & 3,67 & 14,31 & 2,80 & 0,68 & 0,00 & 0,00 & 0,00 & 0,00 & 2,00 & 0,00 & 0,00 & 0,00 & 144,00 & 10,06 & 162 & 6,21 & $\mathrm{D}$ \\
\hline 25 & depósito & 3,64 & 2,8 & 10,19 & 2,80 & 0,57 & 0,00 & 0,00 & 0,00 & 0,00 & 1,00 & 0,00 & 0,00 & 0,00 & 72,00 & 7,06 & 100 & 7,06 & $\mathrm{D}$ \\
\hline 26 & \begin{tabular}{|l|l} 
escritório \\
\end{tabular} & 3,64 & 3,27 & 11,90 & 2,80 & 0,62 & 0,00 & 0,00 & 0,00 & 0,00 & 1,00 & 0,00 & 0,00 & 0,00 & 72,00 & 6,05 & 97 & \begin{tabular}{|l|}
6,24 \\
\end{tabular} & D \\
\hline 27 & escritório & 6,12 & 2,8 & 17,14 & 2,80 & 0,69 & 0,00 & 0,00 & 0,00 & 0,00 & 3,00 & 0,00 & 0,00 & 0,00 & 216,00 & 12,61 & 191 & \begin{tabular}{|l|}
6,60 \\
\end{tabular} & $E$ \\
\hline 28 & \begin{tabular}{|l|l} 
escritório \\
\end{tabular} & 11,4 & 6,75 & 76,95 & 2,80 & 1,51 & 0,00 & 0,00 & 0,00 & 0,00 & 16,00 & 0,00 & 0,00 & 0,00 & 1152,00 & 14,97 & 359 & \begin{tabular}{|l|l|}
4,17 \\
\end{tabular} & $E$ \\
\hline 29 & \begin{tabular}{|l|l} 
escritório \\
\end{tabular} & 6,12 & 2,8 & 17,14 & 2,80 & 0,69 & 0,00 & 0,00 & 0,00 & 0,00 & 3,00 & 0,00 & 0,00 & 0,00 & 216,00 & 12,61 & 191 & \begin{tabular}{|l|}
6,60 \\
\end{tabular} & $\mathrm{E}$ \\
\hline 30 & \begin{tabular}{|l|l} 
escritório \\
\end{tabular} & 6,12 & 2,9 & 17,75 & 2,80 & 0,70 & 0,00 & 0,00 & 0,00 & 0,00 & 3,00 & 0,00 & 0,00 & 0,00 & 216,00 & 12,17 & 189 & \begin{tabular}{|l|l|}
6,44 \\
\end{tabular} & $E$ \\
\hline 31 & \begin{tabular}{|l|l} 
escritório \\
\end{tabular} & 5,65 & 5,4 & 30,51 & 2,80 & 0,99 & 0,00 & 0,00 & 0,00 & 0,00 & 4,00 & 0,00 & 0,00 & 0,00 & 288,00 & 9,44 & 192 & \begin{tabular}{|l|}
4,92 \\
\end{tabular} & $E$ \\
\hline 32 & \begin{tabular}{|l|l} 
escritório \\
\end{tabular} & s & 2,49 & 14,19 & 2,80 & 0,62 & 0,00 & 0,00 & 0,00 & 0,00 & 2,0 & 0, & 0,00 & 0,00 & 144,00 & & 151 & \begin{tabular}{|l|l|}
6,72 \\
\end{tabular} & $\mathrm{D}$ \\
\hline 33 & circulação & 10,78 & 1,2 & 12,94 & 2,80 & 0,39 & 0,00 & 0,00 & 0,00 & 0,00 & 1,00 & 0,00 & 0,00 & 0,00 & 72,00 & 5,57 & 49 & 11,36 & c \\
\hline 34 & escritório & 5,73 & 4,34 & 24,87 & 2,80 & 0,88 & 0,00 & 0,00 & 0,00 & 0,00 & 4,00 & 0,00 & 0,00 & 0,00 & 288,00 & 11,58 & 217 & \begin{tabular}{|l|}
5,34 \\
\end{tabular} & $\mathrm{E}$ \\
\hline 35 & escritório & 5,67 & 3,87 & 21,94 & 2,80 & 0,82 & 0,00 & 0,00 & 0,00 & 0,00 & 4,00 & 0,00 & 0,00 & 0,00 & 288,00 & 13,12 & 233 & \begin{tabular}{|l|}
5,63 \\
\end{tabular} & $E$ \\
\hline 36 & escritório & 3,22 & 2,64 & 8,50 & 2,80 & 0,52 & 0,00 & 0,00 & 0,00 & 0,00 & 1,00 & 0,00 & 0,00 & 0,00 & 72,00 & 8,47 & 109 & 7,77 & $\mathrm{D}$ \\
\hline 37 & escritório & 3, & 3,23 & 111,37 & 2,80 & 0,60 & 0,00 & 0,00 & 0,00 & 0,00 & 1,00 & 0,00 & 0,00 & 0,00 & 72,00 & 6,33 & 98 & 6,46 & D \\
\hline 38 & escritório & 3,27 & 3,23 & 10,56 & 2,80 & 0,58 & 0,00 & 0,00 & 0,00 & 0,00 & 1,00 & 0,00 & 0,00 & 0,00 & 72,00 & 6,82 & 101 & \begin{tabular}{|l|}
6,75 \\
\end{tabular} & D \\
\hline 39 & \begin{tabular}{|l|l} 
escritório \\
\end{tabular} & 10,68 & 8 & 85,44 & 2,80 & 1,63 & 0,00 & 0,00 & 0,00 & 0,00 & 16,00 & 0,00 & 0,00 & 0,00 & 1152,00 & 13,48 & 327 & \begin{tabular}{|l|}
4,12 \\
\end{tabular} & $E$ \\
\hline 40 & \begin{tabular}{|l|l} 
escritório \\
\end{tabular} & 3,93 & 3,9 & 15,33 & 2,80 & 0,70 & 0,00 & 0,00 & 0,00 & 0,00 & 2,00 & 0,0 & 0,0 & 1,00 & 204,00 & 13,31 & 157 & \begin{tabular}{|l|}
8,48 \\
\end{tabular} & $E$ \\
\hline 41 & banheiro & 4 & 2,15 & 8,60 & 2,80 & 0,50 & 0,00 & 0,00 & 0,00 & 0,00 & 1,00 & 0,00 & 0,00 & 0,00 & 72,00 & 8,37 & 101 & \begin{tabular}{|l|}
8,29 \\
\end{tabular} & D \\
\hline 42 & \begin{tabular}{|l|l} 
escritório \\
\end{tabular} & 4 & 2,3 & 9,40 & 2,80 & 0,53 & 0,00 & 0,00 & 0,00 & 0,00 & 1,00 & 0,00 & 0,0 & 0,00 & 72, & 7,66 & 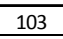 & \begin{tabular}{|l|}
7,44 \\
\end{tabular} & $\mathrm{D}$ \\
\hline 43 & \begin{tabular}{|l|l} 
escritório \\
\end{tabular} & 4 & 2,25 & 9,00 & 2,80 & 0,51 & 0,00 & 0,00 & 0,00 & 0,00 & 1,00 & 0,00 & 0,00 & 0,00 & 72,00 & 8,00 & 100 & 8,00 & D \\
\hline 44 & banheiro & 4 & 1,95 & 7,80 & 2,80 & 0,47 & 0,00 & 0,00 & 0,00 & 1,00 & 0,00 & 0,00 & 0,00 & 0,00 & 67,00 & 8,59 & 104 & \begin{tabular}{|l|}
8,26 \\
\end{tabular} & C \\
\hline 45 & irrculação & 13,1 & 3,01 & 170,56 & 2,80 & 2,33 & 0,00 & 0,00 & 2,00 & 0,00 & 6,00 & 0,00 & 0,00 & 0,00 & 624,00 & 3,66 & 82 & 4,46 & E \\
\hline
\end{tabular}


PRIMEIRO ESTUDO - LEVANTAMENTO DE DADOS - SEGUNDO PAVIMENTO

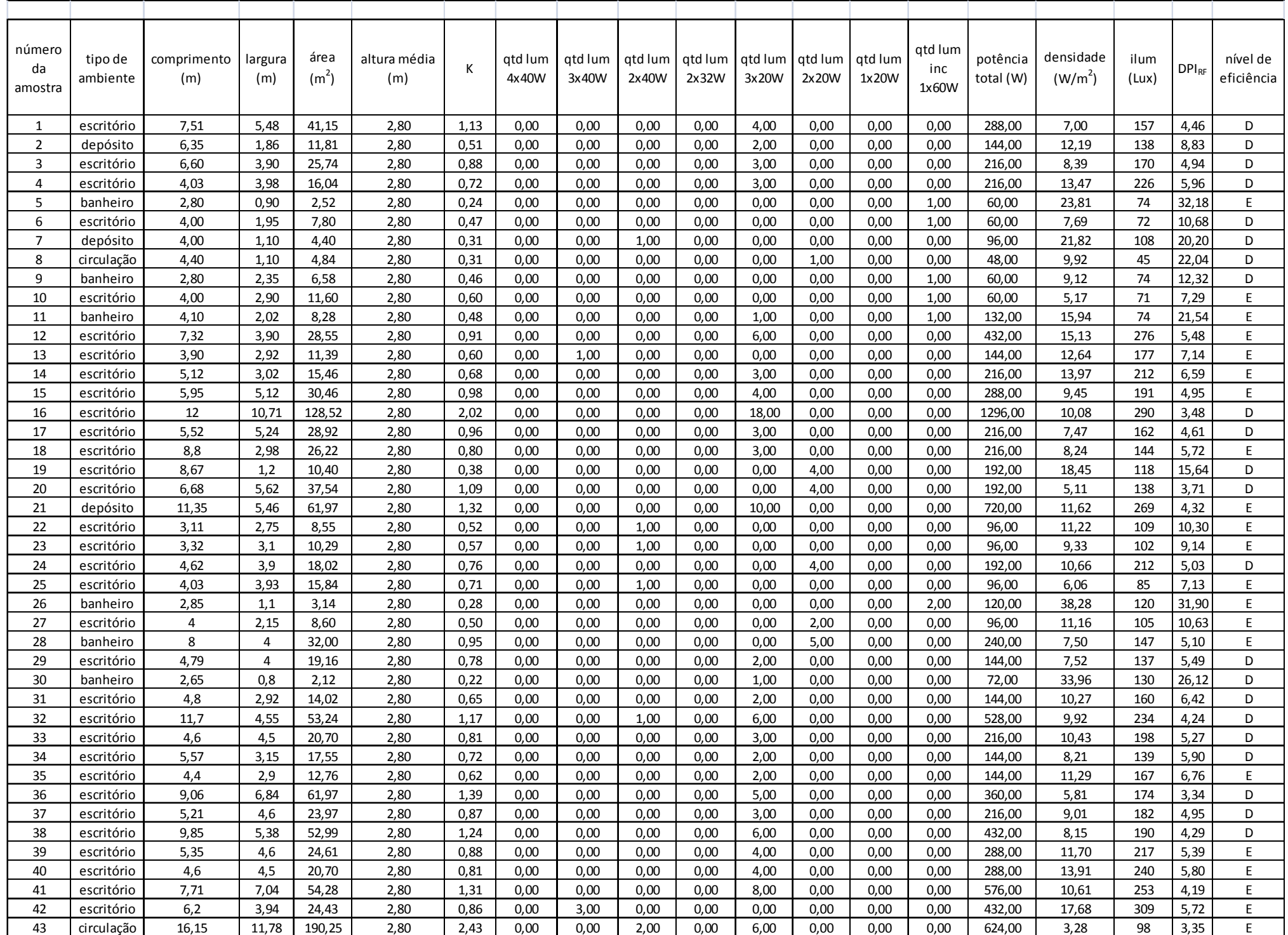


PRIMEIRO ESTUDO - LEVANTAMENTO DE DADOS - TERCEIRO PAVIMENTO

\begin{tabular}{|c|c|c|c|c|c|c|c|c|c|c|c|c|c|c|c|c|c|c|c|}
\hline $\begin{array}{l}\text { número } \\
\text { da } \\
\text { amostra }\end{array}$ & $\begin{array}{l}\text { tipo de } \\
\text { ambiente }\end{array}$ & $\begin{array}{c}\text { comprimento } \\
(\mathrm{m})\end{array}$ & $\begin{array}{c}\text { largura } \\
(\mathrm{m})\end{array}$ & $\begin{array}{l}\text { área } \\
\left(\mathrm{m}^{2}\right)\end{array}$ & $\begin{array}{l}\text { altura média } \\
(\mathrm{m})\end{array}$ & $\mathrm{K}$ & \begin{tabular}{|} 
qtd lum \\
$4 \times 40 \mathrm{~W}$
\end{tabular} & \begin{tabular}{|} 
atd lum \\
$3 \times 40 \mathrm{~W}$
\end{tabular} & $\begin{array}{l}\text { atd lum } \\
2 \times 40 \mathrm{~W}\end{array}$ & \begin{tabular}{|l|} 
atd lum \\
$2 \times 32 \mathrm{~W}$
\end{tabular} & $\begin{array}{l}\text { atd lum } \\
3 \times 20 \mathrm{~W}\end{array}$ & $\begin{array}{l}\text { atd lum } \\
2 \times 20 \mathrm{~W}\end{array}$ & \begin{tabular}{|l|} 
atd lum \\
$1 \times 20 \mathrm{~W}$
\end{tabular} & \begin{tabular}{|c} 
atd lum \\
inc \\
$1 \times 60 \mathrm{~W}$
\end{tabular} & $\begin{array}{l}\text { potência } \\
\text { total (W) }\end{array}$ & $\begin{array}{c}\text { densidade } \\
\left(\mathrm{W} / \mathrm{m}^{2}\right)\end{array}$ & $\begin{array}{l}\text { ilum } \\
\text { (Lux) }\end{array}$ & $\mathrm{DPl}_{\mathrm{RF}}$ & $\begin{array}{l}\text { nível de } \\
\text { eficiência }\end{array}$ \\
\hline 1 & depósito & 18,81 & 10,28 & $\begin{array}{l}193,37 \\
\end{array}$ & 2,80 & 2,37 & 0,00 & 0,00 & 0,00 & 0,00 & 16,00 & 0,00 & 0,00 & 0,00 & 1152,00 & 5,96 & 171 & \begin{tabular}{|l|}
3,48 \\
\end{tabular} & $\mathrm{E}$ \\
\hline 2 & escritório & 8,45 & 5,80 & 49,01 & 2,80 & 1,23 & 0,00 & 0,00 & 0,00 & 0,00 & 5,00 & 0,00 & 0,00 & 0,00 & 360,00 & 7,35 & 189 & \begin{tabular}{|l|}
3,89 \\
\end{tabular} & $\mathrm{D}$ \\
\hline 3 & escritório & 4,47 & 2,98 & 13,32 & 2,80 & 0,64 & 0,00 & 0,00 & 0,00 & 0,00 & 2,00 & 0,00 & 0,00 & 0,00 & 144,00 & 10,81 & 164 & \begin{tabular}{|l|l|}
6,59 \\
\end{tabular} & $E$ \\
\hline 4 & banheiro & 3,40 & 2,35 & 7,99 & 2,80 & 0,50 & 0,00 & 0,00 & 0,00 & 0,00 & 0,00 & 0,00 & 0,00 & 2,00 & 120,00 & 15,02 & 120 & 12,52 & $E$ \\
\hline 5 & escritório & 3,57 & 3,86 & 13,78 & 2,80 & 0,66 & 0,00 & 0,00 & 0,00 & 0,00 & 1,00 & 0,00 & 0,00 & 0,00 & 72,00 & 5,22 & 91 & \begin{tabular}{|l|}
5,74 \\
\end{tabular} & $\mathrm{D}$ \\
\hline 6 & circulação & 4,40 & 1,10 & 4,84 & 2,80 & 0,31 & 0,00 & 0,00 & 1,00 & 0,00 & 0,00 & 0,00 & 0,00 & 0,00 & 96,00 & 19,83 & 102 & 19,45 & $\mathrm{D}$ \\
\hline 7 & escritório & 4,00 & 2,35 & 9,40 & 2,80 & 0,53 & 0,00 & 0,00 & 0,00 & 0,00 & 1,00 & 0,00 & 0,00 & 0,00 & 72,00 & 7,66 & 103 & \begin{tabular}{|l|}
7,44 \\
\end{tabular} & D \\
\hline 8 & banheiro & 4,00 & 3,88 & 15,52 & 2,80 & 0,70 & 0,00 & 0,00 & 0,00 & 0,00 & 1,00 & 0,00 & 0,00 & 1,00 & 132,00 & 8,51 & 156 & \begin{tabular}{|l|}
5,45 \\
\end{tabular} & $\mathrm{D}$ \\
\hline 9 & escritório & 5,52 & 4,70 & 25,94 & 2,80 & 0,91 & 0,00 & 0,00 & 0,00 & 0,00 & 2,00 & 0,00 & 0,00 & 0,00 & 144,00 & 5,55 & 117 & \begin{tabular}{|l|}
4,74 \\
\end{tabular} & D \\
\hline 10 & escritório & 5,65 & 4,70 & 26,56 & 2,80 & 0,92 & 0,00 & 0,00 & 0,00 & 0,00 & 2,00 & 0,00 & 0,00 & 0,00 & 144,00 & 5,42 & 115 & \begin{tabular}{|l|}
4,72 \\
\end{tabular} & $\mathrm{D}$ \\
\hline 11 & escritório & 3,70 & 2,80 & 10,36 & 2,80 & 0,57 & 1,00 & 0,00 & 0,00 & 0,00 & 0,00 & 0,00 & 0,00 & 0,00 & 153,60 & 14,83 & 272 & \begin{tabular}{|l|}
5,45 \\
\end{tabular} & C \\
\hline 12 & escritório & 3,70 & 3,28 & 12,14 & 2,80 & 0,62 & 1,00 & 0,00 & 0,00 & 0,00 & 0,00 & 0,00 & 0,00 & 0,00 & 153,60 & 12,66 & 257 & \begin{tabular}{|l|}
4,92 \\
\end{tabular} & C \\
\hline 13 & \begin{tabular}{|l|l} 
escritório \\
\end{tabular} & 6,12 & 2,98 & 18,24 & 2,80 & 0,72 & 0,00 & 0,00 & 1,00 & 0,00 & 0,00 & 0,00 & 0,00 & 0,00 & 96,00 & 5,26 & 72 & $\begin{array}{l}7,31 \\
\end{array}$ & $E$ \\
\hline 14 & escritório & 6,12 & 2,80 & 17,14 & 2,80 & 0,69 & 0,00 & 1,00 & 0,00 & 0,00 & 1,00 & 0,00 & 0,00 & 0,00 & 216,00 & 12,61 & 203 & \begin{tabular}{|l|}
6,21 \\
\end{tabular} & $E$ \\
\hline 15 & escritório & 6,12 & 2,62 & 16,03 & 2,80 & 0,66 & 0,00 & 0,00 & 0,00 & 0,00 & 2,00 & 0,00 & 0,00 & 0,00 & 144,00 & 8,98 & 138 & \begin{tabular}{|l|}
6,51 \\
\end{tabular} & $E$ \\
\hline 16 & \begin{tabular}{|l|l} 
escritório \\
\end{tabular} & 9,95 & 7,44 & 74,03 & 2,80 & 1,52 & 0,00 & 0,00 & 0,00 & 0,00 & 6,00 & 0,00 & 0,00 & 0,00 & 432,00 & 5,84 & 153 & \begin{tabular}{|l|}
3,81 \\
\end{tabular} & D \\
\hline 17 & depósito & 5,64 & 4,08 & 23,01 & 2,80 & 0,85 & 0,00 & 0,00 & 0,00 & 0,00 & 2,00 & 0,00 & 0,00 & 0,00 & 144,00 & 6,26 & 124 & \begin{tabular}{|l|l|}
5,05 \\
\end{tabular} & D \\
\hline 18 & escritório & 5,04 & 4,11 & 20,71 & 2,80 & 0,81 & 0,00 & 0,00 & 0,00 & 0,00 & 1,00 & 0,00 & 0,00 & 0,00 & 72,00 & 3,48 & 58 & \begin{tabular}{|l|}
5,99 \\
\end{tabular} & $E$ \\
\hline 19 & escritório & 4 & 2,25 & 9,00 & 2,80 & 0,51 & 0,00 & 0,00 & 0,00 & 0,00 & 1,00 & 0,00 & 0,00 & 0,00 & 72,00 & 8,00 & 104 & \begin{tabular}{|l|}
7,69 \\
\end{tabular} & $S_{0}$ \\
\hline 20 & escritório & 5,7 & 5,26 & 29,98 & 2,80 & 0,98 & 0,00 & 0,00 & 0,00 & 0,00 & 4,00 & 0,00 & 0,00 & 0,00 & 288,00 & 9,61 & 194 & 4,95 & $E$ \\
\hline 21 & escritório & 5,7 & 4,19 & 23,88 & 2,80 & 0,86 & 0,00 & 0,00 & 0,00 & 0,00 & 0,00 & 2,00 & 0,00 & 0,00 & 96,00 & 4,02 & 54 & \begin{tabular}{|l|}
7,44 \\
\end{tabular} & $E$ \\
\hline 22 & escritório & 5,7 & 2,7 & 15,39 & 2,80 & 0,65 & 0,00 & 0,00 & 0,00 & 0,00 & 2,00 & 0,00 & 0,00 & 0,00 & 144,00 & 9,36 & 139 & 6,73 & $\mathrm{E}$ \\
\hline 23 & escritório & 5,7 & 2,85 & 16,25 & 2,80 & 0,68 & 0,00 & 0,00 & 0,00 & 0,00 & 1,00 & 1,00 & 0,00 & 0,00 & 120,00 & 7,39 & 141 & 5,24 & $\mathrm{D}$ \\
\hline 24 & escritório & 5,7 & 3,62 & 20,63 & 2,80 & 0,79 & 0,00 & 0,00 & 4,00 & 0,00 & 0,00 & 0,00 & 0,00 & 0,00 & 384,00 & 18,61 & 322 & 5,78 & $E$ \\
\hline 25 & escritório & 5,7 & 2,5 & 14,25 & 2,80 & 0,62 & 0,00 & 0,00 & 2,00 & 0,00 & 0,00 & 0,00 & 0,00 & 0,00 & 192,00 & 13,47 & 219 & 6,15 & D \\
\hline 26 & \begin{tabular}{|l|l|} 
escritório \\
\end{tabular} & 6,05 & 5,83 & 35,27 & 2,80 & 1,06 & 0,00 & 0,00 & 0,00 & 0,00 & 5,00 & 0,00 & 0,00 & 0,00 & 360,00 & 10,21 & 237 & \begin{tabular}{|l|}
4,31 \\
\end{tabular} & $\mathrm{D}$ \\
\hline 27 & escritório & 3,9 & 3,5 & 13,65 & 2,80 & 0,66 & 0,00 & 0,00 & 0,00 & 0,00 & 1,00 & 0,00 & 0,00 & 0,00 & 72,00 & 5,27 & 91 & 5,80 & D \\
\hline 28 & escritório & 44 & 3,9 & 17,32 & 2,80 & 0,74 & 0,00 & 0,00 & 0,00 & 0,00 & 2,00 & 0,00 & 0,00 & 0,00 & 144,00 & 8,32 & 144 & \begin{tabular}{|l|} 
\\
\end{tabular} & D \\
\hline 29 & escritório & 5,01 & 3,9 & 19,54 & 2,80 & 0,78 & 0,00 & 0,00 & 0,00 & 0,00 & 2,00 & 0,00 & 0,00 & 0,00 & 144,00 & 7,37 & 137 & 5,38 & $\mathrm{D}$ \\
\hline 30 & circulação & 17,04 & 2,1 & 35,78 & 2,80 & 0,67 & 0,00 & 0,00 & 0,00 & 0,00 & 6,00 & 0,00 & 0,00 & 0,00 & 432,00 & 12,07 & 170 & $\begin{array}{l}7,10 \\
\end{array}$ & $\mathrm{E}$ \\
\hline 31 & banheiro & 3,9 & 2,05 & 8,00 & 2,80 & 0,48 & 0,00 & 0,00 & 0,00 & 0,00 & 0,00 & 0,00 & 0,00 & 3,00 & 180,00 & 22,51 & 122 & 18,45 & $E$ \\
\hline 32 & banheiro & 9,15 & 4 & 36,60 & 2,80 & 0,99 & 0,00 & 0,00 & 0,00 & 0,00 & 4,00 & 0,00 & 0,00 & 0,00 & 288,00 & 7,87 & 160 & \begin{tabular}{|l|}
4,92 \\
\end{tabular} & $E$ \\
\hline 33 & banheiro & 3,9 & 2,42 & 9,44 & 2,80 & 0,53 & 0,00 & 0,00 & 1,00 & 0,00 & 0,00 & 0,00 & 0,00 & 0,00 & 96,00 & 10,17 & 100 & $\begin{array}{l}10,17 \\
\end{array}$ & $\mathrm{E}$ \\
\hline 34 & escritório & 4,18 & 3,9 & 16,30 & 2,80 & 0,72 & 0,00 & 0,00 & 4,00 & 0,00 & 0,00 & 0,00 & 0,00 & 0,00 & 384,00 & 23,56 & 371 & \begin{tabular}{|l|}
6,35 \\
\end{tabular} & $E$ \\
\hline 35 & escritório & 4,14 & 3,9 & 16,15 & 2,80 & 0,72 & 0,00 & 0,00 & 4,00 & 0,00 & 0,00 & 0,00 & 0,00 & 0,00 & 384,00 & 23,78 & 375 & \begin{tabular}{|l|l|}
6,34 \\
\end{tabular} & $\mathrm{E}$ \\
\hline 36 & \begin{tabular}{|l|l} 
escritório \\
\end{tabular} & 5,8 & 3,9 & 22,62 & 2,80 & 0,83 & 0,00 & 0,00 & 6,00 & 0,00 & 0,00 & 0,00 & 0,00 & 0,00 & 576,00 & 25,46 & 437 & \begin{tabular}{|l|}
5,83 \\
\end{tabular} & $\mathrm{E}$ \\
\hline 37 & \begin{tabular}{|l|} 
escritório \\
\end{tabular} & 4, & 3,9 & 17,59 & 2,80 & 0,75 & 0,00 & 0,00 & 4,00 & 0,00 & 0,00 & 0,00 & 0,00 & 0,00 & 384,00 & 21,83 & 356 & 6,13 & $E$ \\
\hline 38 & depósito & 2,32 & 1,95 & 4,52 & 2,80 & 0,38 & 0,00 & 0,00 & 1,00 & 0,00 & 0,00 & 0,00 & 0,00 & 0,00 & 96,00 & 21,22 & 127 & 16,71 & $E$ \\
\hline 39 & circulaçãa & 3,8 & 1,91 & 7,26 & 2,80 & 0,45 & 0,00 & 0,00 & 2,00 & 0,00 & 0,00 & 0,00 & 0,00 & 0,00 & 192,00 & 26,45 & 282 & 9,38 & C \\
\hline 40 & circulaçăo & 12,64 & 1,27 & 16,05 & 2,80 & 0,41 & 0,00 & 0,00 & 3,00 & 0,00 & 0,00 & 0,00 & 0,00 & 0,00 & 288,00 & 17,94 & 157 & \begin{tabular}{|l|l|}
11,43 \\
\end{tabular} & c \\
\hline 41 & escritório & 5,82 & 3,74 & 21,77 & 2,80 & 0,81 & 0,00 & 0,00 & 6,00 & 0,00 & 0,00 & 0,00 & 0,00 & 0,00 & 576,00 & 26,46 & 446 & \begin{tabular}{|l|}
5,93 \\
\end{tabular} & $\mathrm{D}$ \\
\hline 42 & escritório & 5,82 & 2,38 & 13,85 & 2,80 & 0,60 & 0,00 & 0,00 & 3,00 & 0,00 & 0,00 & 0,00 & 0,00 & 0,00 & 288,00 & 20,79 & 266 & 7,82 & $E$ \\
\hline 43 & escritório & 6,89 & 6,48 & 44,65 & 2,80 & 1,19 & 0,00 & 0,00 & 0,00 & 0,00 & 7,00 & 0,00 & 0,00 & 0,00 & 504,00 & 11,29 & 294 & \begin{tabular}{|l|}
3,84 \\
\end{tabular} & $\mathrm{D}$ \\
\hline 44 & escritório & 4,91 & 2,09 & 10,26 & 2,80 & 0,52 & 0,00 & 0,00 & 0,00 & 0,00 & 1,00 & 0,00 & 0,00 & 0,00 & 72,00 & 7,02 & 90 & 7,80 & D \\
\hline 45 & depósito & 4 & 1,1 & 4,40 & 2,80 & 0,31 & 0,00 & 0,00 & 0,00 & 0,00 & 1,00 & 0,00 & 0,00 & 0,00 & 72,00 & 16,36 & 108 & 15,15 & c \\
\hline 46 & circ & 14,25 & 9,55 & 136,09 & 2,80 & 2,04 & 0,00 & 0,00 & 2,00 & 0,00 & 0,00 & 0,00 & 0,00 & 0,00 & 192,00 & 1,41 & 50 & 2,82 & $\mathrm{D}$ \\
\hline
\end{tabular}


PRIMEIRO ESTUDO - LEVANTAMENTO DE DADOS - QUARTO PAVIMENTO

\begin{tabular}{|c|c|c|c|c|c|c|c|c|c|c|c|c|c|c|c|c|c|c|c|}
\hline $\begin{array}{c}\text { número } \\
\text { da } \\
\text { aostra }\end{array}$ & \begin{tabular}{|l} 
tipode \\
ambiente
\end{tabular} & $\begin{array}{c}\text { comprimento } \\
(\mathrm{m})\end{array}$ & $\begin{array}{c}\text { largura } \\
(\mathrm{m})\end{array}$ & $\begin{array}{l}\text { area } \\
\left(\mathrm{m}^{2}\right)\end{array}$ & $\begin{array}{l}\text { altura média } \\
(\mathrm{m})\end{array}$ & k & $\begin{array}{l}\text { qdtlum } \\
4 \times 400 \mathrm{~W}\end{array}$ & $\begin{array}{l}\text { qdt lum } \\
3 \times 40 \mathrm{~W}\end{array}$ & $\begin{array}{l}\text { atd lum } \\
2 \times 40 \mathrm{~W}\end{array}$ & $\begin{array}{l}\text { qut lum } \\
2 \times 32 W\end{array}$ & $\begin{array}{l}q \text { qtd lum } \\
3 \times 20 W\end{array}$ & 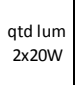 & $\mid \begin{array}{l}\text { tad lum } \\
1 \times 20 \mathrm{~W}\end{array}$ & $\mid \begin{array}{c}\text { atd lum } \\
\text { inc } \\
1 \times 600 \mathrm{~W}\end{array}$ & \begin{tabular}{|c|} 
potência \\
total (W)
\end{tabular} & \begin{tabular}{|c} 
densidade \\
$\left(\mathrm{W} / \mathrm{m}^{2}\right)$
\end{tabular} & $\begin{array}{l}\text { ilum } \\
\text { (Lux) }\end{array}$ & $\mathrm{DP}_{\mathrm{PF}}$ & $\begin{array}{l}\text { nivel de } \\
\text { eficiência }\end{array}$ \\
\hline 1 & escritório & 6,06 & 5,71 & 34,60 & 2,80 & 1,05 & 0,00 & 0,00 & 0,00 & 0,00 & 4,00 & 0,00 & 0,00 & 0,00 & 288,00 & 8,32 & 178 & \begin{tabular}{|l|}
4,68 \\
\end{tabular} & D \\
\hline 2 & escritório & $\frac{6,12}{560}$ & 3,90 & $\begin{array}{r}23,87 \\
2184\end{array}$ & $\begin{array}{l}2,80 \\
280\end{array}$ & 0,85 & 0,00 & 0,00 & 0,00 & 0,00 & 2,00 & 0,00 & 0,00 & 0,00 & 144,00 & 6,03 & 119 & \begin{tabular}{|l|}
5,07 \\
\end{tabular} & D \\
\hline & escritório & & 3,90 & $\begin{array}{r}21,84 \\
\end{array}$ & 2,80 & 0,82 & 0,00 & 0,00 & 0,00 & 0,00 & 2,00 & 0,00 & 0,00 & 0,00 & 144,00 & 6,59 & 125 & $5,27 \mid$ & D \\
\hline 4 & banheiro & 3,90 & 2,35 & 9,17 & 2,80 & 0,52 & 0,00 & 0,00 & 0,00 & 0,00 & 1,00 & 0,00 & 0,00 & 0,00 & 72,00 & 86 & 101 & 7,78 & $D$ \\
\hline 5 & banheiro & 4,00 & 3,00 & $\begin{array}{l}12,00 \\
010\end{array}$ & $\begin{array}{l}2,80 \\
280\end{array}$ & 0,61 & 0,00 & 0,00 & 0,00 & 0,00 & 2,00 & 0,00 & 0,00 & 0,00 & $\begin{array}{l}144,00 \\
7,00\end{array}$ & 12,00 & 168 & \begin{tabular}{|l|l|}
7,14 \\
\end{tabular} & $E$ \\
\hline$\frac{6}{7}$ & banheiro & & 2,35 & $\begin{array}{l}9,40 \\
900\end{array}$ & 2,80 & 0,53 & 0,00 & 0,00 & 0,00 & 0,00 & 1,00 & 0,00 & 0,00 & 0,00 & 72,00 & 7,66 & 99 & 7,74 & $D$ \\
\hline 8 & \begin{tabular}{|l|} 
banheiro \\
hang
\end{tabular} & 4,00 & 2,25 & 9,00 & $\frac{2,80}{280}$ & $\begin{array}{l}0,51 \\
059\end{array}$ & 0,00 & 0,00 & 0,00 & $\begin{array}{l}0,00 \\
000\end{array}$ & $\frac{1,00}{100}$ & 0,00 & 0,00 & 0,00 & $\begin{array}{l}72,00 \\
7700\end{array}$ & 8,00 & 100 & \begin{tabular}{|l|l|}
8,00 \\
6,72
\end{tabular} & D \\
\hline 8 & \begin{tabular}{|l} 
banheiro \\
escrétió
\end{tabular} & $\frac{4,10}{712}$ & $\frac{2,75}{3,90}$ & $\frac{11,28}{27,77}$ & $\frac{2,80}{280}$ & $\frac{0,59}{0.90}$ & $\begin{array}{l}0,00 \\
0,00\end{array}$ & 0,00 & 0,00 & 0,000 & $\frac{1,00}{300}$ & 0,00 & 0,00 & 0,00 & 72,00 & $\frac{6,39}{778}$ & $\begin{array}{l}95 \\
155\end{array}$ & \begin{tabular}{|l|}
6,72 \\
502
\end{tabular} & $D$ \\
\hline 10 & $\begin{array}{l}\text { escriturórit } \\
\end{array}$ & $\frac{1,12}{689}$ & \begin{tabular}{|l|}
3,00 \\
5,10
\end{tabular} & $\begin{array}{l}35,11 \\
5,14\end{array}$ & $\frac{2,80}{280}$ & $\frac{0,90}{105}$ & $\begin{array}{l}0,00 \\
0,00\end{array}$ & 0,00 & 0,00 & 0,00 & 3,00 & 0,000 & 80 & 80 & 216,00 & $\begin{array}{l}7,78 \\
1229\end{array}$ & $\begin{array}{l}155 \\
255\end{array}$ & & $\mathrm{D}$ \\
\hline 11 & escritórit & & 5,25 & & 2,80 & 1,02 & $\begin{array}{l}, 00 \\
3,00\end{array}$ & 0,000 & 0 & 0,00 & $\frac{0,00}{0,00}$ & 0,0 & 0,0 & $\frac{0,4}{n}$ & $\begin{array}{l}432,00 \\
15680\end{array}$ & $\frac{12,29}{1389}$ & $\frac{256}{354}$ & \begin{tabular}{|l|}
4,80 \\
3
\end{tabular} & \\
\hline 12 & \begin{tabular}{|l|l} 
\\
escritório
\end{tabular} & 6,35 & \begin{tabular}{|l}
6,32 \\
\end{tabular} & 40,13 & 2,80 & 1,13 & $\begin{array}{l}0,00 \\
0,00\end{array}$ & 0,000 & $0,0,00$ & $\begin{array}{l}0,00 \\
0,00\end{array}$ & $\begin{array}{l}0,00 \\
4,00\end{array}$ & $\begin{array}{l}0,00 \\
0,00\end{array}$ & $0,0,00$ & $\begin{array}{l}0,000 \\
0,00\end{array}$ & $\begin{array}{l}466,80 \\
288,00\end{array}$ & $\frac{13,89}{7,18}$ & $\begin{array}{l}354 \\
163\end{array}$ & \begin{tabular}{|l|}
3,92 \\
4,40
\end{tabular} & $\frac{D}{D}$ \\
\hline 13 & circulacăa & 8,59 & 1,66 & $\begin{array}{ll}14,26 \\
\end{array}$ & 2,80 & 0,50 & 0,00 & 2,00 & 0,00 & 0,00 & 0,00 & 0,00 & 0,00 & 0,00 & 288,00 & 20,20 & 161 & \begin{tabular}{|l|}
12,54 \\
\end{tabular} & $E$ \\
\hline 14 & \begin{tabular}{|l|l|} 
escritório \\
\end{tabular} & 4,65 & 4,45 & 20,69 & 2,80 & 0,81 & 0,00 & 0,00 & 0,00 & 0,00 & 2,0 & 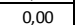 & & 0,0 & 144,00 & 6,9 & 134 & 5,19 & D \\
\hline 15 & \begin{tabular}{|l|l|} 
escritório \\
\end{tabular} & 5,44 & 4,64 & 25,24 & 2,80 & 0,89 & 0,00 & 0,00 & 0,00 & 0,00 & 4,00 & 0,6 & 0, & $0, \mathrm{c}$ & 288,00 & 11 & 214 & 5,33 & $E_{1}$ \\
\hline 16 & \begin{tabular}{|l|l|} 
escritório \\
\end{tabular} & 6,89 & 3,15 & 21,70 & 2,80 & 0,77 & 0,00 & 0,00 & 0,00 & 0,00 & 3,00 & 0,4 & 0,4 & $0, \mathrm{c}$ & 216,00 & 9, & 170 & 5,85 & $\mathrm{E}$ \\
\hline 17 & 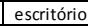 & 5,66 & 4,08 & 23,09 & 2,80 & 0,85 & 0,00 & 0,00 & 0,00 & 0,00 & 2,00 & 0,00 & 0,0 & 0,4 & 144,00 & 6,2 & 123 & \begin{tabular}{|l|}
5,07 \\
\end{tabular} & D \\
\hline 18 & 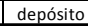 & 6,16 & 2,1 & 12,94 & 2,80 & 0,56 & 0,00 & 0,00 & 0,00 & 0,00 & 1,00 & 0,6 & 0,6 & $0, \mathrm{c}$ & 72,00 & 5,5 & 76 & 7,32 & $D$ \\
\hline 19 & \begin{tabular}{|l|} 
escritório \\
\end{tabular} & 4,03 & 2,78 & 11,20 & 2,80 & 0,59 & 0,00 & 0,000 & 0,00 & 0,00 & 4,0 & & & 0,1 & 288, & 25 & 318 & 8,08 & \\
\hline 20 & \begin{tabular}{|l|l|} 
escritório \\
\end{tabular} & 4,03 & 3,84 & 15,48 & 2,80 & 0,70 & 0,00 & 0,00 & 0,00 & 0,00 & 2,00 & 0,00 & 0,00 & 0,1 & 144,00 & 9,31 & $\begin{array}{ll}156 \\
\end{array}$ & \begin{tabular}{|l|l|}
5,96 \\
\end{tabular} & D \\
\hline 21 & \begin{tabular}{|l|l|} 
escritório \\
\end{tabular} & 6,53 & 4,35 & 28,41 & 2,80 & 0,93 & 4,00 & 0,00 & 0,00 & 0,00 & $0,0 \mathrm{c}$ & 0,0 & 0,0 & $0, \mathrm{c}$ & 614,40 & 21,63 & 482 & \begin{tabular}{|l|l|} 
\\
\end{tabular} & $D$ \\
\hline 22 & | circulaçăa & 11,09 & 1,2 & 13,31 & 2,80 & 0,39 & 0,00 & 0,00 & 0,00 & $\begin{array}{l}0,00 \\
\end{array}$ & 1,00 & 0,00 & 0,00 & 0,00 & 72,00 & 5,41 & 48 & $|11,27|$ & c \\
\hline 23 & 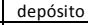 & 4,11 & 2,47 & 10,15 & 2,80 & 0,55 & 0,00 & 0,00 & 0,00 & 0,00 & 1,00 & 0,00 & 0,00 & 0,6 & 72,00 & 7,09 & 97 & 7,31 & $\mathrm{D}$ \\
\hline 24 & |escritório & 6,43 & 2,79 & 17,94 & 2,80 & 0,69 & 0,00 & 0,00 & 0,00 & $\begin{array}{l}0,00 \\
\end{array}$ & 2,00 & & & 0,6 & 144,00 & 8,03 & 127 & 6,32 & $\mathrm{E}$ \\
\hline 25 & \begin{tabular}{|l|l} 
escritório \\
\end{tabular} & 6,43 & 2,85 & 18,33 & 2,80 & 0,71 & 0,00 & 0,00 & 0,00 & 0,00 & 2,00 & 0,00 & 0,00 & 0,00 & 144,00 & 7,86 & 127 & 6,19 & $E$ \\
\hline 26 & \begin{tabular}{|l|} 
escritório \\
\end{tabular} & 6,43 & 5,27 & 33,89 & 2,80 & 1,03 & 4,00 & 0,00 & 0,00 & 0,00 & 0,00 & 0,00 & 00 & 0,00 & 614,40 & 18,13 & 433 & 4,19 & $D$ \\
\hline 27 & |escritório & 6,43 & 3,28 & 21,09 & 2,80 & 0,78 & 0,00 & 0,00 & 0,00 & 0,000 & 2,00 & 0, & & 0,00 & 144,00 & 6,83 & 123 & 5,55 & $D$ \\
\hline 28 & |escritório & 6,55 & 3,91 & 25,61 & 2,80 & 0,87 & 0,00 & 0,00 & 0,00 & \begin{tabular}{|l} 
\\
\end{tabular} & 2,00 & 0,00 & 00 & 0,00 & 144,00 & 5,62 & 113 & 4,98 & D \\
\hline 29 & banheiro & 2,8 & 1,1 & 3,08 & 2,80 & 0,28 & 0,00 & 0,00 & 1,00 & 0,00 & 0,00 & 0,00 & 00 & $0, \mathrm{c}$ & 96,00 & 31,17 & 126 & 24,74 & $E$ \\
\hline 30 & escritório & 4,5 & 4 & 18,00 & & 0,76 & 0,00 & 0,00 & 1,00 & 0,00 & 0,00 & 00 & 00 & 0,6 & 96,00 & ,33 & 80 & \begin{tabular}{|l|l|} 
\\
\end{tabular} & E \\
\hline 31 & | escritório & 3,19 & 4 & 12,76 & 80 & 0,63 & 0,00 & 0,00 & 1,00 & 0,00 & 0,00 & 0,00 & 0,00 & 0,6 & 96,00 & 7,52 & 94 & 8,00 & $\mathrm{E}$ \\
\hline 32 & banheiro & 2 & 1,6 & 4,56 & 2,80 & 0, & 0,00 & 0, & 0,00 & 0,00 & 1,00 & 00 & 00 & & 72, & 15,79 & 122 & 2,94 [ & c \\
\hline 33 & banheiro & $5,4=$ & 2,65 & 14,39 & -4 & 0,64 & 0 & 0, & 0,00 & 0,00 & 1,00 & & & & 120, & , 34 & 145 & 5,75 & $D$ \\
\hline 34 & escritório & 5,42 & 4,09 & 22,17 & -4 & 0, & 0,00 & 0,00 & 0,00 & $\begin{array}{l}0,00 \\
\end{array}$ & 2,00 & 0,00 & 0,00 & 0, & 144,00 & 6,50 & 126 & 5,16 & $D$ \\
\hline 35 & escritór & 5,65 & 5,42 & 30,62 & 2,80 & & $0, c$ & 0,00 & 2,00 & $\begin{array}{l}0,00 \\
\end{array}$ & 0,00 & & & & 192. &, 27 & 157 & 3,99 | & $D$ \\
\hline 36 & escritório & 5, & 3,58 & 20,41 & 2,80 & $0, z$ & 0,00 & 0,00 & 0,00 & 0,00 & 2,00 & 0,00 & 0,00 & 0, & 144,00 & 7,06 & 130 & 5,43 & $D$ \\
\hline 37 & banheiro & 3,58 & 3,28 & 11,74 & 2,80 & 0 & 0,00 & 0,00 & 0,00 & 0,00 & 1,00 & 0,00 & 0,0 & $0, c$ & 72,00 & 6,13 & 96 & 6,39 & D \\
\hline 38 & escritóri & 8,56 & 3, & 33,56 & 2,00 & & 0,6 & 0,00 & 0,0 & 0,6 & 3,00 & & & 0,00 & 216, & 6,44 & 135 & $4,77 \mid$ & D \\
\hline 39 & escritório & 6,29 & 3,65 & 22,96 & 2,80 & 0, & 0,00 & 0,00 & 0,00 & 0,00 & 2,00 & 0,00 & 0,00 & $0, c$ & 144,00 & 6,27 & 120 & 5,23 & $D$ \\
\hline 40 & escritório & 6,29 & 4,73 & 29,75 & 2,80 & 0,96 & 0,00 & 0,00 & 1,00 & 0,00 & 00 & 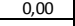 & 0,00 & 0, & 240, & 8,07 & 106 & 7,61 & E \\
\hline 41 & \begin{tabular}{|l|l|ccr} 
\\
\end{tabular} & 7 & 4,86 & 34,26 & 2 & 1, & 0,00 & 0,00 & $0, c$ & 0,00 & 4,00 & & & & 288,00 & 3,41 & 176 & \begin{tabular}{|l|l|} 
\\
\end{tabular} & D \\
\hline 42 & \begin{tabular}{|l|} 
escritt \\
\end{tabular} & & & 23,75 & 2 & 0, & 0, & 0, & 0, & 0, & 2,0 & & & & 144 & 06 & 121 & \begin{tabular}{|l|l|} 
\\
\end{tabular} & D \\
\hline $4=$ & \begin{tabular}{|l|} 
escritc \\
\end{tabular} & 4 & 2,4 & 10,07 & 2 & 0,55 & $0, r$ & 0,6 & 0, & 0, & 2,6 & & & & 144 &, 30 & 181 & $7,90 \mid$ & E \\
\hline 44 & escrit & 5 & 3,5 & 19,07 & & 0,75 & $0, r$ & 0, & 0, & 0,0 & 3,6 & & & & 216 & 11,33 & 192 & $5,90 \mid$ & E \\
\hline 45 & esc & 6,12 & 5,99 & 36,66 & 2,80 & 1, & 0, & 0, & 0 & 0 & 2,00 & & & 0,4 & 144, & 3,93 & 96 & 4,09 & D \\
\hline 46 & esc & 5 & 5,6 & 33,54 & & 1,0 & & & & 0 & & & & & & 4,29 & 101 & 4,25 & D \\
\hline 4 & & 4,34 & 3,04 & 13,19 & & c & & & & & & & & & & 10,91 & 165 & 61 & E \\
\hline 48 & 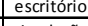 & 5,71 & 2,74 & 15,65 & & 0, & $0, r$ & 0 & 0, & 0,0 & 2,00 & & & 0,6 & 144 & 20 & 138 & 6,67 & E \\
\hline$\frac{44}{5}$ & & 7,8 & 2,25 & 17,55 & & 0,6 & 0 & 0, & 0,4 & 0,4 & & & & & & 10 & 62 & $6,62 \mid$ & D \\
\hline 36 & & 3,9 & 2, & 8, & 2,8 & & 0, & 0, & 0, & 0,0 & 1,6 & & & & & 68 & 190 & 20 & r \\
\hline 5 & & 3,99 & -3 & 15, & 2,80 & 0,7 & 0,0 & 0,0 & 0,0 & 0,0 & 2,0 & & & & & 9,25 & 154 & 6,01 & D \\
\hline 5 & & 2,9 & & & & & & & & 0 & & & & & & & 114 & ,38 & D \\
\hline 33 & & 4 & -1 & 4,4 & $2,8 c$ & 0,3 & 0,00 & & 0, & 0, & 1,1 & & & 0, & & 16,3 & 108 & , 13,15 & c \\
\hline 55 & & 4,4 & 1069 & 51 & & & & 00 & & & & & & & & & 102 & , ,58 & $\frac{c}{c}$ \\
\hline 55 & | circulaçăa & 16,15 & 10,62 & 171,51 & 2,80 & 2,29 & 0,00 & 0,00 & 2,00 & 0,00 & 6,00 & 0,00 & 0,00 & 0,00 & 624,00 & 3,64 & 41 & $8,87 \mid$ & E \\
\hline
\end{tabular}


PRIMEIRO ESTUDO - LEVANTAMENTO DE DADOS - QUINTO PAVIMENTO

\begin{tabular}{|c|c|c|c|c|c|c|c|c|c|c|c|c|c|c|c|c|c|c|c|}
\hline $\begin{array}{c}\text { número } \\
\text { da } \\
\text { amostra }\end{array}$ & $\begin{array}{c}\text { tipo de } \\
\text { ambiente }\end{array}$ & $\begin{array}{l}\text { comprimento } \\
(\mathrm{m})\end{array}$ & $\begin{array}{c}\text { largura } \\
(\mathrm{m})\end{array}$ & $\begin{array}{l}\text { área } \\
\left(\mathrm{m}^{2}\right)\end{array}$ & $\begin{array}{l}\text { altura média } \\
(\mathrm{m})\end{array}$ & K & $\begin{array}{l}\text { qtd lum } \\
4 \times 40 W\end{array}$ & $\begin{array}{l}\text { qtd lum } \\
3 \times 40 W\end{array}$ & $\begin{array}{l}\text { qtd lum } \\
2 \times 40 \mathrm{~W}\end{array}$ & $\begin{array}{l}\text { qtd lum } \\
2 \times 32 \mathrm{~W}\end{array}$ & $\begin{array}{l}\text { qtd lum } \\
3 \times 20 W\end{array}$ & $\begin{array}{l}\text { qtd lum } \\
2 \times 20 \mathrm{~W}\end{array}$ & $\begin{array}{l}\text { qtd lum } \\
1 \times 20 W\end{array}$ & $\begin{array}{l}\text { qtd lum } \\
\text { inc } \\
1 \times 60 \mathrm{~W}\end{array}$ & $\begin{array}{l}\text { potência } \\
\text { total (W) }\end{array}$ & $\begin{array}{c}\text { densidade } \\
\left(\mathrm{W} / \mathrm{m}^{2}\right)\end{array}$ & $\begin{array}{l}\text { ilum } \\
\text { (Lux) }\end{array}$ & $\mathrm{DPI}_{\mathrm{RF}}$ & $\begin{array}{c}\text { nível de } \\
\text { eficiência }\end{array}$ \\
\hline 1 & escritório & 9,95 & 4,92 & 48,95 & 2,80 & 1,18 & 0,00 & 0,00 & 0,00 & 0,00 & 0,00 & 0,00 & 0,00 & 9,00 & 540,00 & 11,03 & 128 & 8,62 & $E$ \\
\hline 2 & escritório & 8,13 & 4,92 & 40,00 & 2,80 & 1,09 & 0,00 & 0,00 & 0,00 & 0,00 & 0,00 & 0,00 & 0,00 & 7,00 & 420,00 & 10,50 & 138 & 7,61 & $\mathrm{E}$ \\
\hline 3 & banheiro & 4,92 & 3,39 & 16,68 & 2,80 & 0,72 & 0,00 & 0,00 & 0,00 & 0,00 & 0,00 & 0,00 & 0,00 & 2,00 & 120,00 & 7,19 & 65 & 11,07 & $E$ \\
\hline 4 & banheiro & 4,00 & 3,20 & 12,80 & 2,80 & 0,63 & 0,00 & 0,00 & 2,00 & 0,00 & 0,00 & 0,00 & 0,00 & 0,00 & 192,00 & 15,00 & 252 & 5,95 & $\mathrm{D}$ \\
\hline 5 & banheiro & 3,90 & 3,30 & 12,87 & 2,80 & 0,64 & 0,00 & 0,00 & 2,00 & 0,00 & 0,00 & 0,00 & 0,00 & 0,00 & 192,00 & 14,92 & 253 & 5,90 & $\mathrm{D}$ \\
\hline 6 & banheiro & 3,90 & 1,61 & 6,28 & 2,80 & 0,41 & 0,00 & 0,00 & 3,00 & 0,00 & 0,00 & 0,00 & 0,00 & 0,00 & 288,00 & $\begin{array}{ll}45,87 \\
\end{array}$ & 373 & 12,30 & $\mathrm{D}$ \\
\hline 7 & escritório & 6,11 & 5,49 & 33,54 & 2,80 & 1,03 & 0,00 & 0,00 & 3,00 & 0,00 & 0,00 & 0,00 & 0,00 & 0,00 & 288,00 & 8,59 & 181 & 4,74 & $\mathrm{D}$ \\
\hline 8 & escritório & 6,11 & 4,30 & 26,27 & 2,80 & 0,90 & 0,00 & 0,00 & 3,00 & 0,00 & 0,00 & 0,00 & 0,00 & 0,00 & 288,00 & 10,96 & 207 & 5,30 & $E$ \\
\hline 9 & escritório & 11,70 & 9,98 & 116,77 & 2,80 & 1,92 & 0,00 & 0,00 & 12,00 & 0,00 & 0,00 & 0,00 & 0,00 & 0,00 & 1152,00 & 9,87 & 261 & 3,78 & $E$ \\
\hline 10 & escritório & 10,88 & 6,12 & 66,59 & 2,80 & 1,40 & 0,00 & 0,00 & 8,00 & 0,00 & 0,00 & 0,00 & 0,00 & 0,00 & 768,00 & 11,53 & 262 & 4,40 & $E$ \\
\hline 11 & circulação & 5,70 & 2,64 & 15,05 & 2,80 & 0,64 & 0,00 & 0,00 & 0,00 & 0,00 & 0,00 & 0,00 & 0,00 & 2,00 & 120,00 & 7,97 & 63 & 12,66 & $E$ \\
\hline 12 & escritório & 7,59 & 5,70 & 43,26 & 2,80 & 1,16 & 0,00 & 0,00 & 0,00 & 0,00 & 0,00 & 0,00 & 0,00 & 6,00 & 360,00 & 8,32 & 98 & 8,49 & $E$ \\
\hline 13 & escritório & 12,95 & 9,63 & 124,71 & 2,80 & 1,97 & 0,00 & 0,00 & 0,00 & 0,00 & 0,00 & 0,00 & 0,00 & 28,00 & 1680,00 & 13,47 & 308 & 4,37 & $E$ \\
\hline 14 & depósito & 3,15 & 2,05 & 6,46 & 2,80 & 0,44 & 0,00 & 0,00 & 1,00 & 0,00 & 0,00 & 0,00 & 0,00 & 0,00 & 96,00 & 14,87 & 116 & 12,82 & C \\
\hline 15 & circulação & 4,13 & 3,75 & 15,49 & 2,80 & 0,70 & 0,00 & 0,00 & 1,00 & 0,00 & 0,00 & 0,00 & 0,00 & 0,00 & 96,00 & 6,20 & 86 & 7,21 & $E$ \\
\hline 16 & escritório & 5,97 & 4,09 & 24,42 & 2,80 & 0,87 & 0,00 & 0,00 & 2,00 & 0,00 & 0,00 & 0,00 & 0,00 & 0,00 & 192,00 & 7,86 & 172 & 4,57 & $\mathrm{D}$ \\
\hline 17 & escritório & 7,12 & 5,25 & 37,38 & 2,80 & 1,08 & 0,00 & 0,00 & 3,00 & 0,00 & 0,00 & 0,00 & 0,00 & 0,00 & 288,00 & 7,70 & 167 & 4,61 & $\mathrm{D}$ \\
\hline 18 & depósito & 5,2 & 3,47 & 18,04 & 2,80 & 0,74 & 0,00 & 0,00 & 0,00 & 0,00 & 2,00 & 0,00 & 0,00 & 0,00 & 144,00 & 7,98 & 139 & 5,74 & D \\
\hline 19 & escritório & 7,98 & 3,45 & 27,53 & 2,80 & 0,86 & 1,00 & 1,00 & 0,00 & 0,00 & 1,00 & 0,00 & 0,00 & 0,00 & 369,60 & 13,42 & 102 & 13,16 & $E$ \\
\hline 20 & escritório & 7,98 & 2,3 & 18,35 & 2,80 & 0,64 & 0,00 & 0,00 & 0,00 & 0,00 & 3,00 & 0,00 & 0,00 & 0,00 & 216,00 & 11,77 & 178 & 6,61 & $E$ \\
\hline 21 & circulação & 13,24 & 1,72 & 22,77 & 2,80 & 0,54 & 0,00 & 0,00 & 3,00 & 0,00 & 0,00 & 0,00 & 0,00 & 0,00 & 288,00 & 12,65 & 147 & 8,60 & $E$ \\
\hline 22 & escritório & 8,95 & 4,92 & 44,03 & 2,80 & 1,13 & 0,00 & 0,00 & 5,00 & 0,00 & 0,00 & 0,00 & 0,00 & 0,00 & 480,00 & 10,90 & 216 & 5,05 & $E$ \\
\hline 23 & escritório & 3,42 & 3,41 & 11,66 & 2,80 & 0,61 & 0,00 & 0,00 & 2,00 & 0,00 & 0,00 & 0,00 & 0,00 & 0,00 & 192,00 & 16,46 & 263 & 6,26 & $\mathrm{D}$ \\
\hline 24 & escritório & 4,75 & 2,7 & 12,83 & 2,80 & 0,61 & 0,00 & 0,00 & 2,00 & 0,00 & 0,00 & 0,00 & 0,00 & 0,00 & 192,00 & 14,97 & 240 & 6,24 & $\mathrm{D}$ \\
\hline 25 & escritório & 6,7 & 2,7 & 18,09 & 2,80 & 0,69 & 0,00 & 0,00 & 3,00 & 0,00 & 0,00 & 0,00 & 0,00 & 0,00 & 288,00 & 15,92 & 232 & 6,86 & $E$ \\
\hline 26 & escritório & 6,7 & 2,82 & 18,89 & 2,80 & 0,71 & 0,00 & 0,00 & 3,00 & 0,00 & 0,00 & 0,00 & 0,00 & 0,00 & 288,00 & 15,24 & 230 & 6,63 & $E$ \\
\hline 27 & escritório & 6,7 & 4,5 & 30,15 & 2,80 & 0,96 & 0,00 & 0,00 & 4,00 & 0,00 & 0,00 & 0,00 & 0,00 & 0,00 & 384,00 & 12,74 & 259 & 4,92 & $\mathrm{D}$ \\
\hline 28 & escritório & 2,75 & 1,84 & 5,06 & 2,80 & 0,39 & 0,00 & 0,00 & 1,00 & 0,00 & 0,00 & 0,00 & 0,00 & 0,00 & 96,00 & 18,97 & 124 & 15,30 & $\mathrm{D}$ \\
\hline 29 & escritório & 4,5 & 4 & 18,00 & 2,80 & 0,76 & 0,00 & 0,00 & 0,00 & 0,00 & 0,00 & 2,00 & 0,00 & 0,00 & 96,00 & 5,33 & 64 & 8,33 & $E$ \\
\hline 30 & banheiro & 4,37 & 4 & 17,48 & 2,80 & 0,75 & 0,00 & 0,00 & 0,00 & 0,00 & 1,00 & 0,00 & 0,00 & 1,00 & 132,00 & 7,55 & 148 & 5,10 & $\mathrm{D}$ \\
\hline 31 & circulação & 4,4 & 0,94 & 4,14 & 2,80 & 0,28 & 0,00 & 0,00 & 0,00 & 0,00 & 1,00 & 0,00 & 0,00 & 0,00 & 72,00 & 17,41 & 102 & 17,07 & C \\
\hline 32 & escritório & 15,14 & 6,2 & $\begin{array}{l}93,87 \\
\end{array}$ & 2,80 & 1,57 & 0,00 & 0,00 & 9,00 & 0,00 & 0,00 & 0,00 & 0,00 & 0,00 & 864,00 & 9,20 & 234 & 3,93 & $E$ \\
\hline 33 & escritório & 8,14 & 6,12 & 49,82 & 2,80 & 1,25 & 0,00 & 0,00 & 0,00 & 0,00 & 0,00 & 0,00 & 0,00 & 8,00 & 480,00 & 9,64 & 119 & 8,10 & $E$ \\
\hline 34 & circulação & 5,7 & 2,7 & 15,39 & 2,80 & 0,65 & 0,00 & 0,00 & 0,00 & 0,00 & 0,00 & 0,00 & 0,00 & 2,00 & 120,00 & 7,80 & 62 & 12,58 & $E$ \\
\hline 35 & banheiro & 4 & 1,1 & 4,40 & 2,80 & 0,31 & 0,00 & 0,00 & 0,00 & 0,00 & 0,00 & 1,00 & 0,00 & 0,00 & 48,00 & 10,91 & 48 & 22,73 & $E$ \\
\hline 36 & circulação & 5,3 & 1,2 & 6,36 & 2,80 & 0,35 & 0,00 & 0,00 & 0,00 & 0,00 & 0,00 & 1,00 & 0,00 & 0,00 & 48,00 & 7,55 & 39 & 19,35 & $E$ \\
\hline 37 & circulação & 12,33 & 8,45 & 104,19 & 2,80 & 1,79 & 0,00 & 0,00 & 2,00 & 0,00 & 0,00 & 0,00 & 0,00 & 0,00 & 192,00 & 1,84 & 65 & 2,84 & C \\
\hline
\end{tabular}


PRIMEIRO ESTUDO - LEVANTAMENTO DE DADOS - SEXTO PAVIMENTO

\begin{tabular}{|c|c|c|c|c|c|c|c|c|c|c|c|c|c|c|c|c|c|c|c|}
\hline $\begin{array}{l}\text { número } \\
\text { da } \\
\text { amostra }\end{array}$ & $\begin{array}{c}\text { tipo de } \\
\text { ambiente }\end{array}$ & $\begin{array}{c}\text { comprimento } \\
(\mathrm{m})\end{array}$ & $\begin{array}{c}\text { largura } \\
(\mathrm{m})\end{array}$ & $\begin{array}{l}\text { área } \\
\left(\mathrm{m}^{2}\right)\end{array}$ & $\begin{array}{l}\text { altura média } \\
(\mathrm{m})\end{array}$ & $\mathrm{K}$ & $\begin{array}{l}\text { gtd lum } \\
4 \times 40 W\end{array}$ & $\begin{array}{l}\text { qtd lum } \\
3 \times 40 \mathrm{~W}\end{array}$ & $\begin{array}{l}\text { qtd lum } \\
2 \times 40 W\end{array}$ & $\begin{array}{l}\text { qtd lum } \\
2 \times 32 W\end{array}$ & $\begin{array}{l}\text { qtd lum } \\
3 \times 20 \mathrm{~W}\end{array}$ & $\begin{array}{l}\text { qtd lum } \\
2 \times 20 W\end{array}$ & $\begin{array}{l}\text { qtd lum } \\
1 \times 20 \mathrm{~W}\end{array}$ & $\begin{array}{c}\text { qtd lum } \\
\text { inc } \\
1 \times 60 \mathrm{~W}\end{array}$ & $\begin{array}{l}\text { potência } \\
\text { total }(W)\end{array}$ & $\begin{array}{c}\text { densidade } \\
\left(\mathrm{W} / \mathrm{m}^{2}\right)\end{array}$ & $\begin{array}{l}\text { ilum } \\
\text { (Lux) }\end{array}$ & $\mathrm{DPl}_{\mathrm{RF}}$ & $\begin{array}{c}\text { nível de } \\
\text { eficiência }\end{array}$ \\
\hline 1 & banheiro & 8,65 & 8,00 & 69,20 & 2,80 & 1,48 & 0,00 & 0,00 & 6,00 & 0,00 & 0,00 & 0,00 & 0,00 & 0,00 & 576,00 & 8,32 & 216 & 3,85 & $\mathrm{D}$ \\
\hline 2 & banheiro & 8,65 & 2,75 & 23,79 & 2,80 & 0,75 & 0,00 & 0,00 & 4,00 & 0,00 & 0,00 & 0,00 & 0,00 & 0,00 & 384,00 & 16,14 & 243 & 6,64 & $E$ \\
\hline 3 & banheiro & 7,00 & 4,05 & 28,35 & 2,80 & 0,92 & 0,00 & 0,00 & 6,00 & 0,00 & 0,00 & 0,00 & 0,00 & 0,00 & 576,00 & 20,32 & 380 & 5,35 & $E$ \\
\hline 4 & banheiro & 9,29 & 5,85 & 54,35 & 2,80 & 1,28 & 0,00 & 0,00 & 10,00 & 0,00 & 0,00 & 0,00 & 0,00 & 0,00 & 960,00 & 17,66 & 367 & 4,81 & $E$ \\
\hline 5 & banheiro & 7,76 & 5,85 & 45,40 & 2,80 & 1,19 & 0,00 & 0,00 & 6,00 & 0,00 & 0,00 & 0,00 & 0,00 & 0,00 & 576,00 & 12,69 & 288 & 4,41 & $E$ \\
\hline 6 & área externa & 21,67 & 14,90 & 322,88 & 2,80 & 3,15 & 0,00 & 0,00 & 0,00 & 0,00 & 0,00 & 0,00 & 0,00 & 3,00 & 180,00 & 0,56 & \multicolumn{3}{|c|}{$\begin{array}{c}\text { não se aplica (área } \\
\text { externa) }\end{array}$} \\
\hline 7 & circulação & 10,90 & 1,20 & 13,08 & 2,80 & 0,39 & 0,00 & 0,00 & 3,00 & 0,00 & 0,00 & 0,00 & 0,00 & 0,00 & 288,00 & 22,02 & 178 & 12,37 & $\mathrm{C}$ \\
\hline 8 & circulação & 5,14 & 3,16 & 16,24 & 2,80 & 0,70 & 0,00 & 0,00 & 2,00 & 0,00 & 0,00 & 0,00 & 0,00 & 0,00 & 192,00 & 11,82 & 209 & 5,66 & $\mathrm{D}$ \\
\hline 9 & escritorio & 4,40 & 3,10 & 13,64 & 2,80 & 0,65 & 0,00 & 0,00 & 2,00 & 0,00 & 0,00 & 0,00 & 0,00 & 0,00 & 192,00 & 14,08 & 232 & 6,07 & D \\
\hline 10 & escritorio & 22,09 & 10,95 & 241,89 & 2,80 & 2,61 & 0,00 & 0,00 & 15,00 & 0,00 & 0,00 & 0,00 & 0,00 & 7,00 & 1860,00 & 7,69 & 184 & 4,18 & $E$ \\
\hline 11 & escritorio & 3,79 & 3,60 & 13,64 & 2,80 & 0,66 & 0,00 & 0,00 & 2,00 & 0,00 & 0,00 & 0,00 & 0,00 & 0,00 & 192,00 & 14,07 & 244 & 5,77 & $\mathrm{D}$ \\
\hline 12 & circulação & 4,65 & 3,10 & 14,42 & 2,80 & 0,66 & 0,00 & 0,00 & 0,00 & 0,00 & 0,00 & 0,00 & 0,00 & 1,00 & 60,00 & 4,16 & 38 & 10,95 & $E$ \\
\hline 13 & circulação & 3,35 & 1,35 & 4,52 & 2,80 & 0,34 & 0,00 & 0,00 & 1,00 & 0,00 & 0,00 & 0,00 & 0,00 & 0,00 & 96,00 & 21,23 & 116 & 18,30 & $\mathrm{D}$ \\
\hline 14 & circulação & 5,00 & 1,00 & 5,00 & 2,80 & 0,30 & 0,00 & 0,00 & 1,00 & 0,00 & 0,00 & 0,00 & 0,00 & 0,00 & 96,00 & 19,20 & 94 & 20,43 & $\mathrm{D}$ \\
\hline 15 & banheiro & 5,00 & 2,20 & 11,00 & 2,80 & 0,55 & 0,00 & 0,00 & 2,00 & 0,00 & 0,00 & 0,00 & 0,00 & 0,00 & 192,00 & 17,45 & 231 & 7,56 & $\mathrm{D}$ \\
\hline 16 & banheiro & 3,5 & 3,26 & 11,41 & 2,80 & 0,60 & 0,00 & 0,00 & 1,00 & 0,00 & 0,00 & 0,00 & 0,00 & 0,00 & 96,00 & 8,41 & 99 & 8,50 & $E$ \\
\hline 17 & banheiro & 3,54 & 2,85 & 10,09 & 2,80 & 0,56 & 0,00 & 0,00 & 1,00 & 0,00 & 0,00 & 0,00 & 0,00 & 0,00 & 96,00 & 9,52 & 102 & 9,33 & $E$ \\
\hline 18 & circulação & 5,5 & 3,1 & 17,05 & 2,80 & 0,71 & 0,00 & 0,00 & 1,00 & 0,00 & 0,00 & 0,00 & 0,00 & 0,00 & 96,00 & 5,63 & 77 & 7,31 & $E$ \\
\hline 19 & área externa & 20,18 & 14,55 & 293,62 & 2,80 & 3,02 & 0,00 & 0,00 & 0,00 & 0,00 & 0,00 & 0,00 & 0,00 & 3,00 & 180,00 & 0,61 & \multicolumn{3}{|c|}{$\begin{array}{c}\text { não se aplica (área } \\
\text { externa) }\end{array}$} \\
\hline
\end{tabular}




\section{ANEXO B}

\begin{tabular}{|c|c|c|c|c|c|c|c|c|c|c|c|c|c|}
\hline \multicolumn{14}{|c|}{ SEGUNDO ESTUDO - PAVIMENTO TÉRREO } \\
\hline $\begin{array}{c}\text { número } \\
\text { da } \\
\text { amostra }\end{array}$ & \begin{tabular}{|c|} 
tipo de \\
ambiente
\end{tabular} & $\begin{array}{c}\text { comprimento } \\
(\mathrm{m})\end{array}$ & $\begin{array}{c}\text { largura } \\
(\mathrm{m})\end{array}$ & $\begin{array}{l}\text { área } \\
\left(\mathrm{m}^{2}\right)\end{array}$ & $\begin{array}{l}\text { altura média } \\
\qquad(\mathrm{m})\end{array}$ & K & $\begin{array}{c}\text { qtd } \\
\text { lum } \\
2 \times 32 W\end{array}$ & $\begin{array}{c}\text { qtd } \\
\text { lum } \\
2 \times 16 W\end{array}$ & $\begin{array}{l}\text { potência } \\
\text { total (W) }\end{array}$ & $\begin{array}{c}\text { densidade } \\
\left(\mathrm{W} / \mathrm{m}^{2}\right)\end{array}$ & $\begin{array}{l}\text { ilum } \\
\text { (Lux) }\end{array}$ & $\mathrm{DPI}_{\mathrm{RF}}$ & $\begin{array}{l}\text { nível de } \\
\text { eficiência }\end{array}$ \\
\hline 1 & escritório & 24,05 & 11,80 & 283,79 & 2,80 & 2,83 & 40,00 & 0,00 & 2680,00 & 9,44 & 482,00 & 1,96 & $\mathrm{~B}$ \\
\hline 2 & escritório & 9,10 & 7,38 & 67,16 & 2,80 & 1,46 & 12,00 & 0,00 & 804,00 & 11,97 & 533,00 & 2,25 & $\mathrm{~B}$ \\
\hline 3 & escritório & 6,06 & 2,75 & 16,67 & 2,80 & 0,68 & 4,00 & 0,00 & 268,00 & 16,08 & 529,00 & 3,04 & $\mathrm{~B}$ \\
\hline 4 & escritório & 6,06 & 2,51 & 15,21 & 2,80 & 0,63 & 4,00 & 0,00 & 268,00 & 17,62 & 557,00 & 3,16 & $\mathrm{~B}$ \\
\hline 5 & escritório & 6,47 & 2,70 & 17,47 & 2,80 & 0,68 & 4,00 & 0,00 & 268,00 & 15,34 & 504,00 & 3,04 & $\mathrm{~B}$ \\
\hline 6 & escritório & 16,75 & 7,29 & 122,11 & 2,80 & 1,81 & 18,00 & 0,00 & 1206,00 & 9,88 & 466,00 & 2,12 & B \\
\hline 7 & escritório & 7,78 & 1,97 & 15,33 & 2,80 & 0,56 & 4,00 & 0,00 & 268,00 & 17,49 & 519,00 & 3,37 & $\mathrm{~B}$ \\
\hline 8 & circulação & 25,00 & 1,89 & 47,25 & 2,80 & 0,63 & 2,00 & 0,00 & 134,00 & 2,84 & 90,00 & 3,15 & B \\
\hline 9 & depósito & 3,75 & 2,10 & 7,88 & 2,80 & 0,48 & 1,00 & 0,00 & 67,00 & 8,51 & 230,00 & 3,70 & $\mathrm{~B}$ \\
\hline 10 & escritório & 3,30 & 3,00 & 9,90 & 2,80 & 0,56 & 2,00 & 0,00 & 134,00 & 13,54 & 401,00 & 3,38 & $\mathrm{~B}$ \\
\hline 11 & escritório & 21,13 & 9,94 & 210,03 & 2,80 & 2,41 & 32,00 & 0,00 & 2144,00 & 10,21 & 508,00 & 2,01 & $\mathrm{~B}$ \\
\hline 12 & depósito & 5,38 & 3,14 & 16,89 & 2,80 & 0,71 & 4,00 & 0,00 & 268,00 & 15,86 & 532,00 & 2,98 & $\mathrm{~B}$ \\
\hline 13 & depósito & 9,05 & 8,40 & 76,02 & 2,80 & 1,56 & 4,00 & 0,00 & 268,00 & 3,53 & 159,00 & 2,22 & B \\
\hline 14 & circulação & 5,75 & 2,05 & 11,79 & 2,80 & 0,54 & 1,00 & 0,00 & 67,00 & 5,68 & 132,00 & 4,31 & $\mathrm{~B}$ \\
\hline 15 & escritório & 4,17 & 2,90 & 12,09 & 2,80 & 0,61 & 4,00 & 0,00 & 268,00 & 22,16 & 686,00 & 3,23 & B \\
\hline 16 & escritório & 4,17 & 2,7 & 11,26 & 2,80 & 0,59 & 3,00 & 0,00 & 201,00 & 17,85 & 631,00 & 2,83 & $\mathrm{~B}$ \\
\hline 17 & escritório & 6,37 & 3,15 & 20,07 & 2,80 & 0,75 & 4,00 & 0,00 & 268,00 & 13,36 & 465,00 & 2,87 & $\mathrm{~B}$ \\
\hline 18 & circulação & 4,65 & 2,5 & 11,63 & 2,80 & 0,58 & 1,00 & 0,00 & 67,00 & 5,76 & 175,00 & 3,29 & $\mathrm{~B}$ \\
\hline 19 & escritório & 5,75 & 2,7 & 15,53 & 2,80 & 0,66 & 4,00 & 0,00 & 268,00 & 17,26 & 557,00 & 3,10 & $\mathrm{~B}$ \\
\hline 20 & circulação & 5,9 & 1,75 & 10,33 & 2,80 & 0,48 & 1,00 & 0,00 & 67,00 & 6,49 & 88,00 & 7,37 & B \\
\hline 21 & banheiro & 5,75 & 2,6 & 14,95 & 2,80 & 0,64 & 2,00 & 0,00 & 134,00 & 8,96 & 283,00 & 3,17 & $\mathrm{~B}$ \\
\hline 22 & escritório & 5,75 & 2,7 & 15,53 & 2,80 & 0,66 & 4,00 & 0,00 & 268,00 & 17,26 & 557,00 & 3,10 & $\mathrm{~B}$ \\
\hline 23 & escritório & 7,35 & 3,05 & 22,42 & 2,80 & 0,77 & 6,00 & 0,00 & 402,00 & 17,93 & 624,00 & 2,87 & $\mathrm{~B}$ \\
\hline 24 & banheiro & 2,6 & 1,35 & 3,51 & 2,80 & 0,32 & 0,00 & 1,00 & 35,00 & 9,97 & 170,00 & 5,87 & $\mathrm{~B}$ \\
\hline 25 & banheiro & 2,6 & 1,4 & 3,64 & 2,80 & 0,33 & 0,00 & 1,00 & 35,00 & 9,62 & 169,00 & 5,69 & $\mathrm{~B}$ \\
\hline 26 & escritório & 2,7 & 2,6 & 7,02 & 2,80 & 0,47 & 2,00 & 0,00 & 134,00 & 19,09 & 505,00 & 3,78 & $\mathrm{~B}$ \\
\hline 27 & depósito & 9,05 & 6,37 & 57,65 & 2,80 & 1,34 & 4,00 & 0,00 & 268,00 & 4,65 & 201,00 & 2,31 & B \\
\hline 28 & circulação & 10,54 & 8,83 & 93,07 & 2,80 & 1,72 & 4,00 & 0,00 & 268,00 & 2,88 & 134,00 & 2,15 & $\mathrm{~B}$ \\
\hline 29 & banheiro & 2,8 & 0,9 & 2,52 & 2,80 & 0,24 & 0,00 & 1,00 & 35,00 & 13,89 & 190,00 & 7,31 & $\mathrm{~B}$ \\
\hline 30 & depósito & 3 & 0,9 & 2,70 & 2,80 & 0,25 & 0,00 & 1,00 & 35,00 & 12,96 & 178,00 & 7,28 & $\mathrm{~B}$ \\
\hline 31 & banheiro & 2,46 & 1,77 & 4,35 & 3,80 & 0,27 & 0,00 & 1,00 & 35,00 & 8,04 & 154,00 & 5,22 & $\mathrm{~B}$ \\
\hline 32 & banheiro & 2,44 & 1,77 & 4,32 & 4,80 & 0,21 & 0,00 & 1,00 & 35,00 & 8,10 & 140,00 & 5,79 & B \\
\hline
\end{tabular}




\begin{tabular}{|c|c|c|c|c|c|c|c|c|c|c|c|c|c|}
\hline \multicolumn{14}{|c|}{ SEGUNDO ESTUDO - PRIMEIRO PAVIMENTO } \\
\hline $\begin{array}{c}\text { número } \\
\text { da } \\
\text { amostra }\end{array}$ & $\begin{array}{l}\text { tipo de } \\
\text { ambiente }\end{array}$ & $\begin{array}{c}\text { comprimento } \\
(\mathrm{m})\end{array}$ & $\begin{array}{l}\text { largura } \\
\text { (m) }\end{array}$ & $\begin{array}{l}\text { área } \\
\left(\mathrm{m}^{2}\right)\end{array}$ & $\begin{array}{l}\text { altura média } \\
(\mathrm{m})\end{array}$ & $\mathrm{K}$ & $\begin{array}{c}\text { gtd } \\
\text { lum } \\
2 \times 32 W\end{array}$ & $\begin{array}{c}\text { qtd } \\
\text { lum } \\
2 \times 16 \mathrm{~W}\end{array}$ & $\begin{array}{l}\text { potência } \\
\text { total (W) }\end{array}$ & $\begin{array}{l}\text { densidade } \\
\left(\mathrm{W} / \mathrm{m}^{2}\right)\end{array}$ & $\begin{array}{l}\text { ilum } \\
\text { (Lux) }\end{array}$ & $D P I_{R F}$ & $\begin{array}{l}\text { nível de } \\
\text { eficiência }\end{array}$ \\
\hline 1 & escritório & 11,88 & 9,20 & 109,30 & 2,80 & 1,85 & 16,00 & 0,00 & 1072,00 & 9,81 & 461,00 & 2,13 & B \\
\hline 2 & escritório & 8,85 & 6,19 & 54,78 & 2,80 & 1,30 & 10,00 & 0,00 & 670,00 & 12,23 & 520,00 & 2,35 & B \\
\hline 3 & escritório & 8,80 & 4,27 & 37,58 & 2,80 & 1,03 & 6,00 & 0,00 & 402,00 & 10,70 & 421,00 & 2,54 & B \\
\hline 4 & escritório & 11,78 & 5,95 & 70,09 & 2,80 & 1,41 & 12,00 & 0,00 & 804,00 & 11,47 & 502,00 & 2,29 & B \\
\hline 5 & escritório & 4,70 & 2,90 & 13,63 & 2,80 & 0,64 & 3,00 & 0,00 & 201,00 & 14,75 & 466,00 & 3,16 & $B$ \\
\hline 6 & escritório & 4,70 & 3,70 & 17,39 & 2,80 & 0,74 & 4,00 & 0,00 & 268,00 & 15,41 & 527,00 & 2,92 & B \\
\hline 7 & banheiro & 4,70 & 2,73 & 12,83 & 2,80 & 0,62 & 0,00 & 2,00 & 70,00 & 5,46 & 144,00 & 3,79 & B \\
\hline 8 & escritório & 7,73 & 6,56 & 50,71 & 2,80 & 1,27 & 9,00 & 0,00 & 603,00 & 11,89 & 506,00 & 2,35 & $B$ \\
\hline 9 & escritório & 4,19 & 3,10 & 12,99 & 2,80 & 0,64 & 3,00 & 0,00 & 201,00 & 15,47 & 489,00 & 3,16 & B \\
\hline 10 & escritório & 3,34 & 2,93 & 9,79 & 2,80 & 0,56 & 2,00 & 0,00 & 134,00 & 13,69 & 406,00 & 3,37 & B \\
\hline 11 & escritório & 8,22 & 7,43 & 61,07 & 2,80 & 1,39 & 12,00 & 0,00 & 804,00 & 13,16 & 577,00 & 2,28 & $B$ \\
\hline 12 & escritório & 4,02 & 1,87 & 7,52 & 2,80 & 0,46 & 2,00 & 0,00 & 134,00 & 17,83 & 460,00 & 3,88 & B \\
\hline 13 & banheiro & 2,75 & 1,25 & 3,44 & 2,80 & 0,31 & 0,00 & 1,00 & 35,00 & 10,18 & 168,00 & 6,06 & $B$ \\
\hline 14 & escritório & 3,95 & 2,62 & 10,35 & 2,80 & 0,56 & 3,00 & 0,00 & 201,00 & 19,42 & 576,00 & 3,37 & $B$ \\
\hline 15 & escritório & 2,95 & 2,80 & 8,26 & 2,80 & 0,51 & 2,00 & 0,00 & 134,00 & 16,22 & 450,00 & 3,61 & B \\
\hline 16 & escritório & 2,65 & 2,05 & 5,43 & 2,80 & 0,41 & 2,00 & 0,00 & 134,00 & 24,67 & 603,00 & 4,09 & $B$ \\
\hline 17 & escritório & 4,9 & 2,7 & 13,23 & 2,80 & 0,62 & 3,00 & 0,00 & 201,00 & 15,19 & 470,00 & 3,23 & B \\
\hline 18 & depósito & 4,2 & 1,85 & 7,77 & 2,80 & 0,46 & 1,00 & 0,00 & 67,00 & 8,62 & 222,00 & 3,88 & $\mathrm{~B}$ \\
\hline 19 & depósito & 4,2 & 2 & 8,40 & 2,80 & 0,48 & 1,00 & 0,00 & 67,00 & 7,98 & 216,00 & 3,69 & $B$ \\
\hline 20 & banheiro & 4 & 2,1 & 8,40 & 2,80 & 0,49 & 0,00 & 2,00 & 70,00 & 8,33 & 192,00 & 4,34 & $B$ \\
\hline 21 & banheiro & 3,9 & 2,55 & 9,95 & 2,80 & 0,55 & 0,00 & 2,00 & 70,00 & 7,04 & 174,00 & 4,05 & B \\
\hline 22 & escritório & 5,08 & 3,9 & 19,81 & 2,80 & 0,79 & 4,00 & 0,00 & 268,00 & 13,53 & 480,00 & 2,82 & $B$ \\
\hline 23 & escritório & 3,9 & 3,24 & 12,64 & 2,80 & 0,63 & 3,00 & 0,00 & 201,00 & 15,91 & 503,00 & 3,16 & $B$ \\
\hline 24 & escritório & 3,9 & 3,67 & 14,31 & 2,80 & 0,68 & 3,00 & 0,00 & 201,00 & 14,04 & 462,00 & 3,04 & $B$ \\
\hline 25 & depósito & 3,64 & 2,8 & 10,19 & 2,80 & 0,57 & 1,00 & 0,00 & 67,00 & 6,57 & 195,00 & 3,37 & B \\
\hline 26 & escritório & 3,64 & 3,27 & 11,90 & 2,80 & 0,62 & 3,00 & 0,00 & 201,00 & 16,89 & 523,00 & 3,23 & B \\
\hline 27 & escritório & 6,12 & 2,8 & 17,14 & 2,80 & 0,69 & 4,00 & 0,00 & 268,00 & 15,64 & 514,00 & 3,04 & $B$ \\
\hline 28 & escritório & 11,4 & 6,75 & 76,95 & 2,80 & 1,51 & 12,00 & 0,00 & 804,00 & 10,45 & 465,00 & 2,25 & $B$ \\
\hline 29 & escritório & 6,12 & 2,8 & 17,14 & 2,80 & 0,69 & 4,00 & 0,00 & 268,00 & 15,64 & 514,00 & 3,04 & B \\
\hline 30 & escritório & 6,12 & 2,9 & 17,75 & 2,80 & 0,70 & 4,00 & 0,00 & 268,00 & 15,10 & 506,00 & 2,98 & $B$ \\
\hline 31 & escritório & 5,65 & 5,4 & 30,51 & 2,80 & 0,99 & 6,00 & 0,00 & 402,00 & 13,18 & 510,00 & 2,58 & B \\
\hline 32 & escritório & 5,7 & 2,49 & 14,19 & 2,80 & 0,62 & 3,00 & 0,00 & 201,00 & 14,16 & 438,00 & 3,23 & $B$ \\
\hline 33 & circulação & 10,78 & 1,2 & 12,94 & 2,80 & 0,39 & 0,00 & 2,00 & 70,00 & 5,41 & 107,00 & 5,06 & $B$ \\
\hline 34 & escritório & 5,73 & 4,34 & 24,87 & 2,80 & 0,88 & 6,00 & 0,00 & 402,00 & 16,17 & 605,00 & 2,67 & B \\
\hline 35 & escritório & 5,67 & 3,87 & 21,94 & 2,80 & 0,82 & 6,00 & 0,00 & 402,00 & 18,32 & 661,00 & 2,77 & $\mathrm{~B}$ \\
\hline 36 & escritório & 3,22 & 2,64 & 8,50 & 2,80 & 0,52 & 2,00 & 0,00 & 134,00 & 15,76 & 447,00 & 3,53 & $\mathrm{~B}$ \\
\hline 37 & escritório & 3,52 & 3,23 & 11,37 & 2,80 & 0,60 & 3,00 & 0,00 & 201,00 & 17,68 & 547,00 & 3,23 & $B$ \\
\hline 38 & escritório & 3,27 & 3,23 & 10,56 & 2,80 & 0,58 & 3,00 & 0,00 & 201,00 & 19,03 & 577,00 & 3,30 & $B$ \\
\hline 39 & escritório & 10,68 & 8 & 85,44 & 2,80 & 1,63 & 16,00 & 0,00 & 1072,00 & 12,55 & 573,00 & 2,19 & $B$ \\
\hline 40 & escritório & 3,93 & 3,9 & 15,33 & 2,80 & 0,70 & 3,00 & 0,00 & 201,00 & 13,11 & 440,00 & 2,98 & B \\
\hline 41 & banheiro & 4 & 2,15 & 8,60 & 2,80 & 0,50 & 0,00 & 2,00 & 70,00 & 8,14 & 192,00 & 4,24 & $B$ \\
\hline 42 & escritório & 4 & 2,35 & 9,40 & 2,80 & 0,53 & 2,00 & 0,00 & 134,00 & 14,26 & 404,00 & 3,53 & $B$ \\
\hline 43 & escritório & 4 & 2,25 & 9,00 & 2,80 & 0,51 & 2,00 & 0,00 & 134,00 & 14,89 & 413,00 & 3,61 & $B$ \\
\hline 44 & banheiro & 4 & 1,95 & 7,80 & 2,80 & 0,47 & 0,00 & 1,00 & 35,00 & 4,49 & 101,00 & 4,44 & B \\
\hline 45 & circulação & 13,11 & 13,01 & 170,56 & 2,80 & 2,33 & 0,00 & 12,00 & 420,00 & 2,46 & 103,00 & 2,39 & B \\
\hline
\end{tabular}




\begin{tabular}{|c|c|c|c|c|c|c|c|c|c|c|c|c|c|}
\hline \multicolumn{14}{|c|}{ SEGUNDO ESTUDO - SEGUNDO PAVIMENTO } \\
\hline $\begin{array}{c}\text { número } \\
\text { da } \\
\text { amostra }\end{array}$ & $\begin{array}{c}\text { tipo de } \\
\text { ambiente }\end{array}$ & $\begin{array}{l}\text { comprimento } \\
(\mathrm{m})\end{array}$ & $\begin{array}{c}\text { largura } \\
(\mathrm{m})\end{array}$ & $\begin{array}{l}\text { área } \\
\left(\mathrm{m}^{2}\right)\end{array}$ & $\begin{array}{l}\text { altura média } \\
\qquad(\mathrm{m})\end{array}$ & K & $\begin{array}{c}\text { qtd } \\
\text { lum } \\
2 \times 32 W\end{array}$ & $\begin{array}{c}\text { qtd } \\
\text { lum } \\
2 \times 16 W\end{array}$ & $\begin{array}{l}\text { potência } \\
\text { total }(W)\end{array}$ & $\begin{array}{l}\text { densidade } \\
\left(\mathrm{W} / \mathrm{m}^{2}\right)\end{array}$ & $\begin{array}{l}\text { ilum } \\
\text { (Lux) }\end{array}$ & $\mathrm{DPI}_{\mathrm{RF}}$ & $\begin{array}{c}\text { nível de } \\
\text { eficiência }\end{array}$ \\
\hline 1 & escritório & 7,51 & 5,48 & 41,15 & 2,80 & 1,13 & 9,00 & 0,00 & 603,00 & 14,65 & 595,00 & 2,46 & B \\
\hline 2 & depósito & 6,35 & 1,86 & 11,81 & 2,80 & 0,51 & 0,00 & 2,00 & 70,00 & 5,93 & 140,00 & 4,23 & B \\
\hline 3 & escritório & 6,60 & 3,90 & 25,74 & 2,80 & 0,88 & 6,00 & 0,00 & 402,00 & 15,62 & 574,00 & 2,72 & B \\
\hline 4 & escritório & 4,03 & 3,98 & 16,04 & 2,80 & 0,72 & 4,00 & 0,00 & 268,00 & 16,71 & 560,00 & 2,98 & $B$ \\
\hline 5 & banheiro & 2,80 & 0,90 & 2,52 & 2,80 & 0,24 & 0,00 & 1,00 & 35,00 & 13,89 & 190,00 & 7,31 & B \\
\hline 6 & escritório & 4,00 & 1,95 & 7,80 & 2,80 & 0,47 & 2,00 & 0,00 & 134,00 & 17,18 & 454,00 & 3,78 & B \\
\hline 7 & depósito & 4,00 & 1,10 & 4,40 & 2,80 & 0,31 & 0,00 & 2,00 & 70,00 & 15,91 & 262,00 & 6,07 & $B$ \\
\hline 8 & circulação & 4,40 & 1,10 & 4,84 & 2,80 & 0,31 & 0,00 & 1,00 & 35,00 & 7,23 & 123,00 & 5,88 & $B$ \\
\hline 9 & banheiro & 2,80 & 2,35 & 6,58 & 2,80 & 0,46 & 0,00 & 1,00 & 35,00 & 5,32 & 117,00 & 4,55 & B \\
\hline 10 & escritório & 4,00 & 2,90 & 11,60 & 2,80 & 0,60 & 3,00 & 0,00 & 201,00 & 17,33 & 536,00 & 3,23 & $B$ \\
\hline 11 & banheiro & 4,10 & 2,02 & 8,28 & 2,80 & 0,48 & 0,00 & 2,00 & 70,00 & 8,45 & 195,00 & 4,33 & $B$ \\
\hline 12 & escritório & 7,32 & 3,90 & 28,55 & 2,80 & 0,91 & 6,00 & 0,00 & 402,00 & 14,08 & 527,00 & 2,67 & $B$ \\
\hline 13 & escritório & 3,90 & 2,92 & 11,39 & 2,80 & 0,60 & 3,00 & 0,00 & 201,00 & 17,65 & 535,00 & 3,30 & B \\
\hline 14 & escritório & 5,12 & 3,02 & 15,46 & 2,80 & 0,68 & 4,00 & 0,00 & 268,00 & 17,33 & 570,00 & 3,04 & B \\
\hline 15 & escritório & 5,95 & 5,12 & 30,46 & 2,80 & 0,98 & 6,00 & 0,00 & 402,00 & 13,20 & 511,00 & 2,58 & B \\
\hline 16 & escritório & 12 & 10,71 & 128,52 & 2,80 & 2,02 & 20,00 & 0,00 & 1340,00 & 10,43 & 498,00 & 2,09 & $B$ \\
\hline 17 & escritório & 5,52 & 5,24 & 28,92 & 2,80 & 0,96 & 6,00 & 0,00 & 402,00 & 13,90 & 538,00 & 2,58 & $B$ \\
\hline 18 & escritório & 8,8 & 2,98 & 26,22 & 2,80 & 0,80 & 6,00 & 0,00 & 402,00 & 15,33 & 544,00 & 2,82 & $B$ \\
\hline 19 & escritório & 8,67 & 1,2 & 10,40 & 2,80 & 0,38 & 0,00 & 2,00 & 70,00 & 6,73 & 129,00 & 5,22 & $B$ \\
\hline 20 & escritório & 6,68 & 5,62 & 37,54 & 2,80 & 1,09 & 8,00 & 0,00 & 536,00 & 14,28 & 580,00 & 2,46 & $B$ \\
\hline 21 & depósito & 11,35 & 5,46 & 61,97 & 2,80 & 1,32 & 6,00 & 0,00 & 402,00 & 6,49 & 279,00 & 2,33 & $B$ \\
\hline 22 & escritório & 3,11 & 2,75 & 8,55 & 2,80 & 0,52 & 2,00 & 0,00 & 134,00 & 15,67 & 445,00 & 3,52 & B \\
\hline 23 & escritório & 3,32 & 3,1 & 10,29 & 2,80 & 0,57 & 3,00 & 0,00 & 201,00 & 19,53 & 579,00 & 3,37 & $B$ \\
\hline 24 & escritório & 4,62 & 3,9 & 18,02 & 2,80 & 0,76 & 4,00 & 0,00 & 268,00 & 14,87 & 518,00 & 2,87 & B \\
\hline 25 & escritório & 4,03 & 3,93 & 15,84 & 2,80 & 0,71 & 4,00 & 0,00 & 268,00 & 16,92 & 567,00 & 2,98 & B \\
\hline 26 & banheiro & 2,85 & 1,1 & 3,14 & 2,80 & 0,28 & 0,00 & 1,00 & 35,00 & 11,16 & 171,00 & 6,53 & $B$ \\
\hline 27 & escritório & 4 & 2,15 & 8,60 & 2,80 & 0,50 & 2,00 & 0,00 & 134,00 & 15,58 & 432,00 & 3,61 & $B$ \\
\hline 28 & banheiro & 8 & 4 & 32,00 & 2,80 & 0,95 & 0,00 & 6,00 & 210,00 & 6,56 & 212,00 & 3,10 & $B$ \\
\hline 29 & escritório & 4,79 & 4 & 19,16 & 2,80 & 0,78 & 4,00 & 0,00 & 268,00 & 13,99 & 487,00 & 2,87 & $B$ \\
\hline 30 & banheiro & 2,65 & 0,8 & 2,12 & 2,80 & 0,22 & 0,00 & 1,00 & 35,00 & 16,51 & 208,00 & 7,94 & $B$ \\
\hline 31 & escritório & 4,8 & 2,92 & 14,02 & 2,80 & 0,65 & 3,00 & 0,00 & 201,00 & 14,34 & 462,00 & 3,10 & B \\
\hline 32 & escritório & 11,7 & 4,55 & 53,24 & 2,80 & 1,17 & 10,00 & 0,00 & 670,00 & 12,59 & 519,00 & 2,42 & $B$ \\
\hline 33 & escritório & 4,6 & 4,5 & 20,70 & 2,80 & 0,81 & 4,00 & 0,00 & 268,00 & 12,95 & 459,00 & 2,82 & B \\
\hline 34 & escritório & 5,57 & 3,15 & 17,55 & 2,80 & 0,72 & 4,00 & 0,00 & 268,00 & 15,27 & 512,00 & 2,98 & B \\
\hline 35 & escritório & 4,4 & 2,9 & 12,76 & 2,80 & 0,62 & 3,00 & 0,00 & 201,00 & 15,75 & 498,00 & 3,16 & $B$ \\
\hline 36 & escritório & 9,06 & 6,84 & 61,97 & 2,80 & 1,39 & 12,00 & 0,00 & 804,00 & 12,97 & 569,00 & 2,28 & $B$ \\
\hline 37 & escritório & 5,21 & 4,6 & 23,97 & 2,80 & 0,87 & 6,00 & 0,00 & 402,00 & 16,77 & 616,00 & 2,72 & $B$ \\
\hline 38 & escritório & 9,85 & 5,38 & 52,99 & 2,80 & 1,24 & 12,00 & 0,00 & 804,00 & 15,17 & 636,00 & 2,39 & $B$ \\
\hline 39 & escritório & 5,35 & 4,6 & 24,61 & 2,80 & 0,88 & 6,00 & 0,00 & 402,00 & 16,33 & 611,00 & 2,67 & $B$ \\
\hline 40 & escritório & 4,6 & 4,5 & 20,70 & 2,80 & 0,81 & 4,00 & 0,00 & 268,00 & 12,95 & 459,00 & 2,82 & B \\
\hline 41 & escritório & 7,71 & 7,04 & 54,28 & 2,80 & 1,31 & 9,00 & 0,00 & 603,00 & 11,11 & 480,00 & 2,31 & $B$ \\
\hline 42 & escritório & 6,2 & 3,94 & 24,43 & 2,80 & 0,86 & 6,00 & 0,00 & 402,00 & 16,46 & 605,00 & 2,72 & $B$ \\
\hline 43 & circulação & 16,15 & 11,78 & 190,25 & 2,80 & 2,43 & 0,00 & 16,00 & 560,00 & 2,94 & 125,00 & 2,35 & B \\
\hline
\end{tabular}




\begin{tabular}{|c|c|c|c|c|c|c|c|c|c|c|c|c|c|}
\hline \multicolumn{14}{|c|}{ SEGUNDO ESTUDO - TERCEIRO PAVIMENTO } \\
\hline $\begin{array}{c}\text { número } \\
\text { da } \\
\text { amostra }\end{array}$ & $\begin{array}{c}\text { tipo de } \\
\text { ambiente }\end{array}$ & $\begin{array}{l}\text { comprimento } \\
(\mathrm{m})\end{array}$ & $\begin{array}{c}\text { largura } \\
(\mathrm{m})\end{array}$ & $\begin{array}{l}\text { área } \\
\left(\mathrm{m}^{2}\right)\end{array}$ & $\begin{array}{l}\text { altura média } \\
\qquad(\mathrm{m})\end{array}$ & K & $\begin{array}{c}\text { qtd } \\
\text { lum } \\
2 \times 32 W\end{array}$ & $\begin{array}{c}\text { qtd } \\
\text { lum } \\
2 \times 16 W\end{array}$ & $\begin{array}{l}\text { potência } \\
\text { total (W) }\end{array}$ & $\begin{array}{c}\text { densidade } \\
\left(\mathrm{W} / \mathrm{m}^{2}\right)\end{array}$ & $\begin{array}{l}\text { ilum } \\
\text { (Lux) }\end{array}$ & $D P I_{R F}$ & $\begin{array}{c}\text { nível de } \\
\text { eficiência }\end{array}$ \\
\hline 1 & depósito & 18,81 & 10,28 & 193,37 & 2,80 & 2,37 & 0,00 & 30,00 & 1050,00 & 5,43 & 229,00 & 2,37 & $\mathrm{~B}$ \\
\hline 2 & escritório & 8,45 & 5,80 & 49,01 & 2,80 & 1,23 & 9,00 & 0,00 & 603,00 & 12,30 & 516,00 & 2,38 & $\mathrm{~B}$ \\
\hline 3 & escritório & 4,47 & 2,98 & 13,32 & 2,80 & 0,64 & 3,00 & 0,00 & 201,00 & 15,09 & 477,00 & 3,16 & $\mathrm{~B}$ \\
\hline 4 & banheiro & 3,40 & 2,35 & 7,99 & 2,80 & 0,50 & 0,00 & 2,00 & 70,00 & 8,76 & 202,00 & 4,34 & $\mathrm{~B}$ \\
\hline 5 & escritório & 3,57 & 3,86 & 13,78 & 2,80 & 0,66 & 3,00 & 0,00 & 201,00 & 14,59 & 470,00 & 3,10 & $B$ \\
\hline 6 & circulação & 4,40 & 1,10 & 4,84 & 2,80 & 0,31 & 0,00 & 1,00 & 35,00 & 7,23 & 123,00 & 5,88 & $\mathrm{~B}$ \\
\hline 7 & escritório & 4,00 & 2,35 & 9,40 & 2,80 & 0,53 & 3,00 & 0,00 & 201,00 & 21,38 & 607,00 & 3,52 & $B$ \\
\hline 8 & banheiro & 4,00 & 3,88 & 15,52 & 2,80 & 0,70 & 0,00 & 2,00 & 70,00 & 4,51 & 129,00 & 3,50 & $B$ \\
\hline 9 & escritório & 5,52 & 4,70 & 25,94 & 2,80 & 0,91 & 6,00 & 0,00 & 402,00 & 15,49 & 579,00 & 2,68 & $B$ \\
\hline 10 & escritório & 5,65 & 4,70 & 26,56 & 2,80 & 0,92 & 6,00 & 0,00 & 402,00 & 15,14 & 566,00 & 2,67 & $B$ \\
\hline 11 & escritório & 3,70 & 2,80 & 10,36 & 2,80 & 0,57 & 3,00 & 0,00 & 201,00 & 19,40 & 575,00 & 3,37 & $\mathrm{~B}$ \\
\hline 12 & escritório & 3,70 & 3,28 & 12,14 & 2,80 & 0,62 & 3,00 & 0,00 & 201,00 & 16,56 & 513,00 & 3,23 & $B$ \\
\hline 13 & escritório & 6,12 & 2,98 & 18,24 & 2,80 & 0,72 & 4,00 & 0,00 & 268,00 & 14,69 & 493,00 & 2,98 & $\mathrm{~B}$ \\
\hline 14 & escritório & 6,12 & 2,80 & 17,14 & 2,80 & 0,69 & 4,00 & 0,00 & 268,00 & 15,64 & 514,00 & 3,04 & $B$ \\
\hline 15 & escritório & 6,12 & 2,62 & 16,03 & 2,80 & 0,66 & 4,00 & 0,00 & 268,00 & 16,71 & 539,00 & 3,10 & $B$ \\
\hline 16 & escritório & 9,95 & 7,44 & 74,03 & 2,80 & 1,52 & 16,00 & 0,00 & 1072,00 & 14,48 & 644,00 & 2,25 & $B$ \\
\hline 17 & depósito & 5,64 & 4,08 & 23,01 & 2,80 & 0,85 & 0,00 & 4,00 & 140,00 & 6,08 & 187,00 & 3,25 & $B$ \\
\hline 18 & escritório & 5,04 & 4,11 & 20,71 & 2,80 & 0,81 & 4,00 & 0,00 & 268,00 & 12,94 & 459,00 & 2,82 & $B$ \\
\hline 19 & escritório & 4 & 2,25 & 9,00 & 2,80 & 0,51 & 3,00 & 0,00 & 201,00 & 22,33 & 619,00 & 3,61 & $B$ \\
\hline 20 & escritório & 5,7 & 5,26 & 29,98 & 2,80 & 0,98 & 6,00 & 0,00 & 402,00 & 13,41 & 519,00 & 2,58 & $B$ \\
\hline 21 & escritório & 5,7 & 4,19 & 23,88 & 2,80 & 0,86 & 6,00 & 0,00 & 402,00 & 16,83 & 619,00 & 2,72 & $B$ \\
\hline 22 & escritório & 5,7 & 2,7 & 15,39 & 2,80 & 0,65 & 4,00 & 0,00 & 268,00 & 17,41 & 561,00 & 3,10 & $\mathrm{~B}$ \\
\hline 23 & escritório & 5,7 & 2,85 & 16,25 & 2,80 & 0,68 & 4,00 & 0,00 & 268,00 & 16,50 & 542,00 & 3,04 & $B$ \\
\hline 24 & escritório & 5,7 & 3,62 & 20,63 & 2,80 & 0,79 & 4,00 & 0,00 & 268,00 & 12,99 & 461,00 & 2,82 & $\mathrm{~B}$ \\
\hline 25 & escritório & 5,7 & 2,5 & 14,25 & 2,80 & 0,62 & 4,00 & 0,00 & 268,00 & 18,81 & 582,00 & 3,23 & $B$ \\
\hline 26 & escritório & 6,05 & 5,83 & 35,27 & 2,80 & 1,06 & 6,00 & 0,00 & 402,00 & 11,40 & 456,00 & 2,50 & $\mathrm{~B}$ \\
\hline 27 & escritório & 3,9 & 3,5 & 13,65 & 2,80 & 0,66 & 3,00 & 0,00 & 201,00 & 14,73 & 475,00 & 3,10 & $B$ \\
\hline 28 & escritório & 4,44 & 3,9 & 17,32 & 2,80 & 0,74 & 4,00 & 0,00 & 268,00 & 15,48 & 529,00 & 2,93 & $B$ \\
\hline 29 & escritório & 5,01 & 3,9 & 19,54 & 2,80 & 0,78 & 4,00 & 0,00 & 268,00 & 13,72 & 486,00 & 2,82 & $B$ \\
\hline 30 & circulação & 17,04 & 2,1 & 35,78 & 2,80 & 0,67 & 0,00 & 4,00 & 140,00 & 3,91 & 108,00 & 3,62 & $B$ \\
\hline 31 & banheiro & 3,9 & 2,05 & 8,00 & 2,80 & 0,48 & 0,00 & 2,00 & 70,00 & 8,76 & 202,00 & 4,33 & $\mathrm{~B}$ \\
\hline 32 & banheiro & 9,15 & 4 & 36,60 & 2,80 & 0,99 & 0,00 & 6,00 & 210,00 & 5,74 & 189,00 & 3,04 & $B$ \\
\hline 33 & banheiro & 3,9 & 2,42 & 9,44 & 2,80 & 0,53 & 0,00 & 2,00 & 70,00 & 7,42 & 179,00 & 4,14 & $\mathrm{~B}$ \\
\hline 34 & escritório & 4,18 & 3,9 & 16,30 & 2,80 & 0,72 & 4,00 & 0,00 & 268,00 & 16,44 & 551,00 & 2,98 & $B$ \\
\hline 35 & escritório & 4,14 & 3,9 & 16,15 & 2,80 & 0,72 & 4,00 & 0,00 & 268,00 & 16,60 & 557,00 & 2,98 & $B$ \\
\hline 36 & escritório & 5,8 & 3,9 & 22,62 & 2,80 & 0,83 & 6,00 & 0,00 & 402,00 & 17,77 & 642,00 & 2,77 & $B$ \\
\hline 37 & escritório & 4,51 & 3,9 & 17,59 & 2,80 & 0,75 & 4,00 & 0,00 & 268,00 & 15,24 & 521,00 & 2,92 & $B$ \\
\hline 38 & depósito & 2,32 & 1,95 & 4,52 & 2,80 & 0,38 & 0,00 & 1,00 & 35,00 & 7,74 & 149,00 & 5,19 & $B$ \\
\hline 39 & circulação & 3,8 & 1,91 & 7,26 & 2,80 & 0,45 & 0,00 & 1,00 & 35,00 & 4,82 & 106,00 & 4,55 & $B$ \\
\hline 40 & circulação & 12,64 & 1,27 & 16,05 & 2,80 & 0,41 & 0,00 & 3,00 & 105,00 & 6,54 & 133,00 & 4,92 & $B$ \\
\hline 41 & escritório & 5,82 & 3,74 & 21,77 & 2,80 & 0,81 & 6,00 & 0,00 & 402,00 & 18,47 & 655,00 & 2,82 & $B$ \\
\hline 42 & escritório & 5,82 & 2,38 & 13,85 & 2,80 & 0,60 & 4,00 & 0,00 & 268,00 & 19,35 & 599,00 & 3,23 & $B$ \\
\hline 43 & escritório & 6,89 & 6,48 & 44,65 & 2,80 & 1,19 & 9,00 & 0,00 & 603,00 & 13,51 & 566,00 & 2,39 & $B$ \\
\hline 44 & escritório & 4,91 & 2,09 & 10,26 & 2,80 & 0,52 & 3,00 & 0,00 & 201,00 & 19,59 & 556,00 & 3,52 & $B$ \\
\hline 45 & depósito & 4 & 1,1 & 4,40 & 2,80 & 0,31 & 0,00 & 2,00 & 70,00 & 15,91 & 262,00 & 6,07 & $B$ \\
\hline 46 & circulação & 14,25 & 9,55 & 136,09 & 2,80 & 2,04 & 0,00 & 12,00 & 420,00 & 3,09 & 127,00 & 2,43 & $\mathrm{~B}$ \\
\hline
\end{tabular}




\begin{tabular}{|c|c|c|c|c|c|c|c|c|c|c|c|c|c|}
\hline \multicolumn{14}{|c|}{ SEGUNDO ESTUDO - QUARTO PAVIMENTO } \\
\hline $\begin{array}{c}\text { número } \\
\text { da } \\
\text { amostra }\end{array}$ & $\begin{array}{c}\text { tipo de } \\
\text { ambiente }\end{array}$ & $\begin{array}{l}\text { comprimento } \\
(\mathrm{m})\end{array}$ & $\begin{array}{c}\text { largura } \\
(\mathrm{m})\end{array}$ & $\begin{array}{l}\text { área } \\
\left(\mathrm{m}^{2}\right)\end{array}$ & $\begin{array}{c}\text { altura média } \\
(\mathrm{m})\end{array}$ & K & $\begin{array}{c}\text { qtd } \\
\text { lum } \\
2 \times 32 W\end{array}$ & $\begin{array}{c}\text { qtd } \\
\text { lum } \\
2 \times 16 W\end{array}$ & $\begin{array}{l}\text { potência } \\
\text { total (W) }\end{array}$ & $\begin{array}{c}\text { densidade } \\
\left(\mathrm{W} / \mathrm{m}^{2}\right)\end{array}$ & $\begin{array}{l}\text { ilum } \\
\text { (Lux) }\end{array}$ & $\mathrm{DPI} \mathrm{RF}_{\mathrm{RF}}$ & $\begin{array}{c}\text { nível de } \\
\text { eficiência }\end{array}$ \\
\hline 1 & escritório & 6,06 & 5,71 & 34,60 & 2,80 & 1,05 & 6,00 & 0,00 & 402,00 & 11,62 & 464,00 & 2,50 & $\mathrm{~B}$ \\
\hline 2 & escritório & 6,12 & 3,90 & 23,87 & 2,80 & 0,85 & 6,00 & 0,00 & 402,00 & 16,84 & \begin{tabular}{|l|}
619,00 \\
\end{tabular} & 2,72 & B \\
\hline 3 & escritório & 5,60 & 3,90 & 21,84 & 2,80 & 0,82 & 6,00 & 0,00 & 402,00 & 18,41 & 665,00 & 2,77 & B \\
\hline 4 & banheiro & 3,90 & 2,35 & 9,17 & 2,80 & 0,52 & 0,00 & 2,00 & 70,00 & 7,64 & 184,00 & 4,15 & $\mathrm{~B}$ \\
\hline 5 & banheiro & 4,00 & 3,00 & 12,00 & 2,80 & 0,61 & 0,00 & 2,00 & 70,00 & 5,83 & 154,00 & 3,79 & B \\
\hline 6 & banheiro & 4,00 & 2,35 & 9,40 & 2,80 & 0,53 & 0,00 & 2,00 & 70,00 & 7,45 & 180,00 & 4,14 & $\mathrm{~B}$ \\
\hline 7 & banheiro & 4,00 & 2,25 & 9,00 & 2,80 & 0,51 & 0,00 & 2,00 & 70,00 & 7,78 & 183,00 & 4,25 & $B$ \\
\hline 8 & banheiro & 4,10 & 2,75 & 11,28 & 2,80 & 0,59 & 0,00 & 2,00 & 70,00 & 6,21 & 160,00 & 3,88 & $\mathrm{~B}$ \\
\hline 9 & escritório & 7,12 & 3,90 & 27,77 & 2,80 & 0,90 & 6,00 & 0,00 & 402,00 & 14,48 & 541,00 & 2,68 & $\mathrm{~B}$ \\
\hline 10 & escritório & 6,89 & 5,10 & 35,14 & 2,80 & 1,05 & 6,00 & 0,00 & 402,00 & 11,44 & 457,00 & 2,50 & $B$ \\
\hline 11 & escritório & 6,32 & 5,25 & 33,18 & 2,80 & 1,02 & 6,00 & 0,00 & 402,00 & 12,12 & 477,00 & 2,54 & $B$ \\
\hline 12 & escritório & 6,35 & 6,32 & 40,13 & 2,80 & 1,13 & 8,00 & 0,00 & 536,00 & 13,36 & 543,00 & 2,46 & $B$ \\
\hline 13 & circulação & 8,59 & 1,66 & 14,26 & 2,80 & 0,50 & 0,00 & 2,00 & 70,00 & 4,91 & 113,00 & 4,34 & $\mathrm{~B}$ \\
\hline 14 & escritório & 4,65 & 4,45 & 20,69 & 2,80 & 0,81 & 4,00 & 0,00 & 268,00 & 12,95 & 459,00 & 2,82 & $B$ \\
\hline 15 & escritório & 5,44 & 4,64 & 25,24 & 2,80 & 0,89 & 6,00 & 0,00 & 402,00 & 15,93 & 596,00 & 2,67 & $\mathrm{~B}$ \\
\hline 16 & escritório & 6,89 & 3,15 & 21,70 & 2,80 & 0,77 & 6,00 & 0,00 & 402,00 & 18,52 & 645,00 & 2,87 & $B$ \\
\hline 17 & escritório & 5,66 & 4,08 & 23,09 & 2,80 & 0,85 & 6,00 & 0,00 & 402,00 & 17,41 & 640,00 & 2,72 & $\mathrm{~B}$ \\
\hline 18 & depósito & 6,16 & 2,1 & 12,94 & 2,80 & 0,56 & 0,00 & 3,00 & 105,00 & 8,12 & 205,00 & 3,96 & $\mathrm{~B}$ \\
\hline 19 & escritório & 4,03 & 2,78 & 11,20 & 2,80 & 0,59 & 3,00 & 0,00 & 201,00 & 17,94 & 544,00 & 3,30 & $B$ \\
\hline 20 & escritório & 4,03 & 3,84 & 15,48 & 2,80 & 0,70 & 4,00 & 0,00 & 268,00 & 17,32 & 581,00 & 2,98 & $B$ \\
\hline 21 & escritório & 6,53 & 4,35 & 28,41 & 2,80 & 0,93 & 6,00 & 0,00 & 402,00 & 14,15 & 538,00 & 2,63 & $B$ \\
\hline 22 & circulação & 11,09 & 1,2 & 13,31 & 2,80 & 0,39 & 0,00 & 2,00 & 70,00 & 5,26 & 104,00 & 5,06 & $\mathrm{~B}$ \\
\hline 23 & depósito & 4,11 & 2,47 & 10,15 & 2,80 & 0,55 & 0,00 & 2,00 & 70,00 & 6,90 & 170,00 & 4,06 & $\mathrm{~B}$ \\
\hline 24 & escritório & 6,43 & 2,79 & 17,94 & 2,80 & 0,69 & 4,00 & 0,00 & 268,00 & 14,94 & 491,00 & 3,04 & $\mathrm{~B}$ \\
\hline 25 & escritório & 6,43 & 2,85 & 18,33 & 2,80 & 0,71 & 4,00 & 0,00 & 268,00 & 14,62 & 490,00 & 2,98 & $B$ \\
\hline 26 & escritório & 6,43 & 5,27 & 33,89 & 2,80 & 1,03 & 8,00 & 0,00 & 536,00 & 15,82 & 622,00 & 2,54 & $\mathrm{~B}$ \\
\hline 27 & escritório & 6,43 & 3,28 & 21,09 & 2,80 & 0,78 & 6,00 & 0,00 & 402,00 & 19,06 & 664,00 & 2,87 & $\mathrm{~B}$ \\
\hline 28 & escritório & 6,55 & 3,91 & 25,61 & 2,80 & 0,87 & 6,00 & 0,00 & 402,00 & 15,70 & 577,00 & 2,72 & $B$ \\
\hline 29 & banheiro & 2,8 & 1,1 & 3,08 & 2,80 & 0,28 & 0,00 & 1,00 & 35,00 & 11,36 & 175,00 & 6,49 & $\mathrm{~B}$ \\
\hline 30 & escritório & 4,5 & 4 & 18,00 & 2,80 & 0,76 & 4,00 & 0,00 & 268,00 & 14,89 & 518,00 & 2,87 & B \\
\hline 31 & escritório & 3,19 & 4 & 12,76 & 2,80 & 0,63 & 3,00 & 0,00 & 201,00 & 15,75 & 498,00 & 3,16 & $\mathrm{~B}$ \\
\hline 32 & banheiro & 2,85 & 1,6 & 4,56 & 2,80 & 0,37 & 0,00 & 1,00 & 35,00 & 7,68 & 143,00 & 5,37 & $B$ \\
\hline 33 & banheiro & 5,43 & 2,65 & 14,39 & 2,80 & 0,64 & 0,00 & 2,00 & 70,00 & 4,86 & 131,00 & 3,71 & $\mathrm{~B}$ \\
\hline 34 & escritório & 5,42 & 4,09 & 22,17 & 2,80 & 0,83 & 6,00 & 0,00 & 402,00 & 18,13 & 655,00 & 2,77 & $B$ \\
\hline 35 & escritório & 5,65 & 5,42 & 30,62 & 2,80 & 0,99 & 6,00 & 0,00 & 402,00 & 13,13 & 508,00 & 2,58 & $\mathrm{~B}$ \\
\hline 36 & escritório & 5,7 & 3,58 & 20,41 & 2,80 & 0,79 & 4,00 & 0,00 & 268,00 & 13,13 & 466,00 & 2,82 & $B$ \\
\hline 37 & banheiro & 3,58 & 3,28 & 11,74 & 2,80 & 0,61 & 0,00 & 2,00 & 70,00 & 5,96 & 157,00 & 3,80 & B \\
\hline 38 & escritório & 8,56 & 3,92 & 33,56 & 2,80 & 0,96 & 6,00 & 0,00 & 402,00 & 11,98 & 463,00 & 2,59 & $B$ \\
\hline 39 & escritório & 6,29 & 3,65 & 22,96 & 2,80 & 0,82 & 6,00 & 0,00 & 402,00 & 17,51 & 632,00 & 2,77 & $B$ \\
\hline 40 & escritório & 6,29 & 4,73 & 29,75 & 2,80 & 0,96 & 6,00 & 0,00 & 402,00 & 13,51 & 523,00 & 2,58 & $\mathrm{~B}$ \\
\hline 41 & escritório & 7,05 & 4,86 & 34,26 & 2,80 & 1,03 & 6,00 & 0,00 & 402,00 & 11,73 & 461,00 & 2,55 & $\mathrm{~B}$ \\
\hline 42 & escritório & 5,71 & 4,16 & 23,75 & 2,80 & 0,86 & 6,00 & 0,00 & 402,00 & 16,92 & 622,00 & 2,72 & $\mathrm{~B}$ \\
\hline 43 & escritório & 4,16 & 2,42 & 10,07 & 2,80 & 0,55 & 3,00 & 0,00 & 201,00 & 19,97 & 579,00 & 3,45 & $\mathrm{~B}$ \\
\hline 44 & escritório & 5,71 & 3,34 & 19,07 & 2,80 & 0,75 & 4,00 & 0,00 & 268,00 & 14,05 & 489,00 & 2,87 & $B$ \\
\hline 45 & escritório & 6,12 & 5,99 & 36,66 & 2,80 & 1,08 & 8,00 & 0,00 & 536,00 & 14,62 & 585,00 & 2,50 & $B$ \\
\hline 46 & escritório & 5,99 & 5,6 & 33,54 & 2,80 & 1,03 & 8,00 & 0,00 & 536,00 & 15,98 & 628,00 & 2,54 & $\mathrm{~B}$ \\
\hline 47 & escritório & 4,34 & 3,04 & 13,19 & 2,80 & 0,64 & 3,00 & 0,00 & 201,00 & 15,23 & 481,00 & 3,17 & $\mathrm{~B}$ \\
\hline 48 & escritório & 5,71 & 2,74 & 15,65 & 2,80 & 0,66 & 4,00 & 0,00 & 268,00 & 17,13 & 552,00 & 3,10 & B \\
\hline 49 & circulação & 7,8 & 2,25 & 17,55 & 2,80 & 0,62 & 0,00 & 2,00 & 70,00 & 3,99 & 107,00 & 3,73 & $B$ \\
\hline 50 & escritório & 3,9 & 2,25 & 8,78 & 2,80 & 0,51 & 3,00 & 0,00 & 201,00 & 22,91 & 635,00 & 3,61 & B \\
\hline 51 & escritório & 3,99 & 3,9 & 15,56 & 2,80 & 0,70 & 4,00 & 0,00 & 268,00 & 17,22 & 577,00 & 2,98 & $\mathrm{~B}$ \\
\hline 52 & depósito & 2,9 & 2,6 & 7,54 & 2,80 & 0,49 & 0,00 & 2,00 & 70,00 & 9,28 & 214,00 & 4,34 & $\mathrm{~B}$ \\
\hline 53 & depósito & 4 & 1,1 & 4,40 & 2,80 & 0,31 & 0,00 & 2,00 & 70,00 & 15,91 & 262,00 & 6,07 & $\mathrm{~B}$ \\
\hline 54 & circulação & 4,4 & 1,1 & 4,84 & 2,80 & 0,31 & 0,00 & 1,00 & 35,00 & 7,23 & 123,00 & 5,88 & $B$ \\
\hline 55 & circulação & 16,15 & 10,62 & 171,51 & 2,80 & 2,29 & 0,00 & 16,00 & 560,00 & 3,27 & 137,00 & 2,38 & $B$ \\
\hline
\end{tabular}




\begin{tabular}{|c|c|c|c|c|c|c|c|c|c|c|c|c|c|}
\hline \multicolumn{14}{|c|}{ SEGUNDO ESTUDO - QUINTO PAVIMENTO } \\
\hline $\begin{array}{l}\text { número } \\
\text { da } \\
\text { amostra }\end{array}$ & $\begin{array}{c}\text { tipo de } \\
\text { ambiente }\end{array}$ & $\begin{array}{c}\text { comprimento } \\
\text { (m) }\end{array}$ & $\begin{array}{l}\text { largura } \\
\qquad(\mathrm{m})\end{array}$ & $\begin{array}{l}\text { área } \\
\left(\mathrm{m}^{2}\right)\end{array}$ & $\begin{array}{l}\text { altura média } \\
\qquad(\mathrm{m})\end{array}$ & K & $\begin{array}{c}\text { qtd } \\
\text { lum } \\
2 \times 32 W\end{array}$ & $\begin{array}{c}\text { qtd } \\
\text { lum } \\
2 \times 16 W\end{array}$ & $\begin{array}{l}\text { potência } \\
\text { total }(W)\end{array}$ & $\begin{array}{c}\text { densidade } \\
\left(\mathrm{W} / \mathrm{m}^{2}\right)\end{array}$ & $\begin{array}{l}\text { ilum } \\
\text { (Lux) }\end{array}$ & $D P I_{R F}$ & $\begin{array}{c}\text { nível de } \\
\text { eficiência }\end{array}$ \\
\hline 1 & escritório & 9,95 & 4,92 & 48,95 & 2,80 & 1,18 & 9,00 & 0,00 & 603,00 & 12,32 & 508,00 & 2,42 & B \\
\hline 2 & escritório & 8,13 & 4,92 & 40,00 & 2,80 & 1,09 & 8,00 & 0,00 & 536,00 & 13,40 & 544,00 & 2,46 & $\mathrm{~B}$ \\
\hline 3 & banheiro & 4,92 & 3,39 & 16,68 & 2,80 & 0,72 & 0,00 & 4,00 & 140,00 & 8,39 & 239,00 & 3,51 & $B$ \\
\hline 4 & banheiro & 4,00 & 3,20 & 12,80 & 2,80 & 0,63 & 0,00 & 2,00 & 70,00 & 5,47 & 147,00 & 3,72 & $\mathrm{~B}$ \\
\hline 5 & banheiro & 3,90 & 3,30 & 12,87 & 2,80 & 0,64 & 0,00 & 2,00 & 70,00 & 5,44 & 146,00 & 3,73 & $B$ \\
\hline 6 & banheiro & 3,90 & 1,61 & 6,28 & 2,80 & 0,41 & 0,00 & 2,00 & 70,00 & 11,15 & 226,00 & 4,93 & $\mathrm{~B}$ \\
\hline 7 & escritório & 6,11 & 5,49 & 33,54 & 2,80 & 1,03 & 8,00 & 0,00 & 536,00 & 15,98 & 628,00 & 2,54 & $B$ \\
\hline 8 & escritório & 6,11 & 4,30 & 26,27 & 2,80 & 0,90 & 6,00 & 0,00 & 402,00 & 15,30 & 572,00 & 2,67 & $B$ \\
\hline 9 & escritório & 11,70 & 9,98 & 116,77 & 2,80 & 1,92 & 20,00 & 0,00 & 1340,00 & 11,48 & 548,00 & 2,09 & $B$ \\
\hline 10 & escritório & 10,88 & 6,12 & 66,59 & 2,80 & 1,40 & 12,00 & 0,00 & 804,00 & 12,07 & 528,00 & 2,29 & B \\
\hline 11 & circulação & 5,70 & 2,64 & 15,05 & 2,80 & 0,64 & 0,00 & 2,00 & 70,00 & 4,65 & 125,00 & 3,72 & $B$ \\
\hline 12 & escritório & 7,59 & 5,70 & 43,26 & 2,80 & 1,16 & 9,00 & 0,00 & 603,00 & 13,94 & 575,00 & 2,42 & B \\
\hline 13 & escritório & 12,95 & 9,63 & 124,71 & 2,80 & 1,97 & 20,00 & 0,00 & 1340,00 & 10,75 & 511,00 & 2,10 & $B$ \\
\hline 14 & depósito & 3,15 & 2,05 & 6,46 & 2,80 & 0,44 & 0,00 & 2,00 & 70,00 & 10,84 & 232,00 & 4,67 & $B$ \\
\hline 15 & circulação & 4,13 & 3,75 & 15,49 & 2,80 & 0,70 & 0,00 & 2,00 & 70,00 & 4,52 & 129,00 & 3,50 & $B$ \\
\hline 16 & escritório & 5,97 & 4,09 & 24,42 & 2,80 & 0,87 & 6,00 & 0,00 & 402,00 & 16,46 & 605,00 & 2,72 & $B$ \\
\hline 17 & escritório & 7,12 & 5,25 & 37,38 & 2,80 & 1,08 & 9,00 & 0,00 & 603,00 & 16,13 & 645,00 & 2,50 & B \\
\hline 18 & depósito & 5,2 & 3,47 & 18,04 & 2,80 & 0,74 & 0,00 & 4,00 & 140,00 & 7,76 & 226,00 & 3,43 & B \\
\hline 19 & escritório & 7,98 & 3,45 & 27,53 & 2,80 & 0,86 & 6,00 & 0,00 & 402,00 & 14,60 & 537,00 & 2,72 & $\mathrm{~B}$ \\
\hline 20 & escritório & 7,98 & 2,3 & 18,35 & 2,80 & 0,64 & 5,00 & 0,00 & 335,00 & 18,25 & 577,00 & 3,16 & B \\
\hline 21 & circulação & 13,24 & 1,72 & 22,77 & 2,80 & 0,54 & 0,00 & 3,00 & 105,00 & 4,61 & 114,00 & 4,04 & $B$ \\
\hline 22 & escritório & 8,95 & 4,92 & 44,03 & 2,80 & 1,13 & 9,00 & 0,00 & 603,00 & 13,69 & 556,00 & 2,46 & $B$ \\
\hline 23 & escritório & 3,42 & 3,41 & 11,66 & 2,80 & 0,61 & 3,00 & 0,00 & 201,00 & 17,24 & 533,00 & 3,23 & $B$ \\
\hline 24 & escritório & 4,75 & 2,7 & 12,83 & 2,80 & 0,61 & 4,00 & 0,00 & 268,00 & 20,90 & 647,00 & 3,23 & $\mathrm{~B}$ \\
\hline 25 & escritório & 6,7 & 2,7 & 18,09 & 2,80 & 0,69 & 4,00 & 0,00 & 268,00 & 14,81 & 487,00 & 3,04 & $B$ \\
\hline 26 & escritório & 6,7 & 2,82 & 18,89 & 2,80 & 0,71 & 4,00 & 0,00 & 268,00 & 14,18 & 476,00 & 2,98 & $\mathrm{~B}$ \\
\hline 27 & escritório & 6,7 & 4,5 & 30,15 & 2,80 & 0,96 & 6,00 & 0,00 & 402,00 & 13,33 & 516,00 & 2,58 & $B$ \\
\hline 28 & escritório & 2,75 & 1,84 & 5,06 & 2,80 & 0,39 & 2,00 & 0,00 & 134,00 & 26,48 & 615,00 & 4,31 & $B$ \\
\hline 29 & escritório & 4,5 & 4 & 18,00 & 2,80 & 0,76 & 4,00 & 0,00 & 268,00 & 14,89 & 518,00 & 2,87 & $B$ \\
\hline 30 & banheiro & 4,37 & 4 & 17,48 & 2,80 & 0,75 & 4,00 & 0,00 & 268,00 & 15,33 & 233,00 & 6,58 & $\mathrm{~B}$ \\
\hline 31 & circulação & 4,4 & 0,94 & 4,14 & 2,80 & 0,28 & 0,00 & 1,00 & 35,00 & 8,46 & 130,00 & 6,51 & $B$ \\
\hline 32 & escritório & 15,14 & 6,2 & 93,87 & 2,80 & 1,57 & 20,00 & 0,00 & 1340,00 & 14,28 & 646,00 & 2,21 & $\mathrm{~B}$ \\
\hline 33 & escritório & 8,14 & 6,12 & 49,82 & 2,80 & 1,25 & 9,00 & 0,00 & 603,00 & 12,10 & 515,00 & 2,35 & $B$ \\
\hline 34 & circulação & 5,7 & 2,7 & 15,39 & 2,80 & 0,65 & 0,00 & 2,00 & 70,00 & 4,55 & 125,00 & 3,64 & B \\
\hline 35 & banheiro & 4 & 1,1 & 4,40 & 2,80 & 0,31 & 0,00 & 2,00 & 70,00 & 15,91 & 262,00 & 6,07 & $B$ \\
\hline 36 & circulação & 5,3 & 1,2 & 6,36 & 2,80 & 0,35 & 0,00 & 2,00 & 70,00 & 11,01 & 196,00 & 5,62 & B \\
\hline 37 & circulação & 12,33 & 8,45 & 104,19 & 2,80 & 1,79 & 0,00 & 12,00 & 420,00 & 4,03 & 160,00 & 2,52 & $B$ \\
\hline
\end{tabular}


SEGUNDO ESTUDO - SEXTO PAVIMENTO

\begin{tabular}{|c|c|c|c|c|c|c|c|c|c|c|c|c|c|}
\hline $\begin{array}{c}\text { número } \\
\text { da } \\
\text { amostra }\end{array}$ & $\begin{array}{c}\text { tipo de } \\
\text { ambiente }\end{array}$ & $\begin{array}{c}\text { comprimento } \\
\text { (m) }\end{array}$ & $\begin{array}{c}\text { largura } \\
(\mathrm{m})\end{array}$ & $\begin{array}{l}\text { área } \\
\left(\mathrm{m}^{2}\right)\end{array}$ & $\begin{array}{l}\text { altura média } \\
\text { (m) }\end{array}$ & K & $\begin{array}{c}\text { qtd } \\
\text { lum } \\
2 \times 32 W\end{array}$ & $\begin{array}{c}\text { qtd } \\
\text { lum } \\
2 \times 16 W\end{array}$ & $\begin{array}{l}\text { potência } \\
\text { total (W) }\end{array}$ & $\begin{array}{l}\text { densidade } \\
\left(\mathrm{W} / \mathrm{m}^{2}\right)\end{array}$ & $\begin{array}{l}\text { ilum } \\
\text { (Lux) }\end{array}$ & $\mathrm{DPI}_{\mathrm{RF}}$ & $\begin{array}{l}\text { nível de } \\
\text { eficiência }\end{array}$ \\
\hline 1 & banheiro & 8,65 & 8,00 & 69,20 & 2,80 & 1,48 & 0,00 & 12,00 & 420,00 & 6,07 & 230 & 2,64 & $B$ \\
\hline 2 & banheiro & 8,65 & 2,75 & 23,79 & 2,80 & 0,75 & 0,00 & 6,00 & 210,00 & 8,83 & 257 & 3,44 & $B$ \\
\hline 3 & banheiro & 7,00 & 4,05 & 28,35 & 2,80 & 0,92 & 0,00 & 6,00 & 210,00 & 7,41 & 236 & 3,14 & $B$ \\
\hline 4 & banheiro & 9,29 & 5,85 & 54,35 & 2,80 & 1,28 & 0,00 & 9,00 & 315,00 & 5,80 & 210 & 2,76 & $\mathrm{~B}$ \\
\hline 5 & banheiro & 7,76 & 5,85 & 45,40 & 2,80 & 1,19 & 0,00 & 6,00 & 210,00 & 4,63 & 165 & 2,80 & $\mathrm{~B}$ \\
\hline 6 & área externa & 21,67 & 14,90 & 322,88 & 2,80 & 3,15 & 0,00 & 0,00 & 0,00 & 0,00 & \multicolumn{3}{|c|}{ não se aplica (área externa) } \\
\hline 7 & circulação & 10,90 & 1,20 & 13,08 & 2,80 & 0,39 & 0,00 & 2,00 & 70,00 & 5,35 & 106 & 5,05 & $B$ \\
\hline 8 & circulação & 5,14 & 3,16 & 16,24 & 2,80 & 0,70 & 0,00 & 2,00 & 70,00 & 4,31 & 123 & 3,50 & $B$ \\
\hline 9 & escritório & 4,40 & 3,10 & 13,64 & 2,80 & 0,65 & 4,00 & 0,00 & 268,00 & 19,65 & 633 & 3,10 & $B$ \\
\hline 10 & escritório & 22,09 & 10,95 & 241,89 & 2,80 & 2,61 & 35,00 & 0,00 & 2345,00 & 9,69 & 485 & 2,00 & $\mathrm{~B}$ \\
\hline 11 & escritório & 3,79 & 3,60 & 13,64 & 2,80 & 0,66 & 3,00 & 0,00 & 201,00 & 14,73 & 475 & 3,10 & $B$ \\
\hline 12 & circulação & 4,65 & 3,10 & 14,42 & 2,80 & 0,66 & 0,00 & 2,00 & 70,00 & 4,86 & 133 & 3,65 & $\mathrm{~B}$ \\
\hline 13 & circulação & 3,35 & 1,35 & 4,52 & 2,80 & 0,34 & 0,00 & 1,00 & 35,00 & 7,74 & 140 & 5,53 & $B$ \\
\hline 14 & circulação & 5,00 & 1,00 & 5,00 & 2,80 & 0,30 & 0,00 & 1,00 & 35,00 & 7,00 & 111 & 6,31 & $B$ \\
\hline 15 & banheiro & 5,00 & 2,20 & 11,00 & 2,80 & 0,55 & 0,00 & 2,00 & 70,00 & 6,36 & 157 & 4,05 & $B$ \\
\hline 16 & banheiro & 3,5 & 3,26 & 11,41 & 2,80 & 0,60 & 0,00 & 2,00 & 70,00 & 6,13 & 162 & 3,79 & $B$ \\
\hline 17 & banheiro & 3,54 & 2,85 & 10,09 & 2,80 & 0,56 & 0,00 & 2,00 & 70,00 & 6,94 & 175 & 3,96 & $\mathrm{~B}$ \\
\hline 18 & circulação & 5,5 & 3,1 & 17,05 & 2,80 & 0,71 & 0,00 & 2,00 & 70,00 & 4,11 & 117 & 3,51 & $\mathrm{~B}$ \\
\hline 19 & área externa & 20,18 & 14,55 & 293,62 & 2,80 & 3,02 & 0,00 & 0,00 & 0,00 & 0,00 & \multicolumn{3}{|c|}{ não se aplica (área externa) } \\
\hline
\end{tabular}




\section{ANEXO C}

\begin{tabular}{|c|c|c|c|c|c|c|c|c|c|c|c|c|c|}
\hline \multicolumn{14}{|c|}{ TERCEIRO ESTUDO - PAVIMENTO TÉRREO } \\
\hline $\begin{array}{c}\text { número } \\
\text { da } \\
\text { amostra }\end{array}$ & $\begin{array}{c}\text { tipo de } \\
\text { ambiente }\end{array}$ & $\begin{array}{c}\text { comprimento } \\
(\mathrm{m})\end{array}$ & $\begin{array}{c}\text { largura } \\
(\mathrm{m})\end{array}$ & $\begin{array}{l}\text { área } \\
\left(\mathrm{m}^{2}\right)\end{array}$ & $\begin{array}{c}\text { altura média } \\
(\mathrm{m})\end{array}$ & K & $\begin{array}{c}\text { qtd } \\
\text { lum } \\
2 \times 32 W\end{array}$ & $\begin{array}{c}\text { qtd } \\
\text { lum } \\
2 \times 16 W\end{array}$ & $\begin{array}{l}\text { potência } \\
\text { total (W) }\end{array}$ & $\begin{array}{c}\text { densidade } \\
\left(\mathrm{W} / \mathrm{m}^{2}\right)\end{array}$ & $\begin{array}{l}\text { ilum } \\
\text { (Lux) }\end{array}$ & $\mathrm{DPI}_{\mathrm{RF}}$ & $\begin{array}{l}\text { nível de } \\
\text { eficiência }\end{array}$ \\
\hline 1 & escritório & 24,05 & 11,80 & 283,79 & 2,80 & 2,83 & 40,00 & 0,00 & 2680,00 & 9,44 & 421,00 & 2,24 & $\mathrm{~B}$ \\
\hline 2 & escritório & 9,10 & 7,38 & 67,16 & 2,80 & 1,46 & 12,00 & 0,00 & 804,00 & 11,97 & 463,00 & 2,59 & B \\
\hline 3 & escritório & 6,06 & 2,75 & 16,67 & 2,80 & 0,68 & 4,00 & 0,00 & 268,00 & 16,08 & 456,00 & 3,53 & $\mathrm{~B}$ \\
\hline 4 & escritório & 6,06 & 2,51 & 15,21 & 2,80 & 0,63 & 4,00 & 0,00 & 268,00 & 17,62 & 489,00 & 3,60 & $B$ \\
\hline 5 & escritório & 6,47 & 2,70 & 17,47 & 2,80 & 0,68 & 4,00 & 0,00 & 268,00 & 15,34 & 435,00 & 3,53 & $B$ \\
\hline 6 & escritório & 16,75 & 7,29 & 122,11 & 2,80 & 1,81 & 18,00 & 0,00 & 1206,00 & 9,88 & 409,00 & 2,41 & $B$ \\
\hline 7 & escritório & 7,78 & 1,97 & 15,33 & 2,80 & 0,56 & 4,00 & 0,00 & 268,00 & 17,49 & 451,00 & 3,88 & $B$ \\
\hline 8 & circulação & 25,00 & 1,89 & 47,25 & 2,80 & 0,63 & 2,00 & 0,00 & 134,00 & 2,84 & 77,00 & 3,68 & $B$ \\
\hline 9 & depósito & 3,75 & 2,10 & 7,88 & 2,80 & 0,48 & 1,00 & 0,00 & 67,00 & 8,51 & 197,00 & 4,32 & $\mathrm{~B}$ \\
\hline 10 & escritório & 3,30 & 3,00 & 9,90 & 2,80 & 0,56 & 2,00 & 0,00 & 134,00 & 13,54 & 349,00 & 3,88 & $B$ \\
\hline 11 & escritório & 21,13 & 9,94 & 210,03 & 2,80 & 2,41 & 32,00 & 0,00 & 2144,00 & 10,21 & 448,00 & 2,28 & $B$ \\
\hline 12 & depósito & 5,38 & 3,14 & 16,89 & 2,80 & 0,71 & 4,00 & 0,00 & 268,00 & 15,86 & 460,00 & 3,45 & $\mathrm{~B}$ \\
\hline 13 & depósito & 9,05 & 8,40 & 76,02 & 2,80 & 1,56 & 4,00 & 0,00 & 268,00 & 3,53 & 141,00 & 2,50 & $\mathrm{~B}$ \\
\hline 14 & circulação & 5,75 & 2,05 & 11,79 & 2,80 & 0,54 & 1,00 & 0,00 & 67,00 & 5,68 & 114,00 & 4,99 & $B$ \\
\hline 15 & escritório & 4,17 & 2,90 & 12,09 & 2,80 & 0,61 & 4,00 & 0,00 & 268,00 & 22,16 & 600,00 & 3,69 & $B$ \\
\hline 16 & escritório & 4,17 & 2,7 & 11,26 & 2,80 & 0,59 & 3,00 & 0,00 & 201,00 & 17,85 & 556,00 & 3,21 & $\mathrm{~B}$ \\
\hline 17 & escritório & 6,37 & 3,15 & 20,07 & 2,80 & 0,75 & 4,00 & 0,00 & 268,00 & 13,36 & 405,00 & 3,30 & $B$ \\
\hline 18 & circulação & 4,65 & 2,5 & 11,63 & 2,80 & 0,58 & 1,00 & 0,00 & 67,00 & 5,76 & 152,00 & 3,79 & $B$ \\
\hline 19 & escritório & 5,75 & 2,7 & 15,53 & 2,80 & 0,66 & 4,00 & 0,00 & 268,00 & 17,26 & 490,00 & 3,52 & $B$ \\
\hline 20 & circulação & 5,9 & 1,75 & 10,33 & 2,80 & 0,48 & 1,00 & 0,00 & 67,00 & 6,49 & 75,00 & 8,65 & $C$ \\
\hline 21 & banheiro & 5,75 & 2,6 & 14,95 & 2,80 & 0,64 & 2,00 & 0,00 & 134,00 & 8,96 & 249,00 & 3,60 & $B$ \\
\hline 22 & escritório & 5,75 & 2,7 & 15,53 & 2,80 & 0,66 & 4,00 & 0,00 & 268,00 & 17,26 & 490,00 & 3,52 & $B$ \\
\hline 23 & escritório & 7,35 & 3,05 & 22,42 & 2,80 & 0,77 & 6,00 & 0,00 & 402,00 & 17,93 & 543,00 & 3,30 & $B$ \\
\hline 24 & banheiro & 2,6 & 1,35 & 3,51 & 2,80 & 0,32 & 0,00 & 1,00 & 35,00 & 9,97 & 142,00 & 7,02 & $B$ \\
\hline 25 & banheiro & 2,6 & 1,4 & 3,64 & 2,80 & 0,33 & 0,00 & 1,00 & 35,00 & 9,62 & 142,00 & 6,77 & $B$ \\
\hline 26 & escritório & 2,7 & 2,6 & 7,02 & 2,80 & 0,47 & 2,00 & 0,00 & 134,00 & 19,09 & 443,00 & 4,31 & $\mathrm{~B}$ \\
\hline 27 & depósito & 9,05 & 6,37 & 57,65 & 2,80 & 1,34 & 4,00 & 0,00 & 268,00 & 4,65 & 177,00 & 2,63 & $B$ \\
\hline 28 & circulação & 10,54 & 8,83 & 93,07 & 2,80 & 1,72 & 4,00 & 0,00 & 268,00 & 2,88 & 117,00 & 2,46 & $\mathrm{~B}$ \\
\hline 29 & banheiro & 2,8 & 0,9 & 2,52 & 2,80 & 0,24 & 0,00 & 1,00 & 35,00 & 13,89 & 160,00 & 8,68 & $B$ \\
\hline 30 & depósito & 3 & 0,9 & 2,70 & 2,80 & 0,25 & 0,00 & 1,00 & 35,00 & 12,96 & 149,00 & 8,70 & $B$ \\
\hline 31 & banheiro & 2,46 & 1,77 & 4,35 & 3,80 & 0,27 & 0,00 & 1,00 & 35,00 & 8,04 & 128,00 & 6,28 & $\mathrm{~B}$ \\
\hline 32 & banheiro & 2,44 & 1,77 & 4,32 & 4,80 & 0,21 & 0,00 & 1,00 & 35,00 & 8,10 & 129,00 & 6,28 & $B$ \\
\hline
\end{tabular}




\begin{tabular}{|c|c|c|c|c|c|c|c|c|c|c|c|c|c|}
\hline \multicolumn{14}{|c|}{ TERCEIRO ESTUDO - PRIMEIRO PAVIMENTO } \\
\hline $\begin{array}{c}\text { número } \\
\text { da } \\
\text { amostra }\end{array}$ & $\begin{array}{c}\text { tipo de } \\
\text { ambiente }\end{array}$ & $\begin{array}{c}\text { comprimento } \\
\text { (m) }\end{array}$ & $\begin{array}{c}\text { largura } \\
(\mathrm{m})\end{array}$ & $\begin{array}{l}\text { área } \\
\left(\mathrm{m}^{2}\right)\end{array}$ & $\begin{array}{l}\text { altura média } \\
(\mathrm{m})\end{array}$ & K & $\begin{array}{c}\text { qtd } \\
\text { lum } \\
2 \times 32 W\end{array}$ & $\begin{array}{c}\text { qtd } \\
\text { lum } \\
2 \times 16 W\end{array}$ & $\begin{array}{l}\text { potência } \\
\text { total }(W)\end{array}$ & $\begin{array}{l}\text { densidade } \\
\left(\mathrm{W} / \mathrm{m}^{2}\right)\end{array}$ & $\begin{array}{l}\text { ilum } \\
\text { (Lux) }\end{array}$ & $\mathrm{DPI}_{\mathrm{RF}}$ & $\begin{array}{c}\text { nível de } \\
\text { eficiência }\end{array}$ \\
\hline 1 & escritório & 11,88 & 9,20 & 109,30 & 2,80 & 1,85 & 16,00 & 0,00 & 1072,00 & 9,81 & 404,00 & 2,43 & $\mathrm{~B}$ \\
\hline 2 & escritório & 8,85 & 6,19 & 54,78 & 2,80 & 1,30 & 10,00 & 0,00 & 670,00 & 12,23 & 457,00 & 2,68 & $\mathrm{~B}$ \\
\hline 3 & escritório & 8,80 & 4,27 & 37,58 & 2,80 & 1,03 & 6,00 & 0,00 & 402,00 & 10,70 & 372,00 & 2,88 & $\mathrm{~B}$ \\
\hline 4 & escritório & 11,78 & 5,95 & 70,09 & 2,80 & 1,41 & 12,00 & 0,00 & 804,00 & 11,47 & 443,00 & 2,59 & $\mathrm{~B}$ \\
\hline 5 & escritório & 4,70 & 2,90 & 13,63 & 2,80 & 0,64 & 3,00 & 0,00 & 201,00 & 14,75 & 409,00 & 3,61 & B \\
\hline 6 & escritório & 4,70 & 3,70 & 17,39 & 2,80 & 0,74 & 4,00 & 0,00 & 268,00 & 15,41 & 457,00 & 3,37 & $B$ \\
\hline 7 & banheiro & 4,70 & 2,73 & 12,83 & 2,80 & 0,62 & 0,00 & 2,00 & 70,00 & 5,46 & 126,00 & 4,33 & $B$ \\
\hline 8 & escritório & 7,73 & 6,56 & 50,71 & 2,80 & 1,27 & 9,00 & 0,00 & 603,00 & 11,89 & 445,00 & 2,67 & $\mathrm{~B}$ \\
\hline 9 & escritório & 4,19 & 3,10 & 12,99 & 2,80 & 0,64 & 3,00 & 0,00 & 201,00 & 15,47 & 429,00 & 3,61 & $B$ \\
\hline 10 & escritório & 3,34 & 2,93 & 9,79 & 2,80 & 0,56 & 2,00 & 0,00 & 134,00 & 13,69 & 353,00 & 3,88 & $B$ \\
\hline 11 & escritório & 8,22 & 7,43 & 61,07 & 2,80 & 1,39 & 12,00 & 0,00 & 804,00 & 13,16 & 509,00 & 2,59 & $B$ \\
\hline 12 & escritório & 4,02 & 1,87 & 7,52 & 2,80 & 0,46 & 2,00 & 0,00 & 134,00 & 17,83 & 402,00 & 4,43 & B \\
\hline 13 & banheiro & 2,75 & 1,25 & 3,44 & 2,80 & 0,31 & 0,00 & 1,00 & 35,00 & 10,18 & 140,00 & 7,27 & $B$ \\
\hline 14 & escritório & 3,95 & 2,62 & 10,35 & 2,80 & 0,56 & 3,00 & 0,00 & 201,00 & 19,42 & 501,00 & 3,88 & $B$ \\
\hline 15 & escritório & 2,95 & 2,80 & 8,26 & 2,80 & 0,51 & 2,00 & 0,00 & 134,00 & 16,22 & 397,00 & 4,09 & $B$ \\
\hline 16 & escritório & 2,65 & 2,05 & 5,43 & 2,80 & 0,41 & 2,00 & 0,00 & 134,00 & 24,67 & 522,00 & 4,73 & $B$ \\
\hline 17 & escritório & 4,9 & 2,7 & 13,23 & 2,80 & 0,62 & 3,00 & 0,00 & 201,00 & 15,19 & 411,00 & 3,70 & $\mathrm{~B}$ \\
\hline 18 & depósito & 4,2 & 1,85 & 7,77 & 2,80 & 0,46 & 1,00 & 0,00 & 67,00 & 8,62 & 195,00 & 4,42 & $\mathrm{~B}$ \\
\hline 19 & depósito & 4,2 & 2 & 8,40 & 2,80 & 0,48 & 1,00 & 0,00 & 67,00 & 7,98 & 185,00 & 4,31 & $B$ \\
\hline 20 & banheiro & 4 & 2,1 & 8,40 & 2,80 & 0,49 & 0,00 & 2,00 & 70,00 & 8,33 & 165,00 & 5,05 & B \\
\hline 21 & banheiro & 3,9 & 2,55 & 9,95 & 2,80 & 0,55 & 0,00 & 2,00 & 70,00 & 7,04 & 151,00 & 4,66 & $B$ \\
\hline 22 & escritório & 5,08 & 3,9 & 19,81 & 2,80 & 0,79 & 4,00 & 0,00 & 268,00 & 13,53 & 419,00 & 3,23 & $B$ \\
\hline 23 & escritório & 3,9 & 3,24 & 12,64 & 2,80 & 0,63 & 3,00 & 0,00 & 201,00 & 15,91 & 441,00 & 3,61 & $\mathrm{~B}$ \\
\hline 24 & escritório & 3,9 & 3,67 & 14,31 & 2,80 & 0,68 & 3,00 & 0,00 & 201,00 & 14,04 & 398,00 & 3,53 & $\mathrm{~B}$ \\
\hline 25 & depósito & 3,64 & 2,8 & 10,19 & 2,80 & 0,57 & 1,00 & 0,00 & 67,00 & 6,57 & 170,00 & 3,87 & $\mathrm{~B}$ \\
\hline 26 & escritório & 3,64 & 3,27 & 11,90 & 2,80 & 0,62 & 3,00 & 0,00 & 201,00 & 16,89 & 457,00 & 3,70 & $\mathrm{~B}$ \\
\hline 27 & escritório & 6,12 & 2,8 & 17,14 & 2,80 & 0,69 & 4,00 & 0,00 & 268,00 & 15,64 & 454,00 & 3,44 & $B$ \\
\hline 28 & escritório & 11,4 & 6,75 & 76,95 & 2,80 & 1,51 & 12,00 & 0,00 & 804,00 & 10,45 & 411,00 & 2,54 & $\mathrm{~B}$ \\
\hline 29 & escritório & 6,12 & 2,8 & 17,14 & 2,80 & 0,69 & 4,00 & 0,00 & 268,00 & 15,64 & 454,00 & 3,44 & B \\
\hline 30 & escritório & 6,12 & 2,9 & 17,75 & 2,80 & 0,70 & 4,00 & 0,00 & 268,00 & 15,10 & 438,00 & 3,45 & $B$ \\
\hline 31 & escritório & 5,65 & 5,4 & 30,51 & 2,80 & 0,99 & 6,00 & 0,00 & 402,00 & 13,18 & 450,00 & 2,93 & $B$ \\
\hline 32 & escritório & 5,7 & 2,49 & 14,19 & 2,80 & 0,62 & 3,00 & 0,00 & 201,00 & 14,16 & 384,00 & 3,69 & $B$ \\
\hline 33 & circulação & 10,78 & 1,2 & 12,94 & 2,80 & 0,39 & 0,00 & 2,00 & 70,00 & 5,41 & 89,00 & 6,08 & $\mathrm{~B}$ \\
\hline 34 & escritório & 5,73 & 4,34 & 24,87 & 2,80 & 0,88 & 6,00 & 0,00 & 402,00 & 16,17 & 521,00 & 3,10 & $B$ \\
\hline 35 & escritório & 5,67 & 3,87 & 21,94 & 2,80 & 0,82 & 6,00 & 0,00 & 402,00 & 18,32 & 579,00 & 3,16 & $\mathrm{~B}$ \\
\hline 36 & escritório & 3,22 & 2,64 & 8,50 & 2,80 & 0,52 & 2,00 & 0,00 & 134,00 & 15,76 & 386,00 & 4,08 & $B$ \\
\hline 37 & escritório & 3,52 & 3,23 & 11,37 & 2,80 & 0,60 & 3,00 & 0,00 & 201,00 & 17,68 & 467,00 & 3,79 & $\mathrm{~B}$ \\
\hline 38 & escritório & 3,27 & 3,23 & 10,56 & 2,80 & 0,58 & 3,00 & 0,00 & 201,00 & 19,03 & 503,00 & 3,78 & $B$ \\
\hline 39 & escritório & 10,68 & 8 & 85,44 & 2,80 & 1,63 & 16,00 & 0,00 & 1072,00 & 12,55 & 501,00 & 2,50 & $\mathrm{~B}$ \\
\hline 40 & escritório & 3,93 & 3,9 & 15,33 & 2,80 & 0,70 & 3,00 & 0,00 & 201,00 & 13,11 & 381,00 & 3,44 & $B$ \\
\hline 41 & banheiro & 4 & 2,15 & 8,60 & 2,80 & 0,50 & 0,00 & 2,00 & 70,00 & 8,14 & 165,00 & 4,93 & $B$ \\
\hline 42 & escritório & 4 & 2,35 & 9,40 & 2,80 & 0,53 & 2,00 & 0,00 & 134,00 & 14,26 & 349,00 & 4,08 & $\mathrm{~B}$ \\
\hline 43 & escritório & 4 & 2,25 & 9,00 & 2,80 & 0,51 & 2,00 & 0,00 & 134,00 & 14,89 & 365,00 & 4,08 & $B$ \\
\hline 44 & banheiro & 4 & 1,95 & 7,80 & 2,80 & 0,47 & 0,00 & 1,00 & 35,00 & 4,49 & 86,00 & 5,22 & $B$ \\
\hline 45 & circulação & 13,11 & 13,01 & 170,56 & 2,80 & 2,33 & 0,00 & 12,00 & 420,00 & 2,46 & 91,00 & 2,71 & $\mathrm{D}$ \\
\hline
\end{tabular}




\begin{tabular}{|c|c|c|c|c|c|c|c|c|c|c|c|c|c|}
\hline \multicolumn{14}{|c|}{ TERCEIRO ESTUDO - SEGUNDO PAVIMENTO } \\
\hline $\begin{array}{c}\text { número } \\
\text { da } \\
\text { amostra }\end{array}$ & $\begin{array}{c}\text { tipo de } \\
\text { ambiente }\end{array}$ & $\begin{array}{l}\text { comprimento } \\
(\mathrm{m})\end{array}$ & $\begin{array}{l}\text { largura } \\
(\mathrm{m})\end{array}$ & $\begin{array}{l}\text { área } \\
\left(\mathrm{m}^{2}\right)\end{array}$ & $\begin{array}{l}\text { altura média } \\
(\mathrm{m})\end{array}$ & K & $\begin{array}{c}\text { qtd } \\
\text { lum } \\
2 \times 32 W\end{array}$ & $\begin{array}{c}\text { qtd } \\
\text { lum } \\
2 \times 16 W\end{array}$ & $\begin{array}{l}\text { potência } \\
\text { total (W) }\end{array}$ & $\begin{array}{c}\text { densidade } \\
\left(\mathrm{W} / \mathrm{m}^{2}\right)\end{array}$ & $\begin{array}{l}\text { ilum } \\
\text { (Lux) }\end{array}$ & $\mathrm{DPI}_{\mathrm{RF}}$ & $\begin{array}{c}\text { nível de } \\
\text { eficiência }\end{array}$ \\
\hline 1 & escritório & 7,51 & 5,48 & 41,15 & 2,80 & 1,13 & 9,00 & 0,00 & 603,00 & 14,65 & 529,00 & 2,77 & $\mathrm{~B}$ \\
\hline 2 & depósito & 6,35 & 1,86 & 11,81 & 2,80 & 0,51 & 0,00 & 2,00 & 70,00 & 5,93 & 124,00 & 4,78 & $\mathrm{~B}$ \\
\hline 3 & escritório & 6,60 & 3,90 & 25,74 & 2,80 & 0,88 & 6,00 & 0,00 & 402,00 & 15,62 & 503,00 & 3,10 & $\mathrm{~B}$ \\
\hline 4 & escritório & 4,03 & 3,98 & 16,04 & 2,80 & 0,72 & 4,00 & 0,00 & 268,00 & 16,71 & 496,00 & 3,37 & $B$ \\
\hline 5 & banheiro & 2,80 & 0,90 & 2,52 & 2,80 & 0,24 & 0,00 & 1,00 & 35,00 & 13,89 & 160,00 & 8,68 & $\mathrm{~B}$ \\
\hline 6 & escritório & 4,00 & 1,95 & 7,80 & 2,80 & 0,47 & 2,00 & 0,00 & 134,00 & 17,18 & 388,00 & 4,43 & $B$ \\
\hline 7 & depósito & 4,00 & 1,10 & 4,40 & 2,80 & 0,31 & 0,00 & 2,00 & 70,00 & 15,91 & 218,00 & 7,30 & $B$ \\
\hline 8 & circulação & 4,40 & 1,10 & 4,84 & 2,80 & 0,31 & 0,00 & 1,00 & 35,00 & 7,23 & 103,00 & 7,02 & $B$ \\
\hline 9 & banheiro & 2,80 & 2,35 & 6,58 & 2,80 & 0,46 & 0,00 & 1,00 & 35,00 & 5,32 & 102,00 & 5,21 & $\mathrm{~B}$ \\
\hline 10 & escritório & 4,00 & 2,90 & 11,60 & 2,80 & 0,60 & 3,00 & 0,00 & 201,00 & 17,33 & 458,00 & 3,78 & $\mathrm{~B}$ \\
\hline 11 & banheiro & 4,10 & 2,02 & 8,28 & 2,80 & 0,48 & 0,00 & 2,00 & 70,00 & 8,45 & 167,00 & 5,06 & $B$ \\
\hline 12 & escritório & 7,32 & 3,90 & 28,55 & 2,80 & 0,91 & 6,00 & 0,00 & 402,00 & 14,08 & 463,00 & 3,04 & $\mathrm{~B}$ \\
\hline 13 & escritório & 3,90 & 2,92 & 11,39 & 2,80 & 0,60 & 3,00 & 0,00 & 201,00 & 17,65 & 467,00 & 3,78 & $B$ \\
\hline 14 & escritório & 5,12 & 3,02 & 15,46 & 2,80 & 0,68 & 4,00 & 0,00 & 268,00 & 17,33 & 492,00 & 3,52 & $B$ \\
\hline 15 & escritório & 5,95 & 5,12 & 30,46 & 2,80 & 0,98 & 6,00 & 0,00 & 402,00 & 13,20 & 451,00 & 2,93 & $\mathrm{~B}$ \\
\hline 16 & escritório & 12 & 10,71 & 128,52 & 2,80 & 2,02 & 20,00 & 0,00 & 1340,00 & 10,43 & 437,00 & 2,39 & $\mathrm{~B}$ \\
\hline 17 & escritório & 5,52 & 5,24 & 28,92 & 2,80 & 0,96 & 6,00 & 0,00 & 402,00 & 13,90 & 466,00 & 2,98 & $B$ \\
\hline 18 & escritório & 8,8 & 2,98 & 26,22 & 2,80 & 0,80 & 6,00 & 0,00 & 402,00 & 15,33 & 474,00 & 3,23 & $B$ \\
\hline 19 & escritório & 8,67 & 1,2 & 10,40 & 2,80 & 0,38 & 0,00 & 2,00 & 70,00 & 6,73 & 111,00 & 6,06 & $\mathrm{~B}$ \\
\hline 20 & escritório & 6,68 & 5,62 & 37,54 & 2,80 & 1,09 & 8,00 & 0,00 & 536,00 & 14,28 & 506,00 & 2,82 & $B$ \\
\hline 21 & depósito & 11,35 & 5,46 & 61,97 & 2,80 & 1,32 & 6,00 & 0,00 & 402,00 & 6,49 & 246,00 & 2,64 & $B$ \\
\hline 22 & escritório & 3,11 & 2,75 & 8,55 & 2,80 & 0,52 & 2,00 & 0,00 & 134,00 & 15,67 & 384,00 & 4,08 & $B$ \\
\hline 23 & escritório & 3,32 & 3,1 & 10,29 & 2,80 & 0,57 & 3,00 & 0,00 & 201,00 & 19,53 & 504,00 & 3,87 & $B$ \\
\hline 24 & escritório & 4,62 & 3,9 & 18,02 & 2,80 & 0,76 & 4,00 & 0,00 & 268,00 & 14,87 & 451,00 & 3,30 & $B$ \\
\hline 25 & escritório & 4,03 & 3,93 & 15,84 & 2,80 & 0,71 & 4,00 & 0,00 & 268,00 & 16,92 & 491,00 & 3,45 & $B$ \\
\hline 26 & banheiro & 2,85 & 1,1 & 3,14 & 2,80 & 0,28 & 0,00 & 1,00 & 35,00 & 11,16 & 147,00 & 7,59 & $B$ \\
\hline 27 & escritório & 4 & 2,15 & 8,60 & 2,80 & 0,50 & 2,00 & 0,00 & 134,00 & 15,58 & 372,00 & 4,19 & $B$ \\
\hline 28 & banheiro & 8 & 4 & 32,00 & 2,80 & 0,95 & 0,00 & 6,00 & 210,00 & 6,56 & 205,00 & 3,20 & $B$ \\
\hline 29 & escritório & 4,79 & 4 & 19,16 & 2,80 & 0,78 & 4,00 & 0,00 & 268,00 & 13,99 & 433,00 & 3,23 & $B$ \\
\hline 30 & banheiro & 2,65 & 0,8 & 2,12 & 2,80 & 0,22 & 0,00 & 1,00 & 35,00 & 16,51 & 172,00 & 9,60 & $B$ \\
\hline 31 & escritório & 4,8 & 2,92 & 14,02 & 2,80 & 0,65 & 3,00 & 0,00 & 201,00 & 14,34 & 398,00 & 3,60 & $B$ \\
\hline 32 & escritório & 11,7 & 4,55 & 53,24 & 2,80 & 1,17 & 10,00 & 0,00 & 670,00 & 12,59 & 454,00 & 2,77 & $B$ \\
\hline 33 & escritório & 4,6 & 4,5 & 20,70 & 2,80 & 0,81 & 4,00 & 0,00 & 268,00 & 12,95 & 409,00 & 3,17 & $B$ \\
\hline 34 & escritório & 5,57 & 3,15 & 17,55 & 2,80 & 0,72 & 4,00 & 0,00 & 268,00 & 15,27 & 453,00 & 3,37 & $B$ \\
\hline 35 & escritório & 4,4 & 2,9 & 12,76 & 2,80 & 0,62 & 3,00 & 0,00 & 201,00 & 15,75 & 427,00 & 3,69 & $B$ \\
\hline 36 & escritório & 9,06 & 6,84 & 61,97 & 2,80 & 1,39 & 12,00 & 0,00 & 804,00 & 12,97 & 502,00 & 2,58 & $B$ \\
\hline 37 & escritório & 5,21 & 4,6 & 23,97 & 2,80 & 0,87 & 6,00 & 0,00 & 402,00 & 16,77 & 541,00 & 3,10 & $B$ \\
\hline 38 & escritório & 9,85 & 5,38 & 52,99 & 2,80 & 1,24 & 12,00 & 0,00 & 804,00 & 15,17 & 567,00 & 2,68 & $B$ \\
\hline 39 & escritório & 5,35 & 4,6 & 24,61 & 2,80 & 0,88 & 6,00 & 0,00 & 402,00 & 16,33 & 537,00 & 3,04 & $B$ \\
\hline 40 & escritório & 4,6 & 4,5 & 20,70 & 2,80 & 0,81 & 4,00 & 0,00 & 268,00 & 12,95 & 409,00 & 3,17 & $B$ \\
\hline 41 & escritório & 7,71 & 7,04 & 54,28 & 2,80 & 1,31 & 9,00 & 0,00 & 603,00 & 11,11 & 423,00 & 2,63 & $B$ \\
\hline 42 & escritório & 6,2 & 3,94 & 24,43 & 2,80 & 0,86 & 6,00 & 0,00 & 402,00 & 16,46 & 531,00 & 3,10 & $B$ \\
\hline 43 & circulação & 16,15 & 11,78 & 190,25 & 2,80 & 2,43 & 0,00 & 16,00 & 560,00 & 2,94 & 110,00 & 2,68 & B \\
\hline
\end{tabular}




\begin{tabular}{|c|c|c|c|c|c|c|c|c|c|c|c|c|c|}
\hline \multicolumn{14}{|c|}{ TERCEIRO ESTUDO - TERCEIRO PAVIMENTO } \\
\hline $\begin{array}{c}\text { número } \\
\text { da } \\
\text { amostra }\end{array}$ & $\begin{array}{c}\text { tipo de } \\
\text { ambiente }\end{array}$ & $\begin{array}{l}\text { comprimento } \\
(\mathrm{m})\end{array}$ & $\begin{array}{l}\text { largura } \\
\text { (m) }\end{array}$ & $\begin{array}{l}\text { área } \\
\left(\mathrm{m}^{2}\right)\end{array}$ & $\begin{array}{l}\text { altura média } \\
(\mathrm{m})\end{array}$ & K & $\begin{array}{c}\text { qtd } \\
\text { lum } \\
2 \times 32 W\end{array}$ & $\begin{array}{c}\text { qtd } \\
\text { lum } \\
2 \times 16 W\end{array}$ & $\begin{array}{l}\text { potência } \\
\text { total (W) }\end{array}$ & $\begin{array}{c}\text { densidade } \\
\left(\mathrm{W} / \mathrm{m}^{2}\right)\end{array}$ & $\begin{array}{l}\text { ilum } \\
\text { (Lux) }\end{array}$ & $\mathrm{DPI}_{\mathrm{RF}}$ & $\begin{array}{c}\text { nível de } \\
\text { eficiência }\end{array}$ \\
\hline 1 & depósito & 18,81 & 10,28 & 193,37 & 2,80 & 2,37 & 0,00 & 30,00 & 1050,00 & 5,43 & 199,00 & 2,73 & $\mathrm{D}$ \\
\hline 2 & escritório & 8,45 & 5,80 & 49,01 & 2,80 & 1,23 & 9,00 & 0,00 & 603,00 & 12,30 & 452,00 & 2,72 & $\mathrm{~B}$ \\
\hline 3 & escritório & 4,47 & 2,98 & 13,32 & 2,80 & 0,64 & 3,00 & 0,00 & 201,00 & 15,09 & 418,00 & 3,61 & $\mathrm{~B}$ \\
\hline 4 & banheiro & 3,40 & 2,35 & 7,99 & 2,80 & 0,50 & 0,00 & 2,00 & 70,00 & 8,76 & 178,00 & 4,92 & $B$ \\
\hline 5 & escritório & 3,57 & 3,86 & 13,78 & 2,80 & 0,66 & 3,00 & 0,00 & 201,00 & 14,59 & 419,00 & 3,48 & $\mathrm{~B}$ \\
\hline 6 & circulação & 4,40 & 1,10 & 4,84 & 2,80 & 0,31 & 0,00 & 1,00 & 35,00 & 7,23 & 103,00 & 7,02 & $\mathrm{~B}$ \\
\hline 7 & escritório & 4,00 & 2,35 & 9,40 & 2,80 & 0,53 & 3,00 & 0,00 & 201,00 & 21,38 & 524,00 & 4,08 & $\mathrm{~B}$ \\
\hline 8 & banheiro & 4,00 & 3,88 & 15,52 & 2,80 & 0,70 & 0,00 & 2,00 & 70,00 & 4,51 & 111,00 & 4,06 & $B$ \\
\hline 9 & escritório & 5,52 & 4,70 & 25,94 & 2,80 & 0,91 & 6,00 & 0,00 & 402,00 & 15,49 & 510,00 & 3,04 & $\mathrm{~B}$ \\
\hline 10 & escritório & 5,65 & 4,70 & 26,56 & 2,80 & 0,92 & 6,00 & 0,00 & 402,00 & 15,14 & 498,00 & 3,04 & $\mathrm{~B}$ \\
\hline 11 & escritório & 3,70 & 2,80 & 10,36 & 2,80 & 0,57 & 3,00 & 0,00 & 201,00 & 19,40 & 500,00 & 3,88 & $\mathrm{~B}$ \\
\hline 12 & escritório & 3,70 & 3,28 & 12,14 & 2,80 & 0,62 & 3,00 & 0,00 & 201,00 & 16,56 & 449,00 & 3,69 & $B$ \\
\hline 13 & escritório & 6,12 & 2,98 & 18,24 & 2,80 & 0,72 & 4,00 & 0,00 & 268,00 & 14,69 & 436,00 & 3,37 & $\mathrm{~B}$ \\
\hline 14 & escritório & 6,12 & 2,80 & 17,14 & 2,80 & 0,69 & 4,00 & 0,00 & 268,00 & 15,64 & 454,00 & 3,44 & $\mathrm{~B}$ \\
\hline 15 & escritório & 6,12 & 2,62 & 16,03 & 2,80 & 0,66 & 4,00 & 0,00 & 268,00 & 16,71 & 474,00 & 3,53 & $\mathrm{~B}$ \\
\hline 16 & escritório & 9,95 & 7,44 & 74,03 & 2,80 & 1,52 & 16,00 & 0,00 & 1072,00 & 14,48 & 570,00 & 2,54 & $B$ \\
\hline 17 & depósito & 5,64 & 4,08 & 23,01 & 2,80 & 0,85 & 0,00 & 4,00 & 140,00 & 6,08 & 167,00 & 3,64 & $B$ \\
\hline 18 & escritório & 5,04 & 4,11 & 20,71 & 2,80 & 0,81 & 4,00 & 0,00 & 268,00 & 12,94 & 409,00 & 3,16 & $\mathrm{~B}$ \\
\hline 19 & escritório & 4 & 2,25 & 9,00 & 2,80 & 0,51 & 3,00 & 0,00 & 201,00 & 22,33 & 547,00 & 4,08 & $\mathrm{~B}$ \\
\hline 20 & escritório & 5,7 & 5,26 & 29,98 & 2,80 & 0,98 & 6,00 & 0,00 & 402,00 & 13,41 & 458,00 & 2,93 & $B$ \\
\hline 21 & escritório & 5,7 & 4,19 & 23,88 & 2,80 & 0,86 & 6,00 & 0,00 & 402,00 & 16,83 & 543,00 & 3,10 & $B$ \\
\hline 22 & escritório & 5,7 & 2,7 & 15,39 & 2,80 & 0,65 & 4,00 & 0,00 & 268,00 & 17,41 & 483,00 & 3,61 & $\mathrm{~B}$ \\
\hline 23 & escritório & 5,7 & 2,85 & 16,25 & 2,80 & 0,68 & 4,00 & 0,00 & 268,00 & 16,50 & 468,00 & 3,53 & $\mathrm{~B}$ \\
\hline 24 & escritório & 5,7 & 3,62 & 20,63 & 2,80 & 0,79 & 4,00 & 0,00 & 268,00 & 12,99 & 402,00 & 3,23 & $\mathrm{~B}$ \\
\hline 25 & escritório & 5,7 & 2,5 & 14,25 & 2,80 & 0,62 & 4,00 & 0,00 & 268,00 & 18,81 & 509,00 & 3,69 & $\mathrm{~B}$ \\
\hline 26 & escritório & 6,05 & 5,83 & 35,27 & 2,80 & 1,06 & 6,00 & 0,00 & 402,00 & 11,40 & 397,00 & 2,87 & $\mathrm{~B}$ \\
\hline 27 & escritório & 3,9 & 3,5 & 13,65 & 2,80 & 0,66 & 3,00 & 0,00 & 201,00 & 14,73 & 418,00 & 3,52 & $\mathrm{~B}$ \\
\hline 28 & escritório & 4,44 & 3,9 & 17,32 & 2,80 & 0,74 & 4,00 & 0,00 & 268,00 & 15,48 & 459,00 & 3,37 & $\mathrm{~B}$ \\
\hline 29 & escritório & 5,01 & 3,9 & 19,54 & 2,80 & 0,78 & 4,00 & 0,00 & 268,00 & 13,72 & 425,00 & 3,23 & $\mathrm{~B}$ \\
\hline 30 & circulação & 17,04 & 2,1 & 35,78 & 2,80 & 0,67 & 0,00 & 4,00 & 140,00 & 3,91 & 95,00 & 4,12 & $B$ \\
\hline 31 & banheiro & 3,9 & 2,05 & 8,00 & 2,80 & 0,48 & 0,00 & 2,00 & 70,00 & 8,76 & 173,00 & 5,06 & $\mathrm{~B}$ \\
\hline 32 & banheiro & 9,15 & 4 & 36,60 & 2,80 & 0,99 & 0,00 & 6,00 & 210,00 & 5,74 & 167,00 & 3,44 & $B$ \\
\hline 33 & banheiro & 3,9 & 2,42 & 9,44 & 2,80 & 0,53 & 0,00 & 2,00 & 70,00 & 7,42 & 155,00 & 4,79 & $\mathrm{~B}$ \\
\hline 34 & escritório & 4,18 & 3,9 & 16,30 & 2,80 & 0,72 & 4,00 & 0,00 & 268,00 & 16,44 & 488,00 & 3,37 & $B$ \\
\hline 35 & escritório & 4,14 & 3,9 & 16,15 & 2,80 & 0,72 & 4,00 & 0,00 & 268,00 & 16,60 & 492,00 & 3,37 & $\mathrm{~B}$ \\
\hline 36 & escritório & 5,8 & 3,9 & 22,62 & 2,80 & 0,83 & 6,00 & 0,00 & 402,00 & 17,77 & 561,00 & 3,17 & $B$ \\
\hline 37 & escritório & 4,51 & 3,9 & 17,59 & 2,80 & 0,75 & 4,00 & 0,00 & 268,00 & 15,24 & 462,00 & 3,30 & $\mathrm{~B}$ \\
\hline 38 & depósito & 2,32 & 1,95 & 4,52 & 2,80 & 0,38 & 0,00 & 1,00 & 35,00 & 7,74 & 127,00 & 6,09 & $B$ \\
\hline 39 & circulação & 3,8 & 1,91 & 7,26 & 2,80 & 0,45 & 0,00 & 1,00 & 35,00 & 4,82 & 90,00 & 5,36 & $\mathrm{~B}$ \\
\hline 40 & circulação & 12,64 & 1,27 & 16,05 & 2,80 & 0,41 & 0,00 & 3,00 & 105,00 & 6,54 & 115,00 & 5,69 & $B$ \\
\hline 41 & escritório & 5,82 & 3,74 & 21,77 & 2,80 & 0,81 & 6,00 & 0,00 & 402,00 & 18,47 & 583,00 & 3,17 & $B$ \\
\hline 42 & escritório & 5,82 & 2,38 & 13,85 & 2,80 & 0,60 & 4,00 & 0,00 & 268,00 & 19,35 & 511,00 & 3,79 & $\mathrm{~B}$ \\
\hline 43 & escritório & 6,89 & 6,48 & 44,65 & 2,80 & 1,19 & 9,00 & 0,00 & 603,00 & 13,51 & 496,00 & 2,72 & $B$ \\
\hline 44 & escritório & 4,91 & 2,09 & 10,26 & 2,80 & 0,52 & 3,00 & 0,00 & 201,00 & 19,59 & 480,00 & 4,08 & $\mathrm{~B}$ \\
\hline 45 & depósito & 4 & 1,1 & 4,40 & 2,80 & 0,31 & 0,00 & 2,00 & 70,00 & 15,91 & 218,00 & 7,30 & $B$ \\
\hline 46 & circulação & 14,25 & 9,55 & 136,09 & 2,80 & 2,04 & 0,00 & 12,00 & 420,00 & 3,09 & 112,00 & 2,76 & D \\
\hline
\end{tabular}




\begin{tabular}{|c|c|c|c|c|c|c|c|c|c|c|c|c|c|}
\hline \multicolumn{14}{|c|}{ TERCEIRO ESTUDO - QUARTO PAVIMENTO } \\
\hline $\begin{array}{c}\text { número } \\
\text { da } \\
\text { amostra }\end{array}$ & $\begin{array}{c}\text { tipo de } \\
\text { ambiente }\end{array}$ & $\begin{array}{c}\text { comprimento } \\
(\mathrm{m})\end{array}$ & $\begin{array}{c}\text { largura } \\
(\mathrm{m})\end{array}$ & $\begin{array}{l}\text { área } \\
\left(\mathrm{m}^{2}\right)\end{array}$ & $\begin{array}{l}\text { altura média } \\
(\mathrm{m})\end{array}$ & K & $\begin{array}{c}\text { qtd } \\
\text { lum } \\
2 \times 32 W\end{array}$ & $\begin{array}{l}\text { qtd } \\
\text { lum } \\
2 \times 16 W\end{array}$ & $\begin{array}{l}\text { potência } \\
\text { total }(W)\end{array}$ & $\begin{array}{l}\text { densidade } \\
\left(\mathrm{W} / \mathrm{m}^{2}\right)\end{array}$ & $\begin{array}{l}\text { ilum } \\
\text { (Lux) }\end{array}$ & $\mathrm{DPI} \mathrm{RF}_{\mathrm{RF}}$ & $\begin{array}{c}\text { nível de } \\
\text { eficiência }\end{array}$ \\
\hline 1 & escritório & 6,06 & 5,71 & 34,60 & 2,80 & 1,05 & 6,00 & 0,00 & 402,00 & 11,62 & 405,00 & 2,87 & $\mathrm{~B}$ \\
\hline 2 & escritório & 6,12 & 3,90 & 23,87 & 2,80 & 0,85 & 6,00 & 0,00 & 402,00 & 16,84 & 543,00 & 3,10 & B \\
\hline 3 & escritório & 5,60 & 3,90 & 21,84 & 2,80 & 0,82 & 6,00 & 0,00 & 402,00 & 18,41 & 582,00 & 3,16 & B \\
\hline 4 & banheiro & 3,90 & 2,35 & 9,17 & 2,80 & 0,52 & 0,00 & 2,00 & 70,00 & 7,64 & 159,00 & 4,80 & $B$ \\
\hline 5 & banheiro & 4,00 & 3,00 & 12,00 & 2,80 & 0,61 & 0,00 & 2,00 & 70,00 & 5,83 & 134,00 & 4,35 & $B$ \\
\hline 6 & banheiro & 4,00 & 2,35 & 9,40 & 2,80 & 0,53 & 0,00 & 2,00 & 70,00 & 7,45 & 155,00 & 4,80 & $B$ \\
\hline 7 & banheiro & 4,00 & 2,25 & 9,00 & 2,80 & 0,51 & 0,00 & 2,00 & 70,00 & 7,78 & 162,00 & 4,80 & $B$ \\
\hline 8 & banheiro & 4,10 & 2,75 & 11,28 & 2,80 & 0,59 & 0,00 & 2,00 & 70,00 & 6,21 & 140,00 & 4,43 & $B$ \\
\hline 9 & escritório & 7,12 & 3,90 & 27,77 & 2,80 & 0,90 & 6,00 & 0,00 & 402,00 & 14,48 & 476,00 & 3,04 & $B$ \\
\hline 10 & escritório & 6,89 & 5,10 & 35,14 & 2,80 & 1,05 & 6,00 & 0,00 & 402,00 & 11,44 & 398,00 & 2,87 & $B$ \\
\hline 11 & escritório & 6,32 & 5,25 & 33,18 & 2,80 & 1,02 & 6,00 & 0,00 & 402,00 & 12,12 & 422,00 & 2,87 & $B$ \\
\hline 12 & escritório & 6,35 & 6,32 & 40,13 & 2,80 & 1,13 & 8,00 & 0,00 & 536,00 & 13,36 & 482,00 & 2,77 & $B$ \\
\hline 13 & circulação & 8,59 & 1,66 & 14,26 & 2,80 & 0,50 & 0,00 & 2,00 & 70,00 & 4,91 & 92,00 & 5,34 & $B$ \\
\hline 14 & escritório & 4,65 & 4,45 & 20,69 & 2,80 & 0,81 & 4,00 & 0,00 & 268,00 & 12,95 & 409,00 & 3,17 & $B$ \\
\hline 15 & escritório & 5,44 & 4,64 & 25,24 & 2,80 & 0,89 & 6,00 & 0,00 & 402,00 & 15,93 & 524,00 & 3,04 & $B$ \\
\hline 16 & escritório & 6,89 & 3,15 & 21,70 & 2,80 & 0,77 & 6,00 & 0,00 & 402,00 & 18,52 & 561,00 & 3,30 & $B$ \\
\hline 17 & escritório & 5,66 & 4,08 & 23,09 & 2,80 & 0,85 & 6,00 & 0,00 & 402,00 & 17,41 & 561,00 & 3,10 & $B$ \\
\hline 18 & depósito & 6,16 & 2,1 & 12,94 & 2,80 & 0,56 & 0,00 & 3,00 & 105,00 & 8,12 & 178,00 & 4,56 & $\mathrm{~B}$ \\
\hline 19 & escritório & 4,03 & 2,78 & 11,20 & 2,80 & 0,59 & 3,00 & 0,00 & 201,00 & 17,94 & 474,00 & 3,79 & $B$ \\
\hline 20 & escritório & 4,03 & 3,84 & 15,48 & 2,80 & 0,70 & 4,00 & 0,00 & 268,00 & 17,32 & 502,00 & 3,45 & $B$ \\
\hline 21 & escritório & 6,53 & 4,35 & 28,41 & 2,80 & 0,93 & 6,00 & 0,00 & 402,00 & 14,15 & 474,00 & 2,99 & $\mathrm{~B}$ \\
\hline 22 & circulação & 11,09 & 1,2 & 13,31 & 2,80 & 0,39 & 0,00 & 2,00 & 70,00 & 5,26 & 89,00 & 5,91 & $B$ \\
\hline 23 & depósito & 4,11 & 2,47 & 10,15 & 2,80 & 0,55 & 0,00 & 2,00 & 70,00 & 6,90 & 148,00 & 4,66 & B \\
\hline 24 & escritório & 6,43 & 2,79 & 17,94 & 2,80 & 0,69 & 4,00 & 0,00 & 268,00 & 14,94 & 433,00 & 3,45 & $B$ \\
\hline 25 & escritório & 6,43 & 2,85 & 18,33 & 2,80 & 0,71 & 4,00 & 0,00 & 268,00 & 14,62 & 424,00 & 3,45 & $B$ \\
\hline 26 & escritório & 6,43 & 5,27 & 33,89 & 2,80 & 1,03 & 8,00 & 0,00 & 536,00 & 15,82 & 551,00 & 2,87 & $B$ \\
\hline 27 & escritório & 6,43 & 3,28 & 21,09 & 2,80 & 0,78 & 6,00 & 0,00 & 402,00 & 19,06 & 590,00 & 3,23 & $B$ \\
\hline 28 & escritório & 6,55 & 3,91 & 25,61 & 2,80 & 0,87 & 6,00 & 0,00 & 402,00 & 15,70 & 506,00 & 3,10 & $\mathrm{~B}$ \\
\hline 29 & banheiro & 2,8 & 1,1 & 3,08 & 2,80 & 0,28 & 0,00 & 1,00 & 35,00 & 11,36 & 150,00 & 7,58 & B \\
\hline 30 & escritório & 4,5 & 4 & 18,00 & 2,80 & 0,76 & 4,00 & 0,00 & 268,00 & 14,89 & 451,00 & 3,30 & $B$ \\
\hline 31 & escritório & 3,19 & 4 & 12,76 & 2,80 & 0,63 & 3,00 & 0,00 & 201,00 & 15,75 & 437,00 & 3,60 & $\mathrm{~B}$ \\
\hline 32 & banheiro & 2,85 & 1,6 & 4,56 & 2,80 & 0,37 & 0,00 & 1,00 & 35,00 & 7,68 & 122,00 & 6,29 & $B$ \\
\hline 33 & banheiro & 5,43 & 2,65 & 14,39 & 2,80 & 0,64 & 0,00 & 2,00 & 70,00 & 4,86 & 115,00 & 4,23 & $B$ \\
\hline 34 & escritório & 5,42 & 4,09 & 22,17 & 2,80 & 0,83 & 6,00 & 0,00 & 402,00 & 18,13 & 573,00 & 3,16 & $B$ \\
\hline 35 & escritório & 5,65 & 5,42 & 30,62 & 2,80 & 0,99 & 6,00 & 0,00 & 402,00 & 13,13 & 449,00 & 2,92 & $B$ \\
\hline 36 & escritório & 5,7 & 3,58 & 20,41 & 2,80 & 0,79 & 4,00 & 0,00 & 268,00 & 13,13 & 406,00 & 3,23 & $\mathrm{~B}$ \\
\hline 37 & banheiro & 3,58 & 3,28 & 11,74 & 2,80 & 0,61 & 0,00 & 2,00 & 70,00 & 5,96 & 137,00 & 4,35 & $B$ \\
\hline 38 & escritório & 8,56 & 3,92 & 33,56 & 2,80 & 0,96 & 6,00 & 0,00 & 402,00 & 11,98 & 402,00 & 2,98 & $B$ \\
\hline 39 & escritório & 6,29 & 3,65 & 22,96 & 2,80 & 0,82 & 6,00 & 0,00 & 402,00 & 17,51 & 553,00 & 3,17 & $B$ \\
\hline 40 & escritório & 6,29 & 4,73 & 29,75 & 2,80 & 0,96 & 6,00 & 0,00 & 402,00 & 13,51 & 453,00 & 2,98 & $\mathrm{~B}$ \\
\hline 41 & escritório & 7,05 & 4,86 & 34,26 & 2,80 & 1,03 & 6,00 & 0,00 & 402,00 & 11,73 & 409,00 & 2,87 & $B$ \\
\hline 42 & escritório & 5,71 & 4,16 & 23,75 & 2,80 & 0,86 & 6,00 & 0,00 & 402,00 & 16,92 & 546,00 & 3,10 & $\mathrm{~B}$ \\
\hline 43 & escritório & 4,16 & 2,42 & 10,07 & 2,80 & 0,55 & 3,00 & 0,00 & 201,00 & 19,97 & 502,00 & 3,98 & $B$ \\
\hline 44 & escritório & 5,71 & 3,34 & 19,07 & 2,80 & 0,75 & 4,00 & 0,00 & 268,00 & 14,05 & 426,00 & 3,30 & $B$ \\
\hline 45 & escritório & 6,12 & 5,99 & 36,66 & 2,80 & 1,08 & 8,00 & 0,00 & 536,00 & 14,62 & 519,00 & 2,82 & $\mathrm{~B}$ \\
\hline 46 & escritório & 5,99 & 5,6 & 33,54 & 2,80 & 1,03 & 8,00 & 0,00 & 536,00 & 15,98 & 556,00 & 2,87 & $\mathrm{~B}$ \\
\hline 47 & escritório & 4,34 & 3,04 & 13,19 & 2,80 & 0,64 & 3,00 & 0,00 & 201,00 & 15,23 & 422,00 & 3,61 & $\mathrm{~B}$ \\
\hline 48 & escritório & 5,71 & 2,74 & 15,65 & 2,80 & 0,66 & 4,00 & 0,00 & 268,00 & 17,13 & 486,00 & 3,52 & $\mathrm{~B}$ \\
\hline 49 & circulação & 7,8 & 2,25 & 17,55 & 2,80 & 0,62 & 0,00 & 2,00 & 70,00 & 3,99 & 92,00 & 4,34 & $B$ \\
\hline 50 & escritório & 3,9 & 2,25 & 8,78 & 2,80 & 0,51 & 3,00 & 0,00 & 201,00 & 22,91 & 546,00 & 4,20 & $\mathrm{~B}$ \\
\hline 51 & escritório & 3,99 & 3,9 & 15,56 & 2,80 & 0,70 & 4,00 & 0,00 & 268,00 & 17,22 & 500,00 & 3,44 & $B$ \\
\hline 52 & depósito & 2,9 & 2,6 & 7,54 & 2,80 & 0,49 & 0,00 & 2,00 & 70,00 & 9,28 & 183,00 & 5,07 & $B$ \\
\hline 53 & depósito & 4 & 1,1 & 4,40 & 2,80 & 0,31 & 0,00 & 2,00 & 70,00 & 15,91 & 218,00 & 7,30 & $\mathrm{~B}$ \\
\hline 54 & circulação & 4,4 & 1,1 & 4,84 & 2,80 & 0,31 & 0,00 & 1,00 & 35,00 & 7,23 & 103,00 & 7,02 & $\mathrm{~B}$ \\
\hline 55 & circulação & 16,15 & 10,62 & 171,51 & 2,80 & 2,29 & 0,00 & 16,00 & 560,00 & 3,27 & 136,00 & 2,40 & $B$ \\
\hline
\end{tabular}


TERCEIRO ESTUDO - QUINTO PAVIMENTO

\begin{tabular}{|c|c|c|c|c|c|c|c|c|c|c|c|c|c|}
\hline $\begin{array}{l}\text { número } \\
\text { da } \\
\text { amostra }\end{array}$ & $\begin{array}{c}\text { tipo de } \\
\text { ambiente }\end{array}$ & $\begin{array}{l}\text { comprimento } \\
\text { (m) }\end{array}$ & $\begin{array}{l}\text { Iargura } \\
(\mathrm{m})\end{array}$ & $\begin{array}{l}\text { área } \\
\left(\mathrm{m}^{2}\right)\end{array}$ & $\begin{array}{l}\text { altura média } \\
\qquad(\mathrm{m})\end{array}$ & K & $\begin{array}{c}\text { qtd } \\
\operatorname{lum} \\
2 \times 32 W\end{array}$ & $\begin{array}{c}\text { qtd } \\
\text { lum } \\
2 \times 16 W\end{array}$ & $\begin{array}{l}\text { potência } \\
\text { total (W) }\end{array}$ & $\begin{array}{l}\text { densidade } \\
\left(\mathrm{W} / \mathrm{m}^{2}\right)\end{array}$ & $\begin{array}{l}\text { ilum } \\
\text { (Lux) }\end{array}$ & $\mathrm{DPI}_{\mathrm{RF}}$ & $\begin{array}{l}\text { nível de } \\
\text { eficiência }\end{array}$ \\
\hline 1 & escritório & 9,95 & 4,92 & 48,95 & 2,80 & 1,18 & 9,00 & 0,00 & 603,00 & 12,32 & 453,00 & 2,72 & B \\
\hline 2 & escritório & 8,13 & 4,92 & 40,00 & 2,80 & 1,09 & 8,00 & 0,00 & 536,00 & 13,40 & 475,00 & 2,82 & B \\
\hline 3 & banheiro & 4,92 & 3,39 & 16,68 & 2,80 & 0,72 & 0,00 & 4,00 & 140,00 & 8,39 & 212,00 & 3,96 & $\mathrm{~B}$ \\
\hline 4 & banheiro & 4,00 & 3,20 & 12,80 & 2,80 & 0,63 & 0,00 & 2,00 & 70,00 & 5,47 & 129,00 & 4,24 & $\mathrm{~B}$ \\
\hline 5 & banheiro & 3,90 & 3,30 & 12,87 & 2,80 & 0,64 & 0,00 & 2,00 & 70,00 & 5,44 & 128,00 & 4,25 & $B$ \\
\hline 6 & banheiro & 3,90 & 1,61 & 6,28 & 2,80 & 0,41 & 0,00 & 2,00 & 70,00 & 11,15 & 196,00 & 5,69 & $B$ \\
\hline 7 & escritório & 6,11 & 5,49 & 33,54 & 2,80 & 1,03 & 8,00 & 0,00 & 536,00 & 15,98 & 556,00 & 2,87 & $B$ \\
\hline 8 & escritório & 6,11 & 4,30 & 26,27 & 2,80 & 0,90 & 6,00 & 0,00 & 402,00 & 15,30 & 503,00 & 3,04 & B \\
\hline 9 & escritório & 11,70 & 9,98 & 116,77 & 2,80 & 1,92 & 20,00 & 0,00 & 1340,00 & 11,48 & 481,00 & 2,39 & $B$ \\
\hline 10 & escritório & 10,88 & 6,12 & 66,59 & 2,80 & 1,40 & 12,00 & 0,00 & 804,00 & 12,07 & 466,00 & 2,59 & $B$ \\
\hline 11 & circulação & 5,70 & 2,64 & 15,05 & 2,80 & 0,64 & 0,00 & 2,00 & 70,00 & 4,65 & 110,00 & 4,23 & $B$ \\
\hline 12 & escritório & 7,59 & 5,70 & 43,26 & 2,80 & 1,16 & 9,00 & 0,00 & 603,00 & 13,94 & 503,00 & 2,77 & $B$ \\
\hline 13 & escritório & 12,95 & 9,63 & 124,71 & 2,80 & 1,97 & 20,00 & 0,00 & 1340,00 & 10,75 & 449,00 & 2,39 & $B$ \\
\hline 14 & depósito & 3,15 & 2,05 & 6,46 & 2,80 & 0,44 & 0,00 & 2,00 & 70,00 & 10,84 & 202,00 & 5,37 & $B$ \\
\hline 15 & circulação & 4,13 & 3,75 & 15,49 & 2,80 & 0,70 & 0,00 & 2,00 & 70,00 & 4,52 & 112,00 & 4,04 & $B$ \\
\hline 16 & escritório & 5,97 & 4,09 & 24,42 & 2,80 & 0,87 & 6,00 & 0,00 & 402,00 & 16,46 & 531,00 & 3,10 & $B$ \\
\hline 17 & escritório & 7,12 & 5,25 & 37,38 & 2,80 & 1,08 & 9,00 & 0,00 & 603,00 & 16,13 & 572,00 & 2,82 & $B$ \\
\hline 18 & depósito & 5,2 & 3,47 & 18,04 & 2,80 & 0,74 & 0,00 & 4,00 & 140,00 & 7,76 & 200,00 & 3,88 & $B$ \\
\hline 19 & escritório & 7,98 & 3,45 & 27,53 & 2,80 & 0,86 & 6,00 & 0,00 & 402,00 & 14,60 & 471,00 & 3,10 & $B$ \\
\hline 20 & escritório & 7,98 & 2,3 & 18,35 & 2,80 & 0,64 & 5,00 & 0,00 & 335,00 & 18,25 & 506,00 & 3,61 & $B$ \\
\hline 21 & circulação & 13,24 & 1,72 & 22,77 & 2,80 & 0,54 & 0,00 & 3,00 & 105,00 & 4,61 & 99,00 & 4,66 & $B$ \\
\hline 22 & escritório & 8,95 & 4,92 & 44,03 & 2,80 & 1,13 & 9,00 & 0,00 & 603,00 & 13,69 & 494,00 & 2,77 & $B$ \\
\hline 23 & escritório & 3,42 & 3,41 & 11,66 & 2,80 & 0,61 & 3,00 & 0,00 & 201,00 & 17,24 & 467,00 & 3,69 & $B$ \\
\hline 24 & escritório & 4,75 & 2,7 & 12,83 & 2,80 & 0,61 & 4,00 & 0,00 & 268,00 & 20,90 & 566,00 & 3,69 & B \\
\hline 25 & escritório & 6,7 & 2,7 & 18,09 & 2,80 & 0,69 & 4,00 & 0,00 & 268,00 & 14,81 & 430,00 & 3,45 & $B$ \\
\hline 26 & escritório & 6,7 & 2,82 & 18,89 & 2,80 & 0,71 & 4,00 & 0,00 & 268,00 & 14,18 & 412,00 & 3,44 & $B$ \\
\hline 27 & escritório & 6,7 & 4,5 & 30,15 & 2,80 & 0,96 & 6,00 & 0,00 & 402,00 & 13,33 & 447,00 & 2,98 & $B$ \\
\hline 28 & escritório & 2,75 & 1,84 & 5,06 & 2,80 & 0,39 & 2,00 & 0,00 & 134,00 & 26,48 & 529,00 & 5,01 & $B$ \\
\hline 29 & escritório & 4,5 & 4 & 18,00 & 2,80 & 0,76 & 4,00 & 0,00 & 268,00 & 14,89 & 451,00 & 3,30 & $\mathrm{~B}$ \\
\hline 30 & banheiro & 4,37 & 4 & 17,48 & 2,80 & 0,75 & 4,00 & 0,00 & 268,00 & 15,33 & 206,00 & 7,44 & $E$ \\
\hline 31 & circulação & 4,4 & 0,94 & 4,14 & 2,80 & 0,28 & 0,00 & 1,00 & 35,00 & 8,46 & 107,00 & 7,91 & $B$ \\
\hline 32 & escritório & 15,14 & 6,2 & 93,87 & 2,80 & 1,57 & 20,00 & 0,00 & 1340,00 & 14,28 & 572,00 & 2,50 & $B$ \\
\hline 33 & escritório & 8,14 & 6,12 & 49,82 & 2,80 & 1,25 & 9,00 & 0,00 & 603,00 & 12,10 & 453,00 & 2,67 & $B$ \\
\hline 34 & circulação & 5,7 & 2,7 & 15,39 & 2,80 & 0,65 & 0,00 & 2,00 & 70,00 & 4,55 & 107,00 & 4,25 & $B$ \\
\hline 35 & banheiro & 4 & 1,1 & 4,40 & 2,80 & 0,31 & 0,00 & 2,00 & 70,00 & 15,91 & 218,00 & 7,30 & B \\
\hline 36 & circulação & 5,3 & 1,2 & 6,36 & 2,80 & 0,35 & 0,00 & 2,00 & 70,00 & 11,01 & 166,00 & 6,63 & B \\
\hline 37 & circulação & 12,33 & 8,45 & 104,19 & 2,80 & 1,79 & 0,00 & 12,00 & 420,00 & 4,03 & 156,00 & 2,58 & $B$ \\
\hline
\end{tabular}




\begin{tabular}{|c|c|c|c|c|c|c|c|c|c|c|c|c|c|}
\hline \multicolumn{14}{|c|}{ TERCEIRO ESTUDO - SEXTO PAVIMENTO } \\
\hline $\begin{array}{c}\text { número } \\
\text { da } \\
\text { amostra }\end{array}$ & $\begin{array}{c}\text { tipo de } \\
\text { ambiente }\end{array}$ & $\begin{array}{l}\text { comprimento } \\
\text { (m) }\end{array}$ & $\begin{array}{l}\text { largura } \\
(\mathrm{m})\end{array}$ & $\begin{array}{l}\text { área } \\
\left(\mathrm{m}^{2}\right)\end{array}$ & $\begin{array}{l}\text { altura média } \\
(\mathrm{m})\end{array}$ & K & $\begin{array}{c}\text { qtd } \\
\text { lum } \\
2 \times 32 W\end{array}$ & $\begin{array}{c}\text { qtd } \\
\text { lum } \\
2 \times 16 W\end{array}$ & $\begin{array}{l}\text { potência } \\
\text { total (W) }\end{array}$ & $\begin{array}{c}\text { densidade } \\
\left(\mathrm{W} / \mathrm{m}^{2}\right)\end{array}$ & $\begin{array}{l}\text { ilum } \\
\text { (Lux) }\end{array}$ & $\mathrm{DPI}_{\mathrm{RF}}$ & $\begin{array}{l}\text { nível de } \\
\text { eficiência }\end{array}$ \\
\hline 1 & banheiro & 8,65 & 8,00 & 69,20 & 2,80 & 1,48 & 0,00 & 12,00 & 420,00 & 6,07 & 219,00 & 2,77 & $B$ \\
\hline 2 & banheiro & 8,65 & 2,75 & 23,79 & 2,80 & 0,75 & 0,00 & 6,00 & 210,00 & 8,83 & 228,00 & 3,87 & $B$ \\
\hline 3 & banheiro & 7,00 & 4,05 & 28,35 & 2,80 & 0,92 & 0,00 & 6,00 & 210,00 & 7,41 & 215,00 & 3,45 & $B$ \\
\hline 4 & banheiro & 9,29 & 5,85 & 54,35 & 2,80 & 1,28 & 0,00 & 9,00 & 315,00 & 5,80 & 202,00 & 2,87 & B \\
\hline 5 & banheiro & 7,76 & 5,85 & 45,40 & 2,80 & 1,19 & 0,00 & 6,00 & 210,00 & 4,63 & 154,00 & 3,00 & $\mathrm{~B}$ \\
\hline 6 & área externa & 21,67 & 14,90 & 322,88 & 2,80 & 3,15 & 0,00 & 0,00 & 0,00 & 0,00 & não se a & ca lá & a externa) \\
\hline 7 & circulação & 10,90 & 1,20 & 13,08 & 2,80 & 0,39 & 0,00 & 2,00 & 70,00 & 5,35 & 91,00 & 5,88 & $B$ \\
\hline 8 & circulação & 5,14 & 3,16 & 16,24 & 2,80 & 0,70 & 0,00 & 2,00 & 70,00 & 4,31 & 106,00 & 4,07 & $\mathrm{~B}$ \\
\hline 9 & escritório & 4,40 & 3,10 & 13,64 & 2,80 & 0,65 & 4,00 & 0,00 & 268,00 & 19,65 & 545,00 & 3,61 & $B$ \\
\hline 10 & escritório & 22,09 & 10,95 & 241,89 & 2,80 & 2,61 & 35,00 & 0,00 & 2345,00 & 9,69 & 429,00 & 2,26 & $\mathrm{~B}$ \\
\hline 11 & escritório & 3,79 & 3,60 & 13,64 & 2,80 & 0,66 & 3,00 & 0,00 & 201,00 & 14,73 & 418,00 & 3,52 & $B$ \\
\hline 12 & circulação & 4,65 & 3,10 & 14,42 & 2,80 & 0,66 & 0,00 & 2,00 & 70,00 & 4,86 & 117,00 & 4,15 & $B$ \\
\hline 13 & circulação & 3,35 & 1,35 & 4,52 & 2,80 & 0,34 & 0,00 & 1,00 & 35,00 & 7,74 & 119,00 & 6,50 & $\mathrm{~B}$ \\
\hline 14 & circulação & 5,00 & 1,00 & 5,00 & 2,80 & 0,30 & 0,00 & 1,00 & 35,00 & 7,00 & 96,00 & 7,29 & B \\
\hline 15 & banheiro & 5,00 & 2,20 & 11,00 & 2,80 & 0,55 & 0,00 & 2,00 & 70,00 & 6,36 & 136,00 & 4,68 & $B$ \\
\hline 16 & banheiro & 3,5 & 3,26 & 11,41 & 2,80 & 0,60 & 0,00 & 2,00 & 70,00 & 6,13 & 138,00 & 4,45 & $\mathrm{~B}$ \\
\hline 17 & banheiro & 3,54 & 2,85 & 10,09 & 2,80 & 0,56 & 0,00 & 2,00 & 70,00 & 6,94 & 152,00 & 4,56 & $\mathrm{~B}$ \\
\hline 18 & circulação & 5,5 & 3,1 & 17,05 & 2,80 & 0,71 & 0,00 & 2,00 & 70,00 & 4,11 & 101,00 & 4,06 & $B$ \\
\hline 19 & área externa & 20,18 & 14,55 & 293,62 & 2,80 & 3,02 & 0,00 & 0,00 & 0,00 & 0,00 & não se & plica (á & a externa) \\
\hline
\end{tabular}




\section{ANEXO D}

ITAIM

\section{ESPECIFICACÃO TÉ CNICA}

$23202 \times 12610 \mathrm{~W}$

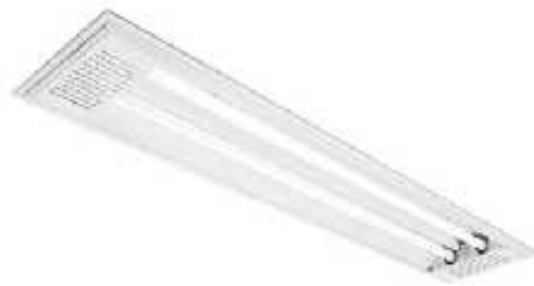

2320.210 .000

Especificacâot Luminána de embutir em forro de gesso para 2 lämpadas fluorescentes tubulares de $16 \mathrm{~W}$. Corpo em chapa de aco tratada com acabamento em pintura eletrostatica epobd-pó na cor branca. Refletor em aluminio anodizado de alto brilho. Equipada com porta-lampada antivibratínio em policarbonato, com trava de segurança e proteço contra aquecimento nos contatos.

Aplicacajo: Uso oeral, onde exercam tarefas com requisitos visuais normais como lofa de servico, hosptal, refeitorio, sala de aula, banco, escritorio, almoxarifado, etc.

Rendimento: $84 \%$

Dimensōes: A $=55 \times \mathrm{L}=297 \times \mathrm{C}=793 \mathrm{~mm}$. / Nicho: $278 \times 770 \mathrm{~mm}$.

DESENHO

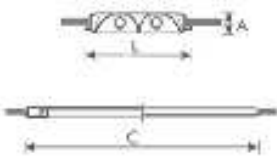

CURVA DE DISTRIBUICAAO LUMINOSA

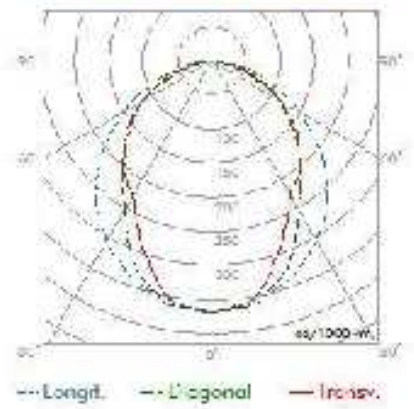

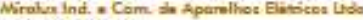

if 11 478s 1010

Rod Nigiz Eittenceurt, bon 27

06818300 Emb

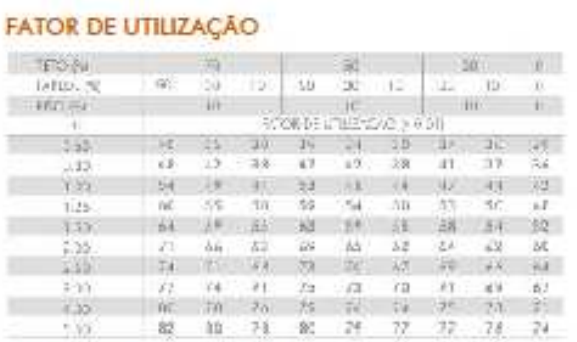

DLAGRAMA DE LUMINAINCLA

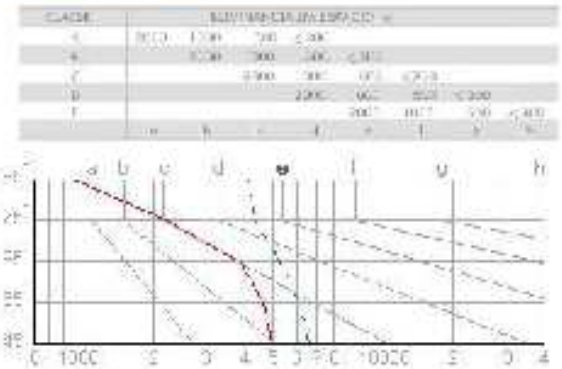

Fonte: Catálogo de produtos Itaim 2008. 


\section{ITAIM}

\section{ESPECIFICACÃO TÉCNICA}

$23202 \times 12632 \mathrm{~W}$

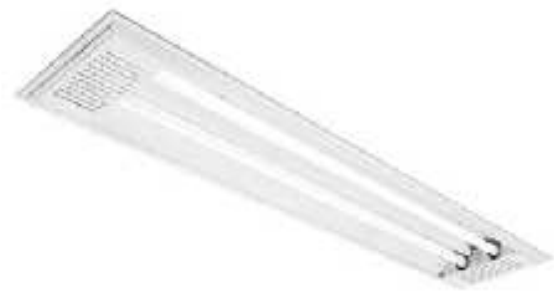

2320.72000

Especificacalot Luminária de embutir em forro de gesso para 2 tâmpadas fluorescentes tubulares de $32 W$. Corpo em chapa de aco tratada com acabamento em pintura eletrostatica epoxd-pó na cor branca. Refletor em aluminio anodizado de alto brilho. Equipada com porta-lampada antivibratidrio em policarbonato, com trava de segurança e proteça contra aquecimento nos contatos.

Aplicaço: Uso oeral, onde exercam tarefas com requisitos visuais normais como loja de servico, hosptal, refeitorio, sala de aula, banco, escritorio, almoxarifado, etc

Rendimento: $84 \%$

Dimensöes: $A=55 \times L=297 \times C=1403 \mathrm{~mm}$. $/$ Nicho: $278 \times 1380 \mathrm{~mm}$.

DESENHO

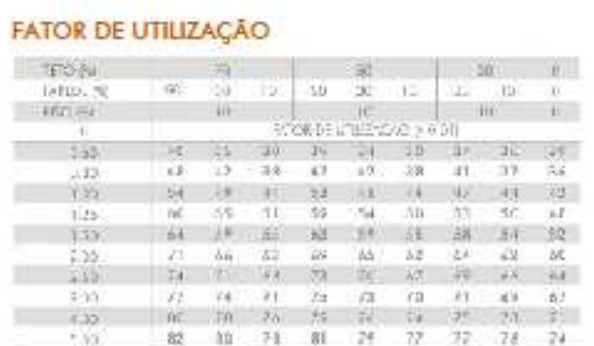

CURVA DE DISTRIBUIÇÁO LUMINOSA

DLAGRAMA DE LUMINAINCLA
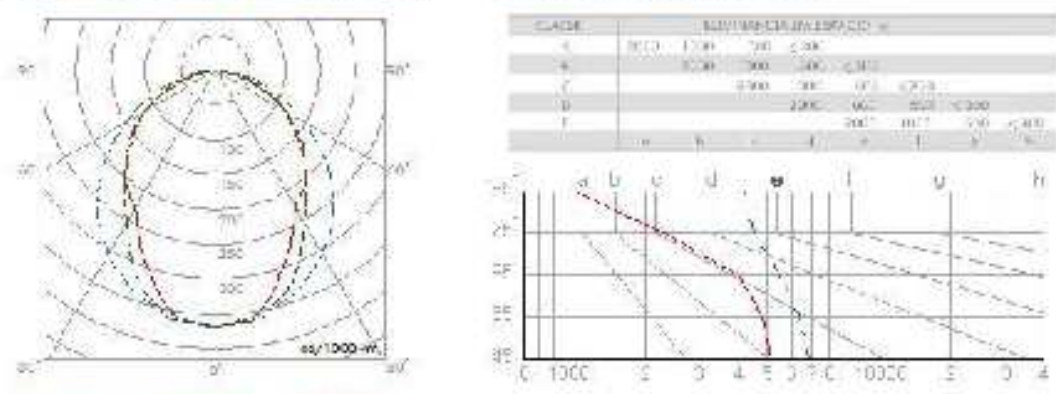

-.. Longrt. -. Egonal - Ireas.

Fonte: Catálogo de produtos Itaim 2008. 
ITAIM

ESPECIFICACĀO TÉCNICA

$27802 \times 12610 \mathrm{~W}$

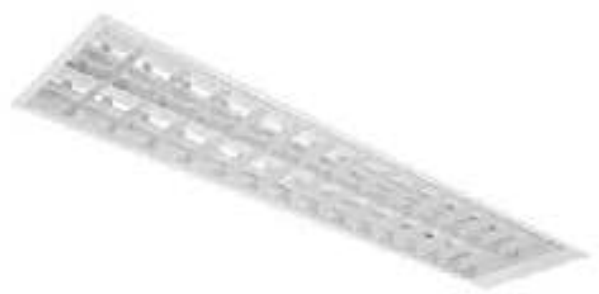

2100בrasoc

Especificaçaot Luminaria de embuttr em forro modulado para 2 lampadas fluorescentes tubulares de $16 W$. Corpo e aletas planas em chapa de aço tratada com acabamento em pintura eletrostática epóxd-pó na cor branca. Refietor em aluminio anodizado de alto brilho. Equipada com porta-limpada antivibratbrio em policerbonato, com trave de segurança e proteşo contra aquecimento nos contatcos.

Aplicaçot Ambientes onde há o exercicio de tarefas mistas com uso de computadores, exigindo controle de ofuscamento e alto rendimento como escritorio, loja, biblicteca, escola, banos, hospital, etc.

Rendimento: $73 \%$

Dimensōes: $A=70 \times \mathrm{L}=302 \times C=618 \mathrm{~mm}$. / Modulaçä: $\mathrm{L}=312 \times \mathrm{C}=625 \mathrm{~mm}$.

DESENHO

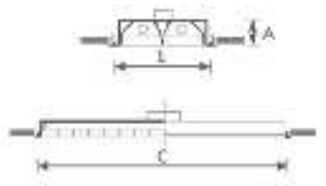

CURVA DE DISTRIBUIÇAOO LUMINOSA

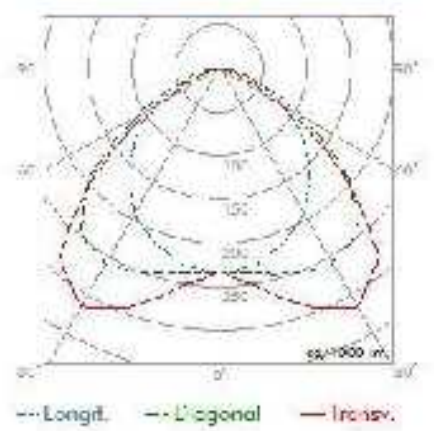

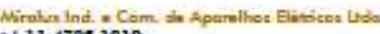
if 111478851010

Rod Nigiz Eittencourt, $10 \mathrm{~m} 276$

06818300 Embu

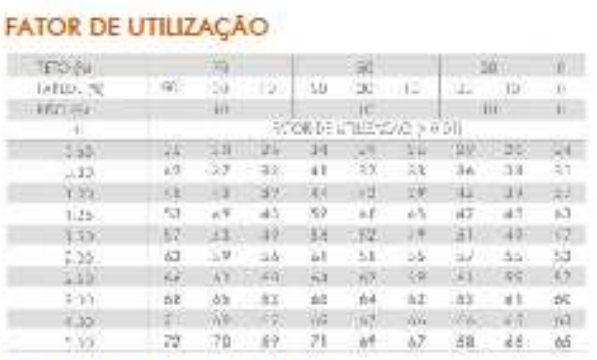

DLAGRAMA DE LUMINÁNCLA

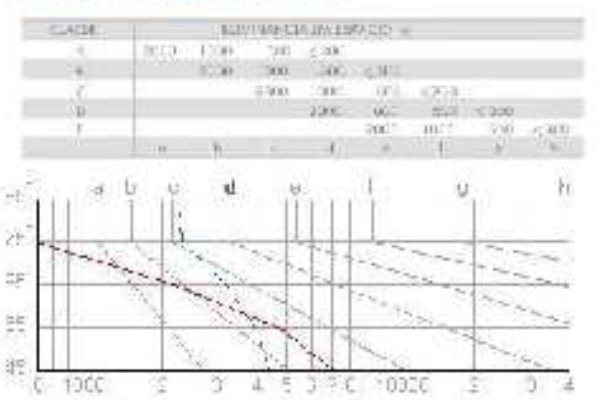

Fonte: Catálogo de produtos Itaim 2008. 
ITAIM

ESPECIFICACĀO TÉCNICA

$27802 \times 12632 \mathrm{~W}$

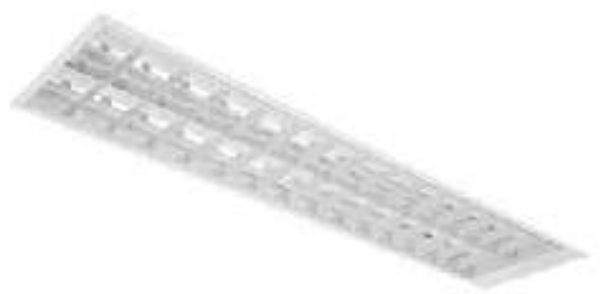

2100.32 .100

Especificação: Luminária de embutir em forro de gesso ou modulado para 2 lâmpadas fluorescentes tubulares de $32 W$. Corpo e aletas planas em chapa de aco tratada com acabamento em pintura eletrostatica epbxi-po na cor branca. Refletor em aluminio anodizado de alto brilho. Equipada com porta-lampada antivibratório em policerbonato, com trave de segurança e proteço contra aquecimento nos contatos.

Aplicaçä Ambientes onde há o exercicio de tarefas mistas com uso de computadores, exigindo contrcie de ofuscamento e alto rendimento como escritorio, loja, biblicteca, eecola, banos, hospital, etc.

Rendimento: $73 \%$

Dimensōes: $A=70 \times L=302 \times C=1243 \mathrm{~mm}$. / Modulaçă: $312 \times 1250 \mathrm{~mm}$. / Nicho: $290 \times 1230 \mathrm{~mm}$.

DESENHO

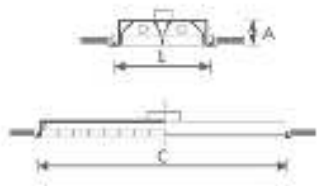

CURVA DE DISTRIBUIÇAOO LUMINOSA

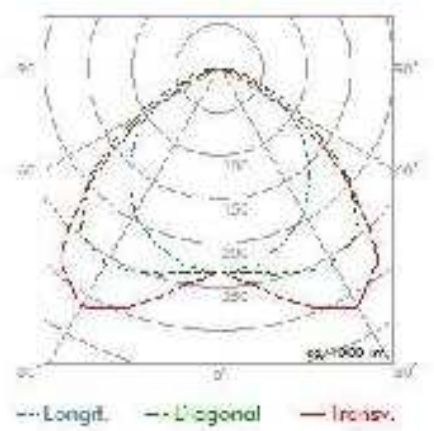

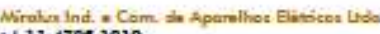
if 111478851010

Rod Nigiz Eittencourt, $10 \mathrm{~m} 276$

06818300 Embu

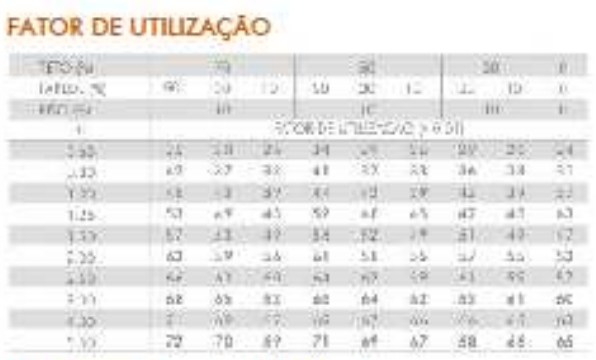

DLAGRAMA DE LUMINẢNCLA

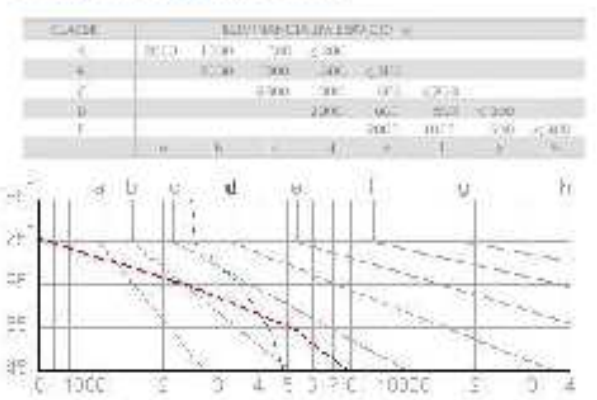

Fonte: Catálogo de produtos Itaim 2008. 